\title{
Stromal and epithelial mechanisms of chemotherapeutic resistance in pancreatic cancer
}

\section{Dissertation}

for the award of the degree

"Doctor rerum naturalium"

of the Georg-August-Universität Göttingen

within the doctoral program Molecular Medicine

of the Georg-August University School of Science (GAUSS)

submitted by

Melanie Susanne Patzak

from Gräfelfing, Germany

Göttingen, 2018 


\section{Thesis Committee}

PD Dr. Dr. med. Albrecht Neeße, Department of Gastroenterology and Gastrointestinal Oncology, University Medical Center Göttingen

Prof. Dr. Steven A. Johnsen, Department of General, Visceral and Pediatric Surgery, University Medical Center Göttingen

Prof. Dr. med. Frauke Alves, Department of Hematology and Oncology, University Medical Center Göttingen and Max Planck Institute of Experimental Medicine Göttingen

\section{Members of the Examination Board}

Referee: PD Dr. Dr. med. Albrecht Neeße, Department of Gastroenterology and Gastrointestinal Oncology, University Medical Center Göttingen

$2^{\text {nd }}$ Referee: Prof. Dr. Steven A. Johnsen, Department of General, Visceral and Pediatric Surgery, University Medical Center Göttingen

\section{Further members of the Examination Board}

Prof. Dr. med. Frauke Alves, Department of Hematology and Oncology, University Medical Center Göttingen and Max Planck Institute of Experimental Medicine Göttingen

Prof. Dr. Matthias Dobbelstein, Department of Molecular Oncology, University Medical Center Göttingen

Univ. Prof. Dr. med. Michael P. Schön, Department of Dermatology, Venereology and Allergology, University Medical Center Göttingen

Prof. Dr. med. Michael Zeisberg, Department of Nephrology and Rheumatology, University Medical Center Göttingen 


\section{Table of contents}

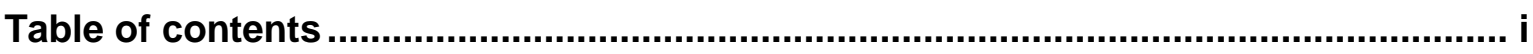

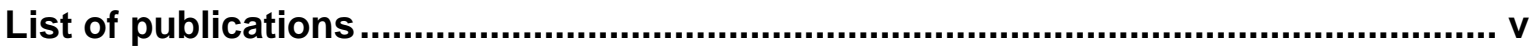

List of figures ..............................................................................................................

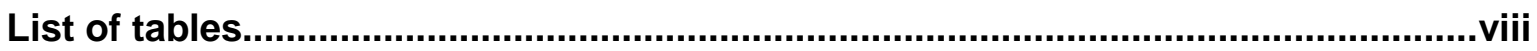

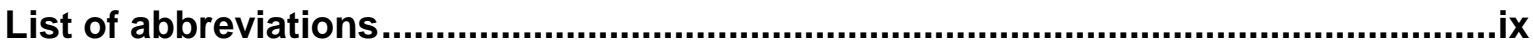

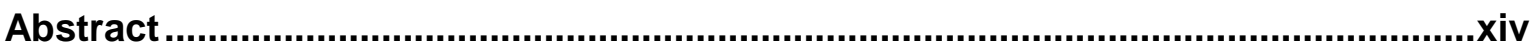

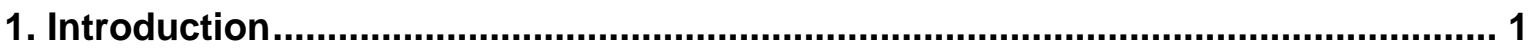

1.1 Pancreas anatomy and physiological function .............................................. 1

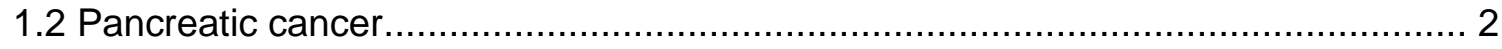

1.3 Pancreatic ductal adenocarcinoma ............................................................. 2

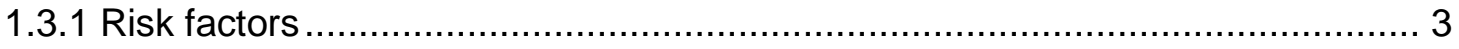

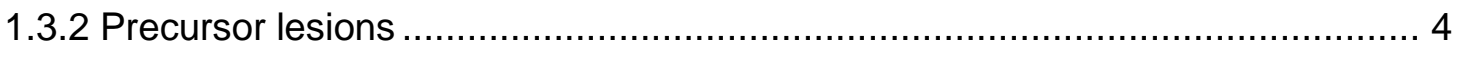

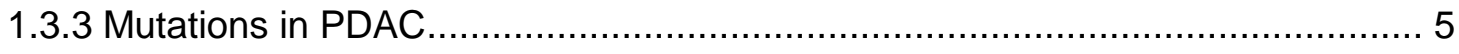

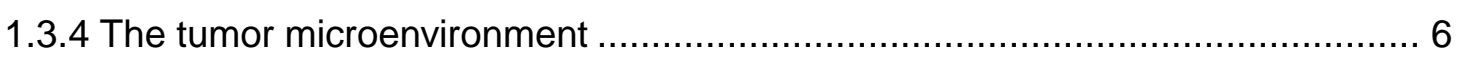

1.3.4.1 Cancer-associated fibroblasts.......................................................... 7

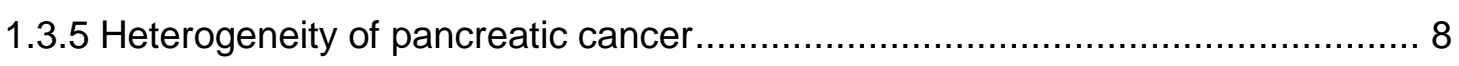

1.3.6 Mouse models of PDAC ...................................................................... 8

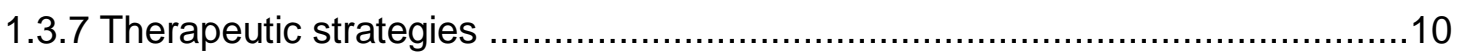

1.3.7.1 Resectable pancreatic cancer.........................................................

1.3.7.2 Unresectable pancreatic cancer ......................................................10

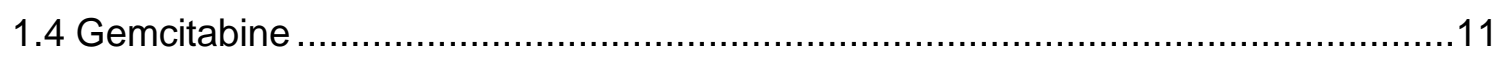

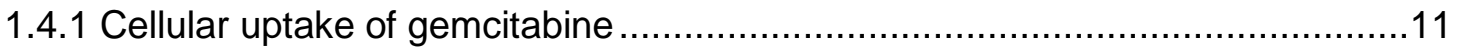

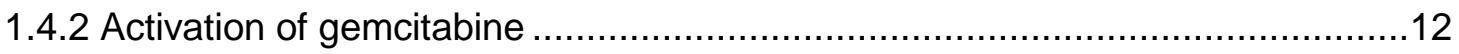

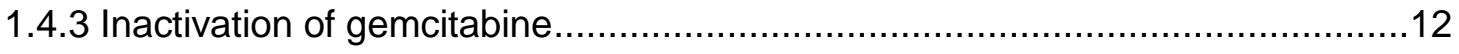

1.4.4 Mechanisms of action of gemcitabine ................................................ 14

1.5 Chemotherapeutic resistance in pancreatic cancer ..........................................14

1.5.1 Chemotherapeutic resistance towards gemcitabine .................................15

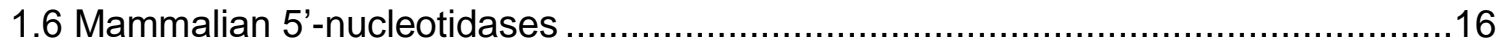

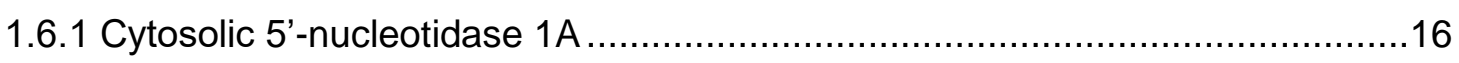

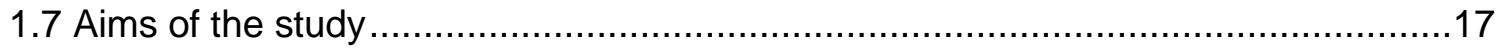




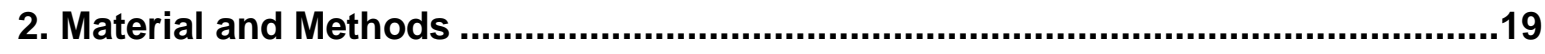

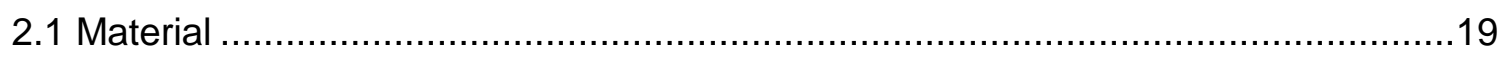

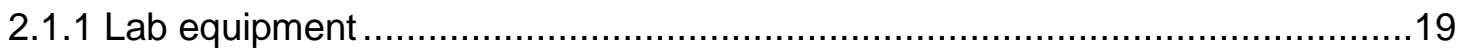

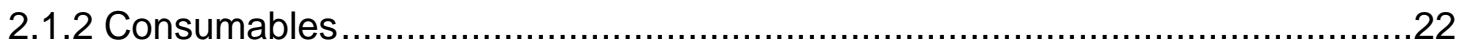

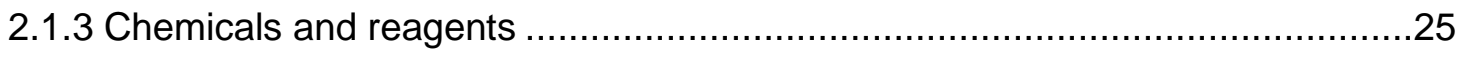

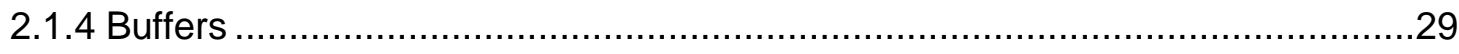

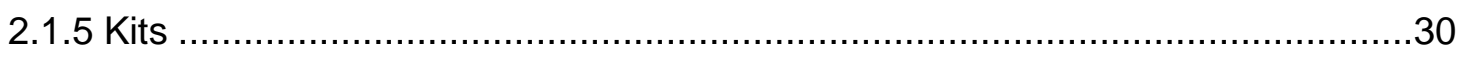

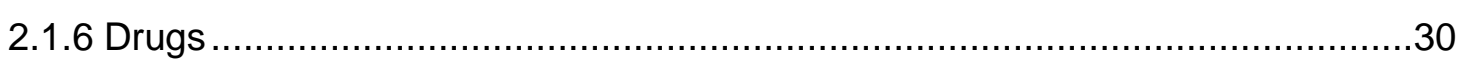

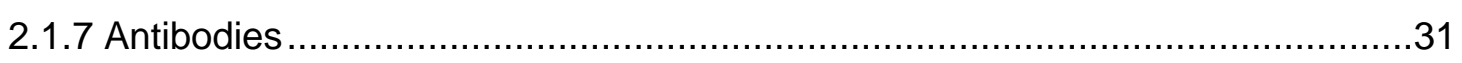

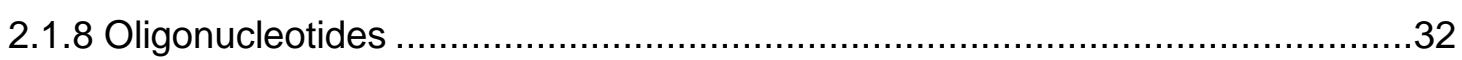

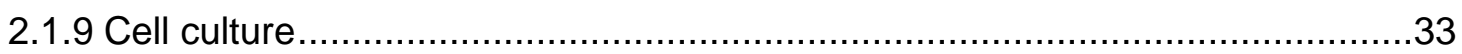

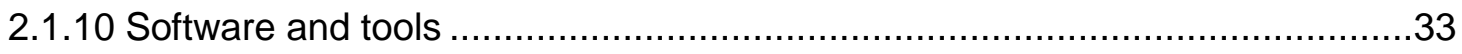

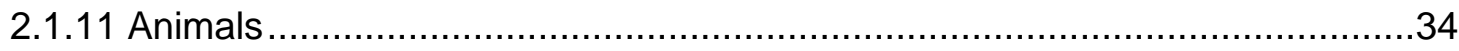

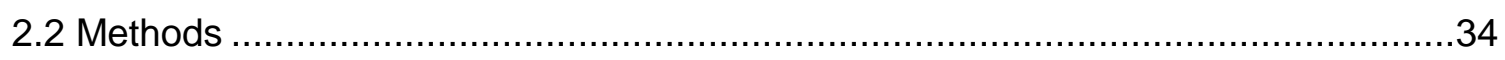

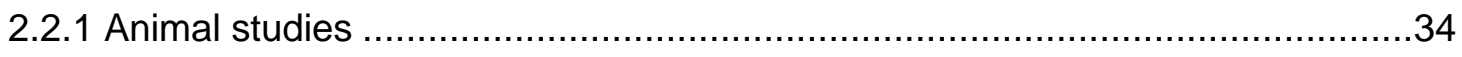

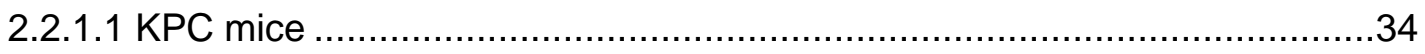

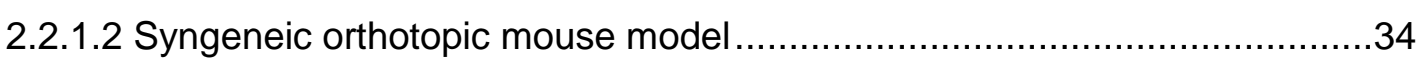

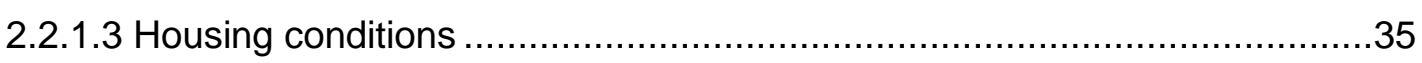

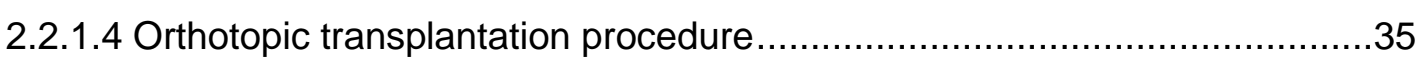

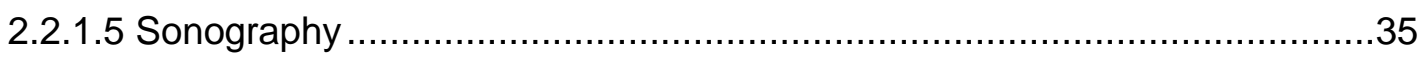

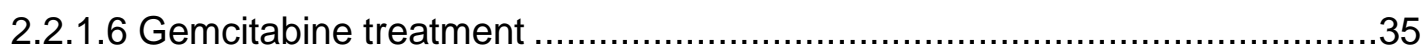

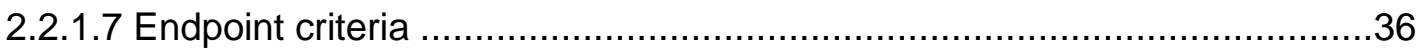

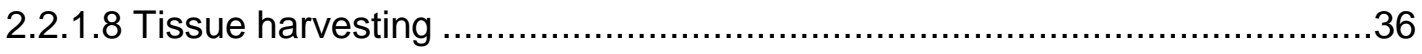

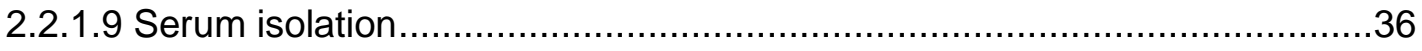

2.2.1.10 Tissue preparation for paraffin-embedding …....................................36

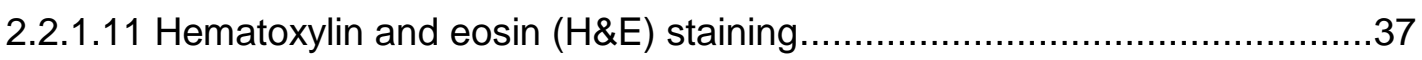

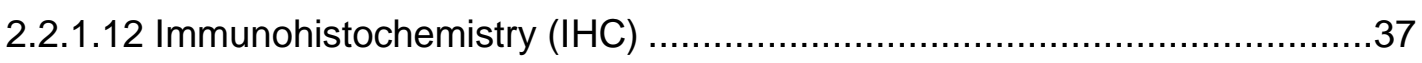

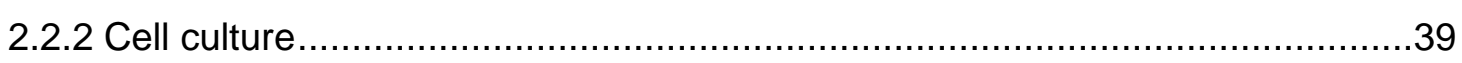

2.2.2.1 Cell culture conditions for adherent cells .............................................39

2.2.2.2 Mycoplasma test ........................................................................ 39

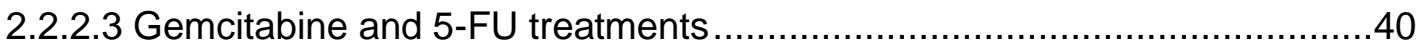

2.2.2.4 Establishment of cell lines stably expressing NT5C1A ............................40

2.2.2.5 Crystal violet cell proliferation assay ....................................................43

2.2.2.6 Co-culture studies with conditioned medium ..........................................43

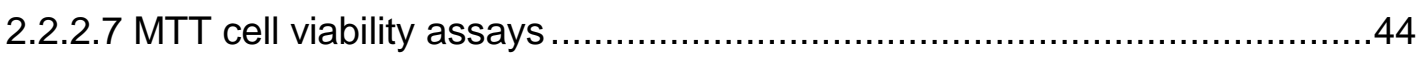

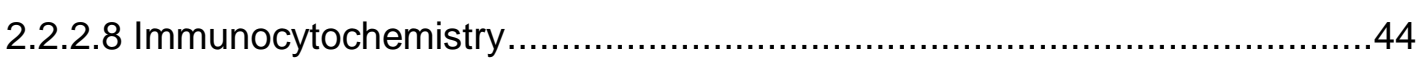




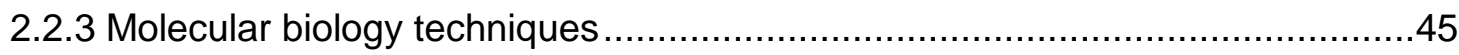

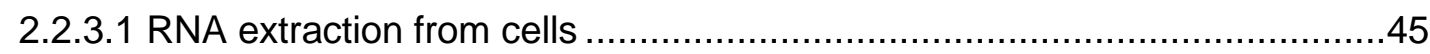

2.2.3.2 RNA extraction from tissue .............................................................. 45

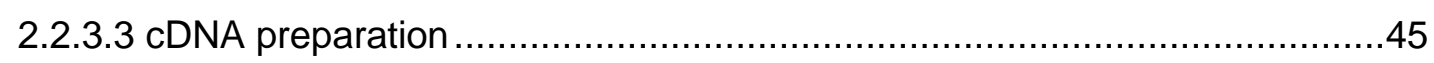

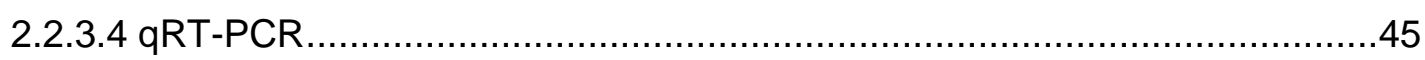

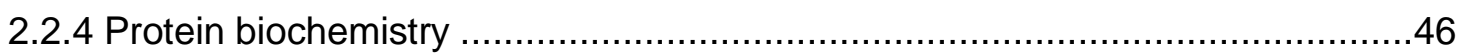

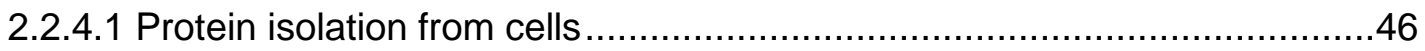

2.2.4.2 Protein isolation from tissue .................................................................46

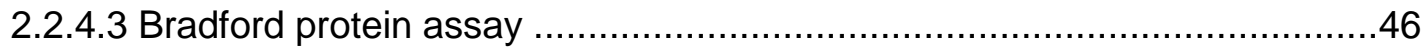

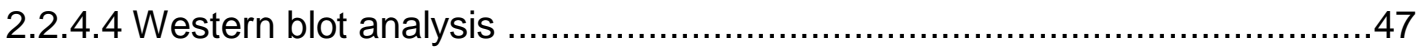

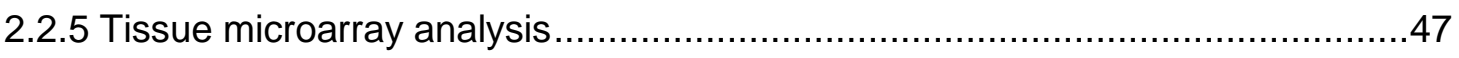

2.2.6 Liquid chromatography tandem mass-spectrometry....................................48

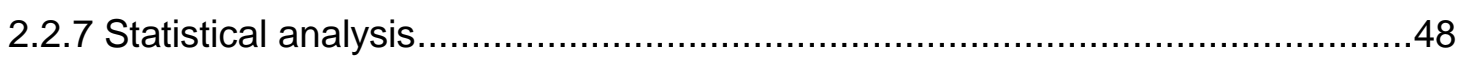

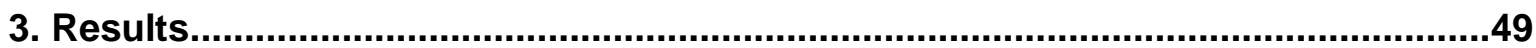

3.1 Intratumoral gemcitabine accumulation in murine PDAC results from fibroblast drug

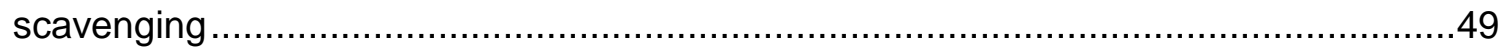

3.1.1 Gemcitabine treatment and the tumor stroma in pancreatic cancer. .50

3.1.2 Increased gemcitabine accumulation in primary KPC tumors compared with

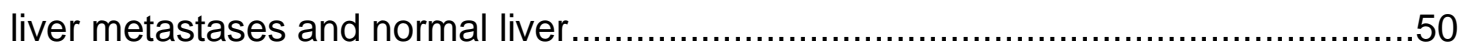

3.1.3 Higher stromal content in primary pancreatic tumors than in liver metastases .52

3.1.4 Fibroblast drug scavenging increases intratumoral gemcitabine accumulation.53

3.1.4.1 CAFs and PSCs accumulate significant amounts of gemcitabine in vitro...53

3.1.4.2 Low expression of gemcitabine-inactivating genes in stromal cells in vitro

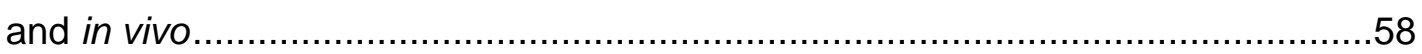

3.1.4.3 CAFs are intrinsically resistant to gemcitabine treatment.......................60

3.2 Cytosolic 5'-nucleotidase $1 \mathrm{~A}$ is overexpressed in pancreatic cancer and mediates gemcitabine resistance by reducing intracellular gemcitabine metabolites 62

3.2.1 NT5C1A is strongly expressed in murine and human PDAC and is not

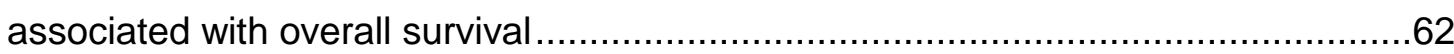

3.2.2 NT5C1A expression in murine and human PDAC cell lines ............................65

3.2.3 Pharmacokinetics of gemcitabine upon recombinant NT5C1A expression .......68

3.2.4 NT5C1A overexpression confers chemotherapeutic resistance towards

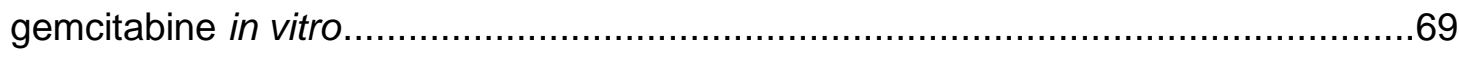

3.2.5 NT5C1A expression and function in the tumor stroma ................................73 
3.2.6 Reduced accumulation of the cytotoxic gemcitabine metabolite dFdCTP in

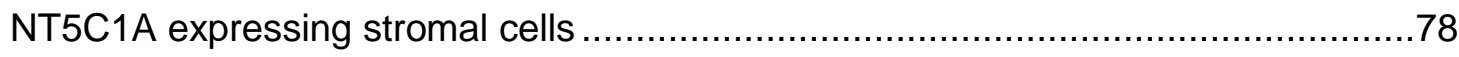

3.2.7 NT5C1A expression mediates chemoresistance in vivo................................79

4. Discussion. . .83

4.1 Gemcitabine resistance and its association with the pancreatic cancer stroma ......83

4.1.1 Gemcitabine accumulation in stroma-rich pancreatic tumors .........................84

4.1.2 The tumor microenvironment is actively involved in drug metabolism ..............86

4.1.3 Stromal expression of gemcitabine-metabolizing enzymes and gemcitabine

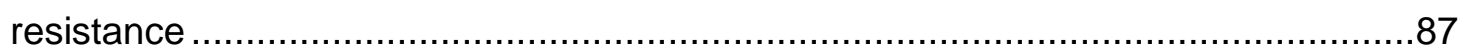

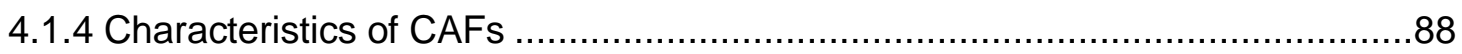

4.1.5 Gemcitabine drug scavenging by further stromal components .......................89

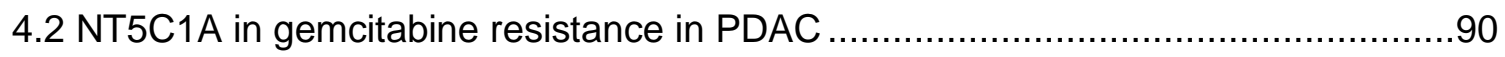

4.2.1 NT5C1A in inclusion body myositis and in malignancies .91

4.2.2 Influence of stromal NT5C1A expression on non-cell-autonomous gemcitabine resistance in PDAC.

4.2.3 NT5C1A expression in the epithelial compartment of PDAC is not a prognostic

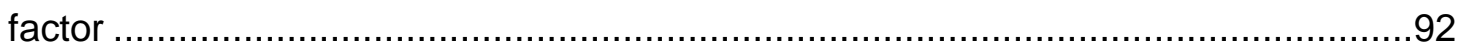

4.2.4 Recombinant overexpression of NT5C1A in pancreatic cancer cells................93

4.2.5 NT5C1A as predictive marker for gemcitabine therapy response ....................94

4.2.6 Differential expression of NT5C1A fuels chemotherapeutic resistance..............97

4.2.7 NT5C1A regulation in pancreatic cancer ......................................................98

4.2.8 Specificity of NT5C1A-driven chemoresistance towards gemcitabine ..............99

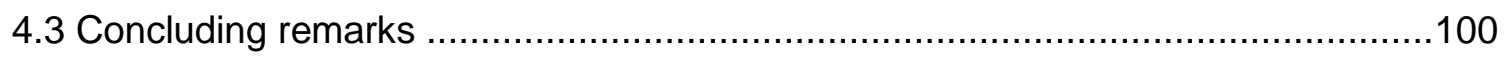

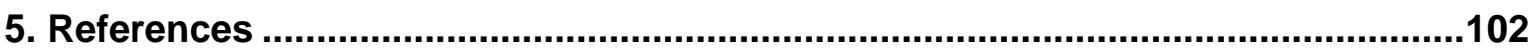

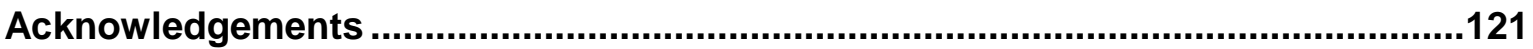

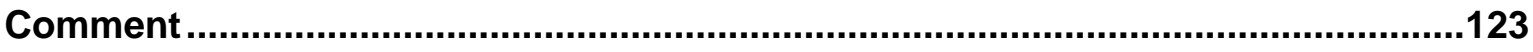




\section{List of publications}

\section{Original articles}

Patzak, M.S., Kari, V., Patil, S., Hamdan, F.H., Goetze, R.G., Brunner, M., Gaedcke, J., Kitz, J., Jodrell, D.I., Richards, F.M., Pilarsky, C., Gruetzmann, R., Rümmele, P., Knösel, T., Hessmann, E., Ellenrieder, V., Johnsen, S.A., and Neesse, A (2019). Cytosolic 5 -nucleotidase $1 \mathrm{~A}$ is overexpressed in pancreatic cancer and mediates gemcitabine resistance by reducing intracellular gemcitabine metabolites. EBioMedicine, 40, 394-405. https://doi.org/10.1016/j.ebiom.2019.01.037 (in revision at the time of thesis submission)

Hessmann, E. ${ }^{*}$ Patzak, M.S. ${ }^{*}$, Klein, L., Chen, N., Kari, V., Ramu, I., Bapiro, T.E., Frese, K.K., Gopinathan, A., Richards, F.M., Jodrell, D.I., Verbeke, C., Li, X., Heuchel, R., Löhr, J.M., Johnsen, S.A., Gress, T.M., Ellenrieder, V., and Neesse, A. (2018). Fibroblast drug scavenging increases intratumoural gemcitabine accumulation in murine pancreas cancer. Gut, 67(3), 497-507. https://doi.org/10.1136/gutjnl-2016-311954

\section{${ }^{\star}$ Co-first authors}

\section{Editorial}

Patzak, M. S., Ellenrieder, V., and Neesse, A. (2018). Intratumoral bacteria as potential contributor of gemcitabine resistance. Translational Cancer Research, 7(Suppl 1), S21-S23. https://doi.org/10.21037/tcr.2017.12.21

\section{Published abstracts (first author only)}

Patzak, M. S., Hessmann, E., Kari, V., Kitz, J., Patil, S., Richards, F. M., Jodrell, D. I., Johnsen, S. A., Ellenrieder, V., and Neesse, A. (2018). Impact of cytosolic 5 '-nucleotidase $1 \mathrm{~A}$ on chemotherapeutic resistance in pancreatic cancer. Pancreatology, 18(4S), S91. https://doi.org/10.1016/j.pan.2018.05.247

Patzak, M. S., Hessmann, E., Kari, V., Richards, F. M., Jodrell, D. I., Johnsen, S. A., Ellenrieder, V., and Neesse, A. (2017). Metabolic Reprogramming of Fibroblasts to Enhance Gemcitabine Availability in Murine Pancreatic Cancer. Pancreatology, 17(3S), S13. https://doi.org/10.1016/j.pan.2017.05.041

Patzak, M., Hessmann, E., Bapiro, T., Frese, K., Jodrell, D., Ellenrieder, V., and Neesse, A. (2016). Gemcitabine uptake and metabolism of cancer associated fibroblasts in murine pancreatic cancer. Zeitschrift für Gastroenterologie, 54(8), KV466. https://doi.org/10.1055/s-0036-1587242 


\section{List of figures}

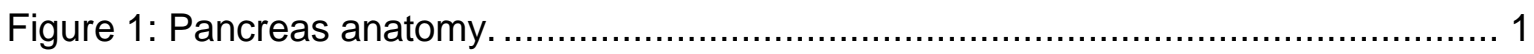

Figure 2: Schematic overview of pancreatic cancer characteristics............................... 3

Figure 3: Precursor lesions of pancreatic cancer. .................................................... 5

Figure 4: Pancreatic cancer progression in KC mice............................................... 9

Figure 5: Schematic illustration of gemcitabine uptake and metabolism..........................13

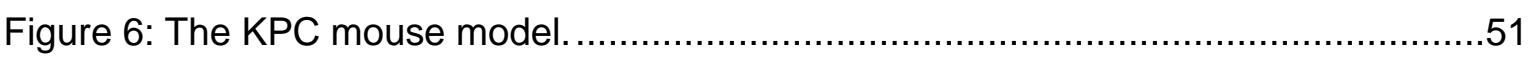

Figure 7: Pharmacokinetic distribution of gemcitabine metabolites in murine pancreatic cancer tissue.

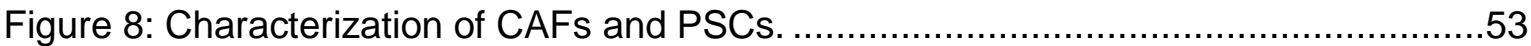

Figure 9: Accumulation and decreased inactivation of gemcitabine in CAFs...................55

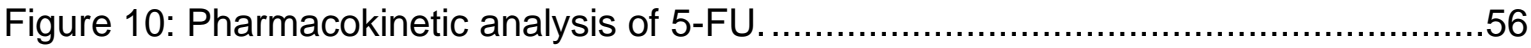

Figure 11: Fibroblasts increase murine pancreatic tumor cell survival in vitro by scavenging gemcitabine.

Figure 12: Low expression of gemcitabine-inactivating genes in stromal cells in vitro. .....59

Figure 13: Gemcitabine-inactivating enzymes are hardly expressed in the pancreatic cancer stroma.

Figure 14: CAFs are intrinsically resistant to gemcitabine treatment.

Figure 15: Expression of NT5C1A in resected PDAC patients.

Figure 16: NT5C1A is not prognostic for the survival of PDAC patients.

Figure 17: Expression of NT5C1A in the KPC mouse model.

Figure 18: Reduced expression of NT5C1A in murine and human pancreatic cancer cell lines in vitro.

Figure 19: Recombinant expression of NT5C1A in human and murine pancreatic cancer cell lines.

Figure 20: NT5C1A overexpression decreases dFdCTP accumulation in pancreatic cancer cell lines.

Figure 21: High levels of NT5C1A increase chemotherapeutic resistance towards gemcitabine in pancreatic cancer cells.

Figure 22: High levels of NT5C1A reduce chemotherapeutic response to gemcitabine in pancreatic cancer cells.

Figure 23: Pancreatic cancer cell lines expressing high levels of NT5C1A are still sensitive to paclitaxel treatment.

Figure 24: Reduced apoptosis in murine pancreatic cancer cells overexpressing NT5C1A. 
Figure 26: NT5C1A expression and function in PDAC stroma in vivo.

Figure 27: Stromal NT5C1A expression does not correlate with overall survival in resected

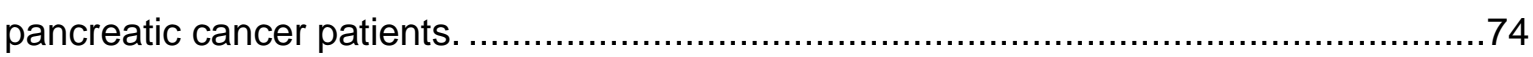

Figure 28: NT5C1A overexpression in stably transfected PSC cell lines. .........................75

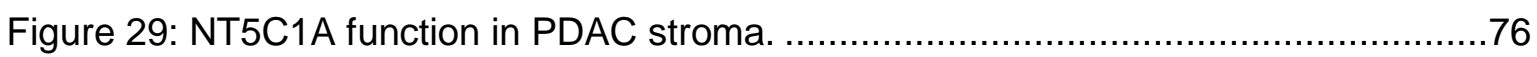

Figure 30: Stromal NT5C1A expression enhances gemcitabine resistance in vitro. .........77

Figure 31: Stromal cells expressing NT5C1A increase available amounts of gemcitabine for tumor cells in vitro.

Figure 32: Pharmacokinetic analysis of the gemcitabine metabolite dFdCTP in murine PSCs. .78

Figure 33: Syngeneic orthotopic transplantation of modified KPC tumor cells.................79

Figure 34: Tumor detection by high-resolution ultrasound.........................................79

Figure 35: NT5C1A is robustly expressed in tumors from mice with orthotopically transplanted NT5C1A overexpressing tumor cells. 80

Figure 36: NT5C1A expression mediates chemoresistance in vivo. .81

Figure 37: Apoptotic cell numbers were not changed upon NT5C1A expression in murine tumors.

Figure 38: Enhanced inactivation of gemcitabine in NT5C1A expressing orthotopic tumors

Figure 39: Tumor growth was not altered in NT5C1A-expressing tumors following saline treatment.

Figure 40: Gemcitabine treatment does not alter NT5C1A expression using an orthotopic mouse model of PDAC. 82

Figure 41: Mechanism of NT5C1A-mediated gemcitabine resistance. .95

Figure 42: Schematic illustration of NT5C1A expression in pancreatic cancer. 


\section{List of tables}

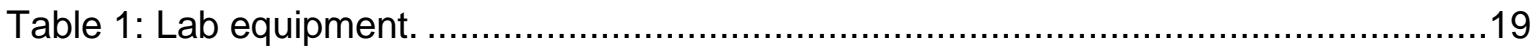

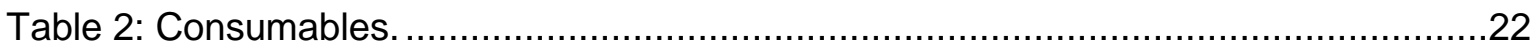

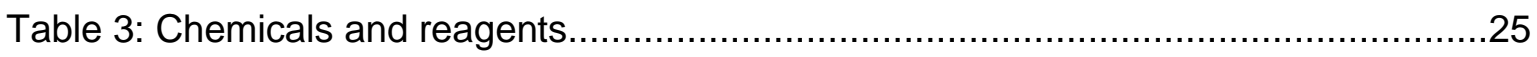

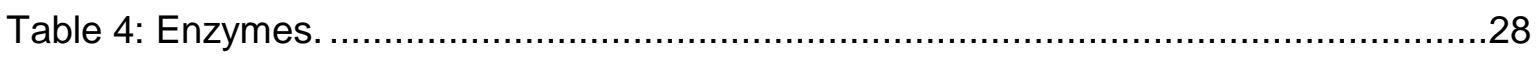

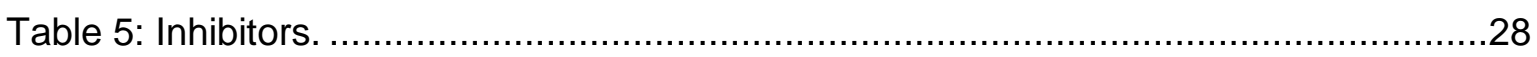

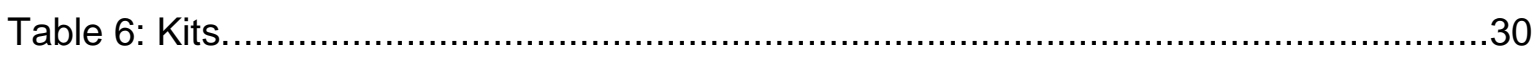

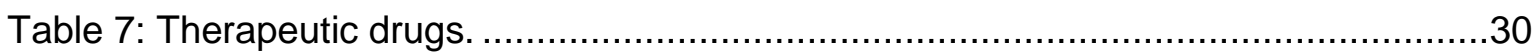

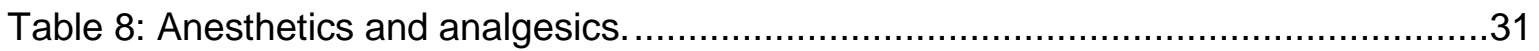

Table 9: Primary antibodies for Western blot, IHC, and ICC...........................................

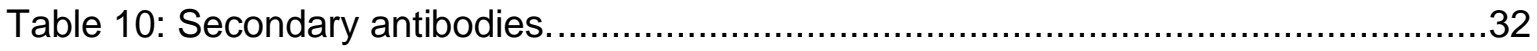

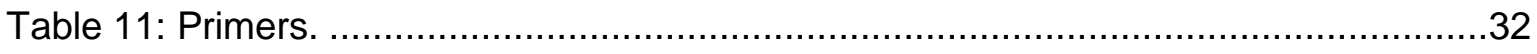

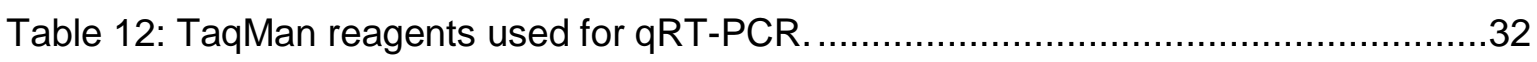

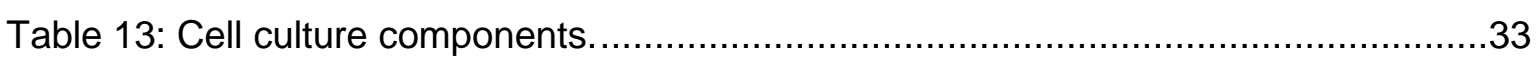

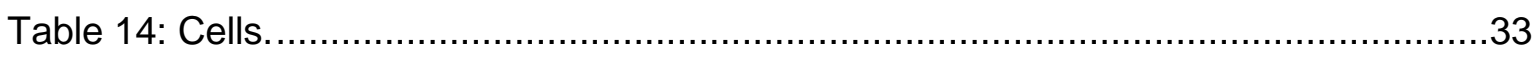

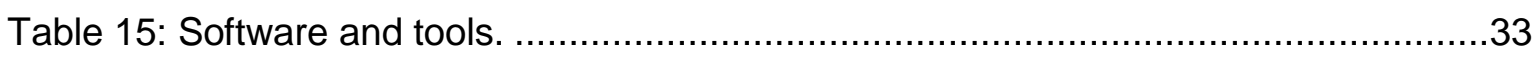

Table 16: Reaction mixture for cloning of NT5C1A-insert.............................................41

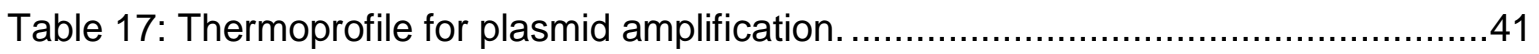

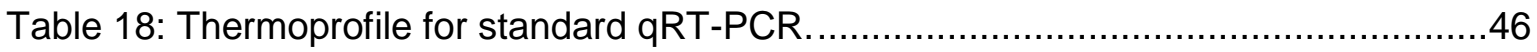




\section{List of abbreviations}

$\%$

${ }^{\circ} \mathrm{C}$

$\mu$

2D

3D

5-FU

$\mathrm{ABC}$

ADM

AEC

ALL

AMP

AMPK

ANOVA

bp

BRCA1/ BRCA2

BSA

CA-19-9

$\mathrm{Ca}^{2+}$

CAFs

CC3

CDA

CDKN2A

cDNA

$\mathrm{CM}$

$\mathrm{CO}_{2}$

CONKO

d

$D A B$

DAPI

dCK

DCTD

$\mathrm{dFdC}$

$\mathrm{dFdCDP}$

dFdCMP

dFdCTP per cent

degree Celsius

micro

two-dimensional

three-dimensional

5-fluorouracil

avidin-biotin-complex

acinar-to-ductal metaplasia

3-amino-9-ethylcarbazol

acute lymphoblastic leukaemia

adenosine monophosphate

AMP-activated protein kinase

analysis of variance

base pairs

breast cancer gene 1/ gene 2

bovine serum albumin

carbohydrate antigen 19-9

calcium

cancer-associated fibroblasts

cleaved caspase-3

cytidine deaminase

cyclin dependent kinase inhibitor $2 \mathrm{~A}$

complementary DNA

conditioned medium

carbon dioxide

Charité-Onkologie

day

3,3'-diaminobenzidine

4',6-diamidino-2-phenylindole

deoxycytidine kinase

deoxycytidylate deaminase

2',2'-difluoro 2'-deoxycytidine

2',2'-difluoro 2'-deoxycytidine diphosphate

2',2'-difluoro 2'-deoxycytidine monophosphate

2',2'-difluoro 2'-deoxycytidine triphosphate 


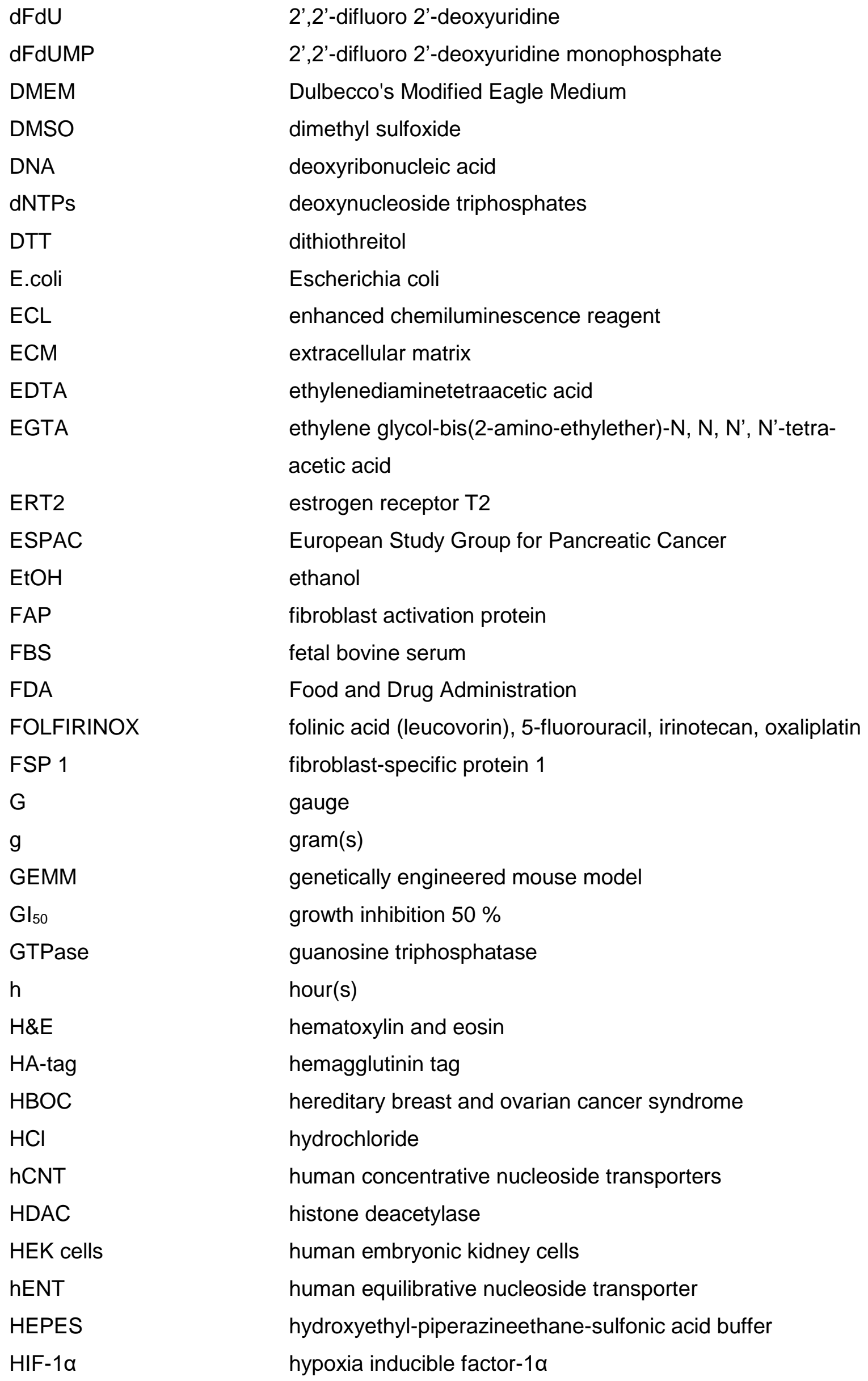




\begin{tabular}{|c|c|}
\hline HPF & high performance field \\
\hline HRP & horseradish peroxidase \\
\hline HSP90 & heat shock protein 90 \\
\hline Hygro & hygromycin \\
\hline i.p. & intraperitoneal \\
\hline IBM & inclusion body myositis \\
\hline $\mathrm{IC}_{50}$ & inhibitory concentration $50 \%$ \\
\hline ICC & immunocytochemistry \\
\hline IF & immunofluorescence \\
\hline $\lg G$ & immunoglobulin G \\
\hline $\mathrm{IHC}$ & immunohistochemistry \\
\hline IL-6 & interleukin-6 \\
\hline IPMN & intraductal papillary mucinous neoplasms \\
\hline k & kilo \\
\hline $\mathrm{kb}$ & kilobase \\
\hline KC & LSL-KRAS ${ }^{\mathrm{G} 12 \mathrm{D}} ; \mathrm{P} 48^{+/ \mathrm{Cre}}$ \\
\hline $\mathrm{kDa}$ & kilo Dalton \\
\hline $\mathrm{Km}$ & Michaelis-Menten kinetics constant \\
\hline KPC & LSL-Kras $^{\mathrm{G} 12 \mathrm{D} /+} ; \mathrm{LSL}-\operatorname{Trp} 53^{\mathrm{R} 172 \mathrm{H} /+; P d x-1-C r e}$ \\
\hline KRAS & Kirsten rat sarcoma viral oncogene homolog \\
\hline I & liter \\
\hline L3.6pl & L3.6 pancreas to liver \\
\hline LC-MS/MS & liquid chromatography tandem mass-spectrometry \\
\hline LDS & lithium dodecyl sulfate \\
\hline LM & liver metastasis \\
\hline LSL & Lox-STOP-Lox \\
\hline $\mathrm{m}$ & milli \\
\hline M & molar \\
\hline M.O.M. ${ }^{\mathrm{TM}}$ kit & mouse on mouse kit \\
\hline MCN & mucinous cystic neoplasms \\
\hline MCS & multiple cloning site \\
\hline MDSC & myeloid-derived suppressor cells \\
\hline MEM & Minimum Essential Media \\
\hline $\mathrm{Mg}^{2+}$ & magnesium \\
\hline $\min$. & minutes \\
\hline M-MLV & Moloney Murine Leukemia Virus \\
\hline MMPs & matrix metalloproteinases \\
\hline
\end{tabular}




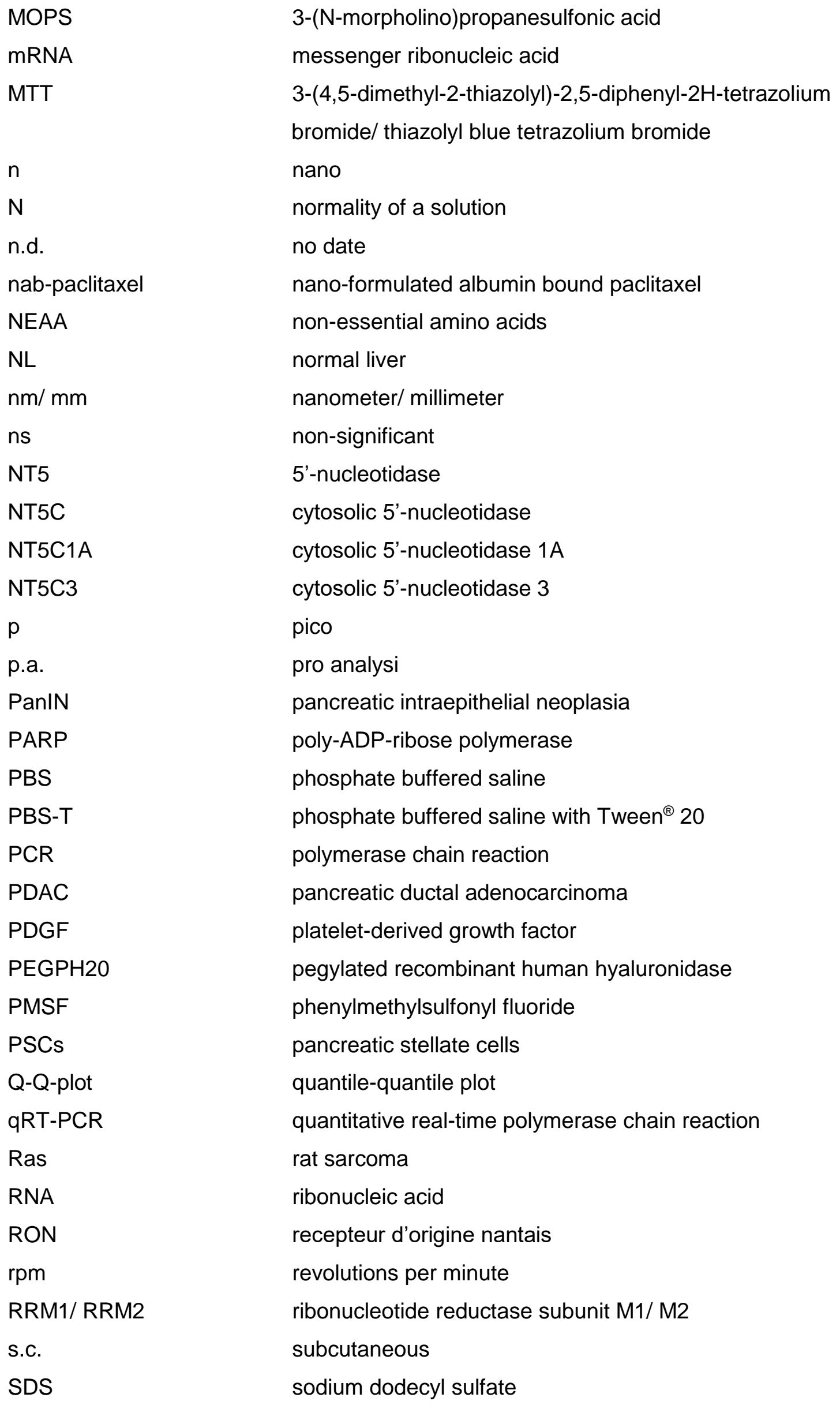


sec.

SEM

SLC28/ SLC29

SMA

Smo

SPARC

TAE buffer

TAM

Taq

TBE buffer

TBS

TBS-T

TE buffer

TGF- $\beta$

THU

TMA

TME

TNF- $\alpha$

TRIS

U

U.S.

UV

$\mathrm{V}$

$\mathrm{v} / \mathrm{v}$

vs.

WB

$\alpha$

$\beta$ seconds

standard error of mean

solute carrier family $28 / 29$

smooth muscle actin

smoothened

secreted protein acidic and rich in cysteine

TRIS-acetate-EDTA buffer

tumor-associated macrophage

thermus aquaticus

TRIS-borate-EDTA buffer

TRIS-buffered saline

TRIS-buffered saline with Tween ${ }^{\circledR} 20$

TRIS-EDTA buffer

transforming growth factor- $\beta$

tetrahydrouridine

tissue microarray

tumor microenvironment

tumor necrosis factor- $\alpha$

Tris-(hydroxymethyl)-aminomethan

unit(s)

United States

ultraviolet

volt(s)

volume percent

versus

Western blot

alpha

beta 


\section{Abstract}

Pancreatic ductal adenocarcinoma (PDAC) is a devastating disease with a 5-year survival rate of less than $8 \%$. Hallmarks of pancreatic cancer are extensive desmoplasia and strong resistance to standard chemotherapeutic agents, e.g. gemcitabine. In this context, impaired drug delivery and drug metabolism pathways might play a crucial role in mediating this pronounced chemoresistance.

In this study, I investigated tumor cell intrinsic and extrinsic mechanisms of chemotherapeutic resistance in PDAC.

Pharmacokinetic characteristics of gemcitabine $(\mathrm{dFdC})$ were analyzed in the widely used LSL-Kras ${ }^{G 12 D /+} ; L S L-T r p 53^{R 172 H /+;} P d x-1-C r e(K P C)$ mouse model by liquid chromatography tandem mass-spectrometry (LC-MS/MS). Surprisingly, the levels of gemcitabine were elevated in the primary, stroma-rich and hypovascular tumor samples compared with matched normal liver samples and samples from liver metastases. A more detailed analysis by our group revealed an increased ratio of cancer-associated fibroblasts (CAFs) in primary tumors compared to liver metastases. Notably, gemcitabine metabolizing enzymes were highly expressed in epithelial but not stromal cells. The inactivating enzymes cytidine deaminase (CDA), deoxycytidylate deaminase (DCTD), and cytosolic 5'-nucleotidase 1A (NT5C1A) were hardly expressed in the stromal compartment of murine and human PDAC samples in vivo. In contrast, these enzymes were robustly expressed in the epithelial compartment. Consequently, the cytotoxic gemcitabine metabolite dFdCTP accumulated in murine CAFs, as the phosphorylated metabolites are unable to cross the cell membrane. Drug scavenging of CAFs was confirmed in conditioned medium (CM) assays. Incubation of tumor cells with $\mathrm{CM}$ of gemcitabine treated CAFs reduced the available amount of gemcitabine for tumor cells in vitro. Due to the low proliferation rate of CAFs in vivo, these cells might have exhibited intrinsic resistance to the increased amounts of dFdCTP.

Further experiments were aimed to characterize NT5C1A, a previously unrecognized gemcitabine inactivating enzyme in pancreatic cancer that reverses the initial phosphorylation step of gemcitabine. Immunohistochemical staining of tissue microarrays (TMAs) with more than 400 tumor samples, from two independent cohorts of resected PDAC patients, were used to study the expression pattern of NT5C1A in PDAC. We found robust protein expression in the epithelial compartment of $64-70 \%$ of PDAC patients, whereas robust stromal expression of NT5C1A was detectable in less than $20 \%$ of these patients. A prognostic role of NT5C1A was not observed in both patient cohorts. 
Recombinant expression of this enzyme was used to elucidate its impact on chemotherapeutic resistance. Re-expression of NT5C1A in pancreatic stellate cells (PSCs) reduced the intracellular levels of the active gemcitabine metabolite dFdCTP, suggesting NT5C1A as novel target for stromal reprogramming.

Gemcitabine response in tumor cells overexpressing NT5C1A was investigated using standard biochemical assays and orthotopic transplantation of the modified tumor cells into mice. Indeed, cells overexpressing NT5C1A showed higher resistance towards gemcitabine and had decreased levels of intracellular dFdCTP and of cleaved caspase 3 (CC3) levels following treatment with gemcitabine. Tumor weights were increased in mice that were transplanted with NT5C1A expressing cells compared to control cells upon gemcitabine treatment, showing the relevance of this enzyme in therapeutic effectiveness. Given its role in dephosphorylation of nucleoside monophosphates, NT5C1A overexpression in pancreatic cancer cells did not reduce chemosensitivity towards paclitaxel, a standard chemotherapeutic agent that acts independently of intracellular phosphorylation.

In conclusion, our study gave new insight into the impact of drug metabolizing enzymes on chemotherapeutic resistance in PDAC. We demonstrated that alterations in drug metabolism and not impaired drug delivery mainly determine the response to gemcitabine in PDAC. Our results further demonstrated NT5C1A as target for stromal reprogramming. Most importantly, our findings pave the way for a more detailed stratification of patients for treatments and suggest NT5C1A to be considered as a possible predictor of treatment response to gemcitabine in PDAC patients. 


\section{Introduction}

\subsection{Pancreas anatomy and physiological function}

The pancreas plays an important role as a key regulator of glucose homeostasis and protein, lipid, as well as carbohydrate digestion (Hezel et al., 2006; Prinz, 2012). The pancreatic gland is anatomically divided into three parts, namely the pancreas head, the pancreas body, and the pancreas tail (Prinz, 2012).

Physiologically, the pancreas has important endocrine and exocrine functions. The endocrine function is accomplished by the islets of Langerhans, as depicted in Figure 1, and results in the production of insulin and its antagonist glucagon (Prinz, 2012).

The exocrine part of the pancreas is responsible for the production of digestive enzymes and their delivery into the gastrointestinal tract (Prinz, 2012). This part of the pancreas is an organized network of acinar and duct cells and makes up around $80 \%$ of the total tissue mass (Figure 1) (Hezel et al., 2006). The main cell types of the exocrine pancreas are the acinar cells, centro-acinar cells, and bicarbonate-secreting duct cells (Kleeff et al., 2016). Acinar cells are organized along the ductal cells and act in response to signals from the stomach and duodenum. The secretion of enzymes into the ductal lumen is achieved by centro-acinar cells (Hezel et al., 2006; Kleeff et al., 2016). The produced pancreatic juice mainly consists of water, bicarbonate, and digestive enzymes. Lipase and $\alpha$-amylase are secreted in their active forms, whereas trypsinogen, chymotrypsinogen, and phospholipase A are proenzymes (Renz-Polster \& Krautzig, 2013). Following secretion into the duodenum, the proenzymes become activated through enzymes of the intestinal mucosa. The active enzymes are able to digest carbohydrates (amylase), proteins (trypsin, chymotrypsin), and fats (lipase) (Hall, 2016; Renz-Polster \& Krautzig, 2013).

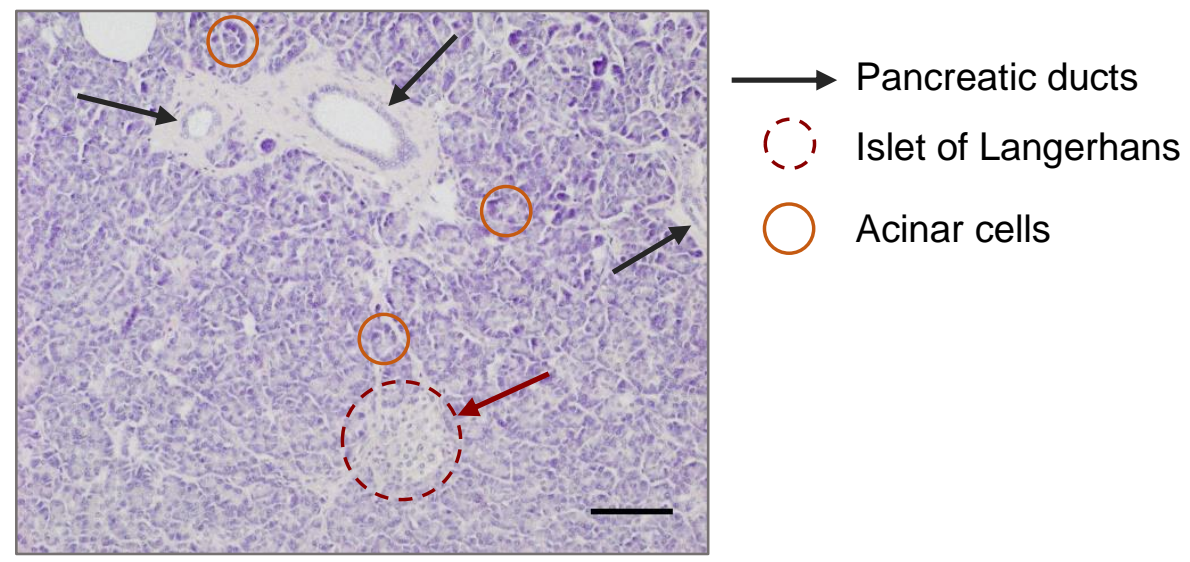

Figure 1: Pancreas anatomy. The main cell types of the exocrine pancreas are ductal cells (black arrow) and acinar cell networks (orange circle). Islets of Langerhans (red dotted circle) belong to the endocrine part of the pancreas. Representative image of hematoxylin and eosin (H\&E) staining of human PDAC tissue is shown. Scale bar $100 \mu \mathrm{m}$. 


\subsection{Pancreatic cancer}

Management of cancer is a major challenge regarding public health. The various cancer types differ strongly in their characteristics, aggressiveness, and response to treatment. Cancer is the second most common cause of death, only cardiovascular diseases lead to a higher number of deaths in the United States (U.S.) (Kochanek et al., 2016). However, within Europe cancer became already the number one among the causes of death in 13 countries (Townsend et al., 2015).

One of the most aggressive solid tumor entities is pancreatic cancer, which is currently the fourth leading cause of cancer-associated death (U.S. cancer statistic 2015) (Nielsen et al., 2016; Siegel et al., 2018) due to late diagnosis, strong heterogeneity and plasticity, and consequently strong resistance to chemotherapy (Adamska et al., 2017; Siegel et al., 2018) The most common type of pancreatic cancer is PDAC, which accounts for more than $90 \%$ of pancreatic tumor cases (Hezel et al., 2006; Prinz, 2012). Further categories of pancreatic neoplasms are neuroendocrine tumors, cystic pancreatic tumors, and acinar cell carcinomas. Rare types of pancreatic tumors include colloid carcinomas, pancreatoblastomas, and solid-pseudopapillary neoplasms (Kleeff et al., 2016; Prinz, 2012).

\subsection{Pancreatic ductal adenocarcinoma}

As previously mentioned, adenocarcinomas are the most common type of pancreatic cancer, with a low survival rate, highlighted by a mortality to incidence ratio of 0.98 (GLOBOCAN 2012) (Ferlay et al., 2015). Pancreatic cancer is projected to become the second most common cause of cancer-related death by 2030 not only in the U.S., but also in Germany (Quante et al., 2016; Rahib et al., 2014).

The relative 5-year survival rate for all stages is only $8 \%$, which increases to $32 \%$ if the tumor is still localized at the time of diagnosis (Siegel et al., 2018). The one-year survival rate is less than $20 \%$ and median overall survival is 6-9 months for locally advanced PDAC and 3 months if the disease is diagnosed at a metastatic stage (Adamska et al., 2017; Kleeff et al., 2016). Most PDAC cases are diagnosed at locally advanced or distant stages (e.g. $80 \%$ of cases in the U.S. between 2007 and 2013) (Siegel et al., 2018) due to a lack of biomarkers and screening methods for early detection (Cid-Arregui \& Juarez, 2015). Additionally, PDAC initially exerts no or unspecific symptoms, like abdominal pain or weight loss (Kleeff et al., 2016; Oberstein \& Olive, 2013). Symptoms in a progressed state of PDAC are bile duct or duodenal obstruction, consequently leading to jaundice, anorexia, vomiting, 
and nausea. In later stages the tumor can cause severe pain by the infiltration of mesenteric and retroperitoneal nerves (Drewes et al., 2018; Kleeff et al., 2016).

Moreover, pancreatic cancer (in the further course of the text used as synonym for PDAC) is one of the most aggressive tumor entities among solid neoplasms with perineural invasion and early distant metastases (Kleeff et al., 2016). Most commonly, PDAC metastasizes to the liver, lung, and/ or peritoneum (Makohon-Moore \& lacobuzio-Donahue, 2016). Therefore, less than $20 \%$ of PDAC patients are eligible for surgery with curative intention (Kleeff et al., 2016). Additionally, even if surgery is possible and no lymph-node or distant metastases are detected, recurrence of the tumor is a major problem (Erkan, Hausmann, et al., 2012). Moreover, a major challenge for the treatment of PDAC patients is the fact that PDAC is highly refractory to systemic therapies (Kleeff et al., 2016).

In contrast to other cancer types, histological hallmark features of PDAC are hypovascularity and an extensive desmoplastic reaction (tumor microenvironment) leading to local hypoxia and low nutrient availability (Ying et al., 2016). The desmoplastic reaction will be discussed in detail in a separate chapter. The main characteristics of PDAC are summarized in Figure 2.

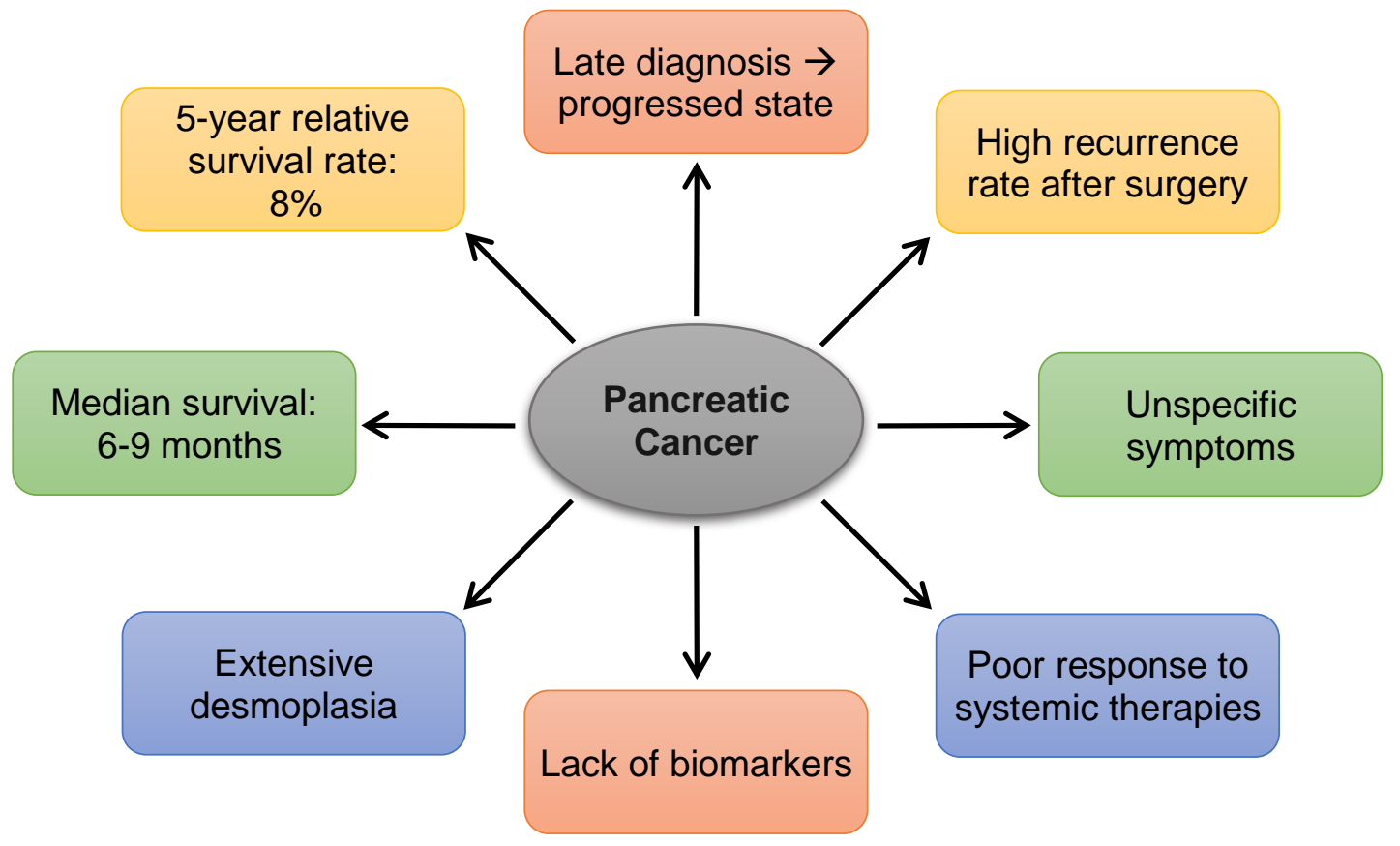

Figure 2: Schematic overview of pancreatic cancer characteristics. As described in this chapter, PDAC is marked by low survival rates, late diagnosis, and an extensive desmoplastic reaction. Due to these hallmark features PDAC treatment is extremely challenging.

\subsubsection{Risk factors}

Pancreatic cancer is a disease that commonly occurs in the elderly, thereby defining age as a risk factor. Moreover, an approximately two-fold increased risk is associated with long-term diabetes mellitus type 2 (Batabyal et al., 2014; Kleeff et al., 2016). Preventable 
risk factors for pancreatic cancer are tobacco smoking and heavy alcohol consumption (Bosetti et al., 2012; Duell, 2012; Genkinger et al., 2009; lodice et al., 2008). The latter can result in chronic pancreatitis, which also occurs independently of alcohol consumption, and increases the risk for pancreatic cancer by more than tenfold (Kleeff et al., 2016; Raimondi et al., 2010). Altogether, smoking, diabetes type 2, and chronic pancreatitis account for 25-30\% of all cases of PDAC (Kleeff et al., 2016). Furthermore, the risk for pancreatic cancer was reported to be increased with obesity, low physical activity, and nutritional aspects like high intake of saturated fats (Becker et al., 2014; Kleeff et al., 2016).

A further important point to mention is genetic factors, which increase the risk for pancreatic cancer. Although, sporadic pancreatic cancer accounts for approximately $90 \%$ of PDAC cases, $10 \%$ of PDAC patients have a family history of pancreatic cancer or inherited cancer syndromes (Becker et al., 2014; Chari et al., 2015). Most commonly, a specific genetic component leading to PDAC cannot be found in patients with familial pancreatic cancer. However, hereditary breast and ovarian cancer syndrome (HBOC), familial adenomatous polyposis, familial atypical multiple mole melanoma, Lynch syndrome, Peutz-Jeghers syndrome, and Li-Fraumeni syndrome were identified to increase the risk for pancreatic cancer development (Carrera et al., 2017; Grover \& Syngal, 2010). For instance, mutations in the tumor suppressors $B R C A 1$ and $B R C A 2$, which have relevant functions in DNA repair, are the genetic basis of $\mathrm{HBOC}$ syndrome, and BRCA2 mutations have been associated with an at least 3.5-fold increased risk to develop PDAC (Becker et al., 2014; The Breast Cancer Linkage Consortium, 1999). Consequently, the detection of genetic risk factors might help for early tumor detection and gives the possibility for gene-specific therapies (Becker et al., 2014).

\subsubsection{Precursor lesions}

PDAC develops through acinar-to-ductal metaplasia (ADM) and neoplastic precursor lesions (Eser et al., 2014). Three types of precursor lesions are known, explicitly microscopic pancreatic intraepithelial neoplasia (PanIN), which are the most important precursors for PDAC, intraductal papillary mucinous neoplasms (IPMN), and mucinous cystic neoplasms (MCN) (Ying et al., 2016). The definition of PanIN lesions is based on the observation that patients presented intraductal lesions years before they developed invasive adenocarcinoma and also on the finding that patients with fully resected tumors but ductal lesions in the remaining tissue developed adenocarcinomas. Furthermore, genetic mutations like KRAS mutations were described in these lesions (Brat et al., 1998; Klimstra \& Longnecker, 1994). Based on this, Hruban et al. described a progression model for PDAC referring to the different stages of PanIN lesions and their association with a 
distinctive pattern of genetic alterations (Hruban et al., 2000). PanIN lesions can be classified into three grades according to the extent of histopathological alterations. The lowest grades of lesions are PanIN-1A with flat lesions and PanIN-1B presenting low-grade dysplasia with papillary architecture. PanIN-2 already shows loss of polarity, nuclear crowding, and cell enlargement. Advanced PanIN-3 lesions, which are crucial for the progression into invasive carcinomas, exhibit severe nuclear atypia with nuclear enlargement and poor orientation of the nuclei. Furthermore, these lesions demonstrate with luminal necrosis and epithelial cell budding into the ductal lumen occurs (Hruban et al., 2008; Ying et al., 2016). An overview of the PanIN stages is given in Figure 3. PanIN-1 and PanIN-2 lesions can also be found in older people and in pancreatitis patients, but do not necessarily progress to PDAC (Hruban et al., 2008). Furthermore, PanIN lesion progression was found to be associated with an increase in extracellular matrix (ECM) deposition (Erkan, Hausmann, et al., 2012).

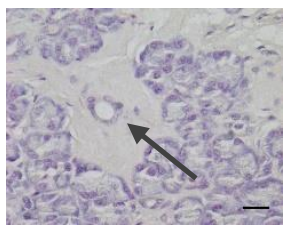

Normal duct

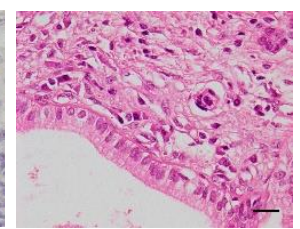

PanlN-1

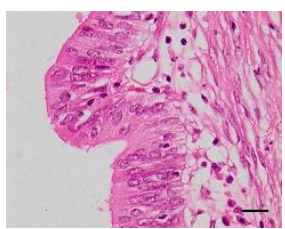

PanIN-2

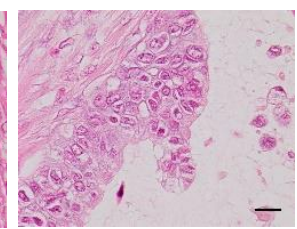

PanIN-3

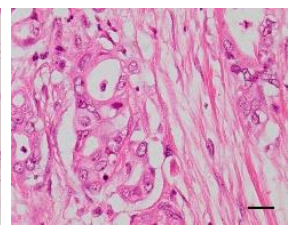

PDAC

KRAS

p16/CDKN2A

TP53

SMAD4

BRCA2

Figure 3: Precursor lesions of pancreatic cancer. Representative H\&E images for the different progression stages from normal pancreatic tissue to invasive PDAC are shown in human tissue. From left to right, normal acinar tissue with a normal duct (arrow), early PanIN-1, PanIN-2, and finally PanIN-3 lesions and invasive PDAC are presented. The most common genetic mutations in oncogenes and tumor suppressor genes are indicated in the order they usually occur during PDAC progression. Scale bars $20 \mu \mathrm{m}$. Own illustration, content based on (Hruban et al., 2008).

\subsubsection{Mutations in PDAC}

Genetically, PDAC harbors oncogenic KRAS mutations that are present in $88 \%$ to $100 \%$ of all PDAC patients and are thus seen as driver mutations for invasive PDAC. KRAS mutations are the earliest genetic alteration in human PDAC development, which are already present in PanIN-1 lesions, and are most commonly G12D and G12V KRAS-activating mutations (Almoguera et al., 1988; Eser et al., 2014; Hruban et al., 2008; Ying et al., 2016). Telomere shortening is another event that occurs during the early phase of carcinogenesis (Van Heek et al., 2002). The tumor suppressor gene CDKN2A ( $p 16)$ commonly gets inactivated in early carcinogenesis and is therefore commonly present in PanIN-2 lesions. Mutations in the TP53 (p53) tumor suppressor gene occur at high 
frequencies in PDAC patients in later stages of PDAC development (PanIN-3 lesions). Further tumor suppressor genes are mutated at lower frequencies, as there are DPC4/SMAD4 and BRCA2 genetic mutations, which are also described to occur later in PDAC progression (Figure 3) (Hruban et al., 2008; Jaffee et al., 2002; Neesse et al., 2015).

\subsubsection{The tumor microenvironment}

The tumor microenvironment (TME) in PDAC, also termed pancreatic cancer stroma is significantly involved in PDAC initiation, progression, and invasion. Furthermore, the tumor stroma has been strongly implicated in mediating chemoresistance in PDAC. The stromal components can make up as much as $90 \%$ of the total tumor mass (Ying et al., 2016).

The tumor stroma was proposed to exert a biophysical barrier to chemotherapeutic drug delivery due to its hypovascularity and high interstitial fluid pressure and subsequent vessel compression (Lunardi et al., 2014). Recently, the stroma was described to have tumorpromoting as well as tumor-restraining properties. Stromal depletion approaches were consequently discussed in detail in the current literature (Gore \& Korc, 2014; Jacobetz et al., 2013; Oezdemir et al., 2014; Olive et al., 2009; Provenzano et al., 2012; Rhim et al., 2014). However, the detailed contribution of the various stromal components remains largely unknown. Thus, it is necessary to elucidate the key players in the desmoplastic reaction and to understand the underlying mechanisms in more detail.

Major cellular components of the tumor stroma are CAFs and myofibroblasts, inflammatory cells, blood and lymphatic vessels that differ from normal vessel architecture, as well as immune cells, such as myeloid-derived suppressor cells (MDSCs), regulatory T cells, and tumor-associated macrophages (Neesse et al., 2011; Ying et al., 2016). Further components of the ECM in PDAC are collagen, glycosaminoglycans like hyaluronic acid, cytokines, soluble growth factors, matrix metalloproteinases, and secreted protein acidic and rich in cysteine (SPARC) (Lunardi et al., 2014; Neesse et al., 2011; Ying et al., 2016). As the desmoplastic reaction leads to a complex network of cellular and acellular components, complex signaling cues between tumor cells and the various stromal components occur. This tumor-stroma crosstalk results in transcriptional alterations of stromal cells, alterations in tumor cell biology, and consequently, leads to cancer cell motility, stromal neovascularization, and resistance to hypoxia and systemic therapies (Adamska et al., 2017; Neesse et al., 2011). For instance, Bachem et al. demonstrated that pancreatic cancer cells induced stromal cell proliferation and synthesis of ECM components by stromal cells, like collagen type I and type III, as well as fibronectin (Bachem et al., 2005). 


\subsubsection{Cancer-associated fibroblasts}

CAFs are key components in the stromal reaction and are mainly derived from PSCs (Apte et al., 2004). In a quiescent state PSCs are located in the periacinar space, have a stellate morphology, and store vitamin A droplets in the cytoplasm (Erkan, Adler, et al., 2012; Nielsen et al., 2016). Characteristic markers are vimentin, desmin, and nestin, however, these cells do not express $\alpha$-smooth muscle actin ( $\alpha$-SMA) (Omary et al., 2007).

Quiescent PSCs become activated in response to tissue injury or during carcinogenesis. Activation is mediated by oxidant stress, platelet-derived growth factor, transforming growth factor- $\beta$ (TGF- $\beta$ ), tumor necrosis factor- $\alpha$ (TNF- $\alpha$ ), and by several interleukins and cytokines as well as toxins (Erkan, Adler, et al., 2012; Nielsen et al., 2016). Activated PSCs acquire a spindle-shape myofibroblast-like phenotype, lose their vitamin A lipid droplets, and can be characterized by expression of $\alpha$-SMA as a typical marker (Nielsen et al., 2016). Further markers of activated fibroblasts are fibroblast activation protein (FAP), platelet-derived growth factor receptor- $\alpha$ (PDGFa) and PDGF $\beta$, and desmin. In contrast, fibroblast-specific protein 1 (FSP1) is a marker of quiescent fibroblasts (Kalluri, 2016). Of note, none of these markers are specific for fibroblasts and activated fibroblasts do not express all markers to the same extent, thus, illustrating the heterogeneity of this cell type (Kalluri, 2016). Moreover, in 2017, Öhlund et al. presented data regarding subpopulations of CAFs in pancreatic cancer, which significantly differ in their characteristics (Öhlund et al., 2017). The authors described one group of CAFs, the so-called myCAFs, being located in direct proximity to the tumor cells and expressing high levels of a-SMA. The second subgroup is involved in the immune reaction by expression of high levels of interleukin-6 (IL-6), therefore, termed iCAFs. These cells are located more distantly from tumor cells and express $\alpha$-SMA at lower levels (Öhlund et al., 2017).

Additionally, CAFs are proliferative, develop migratory and phagocytic properties, produce excessive amounts of ECM components, like collagen I and III as well as fibronectin, and furthermore, secrete a variety of proteins associated with proliferation, cell motility, invasion, and inflammation (Nielsen et al., 2016; Omary et al., 2007). Moreover, PSCs were shown to have the ability to produce matrix metalloproteinases (MMPs), enzymes that are responsible for ECM protein degradation and thus, were suggested to be critically involved in ECM turnover (Phillips et al., 2003). Consequently, activated PSCs are key components of the tumor-stroma crosstalk and thus, are strongly involved in tumor growth and progression (Nielsen et al., 2016). 


\subsubsection{Heterogeneity of pancreatic cancer}

The strong variability in the composition of the tumor stroma leads to another characteristic feature of pancreatic cancer, the heterogeneity. PDAC is a very heterogeneous disease in terms of genetic mutations, stromal composition, and tumor cell metabolic profiles (Adamska et al., 2017; Carr \& Fernandez-Zapico, 2016; Ying et al., 2016). Consequently, various subtypes of PDAC were defined aiming at patient stratification for more effective treatments according to the individual tumor characteristics.

Collisson et al., Bailey et al., and Moffitt et al. presented relevant data regarding genetic heterogeneity of PDAC (Bailey et al., 2016; Collisson et al., 2011; Moffitt et al., 2015). In 2011, Collisson and colleagues defined the classical, quasi-mesenchymal, and exocrine-like subtypes of PDAC, dependent on global gene expression data from resected PDAC patients. The classical subtype was associated with better survival and higher gene expression levels of GATA6 and enhanced dependency on KRAS. However, cell lines with the quasi-mesenchymal subtype showed better sensitivity towards gemcitabine treatment than cells with the classical subtype (Collisson et al., 2011).

Dependent on transcription factor expression and the respective downstream targets, the subtypes defined by Bailey et al. were the squamous, the pancreatic progenitor, the immunogenic, and the aberrantly differentiated endocrine exocrine subtypes (Bailey et al., 2016).

Interestingly, Moffitt et al. defined normal and activated stromal subtypes. SPARC, WNT family members, and MMPs were associated with the activated stroma subtype. The FAP gene that encodes for the fibroblast activation protein was furthermore detected in the activated subtype. Taken together, these characteristics resulted in lower median survival times in the activated stroma subtype (Moffitt et al., 2015).

\subsubsection{Mouse models of PDAC}

In order to find model systems that represent the heterogeneity of PDAC as well as the pronounced desmoplastic reaction, great effort was taken to translate the knowledge about genetic factors involved in PDAC progression into suitable in vivo models.

Most importantly to mention are the genetically engineered mouse models (GEMM). In 2003, Hingorani et al. presented promising data from PDX-1-Cre;LSL-KRAS ${ }^{G 12 D}$ and $P 48^{+C r e} ; L S L-K R A S^{G 12 D}(K C)$ mice that harbor a heterozygous activating $K R A S^{G 12 D}$ mutation (Hingorani et al., 2003). A Lox-STOP-Lox (LSL) construct was inserted into the KRAS locus of the mouse genome, which leads to inhibition of transcription and translation. The modified exon 1 was engineered to contain a glycine to aspartic acid transition in codon 12, which is the most common mutation in human PDAC (Hingorani et al., 2003). Consequently, this 
results in GTPase activity and thus, constitutively active downstream signaling pathways of Ras. These mice require interbreeding with mice that express Cre-recombinase from pancreas-specific promotors, like PDX-1 or P48 promoters. Excision of the silencing cassette with subsequent recombination results in conditional expression of the mutant allele in the pancreas (Hingorani et al., 2003). Pancreata of these KC mice are larger and have nodular parenchyma. Histologically, all stages of PanIN lesions were found with $100 \%$ penetrance and after 7-10 months there were more neoplastic ducts found than normal ducts. Moreover, in a few animals the disease progressed to invasive and metastatic PDAC. Therefore, this mouse model recapitulates a wide range of histopathological features of human PDAC (Figure 4) (Hingorani et al., 2003).

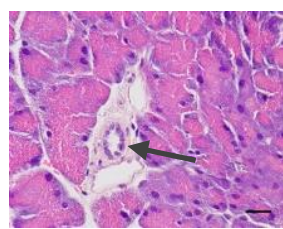

Normal duct

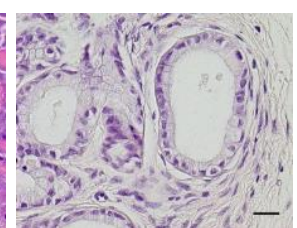

PanlN-1

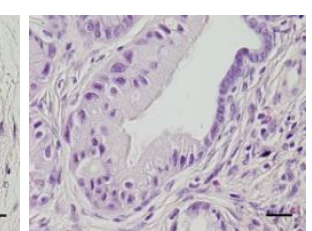

PanlN-2

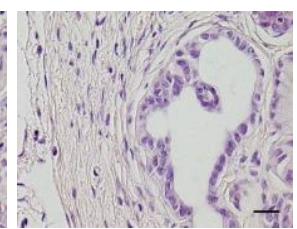

PanIN-3

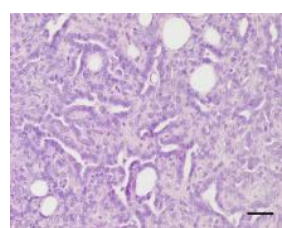

PDAC

Figure 4: Pancreatic cancer progression in KC mice. As described by Hingorani et al. in 2003, the $\mathrm{KC}$ model closely resembles the histological features of human PDAC with the typical precursor lesions (PanIN-1, PanIN-2, and PanIN-3). The normal duct is indicated by an arrow. Representative images of H\&E stainings, scale bars $20 \mu \mathrm{m}$.

LSL-Kras ${ }^{G 12 D /+} ; L S L-T r p 53^{R 172 H /+} ; P d x-1-C r e(K P C)$ mice additionally harbor an inactivating point mutant allele of $\operatorname{Trp} 53^{R 172 H}$, also silenced by the Lox-STOP-Lox cassette (Hingorani et al., 2005). These mice have a median survival of only 5 months and nearly all mice showed invasive carcinomas at time of necropsy (Hingorani et al., 2005). A large, firm, and fibrotic pancreas tumor can be found in nearly all of these mice. Usually mice develop cachexia, abdominal distension, and frequently hemorrhagic ascites. Moreover, biliary and small bowel obstructions are also present in these animals, which are also typical symptoms in PDAC patients (Hingorani et al., 2005). Both models are commonly used GEMMs, which recapitulate a wide spectrum of the human disease.

Additionally, xenograft and syngeneic models of PDAC are used, which can be based on murine or human cell lines or tissue fragments. In these models it is important to distinguish between heterotopic (subcutaneous) and orthotopic transplantation (into the mouse pancreas) (Ponz-Sarvise et al., 2015). Orthotopically transplanted mice resemble the clinical situation much better than heterotopically transplanted mice, develop metastases, and hence, allow conclusive studies of chemotherapeutic responses (Herreros-Villanueva et al., 2012). Moreover, several modifications of the tumor cells are possible prior to transplantation. 


\subsubsection{Therapeutic strategies}

Available treatment options are limited in pancreatic cancer due to its fast progression, early metastatic spread, and the high refractoriness to chemotherapeutics. Consequently, the disease status at time of diagnosis is crucial for the decision of the most suitable therapy (Adamska et al., 2017; Stathis \& Moore, 2010).

\subsubsection{Resectable pancreatic cancer}

Surgery remains the only potential curative strategy for PDAC but is limited to early disease stages (Adamska et al., 2017). Surgery is usually combined with adjuvant chemotherapeutic treatment to reduce the risk for recurrence (Garrido-Laguna \& Hidalgo, 2015). In the adjuvant setting 5-fluorouracil (5-FU) with folinic acid or gemcitabine, respectively, were shown in important clinical trials (European Study Group for Pancreatic Cancer (ESPAC)-1 and ESPAC-3, as well as Charité-Onkologie (CONKO)-001) to be superior in regards to median survival compared to observation groups (Neoptolemos et al., 2009; Oettle et al., 2013). Furthermore, gemcitabine with capecitabine was demonstrated in the ESPAC-4 phase III clinical trial to increase median overall survival in resected PDAC patients, compared to the gemcitabine group (Neoptolemos et al., 2017).

Neoadjuvant chemotherapy should be considered in borderline resectable pancreatic tumors to increase the chance for R0 resection (Adamska et al., 2017). Furthermore, neoadjuvant therapeutic regimens are used in clinical trials (Assifi et al., 2011; Philip et al., 2009).

\subsubsection{Unresectable pancreatic cancer}

5-FU alone or the combination with other cytotoxic drugs was used as first-line treatment for unresectable pancreatic cancer patients in earlier decades (Adamska et al., 2017). In 1997, gemcitabine monotherapy was described to be superior to 5-FU with regards to overall survival (1.2 months increase), performance status of patients, as well as pain intensity and reduction of analgesic treatment (Burris et al., 1997), thus becoming the standard treatment for metastatic pancreatic cancer (Ellenrieder et al., 2016). Chemotherapy with gemcitabine is usually well tolerated and rarely severe side-effects occur, e.g. hematotoxicity, vomiting, and increased liver enzymes (Ellenrieder et al., 2016). Several clinical trials failed to identify partner drugs for gemcitabine-based therapy in locally advanced PDAC to further improve patient outcome. Thus, gemcitabine monotherapy remained the standard treatment at this stage of the disease (Ellenrieder et al., 2016). 
Nevertheless, two novel treatment strategies were found to improve patient survival in the palliative setting. The treatment regimen FOLFIRINOX, which is a combination of oxaliplatin, irinotecan, leucovorin, and 5-fluorouracil, as first-line therapy in metastatic PDAC increased survival rates compared to gemcitabine (11.1 vs. 6.8 months) (Conroy et al., 2011). Progression-free survival times and response rates were also improved in the FOLFIRINOX group. However, severe side-effects like febrile neutropenia limit the use of this therapy regimen to patients with good performance status (Conroy et al., 2011).

The second combination therapy is nano-formulated albumin bound (nab)-paclitaxel plus gemcitabine (Von Hoff et al., 2013). Albumin is known as a natural carrier of endogenous hydrophobic molecules. Consequently, an albumin-bound formulation of paclitaxel, a waterinsoluble chemotherapeutic drug, was designed. In this formulation, albumin binds to paclitaxel in a reversible non-covalent manner to improve the pharmacokinetic profile of the drug (Miele et al., 2009). Von Hoff et al. reported the results of a clinical phase III study of metastatic pancreatic cancer patients treated either with nanoparticle albumin bound (nab)-paclitaxel plus gemcitabine or gemcitabine monotherapy. The trial clearly demonstrated that the combination therapy is superior over monotherapy in regards to median overall survival (8.5 vs. 6.7 months), survival and response rates, and progression free survival. Similar to the FOLFIRINOX regimen, the adverse effects increased in the combination therapy (Von Hoff et al., 2013).

The identification of molecular targets for novel treatment opportunities are subject to intensive research. Subgroup analysis is a promising strategy for personalized treatment and is required for novel PDAC treatment approaches due to the high heterogeneity of mutations in these tumors (Adamska et al., 2017).

In case of tumor progression during chemotherapy, second-line treatment might be beneficial for those patients. The choice of appropriate treatment protocols depends on the first-line therapeutics and the patient performance status. Most protocols are based on gemcitabine or 5-FU (Ellenrieder et al., 2016).

\subsection{Gemcitabine}

\subsubsection{Cellular uptake of gemcitabine}

Gemcitabine is a cytidine analogue that has potent antitumor activity and is routinely used in chemotherapeutic treatment regimens in varying cancer types. It is administered as the prodrug 2',2'-difluoro 2'-deoxycytidine (dFdC), the native form of gemcitabine (Mini et al., 2006). It requires cellular uptake and subsequent sequential intracellular phosphorylation to exert its cytotoxic activity (Mini et al., 2006), as visualized in Figure 5. 
Cellular uptake is achieved by specific nucleoside transporters on the cell plasma membrane. Two different types of these transporters exist. SLC28 human concentrative nucleoside transporters (hCNTs) are sodium-dependent carriers, whereas SLC29 transporters, the human equilibrative nucleoside transporters (hENTs) work sodiumindependently (Mini et al., 2006; Wong et al., 2009). The most important transporter is hENT1, but also hENT2, hCNT1, and hCNT3 were demonstrated to play important roles in gemcitabine transport through the plasma cell membrane (De Sousa Cavalcante \& Monteiro, 2014) (Figure 5). Consequently, the expression levels of nucleoside transporters are intensively investigated for its impact on gemcitabine effectiveness as anticancer drug. For instance, Greenhalf et al. presented data from the ESPAC-3 clinical trial showing high hENT1 expression being correlated with increased overall survival in gemcitabine-treated resected PDAC patients (Greenhalf et al., 2014).

\subsubsection{Activation of gemcitabine}

Intracellularly, gemcitabine is phosphorylated to 2',2'-difluoro 2'-deoxycytidine monophosphate (dFdCMP) by deoxycytidine kinase (dCK), which is considered to be the rate-limiting step in gemcitabine activation. Nucleoside kinases are required for further gemcitabine phosphorylation. These are the pyrimidine nucleoside monophosphate kinase (UMP-CMP), which was described to catalyze the second phosphorylation step to dFdCDP, and the nucleoside diphosphate kinase, which is involved in the final phosphorylation step (De Sousa Cavalcante \& Monteiro, 2014; Wong et al., 2009) (Figure 5). Other kinases, like the mitochondrial enzyme thymidine kinase 2, are also involved in gemcitabine phosphorylation to its cytotoxic form, but their impact is comparably low (Mini et al., 2006; Wang et al., 1999).

\subsubsection{Inactivation of gemcitabine}

The main inactive form of gemcitabine is 2',2'-difluoro 2'-deoxyuridine (dFdU). Several enzymes are involved in the inactivation of gemcitabine, but the most important one is CDA, which is responsible for deamination of the majority of intracellular native gemcitabine to $\mathrm{dFdU}$. Additionally, the monophosphate form of gemcitabine dFdCMP is deaminated by deoxycytidine deaminase (DCTD) (Alvarellos et al., 2014). Reversion of the initial phosphorylation step is catalyzed by an enzyme group so called cytosolic 5'-nucleotidases (NT5Cs) and is therefore another inactivation pathway for intracellular gemcitabine. These enzymes do not produce inactive $\mathrm{dFdU}$ metabolites but generate native $\mathrm{dFdC}$ (Alvarellos et al., 2014) (Figure 5). 

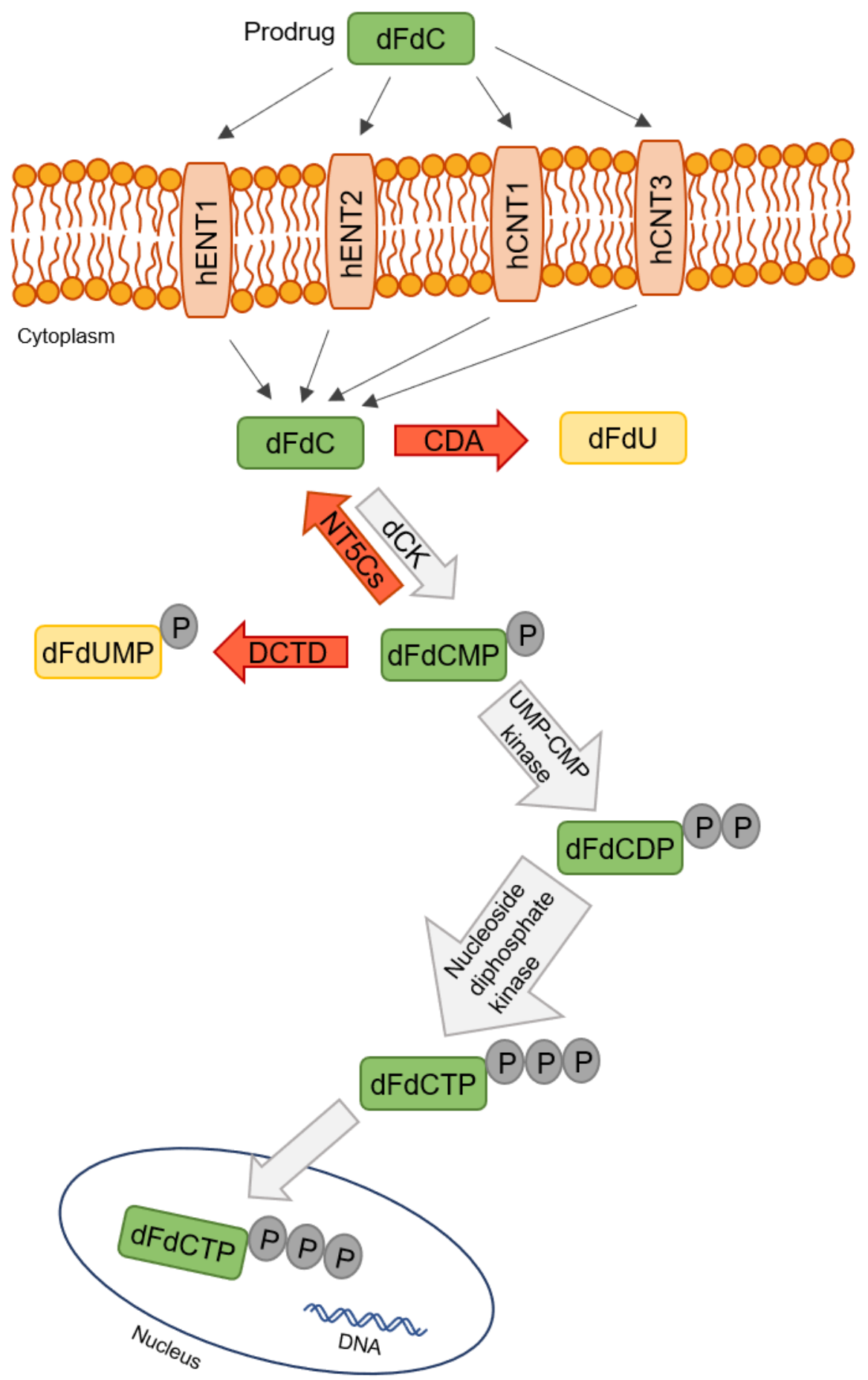

Figure 5: Schematic illustration of gemcitabine uptake and metabolism. Gemcitabine is a prodrug which requires cellular uptake by specific transporters and intracellular phosphorylation to become cytotoxically active. Cellular uptake of the gemcitabine prodrug $(\mathrm{dFdC})$ is mainly achieved by the hENT1, hENT2, hCNT1, and hCNT3 transporters. Intracellular gemcitabine is phosphorylated by deoxycytidine kinase (dCK) and other kinases to the cytotoxic triphosphate metabolite (dFdCTP), which is the active form and thus, is finally incorporated into DNA. Gemcitabine is rapidly inactivated to 2',2'-difluoro 2'-deoxyuridine ( $\mathrm{dFdU}$ ) through deamination by key inactivating enzymes, like CDA and DCTD. Gemcitabine is further inactivated through dephosphorylation to dFdC by cytosolic 5'-nucleotidases (NT5Cs). Own illustration, based on (De Sousa Cavalcante \& Monteiro, 2014; Mini et al., 2006). 


\subsubsection{Mechanisms of action of gemcitabine}

Gemcitabine in its active form inhibits DNA synthesis by incorporation into DNA and subsequent termination of chain elongation (De Sousa Cavalcante \& Monteiro, 2014). Interestingly, following dFdCTP incorporation into DNA, another single deoxynucleotide will still be incorporated before chain elongation stops. Given this non-terminal position of gemcitabine, DNA polymerases are unable to proceed with chain elongation. Accordingly, this is known as 'masked chain-termination'. Furthermore, exactly the same fact also prevents DNA repair enzymes to remove gemcitabine from the DNA (De Sousa Cavalcante \& Monteiro, 2014). Additionally, the cytotoxic effect of gemcitabine is increased by 'selfpotentiating' mechanisms. This refers to enzyme inhibition by gemcitabine metabolites, thus reducing the intracellular levels of competing natural DNA precursors (Mini et al., 2006).

\subsection{Chemotherapeutic resistance in pancreatic cancer}

Broad resistance towards chemotherapeutics is a major challenge in the treatment of pancreatic cancer. Chemotherapeutic resistance can be divided into innate and acquired resistance. Pancreatic cancer is characterized by innate resistance to most therapies. Furthermore, it is distinguished between cell-autonomous and non-cell-autonomous mechanisms of resistance (Oberstein \& Olive, 2013). Notably, important signaling pathways involved in growth regulation, proliferation, differentiation, apoptosis, invasion, and angiogenesis might contribute to chemotherapeutic resistance via both routes (Amrutkar \& Gladhaug, 2017).

The high degree of genetic alterations plays an important role in cell-autonomous chemoresistance. Moreover, epigenetic mechanisms and post-transcriptional gene regulation are involved in cell intrinsic chemotherapeutic resistance (Chand et al., 2016; Oberstein \& Olive, 2013). For instance, Ras mutations promote the desmoplastic reaction by paracrine signals, which is in turn a major contributor to non-cell-autonomous chemotherapeutic resistance (Oberstein \& Olive, 2013). In contrast to the driver mutations, genetic changes that occur in the advanced state of the disease rather contribute to acquired resistance (Oberstein \& Olive, 2013).

The main extrinsic factor of chemotherapeutic resistance is the TME. It is subject of intensive research to reveal the mechanisms underlying the complex interplay between tumor cells and stromal components (Chand et al., 2016). The desmoplastic reaction in PDAC is significantly influenced by this tumor-stroma crosstalk, thus providing a non-cellautonomous barrier for drug delivery and response (Oberstein \& Olive, 2013). Hypoxia and hypovascularization are the main characteristics of PDAC and create a nutrient and 
oxygen poor environment for the tumor cells. Consequently, only the most aggressive tumor cells will survive. They adapt to this challenging environment by acute cellular

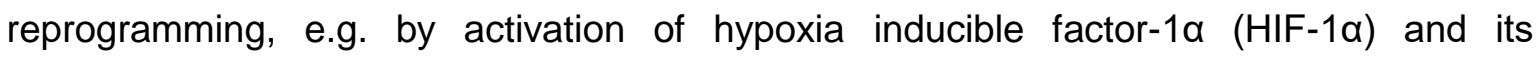
downstream pathways, thereby enhancing chemoresistance (Chand et al., 2016).

CAFs drive ECM remodeling and secrete stromal components like collagen type I and MMPs and are the major fibrosis-producing cells. The resulting dense fibrous stroma causes vessel compression and was described as a biophysical barrier for efficient drug delivery (Amrutkar \& Gladhaug, 2017).

\subsubsection{Chemotherapeutic resistance towards gemcitabine}

The clinical response to gemcitabine is low and various reasons have been proposed, like alterations in drug metabolism, a reduction in cellular uptake of the gemcitabine prodrug, as well as rapid enzymatic inactivation (Frese et al., 2012; Greenhalf et al., 2014; Maréchal et al., 2012; Weizman et al., 2014)

Gemcitabine drug delivery is subject to the described challenges during drug delivery to the tumor. Additional mechanisms need to be considered that are specific to gemcitabine transport, cellular uptake, and activation. Gemcitabine transport through the plasma cell membrane is mainly mediated by the hENT1 nucleoside transporter. Thus, low expression of this transporter was assumed to be associated with gemcitabine resistance (Oberstein \& Olive, 2013). Maréchal et al. (2012) demonstrated a direct correlation of hENT1 expression in human tumor samples with survival of patients who underwent adjuvant gemcitabine therapy following surgery.

Moreover, gemcitabine metabolizing enzymes are involved in resistance. The rate-limiting activation step for gemcitabine is phosphorylation by dCK, hence the expression level of dCK is crucial for gemcitabine efficacy (Maréchal et al., 2012). CDA as main inactivating enzyme is intensively studied for its impact on gemcitabine resistance, and expression was already described to be correlated with overall survival of PDAC patients (Amrutkar \& Gladhaug, 2017). Moreover, enhanced activity of NT5C1A, a mammalian 5'-nucleotidase, prevents intracellular dFdCTP formation, thus making it an interesting subject for further investigation on its role in gemcitabine resistance (Amrutkar \& Gladhaug, 2017). Enhanced activity was described in the context of gemcitabine-resistant leukemia cell lines (Dumontet et al., 1999), but not in solid tumors so far.

Ribonucleotide reductase $(R R)$ is crucial in DNA synthesis by converting ribonucleotides into dNTPs, where subunit M1 (RRM1) is important for enzyme regulation and subunit 2 (RRM2) for enzyme activity (Amrutkar \& Gladhaug, 2017). RR inhibition is achieved by $\mathrm{dFdCDP}$ and leads to reduced levels of dNTPs, thus facilitating dFdCTP incorporation into 
DNA (Heinemann et al., 1990). Furthermore, increased pyrimidine biosynthesis, leading to high levels of deoxycytidine triphosphate, was suggested to reduce gemcitabine effectiveness through molecular competition (Shukla et al., 2017)

\subsection{Mammalian 5'-nucleotidases}

Mammalian 5'-nucleotidases are involved in gemcitabine inactivation and are consequently interesting targets to study in regards to chemotherapeutic resistance. They build a class of enzymes that catalyze the dephosphorylation of non-cyclic nucleoside monophosphates to nucleosides and inorganic phosphates. Thus, these enzymes are also named nucleoside monophosphate phosphohydrolases (Bianchi \& Spychala, 2003).

Seven members of this enzyme family have been characterized so far, explicitly ecto-5'-nucleotidase, cytosolic 5'-nucleotidase IA, cytosolic 5'-nucleotidase IB, cytosolic 5'-nucleotidase II, cytosolic 5'-nucleotidase III, cytosolic 5' (3')-deoxyribonucleotidase, and mitochondrial 5' (3')-deoxyribonucleotidase (Hunsucker et al., 2005). They can be distinguished by their subcellular localization, their substrate specificity, and their tissue-specific expression (Hunsucker et al., 2005). For instance, cytosolic 5 '-nucleotidase 1 and 3 have tissue-specific expression compared to the other ubiquitously expressed 5'-nucleotidases. Typical for all 5'-nucleotidases is a broad substrate specificity and the dependency on magnesium (Bianchi \& Spychala, 2003).

A common catalytic mechanism among intracellular 5'-nucleotidases is assumed due to the presence of common motifs. The formation of a phosphoenzyme intermediate is assumed for all 5'-nucleotidases (Bianchi \& Spychala, 2003; Hunsucker et al., 2005).

\subsubsection{Cytosolic 5'-nucleotidase $1 \mathrm{~A}$}

The cytosolic 5'-nucleotidase 1A (NT5C1A) has tissue-specific expression with the highest expression in skeletal and heart muscle (Bianchi \& Spychala, 2003). The gene is located on chromosome 1 p33-p34.3, consists of 6 exons, and has a length of 1107 bp (Hunsucker et al., 2001). The purified enzyme has a subunit size of $41 \mathrm{kDa}$ and is a tetramer. NT5C1A has a broad substrate-specificity with a preference for adenosine monophosphate (AMP) and pyrimidine deoxyribonucleotides (Hunsucker et al., 2005). Physiologically, NT5C1A is responsible for the formation of adenosine under ischemic and hypoxic conditions (Hunsucker et al., 2005). Due to its catalytic mechanism and a low $\mathrm{Km}$ value for deoxyribonucleoside monophosphates, NT5C1A may play an important role in the regulation of pyrimidine deoxynucleotide pools (Bianchi \& Spychala, 2003; Hunsucker et al., 2005). 
Furthermore, this high affinity for deoxynucleoside monophosphates suggests a high affinity for deoxynucleoside analogues as well. Thus, NT5C1A might reduce the pharmacological activity of deoxynucleoside analogues by reversing the initial activation step and consequently, decreasing intracellular dFdCTP formation (Bianchi \& Spychala, 2003; Dumontet et al., 1999; Hunsucker et al., 2005; Hunsucker et al., 2001; Saliba et al., 2016). This dephosphorylation of deoxynucleoside monophosphates and potentially also its analogues render $\mathrm{NT5C1A}$ an interesting target for detailed investigation regarding its potential in mediating chemotherapeutic resistance.

\subsection{Aims of the study}

Pancreatic cancer is characterized by a dense and hypovascular tumor stroma and exerts strong resistance towards chemotherapeutic agents. The tumor stroma components were described to act as a biophysical barrier to chemotherapeutic drug delivery. This barrier was defined by pronounced vessel compression and high interstitial fluid pressure, being the result of excess collagen and hyaluronan content (Jacobetz et al., 2013; Olive et al., 2009; Provenzano et al., 2012). Especially CAFs, as the predominant source of ECM proteins (Apte et al., 2004; Bachem et al., 2005), play a central role in the desmoplastic reaction. Consequently, several studies proposed stroma depletion as novel strategy to enhance drug responses (Jacobetz et al., 2013; Olive et al., 2009; Provenzano et al., 2012).

Strikingly, tumors from GEMMs with depleted stroma were observed to have a more undifferentiated phenotype and were reported to be more aggressive (Oezdemir et al., 2014; Rhim et al., 2014), thus indicating also tumor restraining properties of stromal components. As a result, stromal reprogramming rather than depletion seems to be a more promising way for improved drug efficacy. Given the intensive cross-talk between stromal components and pancreatic cancer cells, discovering potential biomarkers or therapeutic targets is challenging.

In my thesis, I sought to deepen our understanding about stromal and epithelial cell-driven drug resistance in PDAC. We revisited the drug metabolism of gemcitabine to unravel how differential stromal and epithelial expression of gemcitabine inactivating enzymes contribute to drug resistance. In particular, we set the focus on NT5C1A, a gemcitabine-inactivating nucleotidase, to elucidate its potential role as mediator of gemcitabine resistance in PDAC. 
This was achieved by investigating the following:

1. Analysis of drug metabolites in KPC bulk tissues, matched liver tissues, liver metastases, and also fibroblast and tumor cell lines.

2. Elucidation of the expression pattern of gemcitabine metabolizing enzymes in the epithelial and stromal compartments.

3. Evaluation of NT5C1A for its function in cell-autonomous and non-cell-autonomous resistance to gemcitabine.

My hypotheses are based on the initial finding that highest levels of gemcitabine prodrug and of the cytotoxic metabolite dFdCTP accumulate in primary tumor tissue of KPC mice. Consequently, hypothesis $\mathbf{1}$ is: The tumor stroma is actively involved in drug metabolism in pancreatic cancer by providing a biochemical treatment barrier.

Consequently, we studied differences in the expression of gemcitabine metabolizing enzymes between epithelial cells and stromal cells. In this context, NT5C1A was of utmost interest, as it is a previously unrecognized gemcitabine inactivating enzyme in pancreatic cancer. Thus, the aim was to characterize NT5C1A as mediator of epithelial and stromal driven gemcitabine resistance and to determine its potential as predictive biomarker for improved patient stratification.

Hypothesis 2 is therefore: Pronounced NT5C1A expression in the epithelial compartment and low expression levels in the tumor stroma mediate gemcitabine resistance in pancreatic cancer. 


\section{Material and Methods}

\subsection{Material}

\subsubsection{Lab equipment}

Table 1: Lab equipment.

\begin{tabular}{|l|l|}
\hline Equipment & Company \\
\hline Analog rotator - RS-RD 5 & $\begin{array}{l}\text { Phoenix Instrument GmbH, Garbsen, } \\
\text { Germany }\end{array}$ \\
\hline Analytical lab balance - MC1 AC210P & Sartorius AG, Göttingen, Germany \\
\hline Anesthetic vaporizer - Sigma delta & Penlon Ltd., Abingdon, UK \\
\hline Aspirator - Grant-bio FTA-1 & Grant Instruments, Cambridge, UK \\
\hline Autoclave - FVA2/A1 Fedegari group & $\begin{array}{l}\text { ibs/ tecnomara GmbH, Fernwald, } \\
\text { Germany }\end{array}$ \\
\hline Autoclave - Laboklav & $\begin{array}{l}\text { SHP Steriltechnik AG, Detzel } \\
\text { Schloss/Satuelle, Germany }\end{array}$ \\
\hline AutoClip ${ }^{\circledR}$ system & $\begin{array}{l}\text { Fine Science Tools GmbH, Heidelberg, } \\
\text { Germany }\end{array}$ \\
\hline $\begin{array}{l}\text { Beaker/ Erlenmeyer flask - Schott } \\
\text { DURAN }\end{array}$ & $\begin{array}{l}\text { DWK Life Sciences GmbH, } \\
\text { Wertheim/Main, Germany }\end{array}$ \\
\hline Benchtop Orbital Shaker - MaxQ ${ }^{\text {TM }}$ 4450 & $\begin{array}{l}\text { Thermo Fisher Scientific, Waltham, MA, } \\
\text { USA }\end{array}$ \\
\hline $\begin{array}{l}\text { Biological safety cabinet, class II - Thermo } \\
\text { Scientific }\end{array}$ & $\begin{array}{l}\text { Thermo Electron LED GmbH, } \\
\text { Langenselbold, Germany }\end{array}$ \\
\hline $\begin{array}{l}\text { Cell Counter - Cellometer } \\
\text { with single use cell counting chambers }\end{array}$ & $\begin{array}{l}\text { Nexcelom Bioscience LLC., Lawrence, } \\
\text { MA, USA }\end{array}$ \\
\hline $\begin{array}{l}\text { Centrifuge - Heraeus Megafuge 16/ } \\
\text { Multifuge X1R }\end{array}$ & $\begin{array}{l}\text { Thermo Fisher Scientific, Waltham, MA, } \\
\text { USA }\end{array}$ \\
\hline Centrifuge - Universal 320R & $\begin{array}{l}\text { Andreas Hettich GmbH \& Co. KG, } \\
\text { Tuttlingen, Germany }\end{array}$ \\
\hline CO incubator - HERAcell ${ }^{\circledR}$ 240i & $\begin{array}{l}\text { Thermo Fisher Scientific, Waltham, MA, } \\
\text { USA }\end{array}$ \\
\hline Cryo boxes with grid inserts - Labsolute & $\begin{array}{l}\text { Th. Geyer GmbH \& Co. KG, Renningen, } \\
\text { Germany }\end{array}$ \\
\hline $\begin{array}{l}\text { Dewar flask for liquid nitrogen - KGW- } \\
\text { Isotherm }\end{array}$ & $\begin{array}{l}\text { Karlsruher Glastechnisches Werk - } \\
\text { Schieder GmbH, Karlsruhe, Germany }\end{array}$ \\
\hline Digital camera - Cyber-shot DSC-RX100 & Sony Europe Limited, Surrey, UK \\
\hline Dry bath incubator - BSH 5002-E & $\begin{array}{l}\text { Benchmark Scientific, Inc., Edison, NJ, } \\
\text { USA }\end{array}$ \\
\hline Fluid aspiration system - BVC control & $\begin{array}{l}\text { Vacuubrand GmbH \& Co. KG, Wertheim, } \\
\text { Germany }\end{array}$ \\
\hline & \\
\hline
\end{tabular}




\begin{tabular}{|c|c|}
\hline $\begin{array}{l}\text { Fluorescence microscope - DMi8 } \\
\text { automated }\end{array}$ & $\begin{array}{l}\text { Leica Microsystems CMS GmbH, Wetzlar, } \\
\text { Germany }\end{array}$ \\
\hline Forceps and dissecting scissors & $\begin{array}{l}\text { Karl Hammacher GmbH, Solingen, } \\
\text { Germany }\end{array}$ \\
\hline $\begin{array}{l}\text { Freezer - Mediline/ Fridge - Profi line/ } \\
\text { Fridge and freezer - glass line }\end{array}$ & $\begin{array}{l}\text { Liebherr-International Deutschland } \mathrm{GmbH} \text {, } \\
\text { Biberach an der Riß, Germany }\end{array}$ \\
\hline $\begin{array}{l}\text { Glass bottles } 100 \mathrm{ml}, 250 \mathrm{ml}, 500 \mathrm{ml}, 1 \mathrm{l}- \\
\text { Schott DURAN }{ }^{\circledR}\end{array}$ & $\begin{array}{l}\text { DWK Life Sciences GmbH, } \\
\text { Wertheim/Main, Germany }\end{array}$ \\
\hline $\begin{array}{l}\text { Graduated cylinders - SILBERBRAND } \\
\text { ETERNA - } 100 \mathrm{ml}, 500 \mathrm{ml}, 1 \mathrm{l}\end{array}$ & $\begin{array}{l}\text { BRAND GmbH + Co. KG, Wertheim, } \\
\text { Germany }\end{array}$ \\
\hline $\begin{array}{l}\text { Heated Paraffin Embedding Module - } \\
\text { EG1150 H with cold plate - HistoCore } \\
\text { Arcadia C }\end{array}$ & $\begin{array}{l}\text { Leica Biosystems Nussloch GmbH, } \\
\text { Nussloch, Germany }\end{array}$ \\
\hline $\begin{array}{l}\text { High resolution ultrasound system - Visual } \\
\text { Sonics Vevo2100, including imaging } \\
\text { stage, anesthesia line, and micro scan } \\
\text { transducer (MS-550-D, 22-55 MHz) }\end{array}$ & $\begin{array}{l}\text { FUJIFILM VisualSonics Inc., Toronto, } \\
\text { Canada }\end{array}$ \\
\hline $\begin{array}{l}\text { Horizontal gel electrophoresis system - } \\
41-2025\end{array}$ & $\begin{array}{l}\text { PEQLAB Biotechnologie } \mathrm{GmbH} \text {, Erlangen, } \\
\text { Germany }\end{array}$ \\
\hline Hot plate -062 & $\begin{array}{l}\text { Labotect Labor-Technik-Göttingen GmbH, } \\
\text { Rosdorf, Germany }\end{array}$ \\
\hline Ice bath - 1-6030 & $\begin{array}{l}\text { neoLab Migge } \mathrm{GmbH} \text {, Heidelberg, } \\
\text { Germany }\end{array}$ \\
\hline Ice machine - Scotsman ${ }^{\circledR}$ AF80 & Scotsman Ice Srl, Milano, Italy \\
\hline Imaging system - ChemiDoc ${ }^{\mathrm{TM}}$ XRS+ & $\begin{array}{l}\text { Bio-Rad Laboratories GmbH, Munich, } \\
\text { Germany }\end{array}$ \\
\hline $\begin{array}{l}\text { Immunostaining slide rack and slides - } \\
\text { Thermo Scientific }^{\mathrm{TM}} \text { Shandon Sequenza }\end{array}$ & $\begin{array}{l}\text { Thermo Shandon Limited, Subsidiary of } \\
\text { Thermo Fisher Scientific, Runcorn, UK }\end{array}$ \\
\hline Incubator - UF260/ UN55pa & $\begin{array}{l}\text { Memmert GmbH \& Co. KG, Schwabach, } \\
\text { Germany }\end{array}$ \\
\hline INTAS UV system & $\begin{array}{l}\text { Intas Science Imaging Instruments } \mathrm{GmbH} \text {, } \\
\text { Göttingen, Germany }\end{array}$ \\
\hline Lab balance - PCB 2000-1 & Kern \& Sohn GmbH, Balingen, Germany \\
\hline Lab balance - PT210/ universal PRO11 & Sartorius AG, Göttingen, Germany \\
\hline $\begin{array}{l}\text { Liquid nitrogen cell storage canister - } \\
\text { Bio-cane }^{\mathrm{TM}} 47\end{array}$ & $\begin{array}{l}\text { Thermo Fisher Scientific, Waltham, MA, } \\
\text { USA }\end{array}$ \\
\hline Magnetic stirrer - RH basic & $\begin{array}{l}\text { IKA }{ }^{\circledR} \text {-Werke GmbH \& Co. KG, Staufen, } \\
\text { Germany }\end{array}$ \\
\hline $\begin{array}{l}\text { Microcentrifuge - PerfectSpin } 24 \text { Plus/ } \\
\text { PerfectSpin 24R, refrigerated }\end{array}$ & $\begin{array}{l}\text { PEQLAB Biotechnologie GmbH, Erlangen, } \\
\text { Germany }\end{array}$ \\
\hline Microplate reader - PHOmo & $\begin{array}{l}\text { Autobio Labtec Instruments Co. Ltd., } \\
\text { Zhengzhou, China }\end{array}$ \\
\hline
\end{tabular}




\begin{tabular}{|c|c|}
\hline Microscope - Axiovert 25 & Carl Zeiss AG, Oberkochen, Germany \\
\hline Microscope - BX43F/ CKX53 & Olympus Corporation, Tokyo, Japan \\
\hline Microwave - NN-E209W & $\begin{array}{l}\text { Panasonic Marketing Europe } \mathrm{GmbH} \text {, } \\
\text { Hamburg, Germany }\end{array}$ \\
\hline $\begin{array}{l}\text { Microwave heatpad for animals - } \\
\text { snuggleSafe }^{\circledR}\end{array}$ & $\begin{array}{l}\text { SnuggleSafe Lenric C21, West Sussex, } \\
\text { UK }\end{array}$ \\
\hline Mini centrifuge - sprout ${ }^{\mathrm{TM}}$ & Heathrow Scientific, Vernon Hills, IL, USA \\
\hline $\begin{array}{l}\text { Mini gel tank - Invitrogen, for Western blot } \\
\text { analysis with mini blot module - B1000 }\end{array}$ & $\begin{array}{l}\text { Thermo Fisher Scientific, Waltham, MA, } \\
\text { USA }\end{array}$ \\
\hline $\begin{array}{l}\text { Multi-functional orbital shaker - Grant-bio } \\
\text { PSU-20i }\end{array}$ & Grant Instruments, Cambridge, UK \\
\hline Nano Photometer - P330 & $\begin{array}{l}\text { Intas Science Imaging Instruments } \mathrm{GmbH} \text {, } \\
\text { Göttingen, Germany }\end{array}$ \\
\hline Oxygen generator - Aeroplus 5 & $\begin{array}{l}\text { Kroeber Medizintechnik GmbH, Dieblich, } \\
\text { Germany }\end{array}$ \\
\hline pH meter - FiveEasy Plus & $\begin{array}{l}\text { METTLER TOLEDO AG, Schwerzenbach, } \\
\text { Switzerland }\end{array}$ \\
\hline Pipette filler - pipetus ${ }^{\circledR}$ akku & $\begin{array}{l}\text { Hirschmann Laborgeräte GmbH \& Co. KG, } \\
\text { Eberstadt, Germany }\end{array}$ \\
\hline $\begin{array}{l}\text { Pipettes - Research plus }(10 \mu \mathrm{l}, 20 \mu \mathrm{l}, \\
100 \mu \mathrm{l}, 200 \mu \mathrm{l}, 1000 \mu \mathrm{l}) \text {, Multipette }{ }^{\circledR} \text { plus }\end{array}$ & Eppendorf AG, Hamburg, Germany \\
\hline Plate spinner - PerfectSpin P & $\begin{array}{l}\text { PEQLAB Biotechnologie GmbH, Erlangen, } \\
\text { Germany }\end{array}$ \\
\hline $\begin{array}{l}\text { PowerPac }{ }^{\mathrm{TM}} \mathrm{HC} \text { for gelelectrophoresis } \\
\text { and Western blot analysis }\end{array}$ & $\begin{array}{l}\text { Bio-Rad Laboratories GmbH, Munich, } \\
\text { Germany }\end{array}$ \\
\hline $\begin{array}{l}\text { Real-time PCR system - Applied } \\
\text { Biosystems StepOnePlus }{ }^{\mathrm{TM}}\end{array}$ & $\begin{array}{l}\text { Thermo Fisher Scientific, Waltham, MA, } \\
\text { USA }\end{array}$ \\
\hline Residual gas filter - CONTRAfluran ${ }^{\mathrm{TM}}$ & ZeoSys GmbH, Berlin, Germany \\
\hline $\begin{array}{l}\text { Rotary Microtome - RM2265 with flattening } \\
\text { table for histopathology - HI } 1220\end{array}$ & $\begin{array}{l}\text { Leica Biosystems Nussloch GmbH, } \\
\text { Nussloch, Germany }\end{array}$ \\
\hline Shaker - Duomax 1030 & $\begin{array}{l}\text { Heidolph Instruments GmbH \& CO. KG, } \\
\text { Schwabach, Germany }\end{array}$ \\
\hline Shaver - ER-PA10 & Panasonic Corporation, Osaka, Japan \\
\hline Spectrophotometer - DS-11+ & DeNovix Inc., Wilmington, DE, USA \\
\hline Staining jar/ Staining rack, glass & $\begin{array}{l}\text { Th. Geyer GmbH \& Co. KG, Renningen, } \\
\text { Germany }\end{array}$ \\
\hline Test tube shaker - Lab dancer & $\begin{array}{l}\text { IKA }{ }^{\circledR} \text {-Werke GmbH \& CO. KG, Staufen, } \\
\text { Germany }\end{array}$ \\
\hline Thermal cycler - T100 ${ }^{\mathrm{TM}}$ & $\begin{array}{l}\text { Bio-Rad Laboratories GmbH, Munich, } \\
\text { Germany }\end{array}$ \\
\hline Thermal cycler - T30 & Analytik Jena AG, Jena, Germany \\
\hline ThermoMixer $^{\circledR}$ compact & Eppendorf AG, Hamburg, Germany \\
\hline
\end{tabular}




\begin{tabular}{|l|l|}
\hline Timer - WB-388 & Oregon Scientific, Gennevilliers, France \\
\hline Tissue float bath - 1052 & $\begin{array}{l}\text { Gesellschaft für Labortechnik mbH, } \\
\text { Burgwedel, Germany }\end{array}$ \\
\hline $\begin{array}{l}\text { Tissue lyser - Qiagen with stainless steel } \\
\text { beads, } 5 \text { mm }\end{array}$ & RETSCH GmbH, Haan, Germany \\
\hline Tissue processor - TP1020 & $\begin{array}{l}\text { Leica Biosystems Nussloch GmbH, } \\
\text { Nussloch, Germany }\end{array}$ \\
\hline Ultra-low freezer - Sanyo VIP ${ }^{\text {TM }}$ series, & $\begin{array}{l}\text { EWALD Innovationstechnik GmbH, } \\
\text { Rodenberg, Germany }\end{array}$ \\
\hline Ultrapure water system - arium ${ }^{\circledR}$ pro & Sartorius AG, Göttingen, Germany \\
\hline Ultrasonic homogenizer - Sonopuls HD70 & $\begin{array}{l}\text { BANDELIN Electronic GmbH \& Co. KG, } \\
\text { Berlin, Germany }\end{array}$ \\
\hline Universal small shaker - MS3 basic & $\begin{array}{l}\text { IKA }{ }^{\circledR} \text {-Werke GmbH \& Co. KG, Staufen, } \\
\text { Germany }\end{array}$ \\
\hline Vortex mixer - REAX2000 & $\begin{array}{l}\text { Heidolph Instruments GmbH \& Co. KG, } \\
\text { Schwabach, Germany }\end{array}$ \\
\hline Waterbath WNB 14 & $\begin{array}{l}\text { Memmert GmbH \& Co. KG, Schwabach, } \\
\text { Germany }\end{array}$ \\
\hline
\end{tabular}

\subsubsection{Consumables}

Table 2: Consumables.

\begin{tabular}{|c|c|c|}
\hline Consumable & Catalogue number & Supplier \\
\hline $\begin{array}{l}\text { Adhesion slides for IHC - } \\
\text { SuperFrost }{ }^{\circledR} \text { Plus }\end{array}$ & J1800AMNZ & $\begin{array}{l}\text { Gerhard Menzel B.V. \& Co. KG, } \\
\text { Braunschweig, Germany }\end{array}$ \\
\hline $\begin{array}{l}\text { Blood collection system - } \\
\text { S-Monovette }{ }^{\circledR} 1.2 \mathrm{ml}, \mathrm{Z}\end{array}$ & 06.1663 .001 & $\begin{array}{l}\text { Sarstedt AG \& Co., Nuembrecht, } \\
\text { Germany }\end{array}$ \\
\hline $\begin{array}{l}\text { Cell culture multiwell plate, } \\
24 \text { well/ } 96 \text { well, F-bottom }\end{array}$ & $662160 / 655180$ & $\begin{array}{l}\text { Greiner Bio-One GmbH, } \\
\text { Frickenhausen, Germany }\end{array}$ \\
\hline Cell scraper $25 \mathrm{~cm}$ & 83.1830 & Sarstedt, Inc., Newton, NC, USA \\
\hline $\begin{array}{l}\text { Chamber slide }{ }^{\mathrm{TM}} \text { system - } \\
\text { Lab-Tek }^{\circledR}, 8 \text { well, } \\
\text { Permanox }\end{array}$ & 177445 & $\begin{array}{l}\text { Thermo Fisher Scientific, } \\
\text { Rochester, NY, USA }\end{array}$ \\
\hline $\begin{array}{l}\text { Chromatography paper - } \\
\text { Whatman }^{\mathrm{TM}}, 3 \mathrm{~mm}\end{array}$ & 3030917 & $\begin{array}{l}\text { Merck KGaA, Darmstadt, } \\
\text { Germany }\end{array}$ \\
\hline $\begin{array}{l}\text { Combitips - advanced }^{\circledR} \\
0.5 \mathrm{ml}, 1 \mathrm{ml}, 2.5 \mathrm{ml}, 5 \mathrm{ml} / \\
\text { BIOPUR } 1 \mathrm{ml}, 5 \mathrm{ml}\end{array}$ & $\begin{array}{l}0030089.421 / 430 / \\
448 / 456 / 642 / 669\end{array}$ & $\begin{array}{l}\text { Eppendorf AG, Hamburg, } \\
\text { Germany }\end{array}$ \\
\hline CryoPure tube $1.6 \mathrm{ml}$ red & 72.380 .002 & $\begin{array}{l}\text { Sarstedt AG \& Co., Nuembrecht, } \\
\text { Germany }\end{array}$ \\
\hline $\begin{array}{l}\text { Desinfectant - Desomed } \\
\text { rapid AF }\end{array}$ & DT-311-010 & $\begin{array}{l}\text { DESOMED Dr. Trippen GmbH, } \\
\text { Freiburg, Germany }\end{array}$ \\
\hline
\end{tabular}




\begin{tabular}{|c|c|c|}
\hline Embedding cassettes & 9160844 & $\begin{array}{l}\text { Th. Geyer GmbH \& Co. KG, } \\
\text { Renningen, Germany }\end{array}$ \\
\hline $\begin{array}{l}\text { Eye and nose ointment - } \\
\text { Bepanthen }{ }^{\circledR}\end{array}$ & 6029009.00 .00 & $\begin{array}{l}\text { Bayer Vital GmbH, Leverkusen, } \\
\text { Germany }\end{array}$ \\
\hline $\begin{array}{l}\text { Filter tips - TipOne } \\
10 / 20 \mu \mathrm{l}, 100 \mu \mathrm{l}, 1000 \mu \mathrm{l}\end{array}$ & $\begin{array}{l}\mathrm{S} 1120-3810 / \mathrm{S} 1120- \\
1840 / \mathrm{S} 1126-7810\end{array}$ & $\begin{array}{l}\text { STARLAB INTERNATIONAL } \\
\text { GmbH, Hamburg, Germany }\end{array}$ \\
\hline Folded filters, $185 \mathrm{~mm}$ & 311647 & $\begin{array}{l}\text { Schleicher \& Schuell BioScience } \\
\text { GmbH, Dassel, Germany }\end{array}$ \\
\hline $\begin{array}{l}\text { Gloves - latex/ nitrile - } \\
\text { Starguard }^{\circledR}\end{array}$ & SG-T-M/ SG-C-S & $\begin{array}{l}\text { STARLAB International GmbH, } \\
\text { Hamburg, Germany }\end{array}$ \\
\hline Hair removal cream - Veet & 8319533 & RB Healthcare UK, Hull, UK \\
\hline $\begin{array}{l}\text { Insulin syringes } 30 G-B D \\
\text { Micro-Fine }{ }^{\mathrm{TM}}+\text { Demi }\end{array}$ & 324826 & $\begin{array}{l}\text { Becton, Dickinson and Company, } \\
\text { Franklin Lakes, NJ, USA }\end{array}$ \\
\hline $\begin{array}{l}\text { Micro Amp }{ }^{\circledR} \text { fast optical } 96 \text { - } \\
\text { well reaction plate }(0.1 \mathrm{ml}) \text { - } \\
\text { Applied biosystems }^{\circledR}\end{array}$ & 4346906 & $\begin{array}{l}\text { Life Technologies Corporation, } \\
\text { Carlsbad, CA, USA }\end{array}$ \\
\hline $\begin{array}{l}\text { Microscope coverslips } \\
24 \times 32 \mathrm{~mm}\end{array}$ & 7695028 & $\begin{array}{l}\text { Th. Geyer GmbH \& Co. KG, } \\
\text { Renningen, Germany }\end{array}$ \\
\hline Microtest plate 96 well, $\mathrm{F}$ & 2021-08 & $\begin{array}{l}\text { Sarstedt AG \& Co., Nuembrecht, } \\
\text { Germany }\end{array}$ \\
\hline $\begin{array}{l}\text { Microtome blade - Feather }{ }^{\circledR} \\
\text { S35 }\end{array}$ & 207500000 & $\begin{array}{l}\text { pfm medical AG, Cologne, } \\
\text { Germany }\end{array}$ \\
\hline $\begin{array}{l}\text { Microtube } 0.5 \mathrm{ml}, 1.5 \mathrm{ml} \text {, } \\
2.0 \mathrm{ml}\end{array}$ & $\begin{array}{l}72.699 / 72.690 / \\
72.691\end{array}$ & $\begin{array}{l}\text { Sarstedt AG \& Co., Nuembrecht, } \\
\text { Germany }\end{array}$ \\
\hline $\begin{array}{l}\text { Needle Sterican }{ }^{\circledR} \\
20 \mathrm{G} \times 2 \text { ', } 26 \mathrm{G} \times 1^{\text {“” }}\end{array}$ & $4667093 / 4657683$ & $\begin{array}{l}\text { B. Braun Melsungen AG, } \\
\text { Melsungen, Germany }\end{array}$ \\
\hline $\begin{array}{l}\text { Nitrocellulose blotting } \\
\text { membrane } 0.45 \mu \mathrm{m}- \\
\text { Amersham }^{\mathrm{TM}} \text { Protran }^{\mathrm{TM}}\end{array}$ & 10600002 & $\begin{array}{l}\text { GE Healthcare Europe GmbH, } \\
\text { Freiburg, Germany }\end{array}$ \\
\hline $\begin{array}{l}\text { NuPAGE } 4-12 \% \text { Bis-Tris } \\
\text { Gel } 1,5 \mathrm{~mm} \times 15 \text { well - } \\
\text { novex }^{\circledR}, \text { Invitrogen }\end{array}$ & NP0336BOX & $\begin{array}{l}\text { Life Technologies Corporation, } \\
\text { Carlsbad, CA, USA }\end{array}$ \\
\hline $\begin{array}{l}\text { Optical adhesive covers - } \\
\text { applied biosystems }\end{array}$ & 4360954 & $\begin{array}{l}\text { Life Technologies Holdings Pte. } \\
\text { Ltd., Singapore }\end{array}$ \\
\hline Parafilm $^{\circledR}$ & PM-996 & $\begin{array}{l}\text { Pechiney Plastic Packiging, Inc., } \\
\text { Menasha, WI, USA }\end{array}$ \\
\hline $\begin{array}{l}\text { PCR tubes } 200 \mu l- \\
\text { Multiply }^{\circledR} \mu \text { Strip Pro }\end{array}$ & 72.990 .002 & $\begin{array}{l}\text { Sarstedt AG \& Co., Nuembrecht, } \\
\text { Germany }\end{array}$ \\
\hline $\begin{array}{l}\text { Pipette tips - TipOne }{ }^{\circledR} 10 \mu \mathrm{l}, \\
200 \mu \mathrm{l}, 1000 \mu \mathrm{l}\end{array}$ & $\begin{array}{l}\text { S1111-3000/ S1113- } \\
\text { 1006/ S1111-6001 }\end{array}$ & $\begin{array}{l}\text { STARLAB International GmbH, } \\
\text { Hamburg, Germany }\end{array}$ \\
\hline $\begin{array}{l}\text { Precision Plus Protein }{ }^{\mathrm{TM}} \\
\text { Dual color standards }\end{array}$ & $161-0374$ & $\begin{array}{l}\text { Bio-Rad Laboratories GmbH, } \\
\text { Munich, Germany }\end{array}$ \\
\hline
\end{tabular}




\begin{tabular}{|c|c|c|}
\hline $\begin{array}{l}\text { Razor blades - Apollo } \\
\text { ever-shape blades }\end{array}$ & 9156110 & $\begin{array}{l}\text { Th. Geyer GmbH \& Co. KG, } \\
\text { Renningen, Germany }\end{array}$ \\
\hline $\begin{array}{l}\text { Rolled rim bottles } \\
55 \times 27 \mathrm{~mm}\end{array}$ & 9400240 & $\begin{array}{l}\text { Th. Geyer GmbH \& Co. KG, } \\
\text { Renningen, Germany }\end{array}$ \\
\hline Scalpel & 02.001.30.021 & $\begin{array}{l}\text { Feather Safety Razor Co., LTD, } \\
\text { Osaka, Japan }\end{array}$ \\
\hline $\begin{array}{l}\text { Screw vials - ND8, } 1.5 \mathrm{ml} \text {, } \\
\text { with lid - LABSOLUTE }{ }^{\circledR}\end{array}$ & $\begin{array}{l}7615163,7612 \\
928 \text { (lid) }\end{array}$ & $\begin{array}{l}\text { Th. Geyer GmbH \& Co. KG, } \\
\text { Renningen, Germany }\end{array}$ \\
\hline $\begin{array}{l}\text { Serological pipette } 2 \mathrm{ml} \text {, } \\
25 \mathrm{ml}, 50 \mathrm{ml}\end{array}$ & $\begin{array}{l}86.1252 .001 / \\
86.1685 .001 / \\
86.1256 .001\end{array}$ & $\begin{array}{l}\text { Sarstedt AG \& Co., Nuembrecht, } \\
\text { Germany }\end{array}$ \\
\hline $\begin{array}{l}\text { Serological pipette } 5 \mathrm{ml} \text {, } \\
10 \mathrm{ml}\end{array}$ & $606180 / 607180$ & $\begin{array}{l}\text { Greiner Bio-One GmbH, } \\
\text { Frickenhausen, Germany }\end{array}$ \\
\hline Sterilium ${ }^{\circledR}$ classic pure & 975512 & $\begin{array}{l}\text { BODE Chemie GmbH, Hamburg, } \\
\text { Germany }\end{array}$ \\
\hline $\begin{array}{l}\text { Surgical suture material - } \\
\text { Ethicon }^{\circledR} \text { Vicryl }^{\mathrm{TM}} \\
\text { Polyglactin } 910\end{array}$ & V497 & $\begin{array}{l}\text { Johnson \& Johnson Medical } \\
\text { GmbH, Norderstedt, Germany }\end{array}$ \\
\hline $\begin{array}{l}\text { Syringe } 1 \mathrm{ml}-\mathrm{BD} \\
\text { Plastipak }^{\mathrm{TM}}\end{array}$ & 303172 & $\begin{array}{l}\text { Becton Dickinson S.A., Madrid, } \\
\text { Spain }\end{array}$ \\
\hline Syringe $5 \mathrm{ml}, 10 \mathrm{ml}$ - Injekt ${ }^{\circledR}$ & $\begin{array}{l}4606710 \mathrm{~V} / \\
4606728 \mathrm{~V}\end{array}$ & $\begin{array}{l}\text { B. Braun Melsungen AG, } \\
\text { Melsungen, Germany }\end{array}$ \\
\hline $\begin{array}{l}\text { TC dish 100/ TC plate } \\
6 \text { well }\end{array}$ & $83.3902 / 83.3920$ & $\begin{array}{l}\text { Sarstedt AG \& Co., Nuembrecht, } \\
\text { Germany }\end{array}$ \\
\hline TC flask T25, T75, T175 & $\begin{array}{l}83.3910 .002 / \\
83.3911 .302 / \\
83.3912 .002\end{array}$ & $\begin{array}{l}\text { Sarstedt AG \& Co., Nuembrecht, } \\
\text { Germany }\end{array}$ \\
\hline Tube $5 \mathrm{ml}, 15 \mathrm{ml}, 50 \mathrm{ml}$ & $\begin{array}{l}60.558 .001 / \\
62.554 .502 / \\
62.547 .254\end{array}$ & $\begin{array}{l}\text { Sarstedt AG \& Co., Nuembrecht, } \\
\text { Germany }\end{array}$ \\
\hline Ultrasonic gel & ASUSG1 & $\begin{array}{l}\text { Asmuth GmbH Medizintechnik, } \\
\text { Minden, Germany }\end{array}$ \\
\hline Weighing boats & 9.900786 & $\begin{array}{l}\text { Lab Logistics Group GmbH, } \\
\text { Meckenheim, Germany }\end{array}$ \\
\hline Wound clips - Reflex 9 & $201-1000$ & $\begin{array}{l}\text { CellPoint Scientific, Inc., } \\
\text { Gaithersbury, MD, USA }\end{array}$ \\
\hline
\end{tabular}




\subsubsection{Chemicals and reagents}

Table 3: Chemicals and reagents.

\begin{tabular}{|c|c|c|}
\hline Chemical / Reagent & $\begin{array}{l}\text { Catalogue } \\
\text { number }\end{array}$ & Supplier \\
\hline 2-propanol & 33539 & $\begin{array}{l}\text { Sigma-Aldrich, Co., St. Louis, } \\
\text { MO, USA }\end{array}$ \\
\hline Acetic acid, glacial & 3788.4 & $\begin{array}{l}\text { Carl Roth GmbH + Co. KG, } \\
\text { Karlsruhe, Germany }\end{array}$ \\
\hline $\begin{array}{l}\text { AEC+ High Sensitivity } \\
\text { Substrate Chromogen }\end{array}$ & K3469 & $\begin{array}{l}\text { Dako Denmark A/S, Glostrup, } \\
\text { Denmark }\end{array}$ \\
\hline Agarose & AG 02 & $\begin{array}{l}\text { Nippon Genetics Europe } \\
\text { GmbH, Düren, Germany }\end{array}$ \\
\hline $\begin{array}{l}\text { Albumin Bovine Fraction V, } \\
\mathrm{pH} 7.0\end{array}$ & 11930.03 & $\begin{array}{l}\text { SERVA Electrophoresis GmbH, } \\
\text { Heidelberg, Germany }\end{array}$ \\
\hline $\begin{array}{l}\text { Albumin standards (BSA), } \\
2 \mathrm{mg} / \mathrm{ml}\end{array}$ & 23209 & $\begin{array}{l}\text { Thermo Fisher Scientific Inc., } \\
\text { Rockford, IL, USA }\end{array}$ \\
\hline Ampicillin & K029.2 & $\begin{array}{l}\text { Carl Roth GmbH + Co. KG, } \\
\text { Karlsruhe, Germany }\end{array}$ \\
\hline Aqua/ Aqua ad iniectabilia & $\begin{array}{l}75 / 12604052 / 1212 / \\
6724123.00 .00\end{array}$ & $\begin{array}{l}\text { B. Braun Melsungen AG, } \\
\text { Melsungen, Germany }\end{array}$ \\
\hline $\begin{array}{l}\text { Bromphenol blue indicator } \\
\mathrm{pH} 3.0-4.6, \text { ACS }\end{array}$ & 1.08122 .005 & $\begin{array}{l}\text { Merck KGaA, Darmstadt, } \\
\text { Germany }\end{array}$ \\
\hline $\begin{array}{l}\text { Chemiluminescence reagent } \\
\text { Western Lightning }{ }^{\circledR} \text { Plus/ Ultra }\end{array}$ & $\begin{array}{l}\text { NEL105001EA/ } \\
\text { NEL112001EA }\end{array}$ & $\begin{array}{l}\text { Perkin Elmer, Inc., Waltham, } \\
\text { MA, USA }\end{array}$ \\
\hline Chloroform p. a. & 1.02442 .1000 & $\begin{array}{l}\text { Merck KGaA, Darmstadt, } \\
\text { Germany }\end{array}$ \\
\hline Citric acid monohydrate p. a. & 3958.1 & $\begin{array}{l}\text { Carl Roth GmbH + Co. KG, } \\
\text { Karlsruhe, Germany }\end{array}$ \\
\hline $\begin{array}{l}\text { Coomassie blue G-250 based } \\
\text { protein assay reagent }\end{array}$ & 1856209 & $\begin{array}{l}\text { Thermo Fisher Scientific Inc., } \\
\text { Rockford, IL, USA }\end{array}$ \\
\hline Crystal violet & T123.1 & $\begin{array}{l}\text { Carl Roth GmbH + Co. KG, } \\
\text { Karlsruhe, Germany }\end{array}$ \\
\hline Dimethyl sulfoxide (DMSO) & D8418-100ML & $\begin{array}{l}\text { Sigma-Aldrich, Co., St. Louis, } \\
\text { MO, USA }\end{array}$ \\
\hline $\begin{array}{l}\text { DNA ladder - Gene ruler plus } \\
1 \mathrm{~kb}\end{array}$ & SM0311 & $\begin{array}{l}\text { Thermo Fisher Scientific, } \\
\text { Waltham, MA, USA }\end{array}$ \\
\hline $\begin{array}{l}\text { DNA ladder - Quick-load }{ }^{\circledR} \\
100 \text { bp }\end{array}$ & N0467S & $\begin{array}{l}\text { New England Biolabs GmbH, } \\
\text { Frankfurt am Main, Germany }\end{array}$ \\
\hline dNTP set $100 \mathrm{mM}$ & $10297-018$ & $\begin{array}{l}\text { Invitrogen Corp., Carlsbad, CA, } \\
\text { USA }\end{array}$ \\
\hline $\begin{array}{l}\text { Dulbecco's Phosphate Buffered } \\
\text { Saline - gibco }\end{array}$ & $14190-094$ & $\begin{array}{l}\text { Life Technologies Corporation, } \\
\text { Paisley, UK }\end{array}$ \\
\hline
\end{tabular}




\begin{tabular}{|c|c|c|}
\hline Embedding wax (Paraffin) & $17932 A$ & $\begin{array}{l}\text { Engelbrecht GmbH, } \\
\text { Edermünde/ Besse, Germany }\end{array}$ \\
\hline Eosin $\mathrm{Y}$ solution aqueous & HT110232-1L & $\begin{array}{l}\text { Sigma-Aldrich, Co., St. Louis, } \\
\text { MO, USA }\end{array}$ \\
\hline $\begin{array}{l}\text { Ethanol - CHEMSOLUTE }{ }^{\circledR} \\
99 \% \text { denatured/ absolute p. a. }\end{array}$ & $\begin{array}{l}2294.1000 \\
2212.5000 / \\
2246.2500\end{array}$ & $\begin{array}{l}\text { Th. Geyer GmbH \& Co. KG, } \\
\text { Renningen, Germany }\end{array}$ \\
\hline $\begin{array}{l}\text { Ethylene glycol-bis(2-amino- } \\
\text { ethylether)-N, N, N', N'-tetra- } \\
\text { acetic acid (EGTA) }\end{array}$ & E4378-100G & $\begin{array}{l}\text { Sigma-Aldrich, Co., St. Louis, } \\
\text { MO, USA }\end{array}$ \\
\hline $\begin{array}{l}\text { Ethylenediaminetetraacetic } \\
\text { acid, disodium salt dihydrate } \\
\text { (EDTA) }\end{array}$ & 147850010 & $\begin{array}{l}\text { Acros Organics N.V., Fair } \\
\text { Lawn, NJ, USA }\end{array}$ \\
\hline $\begin{array}{l}\text { Formaldehyde solution } 4 \% \text {, } \\
\text { buffered, } \mathrm{pH} 6.9\end{array}$ & 1.00496 .5000 & $\begin{array}{l}\text { Merck KGaA, Darmstadt, } \\
\text { Germany }\end{array}$ \\
\hline Glycerin Rotipuran $>99.5 \%$ & 3783.2 & $\begin{array}{l}\text { Carl Roth GmbH + Co. KG, } \\
\text { Karlsruhe, Germany }\end{array}$ \\
\hline Goat serum (normal) & X0907 & $\begin{array}{l}\text { Dako Denmark A/S, Glostrup, } \\
\text { Denmark }\end{array}$ \\
\hline $\begin{array}{l}\text { Hematoxylin solution according } \\
\text { to Mayer }\end{array}$ & $51275-1 \mathrm{~L}$ & $\begin{array}{l}\text { Sigma-Aldrich, Co., St. Louis, } \\
\text { MO, USA }\end{array}$ \\
\hline $\begin{array}{l}\text { HEPES - PUFFERAN }{ }^{\circledR} \text {, buffer } \\
\text { grade }\end{array}$ & HN78.2 & $\begin{array}{l}\text { Carl Roth GmbH + Co. KG, } \\
\text { Karlsruhe, Germany }\end{array}$ \\
\hline Hydrochloric acid 2 N/ $37 \%$ & T134.1/ 9277.1 & $\begin{array}{l}\text { Carl Roth GmbH + Co. KG, } \\
\text { Karlsruhe, Germany }\end{array}$ \\
\hline $\begin{array}{l}\text { Hydrogen Peroxide } 30 \text { \% - } \\
\text { ROTIPURAN }^{\circledR} \text { p.a. }\end{array}$ & 8070.2 & $\begin{array}{l}\text { Carl Roth GmbH \& Co. KG, } \\
\text { Karlsruhe, Germany }\end{array}$ \\
\hline Isotonic saline solution - $0.9 \%$ & 6697366.00 .00 & $\begin{array}{l}\text { B. Braun Melsungen AG, } \\
\text { Melsungen, Germany }\end{array}$ \\
\hline $\begin{array}{l}\text { LB Broth (Miller) - powder, } \\
\text { microbiological growth medium }\end{array}$ & L3522 & $\begin{array}{l}\text { Sigma-Aldrich, Co., St. Louis, } \\
\text { MO, USA }\end{array}$ \\
\hline Lithium chloride & 27026 & $\begin{array}{l}\text { Sigma-Aldrich, Co., St. Louis, } \\
\text { MO, USA }\end{array}$ \\
\hline $\begin{array}{l}\text { Matrigel }^{\circledR} \text { growth factor reduced } \\
\text { basement membrane matrix, } \\
\text { phenol red-free - Corning }{ }^{\circledR}\end{array}$ & 356231 & $\begin{array}{l}\text { VWR International GmbH, } \\
\text { Darmstadt, Germany }\end{array}$ \\
\hline Methanol & 8388.5 & $\begin{array}{l}\text { Carl Roth GmbH + Co. KG, } \\
\text { Karlsruhe, Germany }\end{array}$ \\
\hline $\begin{array}{l}\text { Midori green advance DNA } \\
\text { stain }\end{array}$ & MG04 & $\begin{array}{l}\text { Nippon Genetics Europe } \\
\text { GmbH, Dueren, Germany }\end{array}$ \\
\hline 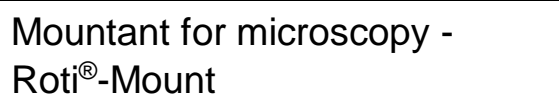 & HP68.2 & $\begin{array}{l}\text { Carl Roth GmbH + Co. KG, } \\
\text { Karlsruhe, Germany }\end{array}$ \\
\hline
\end{tabular}




\begin{tabular}{|c|c|c|}
\hline $\begin{array}{l}\text { Mounting medium for } \\
\text { fluorescence with DAPI - } \\
\text { VECTASHIELD }\end{array}$ & $H-1200$ & $\begin{array}{l}\text { Vector Laboratories, Inc., } \\
\text { Burlingame, CA, USA }\end{array}$ \\
\hline $\begin{array}{l}\text { Non-woven wipes - Desco } \\
\text { wipes }\end{array}$ & 00-915-RD7003-01 & $\begin{array}{l}\text { Dr. Schumacher GmbH, } \\
\text { Malsfeld, Germany }\end{array}$ \\
\hline $\begin{array}{l}\text { NuPAGE }{ }^{\circledR} \text { LDS sample buffer } \\
(4 \mathrm{x}) \text {, Invitrogen, novex }{ }^{\circledR}\end{array}$ & NP0007 & $\begin{array}{l}\text { Life Technologies Corporation, } \\
\text { Carlsbad, CA, USA }\end{array}$ \\
\hline $\begin{array}{l}\text { NuPAGE }^{\circledR} \text { nove }{ }^{\circledR} \text { MOPS SDS } \\
\text { Running Buffer/ Transfer buffer }\end{array}$ & NP0001/ NP0006 & $\begin{array}{l}\text { Life Technologies Corporation, } \\
\text { Carlsbad, CA, USA }\end{array}$ \\
\hline PBS Dulbecco, powder & L182-50 & $\begin{array}{l}\text { Biochrom GmbH, Berlin, } \\
\text { Germany }\end{array}$ \\
\hline $\begin{array}{l}\text { Phenol/ chloroform/ } \\
\text { isoamylalcohol }(25: 24: 1)\end{array}$ & 51371 & $\begin{array}{l}\text { Biomol GmbH, Hamburg, } \\
\text { Germany }\end{array}$ \\
\hline $\begin{array}{l}\text { Phenylmethylsulfonyl fluoride } \\
\text { (PMSF) }\end{array}$ & $78830-56$ & $\begin{array}{l}\text { Sigma-Aldrich, Co., St. Louis, } \\
\text { MO, USA }\end{array}$ \\
\hline Ponceau S solution & P7170-1L & $\begin{array}{l}\text { Sigma-Aldrich, Co., St. Louis, } \\
\text { MO, USA }\end{array}$ \\
\hline Powdered milk & T145.4 & $\begin{array}{l}\text { Carl Roth GmbH + Co. KG, } \\
\text { Karlsruhe, Germany }\end{array}$ \\
\hline Pro Taqs II Antigen-Enhancer & 401602192 & $\begin{array}{l}\text { Biocyc GmbH \& Co. KG, } \\
\text { Potsdam-Golm, Germany }\end{array}$ \\
\hline $\begin{array}{l}\text { Protease inhibitor cocktail } \\
\text { tablets - cOmplete }{ }^{\mathrm{TM}} \text { mini }\end{array}$ & 11836170001 & $\begin{array}{l}\text { Roche Diagnostics GmbH, } \\
\text { Mannheim, Germany }\end{array}$ \\
\hline $\begin{array}{l}\text { RNAlater }{ }^{\circledR} \text { RNA stabilization } \\
\text { reagent }\end{array}$ & 1018087 & $\begin{array}{l}\text { Qiagen GmbH, Hilden, } \\
\text { Germany }\end{array}$ \\
\hline RNase-free water - peqGOLD & 12-RWATER-88 & $\begin{array}{l}\text { VWR International BVBA, } \\
\text { Leuven, Belgium }\end{array}$ \\
\hline Roticlear $^{\circledR}$ for histology & A538.2 & $\begin{array}{l}\text { Carl Roth GmbH + Co. KG, } \\
\text { Karlsruhe, Germany }\end{array}$ \\
\hline Sodium chloride - Fluka ${ }^{\mathrm{TM}}$ & 31434 & $\begin{array}{l}\text { Honeywell International Inc., } \\
\text { Morristown, NJ, USA }\end{array}$ \\
\hline Sodium fluoride & S1504 & $\begin{array}{l}\text { Sigma-Aldrich, Co., St. Louis, } \\
\text { MO, USA }\end{array}$ \\
\hline Sodium hydroxide solution & 5587.2500 & $\begin{array}{l}\text { Merck KGaA, Darmstadt, } \\
\text { Germany }\end{array}$ \\
\hline Sodium orthovanadate & S-6508 & $\begin{array}{l}\text { Sigma-Aldrich, Co., St. Louis, } \\
\text { MO, USA }\end{array}$ \\
\hline $\begin{array}{l}\text { Sodiumpyrophosphate } \\
\text { decahydrate }\end{array}$ & 221368 & $\begin{array}{l}\text { Sigma-Aldrich, Co., St. Louis, } \\
\text { MO, USA }\end{array}$ \\
\hline $\begin{array}{l}\text { TaqMan }^{\circledR} \text { universal PCR master } \\
\text { mix - Applied Biosystems }\end{array}$ & 4324018 & $\begin{array}{l}\text { Life Technologies LTD, } \\
\text { Warrington, UK }\end{array}$ \\
\hline $\begin{array}{l}\text { Thiazolyl blue tetrazolium } \\
\text { bromide }\end{array}$ & M5655 & $\begin{array}{l}\text { Sigma-Aldrich, Co., St. Louis, } \\
\text { MO, USA }\end{array}$ \\
\hline
\end{tabular}




\begin{tabular}{|c|c|c|}
\hline $\begin{array}{l}\text { TRIS/ TRIS-HCI - PUFFERAN }{ }^{\circledR} \\
\text { p. a. }\end{array}$ & $\begin{array}{l}4855.2 / \\
9090.3\end{array}$ & $\begin{array}{l}\text { Carl Roth GmbH + Co. KG, } \\
\text { Karlsruhe, Germany }\end{array}$ \\
\hline Triton $X^{\circledR}-100$ & 3051.4 & $\begin{array}{l}\text { Carl Roth GmbH + Co. KG, } \\
\text { Karlsruhe, Germany }\end{array}$ \\
\hline TRIzol $^{\circledR}$ reagent - ambion ${ }^{\circledR}$ & 15596018 & $\begin{array}{l}\text { Life Technologies Corp., } \\
\text { Carlsbad, CA, USA }\end{array}$ \\
\hline Trypan blue solution $0.4 \%$ & T8154 & $\begin{array}{l}\text { Sigma-Aldrich, Co., St. Louis, } \\
\text { MO, USA }\end{array}$ \\
\hline $\begin{array}{l}\text { TurboFect Transfection } \\
\text { Reagent }\end{array}$ & R0531 & $\begin{array}{l}\text { Thermo Fisher Scientific, } \\
\text { Waltham, MA, USA }\end{array}$ \\
\hline Tween $^{\circledR} 20$ - PanReac & A4974 & AppliChem GmbH, Darmstadt \\
\hline Xylene - J.T. Baker ${ }^{\circledR}$ & 8118 & $\begin{array}{l}\text { Avantor Performance Materials } \\
\text { Poland S.A., Gliwice, Poland }\end{array}$ \\
\hline$\beta$-mercaptoethanol & 4227.3 & $\begin{array}{l}\text { Carl Roth GmbH + Co. KG, } \\
\text { Karlsruhe, Germany }\end{array}$ \\
\hline
\end{tabular}

Table 4: Enzymes.

\begin{tabular}{|c|c|c|}
\hline Enzyme & Catalogue number & Supplier \\
\hline Fast digest BgllI & FD0084 & \multirow{5}{*}{$\begin{array}{l}\text { Thermo Fisher } \\
\text { Scientific, Waltham, } \\
\text { MA, USA }\end{array}$} \\
\hline Fast digest HindIII & FD0504 & \\
\hline Fast digest Nhe1 & FD0974 & \\
\hline Fast digest Not1 & FD0594 & \\
\hline Fast digest Spel (Bcul) - Fermentas & FD1254 & \\
\hline $\begin{array}{l}\text { Jumpstart Taq DNA Polymerase } \\
2.5 \text { units/ } \mu \mathrm{l}\end{array}$ & D9307 & $\begin{array}{l}\text { Sigma-Aldrich, Co., } \\
\text { St. Louis, MO, USA }\end{array}$ \\
\hline $\begin{array}{l}\text { M-MLV reverse transcriptase } \\
(200 U / \mu l)\end{array}$ & $28025-013$ & $\begin{array}{l}\text { Invitrogen Corp., } \\
\text { Carlsbad, CA, USA }\end{array}$ \\
\hline $\begin{array}{l}\text { Phusion high-fidelity DNA } \\
\text { polymerase }(2 \mathrm{U} / \mu \mathrm{l})\end{array}$ & F530L & \multirow{3}{*}{$\begin{array}{l}\text { Thermo Fisher } \\
\text { Scientific, Waltham, } \\
\text { MA, USA }\end{array}$} \\
\hline T4 DNA ligase & EL0011 & \\
\hline Vspl (Asel) & ER0911 & \\
\hline
\end{tabular}

Table 5: Inhibitors.

\begin{tabular}{|l|l|l|}
\hline Inhibitor & Catalogue number & Supplier \\
\hline $\begin{array}{l}\text { RNasin }{ }^{\circledR} \text { Ribonuclease } \\
\text { Inhibitor }\end{array}$ & N2511 & $\begin{array}{l}\text { Promega Corporation, } \\
\text { Madison, WI, USA }\end{array}$ \\
\hline $\begin{array}{l}\text { Tetrahydrouridine - } \\
\text { Calbiochem }\end{array}$ & 584222 & $\begin{array}{l}\text { Merck KGaA, Darmstadt, } \\
\text { Germany }\end{array}$ \\
\hline
\end{tabular}




\subsubsection{Buffers}

Citrate buffer $10 x$ stock solution, pH 6.0:

$100 \mathrm{mM}$ citric acid monohydrate

$\rightarrow$ Ad $1000 \mathrm{ml}$ with ultrapure water, sodium hydroxide for $\mathrm{pH}$ adjustment

TE buffer 10x stock solution, pH 9.0:

10 mM EDTA

100mM TRIS

$\rightarrow$ Ad $1000 \mathrm{ml}$ with ultrapure water

TBE buffer 10x stock solution, pH 8.0:

$0.9 \mathrm{M}$ TRIS

$0.9 \mathrm{M}$ Boric acid

25 mM EDTA

$\rightarrow$ Ad $1000 \mathrm{ml}$ with ultrapure water, hydrochloric acid for $\mathrm{pH}$ adjustment

TAE buffer 50x stock solution, pH 8.3 (protocol from (BiolnfoWeb.com, n.d.)):

2 M TRIS

0.05 M EDTA

$1 \mathrm{M}$ acetic acid glacial

$\rightarrow$ Ad 250 ml with ultrapure water

TBS 10x stock solution, pH 7.5 (protocol from (Stromiedel \& Wittmann, n.d.)):

$165 \mathrm{mM}$ Tris-HCl

$35 \mathrm{mM}$ Tris base

$5 \mathrm{M}$ sodium chloride

$\rightarrow$ Ad 1000 ml with ultrapure water, $\mathrm{pH}$ adjustment not required

$\rightarrow 1 \mathrm{x}$ buffer solutions were prepared by diluting stock solutions with ultrapure water

PBS without $\mathrm{Ca}^{2+}$ and $\mathrm{Mg}^{2+}$ :

$9.55 \mathrm{~g} / \mathrm{l}$ PBS powder

$\rightarrow$ Ad $1000 \mathrm{ml}$ with ultrapure water, autoclaved for use in cell culture

PBS-T $0.1 \%$ :

$1000 \mathrm{ml}$ PBS buffer

$1 \mathrm{ml}$ Tween $^{\circledR} 20$
TBS-T $0.1 \%$ :

$1000 \mathrm{ml}$ TBS buffer

$1 \mathrm{ml}$ Tween $^{\circledR} 20$ 


\section{Protein lysis buffer:}

50 mM HEPES (pH 7.5-7.9)

150 mM Sodium chloride

1 mM EGTA

$10 \%$ Glycerin

$1 \%$ Triton $X^{\circledR}-100$

100 mM Sodium fluoride

$10 \mathrm{mM}$ Sodiumpyrophosphate decahydrate

$\rightarrow$ immediately before use add to $1 \mathrm{ml}$ of lysis buffer:

$10 \mu \mathrm{l}$ of $100 \mathrm{mM}$ PMSF

$40 \mu \mathrm{l}$ of $25 \mathrm{x}$ cOmplete ${ }^{\mathrm{TM}}$

$10 \mu \mathrm{l}$ of $100 \mathrm{mM}$ sodium orthovanadate

$10 \mu \mathrm{l}$ of $100 \mathrm{mM}$ sodium fluoride

\subsubsection{Kits}

Table 6: Kits.

\begin{tabular}{|l|l|l|}
\hline Kit & Catalogue number & Supplier \\
\hline $\begin{array}{l}\text { DAB peroxidase substrate } \\
\text { kit - ImmPACT }\end{array}$ & SK-4105 & $\begin{array}{l}\text { Vector Laboratories, Inc., } \\
\text { Burlingame, CA, USA }\end{array}$ \\
\hline $\begin{array}{l}\text { HistoGreen substrate kit for } \\
\text { peroxidase - Histoprime }\end{array}$ & E109 & $\begin{array}{l}\text { LINARIS Biologische Produkte } \\
\text { GmbH, Dossenheim, Germany }\end{array}$ \\
\hline $\begin{array}{l}\text { ImmPress reagent kit } \\
\text { anti-rabbit IgG }\end{array}$ & MP-7401 & $\begin{array}{l}\text { Vector Laboratories, Inc., } \\
\text { Burlingame, CA, USA }\end{array}$ \\
\hline $\begin{array}{l}\text { Midi prep kit - NucleoBond } \\
\text { Xtra plasmid purification kit }\end{array}$ & 740410.100 & $\begin{array}{l}\text { MACHEREY-NAGEL GmbH \& } \\
\text { Co. KG, Dueren, Germany }\end{array}$ \\
\hline $\begin{array}{l}\text { Mini prep kit - innuPREP } \\
\text { plasmid mini kit plus }\end{array}$ & $845-$ KS-5240250 & Analytik Jena AG, Jena, Germany \\
\hline $\begin{array}{l}\text { Mouse on mouse } \\
\text { (M.O.M. }{ }^{\text {TM }} \text { ) basic kit }\end{array}$ & BMK-2202 & $\begin{array}{l}\text { Vector Laboratories, Inc., } \\
\text { Burlingame, CA, USA }\end{array}$ \\
\hline $\begin{array}{l}\text { Mycoplasma PCR detection } \\
\text { kit - LookOut }\end{array}$ & MP0035 & $\begin{array}{l}\text { Sigma-Aldrich, Co., St. Louis, } \\
\text { MO, USA }\end{array}$ \\
\hline $\begin{array}{l}\text { NucleoSpin } \\
\text { clean-up kit } \text { gel and PCR }\end{array}$ & 740609.10 & $\begin{array}{l}\text { MACHEREY-NAGEL GmbH \& } \\
\text { Co. KG, Dueren, Germany }\end{array}$ \\
\hline peqGold total RNA kit & $12-6834-02$ & $\begin{array}{l}\text { VWR International BVBA, } \\
\text { Leuven, Belgium }\end{array}$ \\
\hline $\begin{array}{l}\text { Peroxidase rabbit/ mouse } \\
\text { lgG - Vectastain }{ }^{\boxplus} \text { ABC Kit }\end{array}$ & PK-4001/ PK-4002 & $\begin{array}{l}\text { Vector Laboratories, Inc., } \\
\text { Burlingame, CA, USA }\end{array}$ \\
\hline RNeasy ${ }^{\boxplus}$ mini kit & 74104 & Qiagen GmbH, Hilden, Germany \\
\hline
\end{tabular}

\subsubsection{Drugs}

Table 7: Therapeutic drugs.

\begin{tabular}{|c|c|c|}
\hline Drug & Catalogue number & Supplier \\
\hline 5-fluorouracil & 03738 & \multirow{3}{*}{$\begin{array}{l}\text { Sigma-Aldrich, Co., St. } \\
\text { Louis, MO, USA }\end{array}$} \\
\hline Gemcitabine hydrochloride & G6423 & \\
\hline Paclitaxel & T7191 & \\
\hline
\end{tabular}


Table 8: Anesthetics and analgesics.

\begin{tabular}{|l|l|l|}
\hline Drug & Approval number & Supplier \\
\hline Carprieve (carprofen) & 401182.00 .00 & $\begin{array}{l}\text { Norbrook Laboratories Limited, } \\
\text { Newry, UK }\end{array}$ \\
\hline Forene $^{\circledR} 100 \%(\mathrm{~V} / \mathrm{V})$ & 2594.00 .00 & $\begin{array}{l}\text { AbbVie Deutschland GmbH \& Co. } \\
\text { KG, Ludwigshafen, Germany }\end{array}$ \\
\hline Temgesic (buprenorphine) & 345928 & Indivior Eu Ltd., Berkshire, UK \\
\hline
\end{tabular}

\subsubsection{Antibodies}

Table 9: Primary antibodies for Western blot, IHC, and ICC.

\begin{tabular}{|c|c|c|c|}
\hline Antibodies & $\begin{array}{l}\text { Catalogue } \\
\text { number }\end{array}$ & Supplier & Dilution \\
\hline $\begin{array}{l}\text { Cytidine deaminase } \\
\text { (Cda) }\end{array}$ & $a b 82346$ & Abcam plc, Cambridge, UK & 1:300 IHC (mouse) \\
\hline $\begin{array}{l}\text { Cytidine deaminase } \\
\text { (Cda) }\end{array}$ & LS-B10533 & $\begin{array}{l}\text { LifeSpan Biosciences Inc., } \\
\text { Seattle, WA, USA }\end{array}$ & 1:50 IHC (human) \\
\hline $\begin{array}{l}\text { Cleaved Caspase-3 } \\
\text { (Asp175) (5A1E) }\end{array}$ & 9664 & $\begin{array}{l}\text { Cell Signaling Technology, } \\
\text { Inc., Danvers, MA, USA }\end{array}$ & $\begin{array}{l}\text { 1:750 (WB)/ 1:100 } \\
\text { Co-IHC }\end{array}$ \\
\hline $\begin{array}{l}\text { Deoxycytidine } \\
\text { kinase }(\mathrm{dCK})\end{array}$ & Ab96599 & Abcam plc, Cambridge, UK & 1:100 IHC (mouse) \\
\hline $\begin{array}{l}\text { Deoxycytidine } \\
\text { kinase }(\mathrm{dCK})\end{array}$ & LS-B10837 & $\begin{array}{l}\text { LifeSpan Biosciences Inc., } \\
\text { Seattle, WA, USA }\end{array}$ & $1: 100 \mathrm{IHC}$ (human) \\
\hline $\begin{array}{l}\text { DCMP deaminase } \\
\text { (DCTD) }\end{array}$ & EPP12174 & $\begin{array}{l}\text { Elabscience Biotechnology, } \\
\text { Inc., Houston, TX, USA }\end{array}$ & $\begin{array}{l}\text { 1:300 IHC (mouse } \\
+ \text { human) }\end{array}$ \\
\hline HA-Tag (C29F4) & 3724 & \multirow[t]{2}{*}{$\begin{array}{l}\text { Cell Signaling Technology, } \\
\text { Inc., Danvers, MA, USA }\end{array}$} & $\begin{array}{l}1: 1000(\mathrm{WB}) / \\
1: 200(\mathrm{ICC}) / 1: 300 \\
(\mathrm{IHC})\end{array}$ \\
\hline HSP90 (E289) & 4875 & & $1: 1000(\mathrm{WB})$ \\
\hline Ki-67 (SP6) & RM9106-S0 & $\begin{array}{l}\text { Thermo Fisher Scientific, } \\
\text { Waltham, MA, USA }\end{array}$ & $\begin{array}{l}1: 200 \mathrm{IHC} / \\
\text { Co-IF }\end{array}$ \\
\hline NT5C1A & ab199632 & Abcam plc, Cambridge, UK & 1:1000 (WB) \\
\hline NT5C1A & C15296 & $\begin{array}{l}\text { Assay Biotechnology } \\
\text { Company Inc., Sunnyvale, } \\
\text { CA, USA }\end{array}$ & 1:100 (IHC, ICC) \\
\hline NT5C1A & HPA050283 & $\begin{array}{l}\text { Atlas Antibodies AB, } \\
\text { Bromma, Sweden }\end{array}$ & 1:100 (TMA-2) \\
\hline $\begin{array}{l}\alpha \text {-smooth muscle } \\
\text { actin, Clone } 1 \mathrm{~A} 4\end{array}$ & M0851 & $\begin{array}{l}\text { Dako Denmark A/S, } \\
\text { Glostrup, Denmark }\end{array}$ & $\begin{array}{l}1: 250(\mathrm{IHC}+ \\
\text { Co-IF) }\end{array}$ \\
\hline
\end{tabular}


Table 10: Secondary antibodies.

\begin{tabular}{|l|l|l|l|}
\hline Antibodies & Catalogue number & Supplier & Dilution \\
\hline $\begin{array}{l}\text { Donkey anti-rabbit IgG - } \\
\text { Alexa Fluor }{ }^{\circledR} 555 / 568\end{array}$ & A31572/ A10042 & $\begin{array}{l}\text { Invitrogen, Eugene, } \\
\text { OR, USA }\end{array}$ & $\begin{array}{l}1: 500 \text { (ICC)/ } \\
1: 1000 \text { (Co-IF) }\end{array}$ \\
\hline $\begin{array}{l}\text { Goat anti-mouse IgG - } \\
\text { Alexa Fluor }{ }^{\circledR} 488\end{array}$ & A21131 & $\begin{array}{l}\text { Invitrogen, Eugene, } \\
\text { OR, USA }\end{array}$ & $1: 1000$ (Co-IF) \\
\hline $\begin{array}{l}\text { Secondary antibody - } \\
\text { goat anti-rabbit/ rabbit } \\
\text { anti-mouse }\end{array}$ & E0432/ E0354 & $\begin{array}{l}\text { Dako Denmark } \\
\text { A/S, Glostrup, } \\
\text { Denmark }\end{array}$ & $\begin{array}{l}1: 300 \text { IHC } \\
\text { (human) }\end{array}$ \\
\hline $\begin{array}{l}\text { Secondary antibody - } \\
\text { swine anti-rabbit/ goat } \\
\text { anti-mouse IgG/ HRP }\end{array}$ & P0217/ P0161 & $\begin{array}{l}\text { Dako Denmark } \\
\text { A/S, Glostrup, } \\
\text { Denmark }\end{array}$ & $1: 2000$ (WB) \\
\hline
\end{tabular}

\subsubsection{Oligonucleotides}

Table 11: Primers.

\begin{tabular}{|l|l|l|}
\hline Primer name & Sequence (5'-3') & Source \\
\hline mNt5c1A insert check & $\begin{array}{l}\text { CCTACAGCTCCTGGGCA } \\
\text { ACG }\end{array}$ & $\begin{array}{l}\text { Sigma-Aldrich, Co., St. } \\
\text { Louis, MO, USA }\end{array}$ \\
\hline mNt5c1a_CI_Nhel_Rev & $\begin{array}{l}\text { GCTGACGCTAGCCTGTG } \\
\text { CACCTAATGACTGCTTCG } \\
\text { CAGCGGCAGCCCG }\end{array}$ & $\begin{array}{l}\text { Eurofins Genomics GmbH, } \\
\text { Ebersberg, Germany }\end{array}$ \\
\hline mNt5c1a_Cl_Notl_For & $\begin{array}{l}\text { GCTGACGCGGCCGCAAT } \\
\text { GGAACCAGGGCAGCCCC } \\
\text { GGGAGGC }\end{array}$ & $\begin{array}{l}\text { Eurofins Genomics GmbH, } \\
\text { Ebersberg, Germany }\end{array}$ \\
\hline $\begin{array}{l}\text { Primer } p(d T) 15 \text { for cDNA } \\
\text { synthesis, } 8 \text { nmol }\end{array}$ & $\begin{array}{l}\text { Catalogue number: } \\
\text { 10814270001 }\end{array}$ & $\begin{array}{l}\text { Roche Diagnostics GmbH, } \\
\text { Mannheim, Germany }\end{array}$ \\
\hline
\end{tabular}

Table 12: TaqMan $^{\circledR}$ reagents used for qRT-PCR.

\begin{tabular}{|c|c|c|}
\hline TaqMan $^{\circledR}$ reagent & Catalogue number & Supplier \\
\hline Human NT5C1A & Hs00261369_m1 & \multirow{6}{*}{$\begin{array}{c}\text { Thermo Fisher Scientific, } \\
\text { Waltham, MA, USA }\end{array}$} \\
\hline Human $\beta$-actin & Hs99999903_m1 & \\
\hline Murine dCK & Mm00432794_m1 & \\
\hline Murine NT5C1A & Mm01192248_m1 & \\
\hline Murine NT5C3 & Mm0046604_m1 & \\
\hline Murine $\beta$-actin & Mm00607939_s1 & \\
\hline
\end{tabular}




\subsubsection{Cell culture}

Table 13: Cell culture components.

\begin{tabular}{|c|c|c|}
\hline Component & Catalogue number & Company \\
\hline $\begin{array}{l}\text { Dulbecco's Modified Eagle } \\
\text { Medium (DMEM) - gibco }\end{array}$ & 41965-039 & $\begin{array}{l}\text { Life Technologies Corp., } \\
\text { Paisley, UK }\end{array}$ \\
\hline $\begin{array}{l}\text { Fetal bovine serum (FBS) - } \\
\text { gibco }^{\circledR}\end{array}$ & $10270-106$ & $\begin{array}{l}\text { Life Technologies Corp., } \\
\text { Paisley, UK }\end{array}$ \\
\hline Hygromycin B Gold & ant-hg-5 & $\begin{array}{l}\text { InvivoGen Europe, Toulouse, } \\
\text { France }\end{array}$ \\
\hline L-glutamine 200 mM - gibco ${ }^{\oplus}$ & $25030-024$ & \multirow{4}{*}{$\begin{array}{c}\text { Life Technologies Corp., } \\
\text { Paisley, UK }\end{array}$} \\
\hline $\begin{array}{l}\text { Minimum Essential Medium } \\
\text { (MEM) - gibco }{ }^{\circledast}\end{array}$ & $51200-046$ & \\
\hline $\begin{array}{l}\text { MEM Non-Essential Amino } \\
\text { Acids (NEAA) - gibco }{ }^{\circledR}\end{array}$ & $11140-035$ & \\
\hline $\begin{array}{l}\text { Opti-MEMTM I Reduced } \\
\text { Serum Medium - gibco }\end{array}$ & 31985047 & \\
\hline Penicillin-streptomycin & P0781 & $\begin{array}{l}\text { Sigma-Aldrich, Co., St. Louis, } \\
\text { MO, USA }\end{array}$ \\
\hline $\begin{array}{l}\text { Trypsin-EDTA } 0.5 \% \text { (10x) - } \\
\text { gibco }^{\circledR}\end{array}$ & $15400-054$ & $\begin{array}{l}\text { Life Technologies Corp., } \\
\text { Paisley, UK }\end{array}$ \\
\hline
\end{tabular}

Table 14: Cells.

\begin{tabular}{|c|c|}
\hline Cell type & Source \\
\hline DH5 $\alpha$ competent E.coli & $\begin{array}{l}\text { Department of Developmental Biochemistry, } \\
\text { Extracellular Signaling Lab, UMG }\end{array}$ \\
\hline KPC tumor cells & \multirow{3}{*}{$\begin{array}{l}\text { Department of Gastroenterology and } \\
\text { Gastrointestinal Oncology, UMG }\end{array}$} \\
\hline KPC tumor cells from metastatic foci & \\
\hline L3.6pl cells & \\
\hline Myoblasts, undifferentiated (RNA) & $\begin{array}{l}\text { Isolated by the group of Prof. Dr. Jens } \\
\text { Schmidt, Department of Neurology, UMG }\end{array}$ \\
\hline PSCs, immortalized & $\begin{array}{l}\text { Department of Gastroenterology and } \\
\text { Gastrointestinal Oncology, UMG }\end{array}$ \\
\hline
\end{tabular}

\subsubsection{Software and tools}

Table 15: Software and tools.

\begin{tabular}{|l|l|}
\hline Software/ Tool & Source \\
\hline $\begin{array}{l}\text { Leica LAS X - Application } \\
\text { Suite X }\end{array}$ & Leica Microsystems CMC GmbH, Wetzlar, Germany \\
\hline Microsoft office 2010 & Microsoft Corporation, Redmond, WA, USA \\
\hline
\end{tabular}




\begin{tabular}{|l|l|}
\hline Nucleotide BLAST & $\begin{array}{l}\text { National Center for Biotechnology Information/ U.S. } \\
\text { National Library of Medicine, Bethesda, MD, USA }\end{array}$ \\
\hline ImageJ 1.50b/ Fiji & $\begin{array}{l}\text { Wayne Rasband, National Institute of Health, USA } \\
\text { (Schindelin et al., 2012) }\end{array}$ \\
\hline Image Lab 5.2.1 build 11 & Bio-Rad Laboratories GmbH, Munich, Germany \\
\hline PVC Viewer v1.5.3.1 & $\begin{array}{l}\text { Intas Science Imaging Instruments GmbH, Göttingen, } \\
\text { Germany }\end{array}$ \\
\hline StepOne v2.3 & Life Technologies Corp., Carlsbad, CA, USA \\
\hline GraphPad Prism 6.05/ 7.03 & GraphPad Software Inc., La Jolla, CA, USA \\
\hline AUTOsoft 2.6 & Autobio Labtec Instruments Co. Ltd., Zhengzhou, China \\
\hline CellSens Entry 1.12 & Olympus Corporation, Tokyo, Japan \\
\hline Statistica 12 (for Q-Q-plots) & StatSoft Europe, Hamburg, Germany \\
\hline GIMP 2.8.16 & Spencer Kimball, Peter Mattis and GIMP team \\
\hline
\end{tabular}

\subsubsection{Animals}

- C57BL/6-J mice: Charles River Laboratories, Inc., Wilmington, MA, USA

- LSL-Kras ${ }^{\mathrm{G} 12 \mathrm{D} /+} ; \mathrm{LSL}-T r p 53^{\mathrm{R} 172 \mathrm{H} /+} ; \mathrm{Pdx}-1-\mathrm{Cre}(\mathrm{KPC})$ mice: archived tissue was used for the present study

\subsection{Methods}

\subsubsection{Animal studies}

\subsubsection{KPC mice}

The study was conducted with KPC mice (Hingorani et al., 2005). Archived tissues from previous preclinical studies were used (Cook et al., 2012; Neesse et al., 2013). Tumor development in these animals had been observed by small animal high-resolution ultrasound from eight weeks of age, and mice had been randomly enrolled into the studies at tumor volumes of 6-9 mm, as previously described (Neesse et al., 2013).

\subsubsection{Syngeneic orthotopic mouse model}

Orthotopic transplantation studies were conducted in C57BL/6-J mice. Surgery was performed at the age of eight weeks and mice were randomly separated into four groups before transplantation ( $n=7$ per group). Stably transfected syngeneic KPC-BL6 cells (+NT5C1A) and respective control cells (+vector) were used for this preclinical study. Before transplantation, cells were trypsinized and counted (1:1-mixture of cell suspension and 
$0.2 \%$ trypan blue solution in PBS). A total number of 150,000 viable cells were used per mouse. Cell suspensions in culture medium were mixed with equal volumes of Matrigel and kept on ice until transplantation.

\subsubsection{Housing conditions}

Mice were housed at a $12 \mathrm{~h}$ light and $12 \mathrm{~h}$ dark cycle and all animal procedures were conducted in accordance with institutional and national regulations. Animals were kept in groups of up to five mice per cage and were separated according to treatments.

\subsubsection{Orthotopic transplantation procedure}

Animals were intraperitoneally (i.p.) treated with buprenorphine $(0.1 \mathrm{mg} / \mathrm{kg}$ body weight) approximately $30 \mathrm{~min}$. prior to surgery. Mice were then anesthetized with isoflurane (2-3\%) for hair removal and the surgical tumor cell implantation. Mice were kept on a warming plate for the duration of the surgical procedure. Carprieve (5 mg/kg body weight) was administered subcutaneously (s.c.) prior to transplantation, which was performed based on a published protocol (Feldmann et al., 2007). Following disinfection of the mouse abdomen, the peritoneum was opened up with a small incision and $40 \mu \mathrm{l}$ of the resuspended cell suspension were injected into the tail of the pancreas. The peritoneum was closed with a single stich suture and the skin wound was closed using wound clips (removed seven days after surgery). Mice were transferred into a pre-warmed recovery cage. Mashed food was provided and mice were observed carefully following surgery. Mice were weighed at least three times per week and checked for general behavior every day during the whole study.

\subsubsection{Sonography}

Performance of small animal high-resolution ultrasound for tumor detection was previously described by our group (Goetze et al., 2018). Briefly, mice were anesthetized with $2 \%$ isoflurane and hairs were removed from the abdomen. Sonography was then performed using a Visual Sonics Vevo 2100 High Resolution Ultrasound System.

\subsubsection{Gemcitabine treatment}

Orthotopically transplanted C57BL/6-J mice were treated with gemcitabine-hydrochloride or saline, starting seven days after surgery. Intraperitoneal injections with gemcitabinehydrochloride were administered with $100 \mathrm{mg} / \mathrm{kg}$ body weight on day $0,3,7,10$, and 13 . Control animals were injected with comparable volumes of isotonic saline. 
KPC mice were treated as stated in the method descriptions of the corresponding preclinical studies (Cook et al., 2012; Hessmann \& Patzak et al., 2018; Neesse et al., 2013).

Archived samples from KPC mice were used for this study. These animals had been dosed with gemcitabine at $100 \mathrm{mg} / \mathrm{kg}$ body weight by i.p. injections (gemcitabine powder, $48 \%$ preparation of $\mathrm{dFdC}$, provided by Addenbrooke's Hospital Pharmacy, Cambridge, UK) (Cook et al., 2012; Hessmann \& Patzak et al., 2018; Neesse et al., 2013). All mice received the last gemcitabine dose $2 \mathrm{~h}$ prior sacrifice.

\subsubsection{Endpoint criteria}

For all studies the endpoint criteria were defined as $20 \%$ body weight loss, general morbidity, lack of social interaction and lethargy, as well as the development of ascites.

\subsubsection{Tissue harvesting}

Animals were sacrificed by cervical dislocation following administration of high doses of isoflurane. The peritoneum was opened up and mice were checked for metastases and other abnormalities. Tumor samples, liver tissue, and liver metastases were isolated and snap frozen. Samples were kept at $-80^{\circ} \mathrm{C}$ for subsequent LC-MS/MS analysis and protein isolation. Further pieces of tumor and liver tissue were incubated in $1 \mathrm{ml}$ RNAlater ${ }^{\circledR}$ per tube for $24 \mathrm{~h}$ at $4{ }^{\circ} \mathrm{C}$. The stabilizing solution was removed prior to storage at $-80{ }^{\circ} \mathrm{C}$. The remaining tumor parts, the pancreas, and liver tissue were fixed in $10 \%$ neutral buffered formalin overnight and were further processed for paraffin embedding.

\subsubsection{Serum isolation}

Blood was collected at study endpoint. For animals that received gemcitabine, $10 \mu$ of $1 \mathrm{mM}$ tetrahydrouridine (THU) were added to the blood to inhibit ex vivo gemcitabine inactivation by CDA. Vials were incubated at room temperature for up to ten minutes and were subsequently put on ice. Samples were centrifuged (4000 g, $4^{\circ} \mathrm{C}, 10 \mathrm{~min}$.) and serum was transferred to new tubes for storage at $-20^{\circ} \mathrm{C}$.

\subsubsection{Tissue preparation for paraffin-embedding}

Formalin-fixed tissues were further processed using a Leica Biosystems tissue processer for dehydration overnight. The following protocol was used: Formalin (75 min.), ethanol (EtOH) $55 \%$ (30 min.), EtOH $85 \%$ (45 min.), EtOH $96 \%$ (60 min.), EtOH 99 \% (75 min.), $\mathrm{EtOH} 99 \%$ (70 min.), EtOH $99 \%$ (90 min.), xylol (20 min.), xylol (30 min.), xylol (70 min.), paraffin (30 min.), paraffin (45 min.), paraffin (90 min.). 
Tissues were subsequently embedded in paraffin and $4 \mu \mathrm{m}$-sections were prepared for H\&E and immunohistochemistry stainings.

\subsubsection{Hematoxylin and eosin (H\&E) staining}

Tissue slides were incubated in Roticlear solution for 2x $10 \mathrm{~min}$. Tissues were rehydrated in a graded alcohol series (99\%, $99 \%, 96 \%, 80 \%, 70 \%, 50 \%)$ for 3 min. each. Following three washing steps using tap water, the slides were stained for $7 \mathrm{~min}$. in hematoxylin, washed again and kept in tap water for $5 \mathrm{~min}$. until the color turned blue. Staining with eosin for $30 \mathrm{sec}$. and further three washing steps followed. Finally, slides were incubated in solutions with increasing alcohol concentrations for dehydration (3 min. each) and further incubated in Roticlear for 4x 10 min. Cover glasses were added using Roti ${ }^{\circledR}$-Mount mounting medium.

\subsubsection{Immunohistochemistry (IHC)}

Tissue sections were processed according to standard procedures (Lang, 2013; Luttmann et al., 2014). Deparaffinization and tissue rehydration was achieved by incubation in Roticlear and in a graded alcohol series as described for H\&E staining. Heat-induced epitope retrieval was performed in citrate buffer $\mathrm{pH} 6.0$ or TE buffer $\mathrm{pH} 9.0$ by boiling the tissue slides for 4-10 min. (according to primary antibody) in a microwave, keeping them inside the microwave for further $10 \mathrm{~min}$., and a subsequent cooling step on ice for $20 \mathrm{~min}$. Slides were washed three times in tap water and treated with freshly prepared $3 \%$ hydrogen peroxide solution for $15 \mathrm{~min}$. in order to block endogenous peroxidases and thus, to reduce background staining. Following three washing steps in tap water, the slides were aligned into the Shandon Sequenza ${ }^{\mathrm{TM}}$ racks using TBS-T. Slides were washed three times with TBS-T, non-specific antibody binding was blocked by incubation in $200 \mu$ l blocking reagent per slide for $1 \mathrm{~h}$ at room temperature. $200 \mu$ l of diluted primary antibody solution were added per slide and incubated overnight at $4^{\circ} \mathrm{C}$. Slides were washed three times before adding $200 \mu \mathrm{l}$ of a 1:200-dilution of the secondary antibody per slide for $1 \mathrm{~h}$ at $37^{\circ} \mathrm{C}$, followed by another three washing steps. Vectastain ${ }^{\circledR} A B C$ kits and DAB peroxidase substrate solution were used for target detection. $A B$ complex formation required $30 \mathrm{~min}$. preincubation before $200 \mu \mathrm{l}$ of the solution were added per tissue slide for $1 \mathrm{~h}$ at room temperature. All slides were disassembled from the staining system and washed three times in tap water. Tissues were directly exposed to $100-150 \mu$ of DAB chromogen for few minutes (depending on primary antibody) and reaction was stopped with water. Counterstaining with hematoxylin was performed (4 min., three washing steps in tap water) with subsequent incubation for 5 min. Rehydration steps and mounting was done as described for H\&E stainings. 
Negative controls without primary antibody or without secondary antibody, respectively, were included in the staining process. Primary antibodies are listed in Table 9. Image acquisition was conducted using an Olympus DP27 camera with 20x or 40x magnification, respectively.

\subsection{IHC using primary antibodies from mouse origin}

The Vector lab mouse on mouse (M.O.M. ${ }^{\mathrm{TM}}$ ) kit was used according to the manufacturer's instructions for IHC stainings with primary antibodies from mouse origin. $200 \mu \mathrm{l}$ of the required solutions were added per slide. Following the blocking step of unspecific binding sites, slides were preincubated with M.O.M ${ }^{\mathrm{TM}}$ diluent for $5 \mathrm{~min}$. at room temperature, incubated with primary antibody for $30 \mathrm{~min}$. at room temperature, secondary antibody incubation at $37^{\circ} \mathrm{C}$ for $10 \mathrm{~min}$., and $\mathrm{AB}$ complex incubation for $30 \mathrm{~min}$. at room temperature.

\subsection{Co-IHC and Co-immunofluorescence}

The standard IHC-protocol was followed and pre-treatment with the second buffer was performed following DAB chromogen addition. Blocking of endogenous peroxidases and immunostaining were carried out as mentioned before and slides were developed for 10 min. using HistoGreen solution according to the manufacturer's recommendations. Slides were washed for $2 \mathrm{~min}$. in TBS and briefly rinsed under tap water. Counterstaining was achieved by 2 min. incubation in hematoxylin and three washing steps under tap water. The dehydration process was shortened to $30 \mathrm{sec}$. incubations in a graded alcohol series and in Roticlear. Slides were finally mounted with coverglasses using Roti $^{\circledR}$-Mount.

Archived tissues from a previously published preclinical trial were used for co-immunofluorescence (Co-IF) (Neesse et al., 2013), which was performed similar to the IHC staining procedure. However, following epitope retrieval, the slides were directly aligned into the Shandon Sequenza ${ }^{\mathrm{TM}}$ racks, blocked using $5 \%$ goat serum in TBS-T and incubated with both primary antibodies together. Incubation with secondary antibodies was performed in the dark (1:1000-dilution of both Alexa Fluor ${ }^{\circledR}$ antibodies in $10 \%$ BSA/TBS-T), followed by five washing steps. DAPI-containing mounting solution was used and slides were kept at $4{ }^{\circ} \mathrm{C}$ in the dark until analysis. Images were acquired at a Leica DMi8 microscope and ten high performance fields (HPF) at 40x-magnification were counted per slide for quantification. Fiji software was used for manual counting of double-positive cells. 


\subsubsection{Cell culture}

\subsubsection{Cell culture conditions for adherent cells}

Archived KPC cells, cells from metastatic foci, and CAF and PSC cell lines were used for these studies. Furthermore, the human L3.6pl (pancreas to liver) tumor cell line (Bruns et al., 1999) was included. A comprehensive description of the establishment of these primary murine KPC cell lines and cell lines from metastatic foci (liver, spleen, ascites) was given in the publication by Hingorani et al. (2005). Moreover, the isolation of CAFs from LSL$\mathrm{Kras}^{\mathrm{G} 12 \mathrm{D} /} ; \mathrm{Ptf1} \mathrm{a}-\mathrm{Cre}(\mathrm{KC})$ mice by serial trypsinization as well as PSC purification by density gradient centrifugation with subsequent immortalization using the SV40 large T antigen, was previously described by Hessmann \& Patzak et al. (2018).

Cells were incubated at $37^{\circ} \mathrm{C}$ with $5 \%$ carbon dioxide supply. High glucose DMEM with phenol red was used for KPC, CAF, and PSC cell lines. Media were supplemented with $10 \%$ fetal bovine serum (FBS) and in case of KPC and CAF cells also with $1 \%$ non-essential amino acids. L3.6pl cells were cultured in MEM without phenol red, supplemented with $10 \% \mathrm{FBS}$ and $1 \%$ L-glutamine. Cells were passaged at $80-95 \%$ of confluency by standard trypsinization (Schmitz, 2011). For functional assays, cell suspensions were centrifuged at $1200 \mathrm{rpm}$ for $3 \mathrm{~min}$., resuspended and counted using the Nexcelom cell counter ( $20 \mu \mathrm{l}$ of cell suspension in single-use counting chambers).

Cell stocks were prepared using $90 \%$ FBS and $10 \%$ dimethyl sulfoxide (DMSO) (1 ml aliquots). A slow freezing process was ensured by the use of an isolating styrofoam box. Frozen cells were either stored at $-80^{\circ} \mathrm{C}$ or transferred into liquid nitrogen cell tanks for long-term storage. For thawing of cells, the stocks were quickly defrosted, mixed with culture medium, centrifuged, resuspended, and transferred into cell culture flasks. Cells were passaged at least once before performing functional assays.

\subsubsection{Mycoplasma test}

Mycoplasma tests of mammalian cells were conducted using a PCR detection kit according to manufacturer's instructions. Cells were at $80-100 \%$ confluency and medium was not older than two days. In brief, cell culture supernatants were incubated for $5 \mathrm{~min}$. at $95^{\circ} \mathrm{C}$ and briefly centrifuged. JumpStart ${ }^{\mathrm{TM}}$ Taq DNA polymerase and rehydration buffer from the kit were mixed and added to the samples and the controls. Samples were analyzed on an $1.2 \%$ agarose gel with Midori green DNA stain. $7 \mu \mathrm{l}$ of a $100 \mathrm{bp}$ DNA ladder and $12 \mu \mathrm{l}$ of each sample (in duplicates) were used, gel electrophoresis performed, and bands visualized at the ChemiDoc XRS+ system. 
The cell lines were tested for mycoplasma contamination prior to orthotopic transplantations (KPC-BL6 cells), prior to LC-MS/MS experiments (L3.6pl cells), and following stable transfections (PSC1 and PSC2 cell lines).

\subsubsection{Gemcitabine and 5-FU treatments}

Gemcitabine-hydrochloride powder and 5-FU powder were used for in vitro studies. Stock solutions with a concentration of $100 \mathrm{mM}$ were prepared in sterile water (gemcitabine) or DMSO (5-FU), respectively, and kept at $-20^{\circ} \mathrm{C}$. For LC-MS/MS analysis, cells were seeded at a density of 700,000 cells per well in 6-well plates and allowed to attach for $24 \mathrm{~h}$. Cells were exposed to $1 \mu \mathrm{M}$ gemcitabine-hydrochloride or water as control for $2 \mathrm{~h}$ at $37^{\circ} \mathrm{C}$. Supernatants $(1 \mathrm{ml})$ were immediately stored at $-80^{\circ} \mathrm{C}$. Cell pellets were harvested by washing twice with PBS, trypsinization, and subsequent incubation at $37^{\circ} \mathrm{C}$ for few min. Culture medium was added, cell suspensions centrifuged at $1200 \mathrm{rpm}$ for $3 \mathrm{~min}$., and subsequently cells were resuspended in $2 \mathrm{ml}$ of fresh medium per sample. Cells were counted and $1^{*} 10^{6}$ or $5^{\star} 10^{5}$ cells per sample, respectively, were transferred into cryovials. Cells were centrifuged at $1500 \mathrm{rpm}$ for $4 \mathrm{~min}$. and washed twice with cold PBS. The supernatant was removed carefully and the cell pellets were stored at $-80^{\circ} \mathrm{C}$.

\subsubsection{Establishment of cell lines stably expressing NT5C1A}

A pSG5-vector (a kind gift of Prof. Johnsen, University Medical Center Göttingen) containing a hemagglutinin tag (HA-tag) upstream of a multiple cloning site (MCS), a P2A-sequence, and a hygromycin resistance gene (pSG5-HA-MCS-P2A-Hygro), was used. Derivatives of the pSG5-vector containing the coding sequence of murine NT5C1A and a control plasmid without the NT5C1A insert were generated following the protocol as described by Kari et al. (2016).

The $1.1 \mathrm{~kb}$ coding region of Mus musculus 5'-nucleotidase, cytosolic IA (NM_001085502.1) was amplified from undiluted KPC-PDA cell cDNA (RNA extraction from cells was performed with the RNeasy ${ }^{\circledR}$ mini kit from Qiagen according to the manufacturer's instructions) using Phusion High-Fidelity DNA Polymerase.

Forward (mNt5c1a_Cl_Notl_For) and reverse primers (mNt5c1a_Cl_Nhel_Rev) were dissolved in water to a working concentration of $5 \mathrm{pmol} / \mu \mathrm{l}$. The PCR reaction mixture $(50 \mu \mathrm{l}$, triplicates) is shown in Table 16 and the PCR thermoprofile in Table 17. The triplicate samples were pooled, mixed with an according amount of 6x DNA loading dye (10 mM TRIS-HCI pH 7.4, 0.2 \% bromophenol blue indicator, 60 mM EDTA pH 8.0, $60 \%$ glycerol, in water), and gel purified using a $1.4 \%$ agarose gel (30 min. at $80 \mathrm{~V}$ and $30 \mathrm{~min}$. at $125 \mathrm{~V}$ ). The appropriate band was marked under UV-light at a wavelength of $312 \mathrm{~nm}$, cut out, and 
the weight of the gel part determined. The Nucleo Spin ${ }^{\circledR}$ gel and PCR clean-up kit was used according to the manufacturer's instructions for purification. $200 \mu \mathrm{l}$ of binding buffer were added per $100 \mathrm{mg}$ of gel, which was then dissolved at $50^{\circ} \mathrm{C}$ in a heating block (1300 rpm, 15 min.). The purified product was eluted with $15 \mu \mathrm{l}$ of elution buffer and DNA concentration was measured at a nanophotometer.

\begin{tabular}{|l|l|}
\hline Component & Volume per tube \\
\hline Phusion DNA Polymerase & $0.5 \mu \mathrm{l}$ \\
\hline Undiluted cDNA & $10 \mu \mathrm{l}$ \\
\hline $5 x$ Phusion HF buffer & $10 \mu \mathrm{l}$ \\
\hline 20 mM dNTPs & $0.5 \mu \mathrm{l}$ \\
\hline mNt5c1a_Cl_Notl_For & $5 \mu \mathrm{l}$ \\
\hline mNt5c1a_Cl_Nhel_Rev & $5 \mu \mathrm{l}$ \\
\hline Water (Aqua B.Braun) & $19 \mu \mathrm{l}$ \\
\hline
\end{tabular}

Table 16: Reaction mixture for cloning of NT5C1A-insert.

\begin{tabular}{|l|l|l|l|l|l|l|}
\hline Number of cycles & \multicolumn{9}{|l|}{ Temperature $\left({ }^{\circ} \mathbf{C}\right)$} & \multicolumn{4}{l|}{ Duration (min.) } \\
\hline 1 & 98 & \multicolumn{4}{l|}{3} & \\
\hline 2 & 98 & 72 & 0.5 & 4 & \\
\hline 2 & 98 & 70 & 72 & 0.5 & 0.5 & 4 \\
\hline 2 & 98 & 68 & 72 & 0.5 & 0.5 & 4 \\
\hline 2 & 98 & 66 & 72 & 0.5 & 0.5 & 4 \\
\hline 2 & 98 & 64 & 72 & 0.5 & 0.5 & 4 \\
\hline 2 & 98 & 62 & 72 & 0.5 & 0.5 & 4 \\
\hline 28 & 98 & 60 & 72 & 0.5 & 0.5 & 4 \\
\hline 1 & 72 & & & 10 & & \\
\hline 1 & 4 & & & & & \\
\hline
\end{tabular}

Table 17: Thermoprofile for plasmid amplification.

Restriction digestion was accomplished with appropriate fast digest enzymes for $15 \mathrm{~min}$. at $37^{\circ} \mathrm{C}$ and $300 \mathrm{rpm}$ with subsequent heat inactivation of enzymes for $5 \mathrm{~min}$. at $65{ }^{\circ} \mathrm{C}$ and $450 \mathrm{rpm}$. The pSG5-vector was incubated with Notl and Spel and the NT5C1A-insert with Notl and Nhel (Spel and Nhel create compatible sticky ends). The product was loaded on a $1.3 \%$ agarose gel (20 min., $200 \mathrm{~V}$ ), cut out and gel purified as described above. The vector-plasmid, the insert, and T4 DNA ligase were mixed with 10x buffer and water for ligation and incubated at $22{ }^{\circ} \mathrm{C}$ for $20 \mathrm{~min}$. with slight agitation at $300 \mathrm{rpm}$. 
For transformation, DH5a competent E.coli $(100 \mu \mathrm{l})$ were added to the reaction tube and incubated $5 \mathrm{~min}$. on ice with subsequent heat shock at $42{ }^{\circ} \mathrm{C}$ for $3 \mathrm{~min}$. The mixture was given on ampicillin-containing LB-plates (the pSG5-vector contains an ampicillin resistance site) and incubated at $37^{\circ} \mathrm{C}$ overnight. Four clones were picked and incubated in LB-medium with $100 \mu \mathrm{g} / \mathrm{ml}$ of ampicillin overnight $\left(37^{\circ} \mathrm{C}, 180 \mathrm{rpm}\right)$. Plasmid DNA was extracted using the innuPREP plasmid mini kit plus according to the manufacturer's protocol (40 $\mu$ l elution buffer).

The plasmids were mixed with water and the 5'-CCTACAGCTCCTGGGCAACG primer ( $2 \mu \mathrm{M}$, Sigma) and subsequently sent to SeqLab Göttingen for sequencing to check for the correct insert sequence. Correct plasmids were amplified using DH5a competent E.coli. Ampicillin $(100 \mu \mathrm{g} / \mathrm{ml})$ was added to overnight cultures in LB-medium $\left(37^{\circ} \mathrm{C}, 180 \mathrm{rpm}\right)$ for selection. Plasmids were purified using the NucleBond ${ }^{\circledR}$ Xtra plasmid purification kit according to the manufacturer's protocol (DNA reconstituted in $200 \mu$ l water). The plasmids were amplified, purified, and DNA concentrations determined.

The control vector without NT5C1A-insert was incubated with Spel and Nhel to obtain compatible sticky ends (HindIII and BgIII were added to the digestions to inactivate an ERT2-site, which was present in the original vector). T4 DNA ligase was added, incubated, and the product directly purified using the PCR clean up kit (1:3-dilution of binding buffer, $30 \mu$ l elution volume). The control vector plasmid was amplified and sequenced as previously described.

To achieve better transfection efficiency, the plasmids were linearized using Asel restriction enzyme with $20 \mu \mathrm{g}$ of plasmid. The mixtures were incubated at $37^{\circ} \mathrm{C}$ overnight under slight agitation with $300 \mathrm{rpm}$ with subsequent phenol-chloroform purification. Here, $100 \mu$ l of water were added to $100 \mu \mathrm{l}$ of the reaction mixture and an equal volume of phenol/ chloroform/ isoamylalcohol (25:24:1) was added. The mixtures were vortexed briefly and centrifuged at $12000 \mathrm{rpm}$ at room temperature for $5 \mathrm{~min}$. The aqueous top phase was transferred into a new reaction tube and mixed with $8 \mathrm{M}$ lithium chloride (1/10 of the volume). An equal volume of isopropanol was added, incubated for $5 \mathrm{~min}$. at room temperature, and centrifuged for $20 \mathrm{~min}$. at $12000 \mathrm{rpm}$ at $4{ }^{\circ} \mathrm{C}$. The precipitates were washed in $200 \mu \mathrm{l} 70 \%$ ethanol, centrifuged again for $10 \mathrm{~min}$. and subsequently $\mathrm{EtOH}$ was discarded, the pellets dried at room temperature, and dissolved in $20 \mu$ water.

The constructs were transfected into murine PSC and KPC cells and into human L3.6pl cells, as recently described by our group (Hessmann \& Patzak et al., 2018). For this purpose, $6 \mu \mathrm{g}$ of linearized plasmids and $20 \mu \mathrm{l}$ of TurboFect transfection reagent were separately preincubated with each $625 \mu \mathrm{l}$ OptiMEM medium for $5 \mathrm{~min}$. Both components were mixed and further incubated for $20 \mathrm{~min}$. at room temperature. Cells were washed using 
PBS and $4 \mathrm{ml}$ of DMEM, respectively MEM, without supplements were added per $10 \mathrm{~cm}$ dish. Cells were kept at $37^{\circ} \mathrm{C}$ following dropwise addition of the transfection mixture.

Medium was changed $8 \mathrm{~h}$ after transfection and penicillin-streptomycin was added to the medium for two days. The vector plasmid without the NT5C1A insert was utilized to obtain control cells.

Successfully transfected cells were selected $48 \mathrm{~h}$ after transfection by treatment with hygromycin B Gold with the following concentrations: PSC1 and PSC2: $250 \mu \mathrm{g} / \mathrm{ml}, \mathrm{KPC} 1$ : $500 \mu \mathrm{g} / \mathrm{ml}$, KPC2: $900 \mu \mathrm{g} / \mathrm{ml}$, and L3.6pl: $500 \mu \mathrm{g} / \mathrm{ml}$. The most suitable concentrations to avoid growth of untransfected cells were determined in advance of the transfection procedure by incubation of untransfected cells with increasing hygromycin concentrations for one week. Only half of the mentioned concentrations were added to the culture media for maintenance, but hygromycin was not added during the performance of functional assays. Successful generation of stably transfected cell lines was confirmed by Western blot, immunocytochemistry, and qRT-PCR.

\subsubsection{Crystal violet cell proliferation assay}

Crystal violet staining was used according to standard procedures to determine cell viability (Feoktistova et al., 2016). Transfected cell lines were seeded at a density of 2000 cells (KPC, PSC cell lines) or 7500 cells (L3.6pl cell lines), respectively, in 24-well plates. Cells were allowed to attach for $24 \mathrm{~h}$ and were then treated with increasing concentrations of gemcitabine or paclitaxel, respectively. Treatment media were renewed every other day for a total treatment time of six days. Subsequently, cells were washed once with PBS, fixed with methanol for $15 \mathrm{~min}$. at room temperature, and incubated with crystal violet solution $(0.1 \%$ in $20 \% \mathrm{EtOH})$. Finally, excess staining solution was removed under tap water. Crystal violet staining intensity was determined using spectrophotometric analysis. $500 \mu \mathrm{l}$ of $10 \%$ acetic acid were added per well to dissolve the crystal violet stain. The plates were incubated for $20 \mathrm{~min}$. under slight agitation. Samples were diluted with water and subsequently absorbance measured at $595 \mathrm{~nm}$ (Elangovan et al., 2008).

\subsubsection{Co-culture studies with conditioned medium}

As recently published (Hessmann \& Patzak et al., 2018), $1^{*} 10^{6}$ cells of primary murine fibroblasts were seeded per $10 \mathrm{~cm}$ dish, allowed to attach for $24 \mathrm{~h}$, and then treated with $30 \mathrm{nM}$ of gemcitabine-hydrochloride or water for $24 \mathrm{~h}$. Conditioned medium (CM) was collected and centrifuged at $1200 \mathrm{rpm}$ for $3 \mathrm{~min}$. Supernatants were then used in MTT cell viability assays. Confluency of CAFs was not less than $80 \%$ at this stage. Conditioned 
media of transfected PSC cells were prepared accordingly following treatment with $25 \mathrm{nM}$ of gemcitabine-hydrochloride (confluency $>70 \%$ ).

\subsubsection{MTT cell viability assays}

KPC tumor cells were seeded at a density of 5000 cells per well in 96 -well plates as technical triplicates and allowed to attach for $24 \mathrm{~h}$.

Previously prepared conditioned media were used for cell treatment. Regarding the CAF cells, the control-CM without gemcitabine was mixed with $30 \mathrm{nM}$ fresh gemcitabinehydrochloride. For transfected PSCs, CM was used directly after centrifugation. The cells were cultured under this treatment for $72 \mathrm{~h}$ with subsequent performance of the MTT cell viability assay (Mosmann, 1983). In brief, MTT reagent (thiazolyl blue tetrazolium bromide) was added to the culture media to a final concentration of $0.5 \mathrm{mg} / \mathrm{ml}$. Media were carefully removed following $2 \mathrm{~h}$ incubation at $37^{\circ} \mathrm{C}$. Precipitates were dissolved under gentle agitation for $15 \mathrm{~min}$. in $100 \mu \mathrm{l}$ of acidified isopropanol (80 ml 2-propanol, $10 \mathrm{ml} 1 \mathrm{M}$ hydrochloric acid, $10 \mathrm{ml}$ Triton $\left.X^{\circledR}-100\right)$. Finally, absorption values were determined at $595 \mathrm{~nm}$ without reference wavelength and cell viability is expressed relative to controls.

\subsubsection{Immunocytochemistry}

For immunocytochemistry (ICC) (Junqueira \& Carneiro, 2005; Luttmann et al., 2014), the cells were seeded at a density of 5000 cells per well in chamber slides and allowed to attach overnight. The cells were washed once with PBS and fixed with ice cold methanol for 20 min. at $-20^{\circ} \mathrm{C}$, with subsequent three washing steps with PBS. Permeabilization was achieved by $30 \mathrm{sec}$. incubation at room temperature in a PBS-Triton $\mathrm{X}^{\circledR}-100$ solution $(0.1 \%)$. Cells were washed four times with PBS and unspecific binding sites were blocked using $10 \%$ goat serum in PBS for $1 \mathrm{~h}$ at room temperature and cells were then washed twice for $5 \mathrm{~min}$. each. Primary antibody solution $(200 \mu \mathrm{l})$ was added and incubated for $1 \mathrm{~h}$ at $37^{\circ} \mathrm{C}$ and further at $4{ }^{\circ} \mathrm{C}$ overnight. Cells were washed again in PBS (2x) for $5 \mathrm{~min}$. each. Alexa Fluor ${ }^{\circledR}$-conjugated secondary antibodies were added to the cells for detection in a 1:500-dilution in $10 \%$ goat serum in PBS and incubated in the dark for $1 \mathrm{~h}$ at room temperature. Subsequently, cells were washed $3 \times 5$ min. with PBS. The chambers were removed carefully from the slides and cells were mounted with DAPI-containing mounting solution $\left(\right.$ Vectashield ${ }^{\circledR}$ ) and stored at $4^{\circ} \mathrm{C}$ in the dark until analysis. Antibodies are listed in Table 9. A Leica DMi8 microscope was used for image acquisition. 


\subsubsection{Molecular biology techniques}

\subsubsection{RNA extraction from cells}

The PeqLab Gold Total RNA kit was used according to the manufacturer's instructions to extract RNA from cell samples. RNA was eluted from the provided columns using $40 \mu \mathrm{l}$ of RNase-free water and RNA concentrations were determined.

\subsubsection{RNA extraction from tissue}

RNA extraction was achieved using the single step method (Mülhardt, 2013b). $1 \mathrm{ml}$ of Trizol reagent was added per tissue piece and one stainless steel bead per tube to process the tissues using the Qiagen tissue lyser at a frequency of 30/sec. for 2 min. Chloroform (200 $\mu \mathrm{l})$ was added to the samples, mixed, incubated $5 \mathrm{~min}$. at room temperature, and subsequently centrifuged at $13500 \mathrm{rpm}$ for $15 \mathrm{~min}$. at $4{ }^{\circ} \mathrm{C}$. The top phase was mixed with $500 \mu \mathrm{l}$ of isopropanol, incubated $10 \mathrm{~min}$. at room temperature, and centrifuged at the same conditions. The supernatants were discarded, the pellets washed with $75 \% \mathrm{EtOH}$, and centrifuged (5 min., $\left.13000 \mathrm{rpm}, 4{ }^{\circ} \mathrm{C}\right)$. The supernatants were removed and the RNA-containing pellets were dissolved in $50 \mu \mathrm{l}$ of water. RNA concentrations were determined at the INTAS nanophotometer.

\subsubsection{3 cDNA preparation}

RNA samples were diluted using RNase-free water to obtain $1 \mu \mathrm{g}$ of RNA and incubated with recombinant $\mathrm{RNasin}{ }^{\circledR}$ ribonuclease inhibitor $\left(10 \mathrm{~min}, 65^{\circ} \mathrm{C}\right.$ ). Samples were briefly centrifuged and cooled on ice before adding reverse transcription buffer $(8 \mu \mathrm{l})$, poly $(\mathrm{dT})_{15}$ oligo primers $(8 \mu \mathrm{l}), 2 \mathrm{mM}$ dNTP's $(8 \mu \mathrm{l}), 0.1 \mathrm{M}$ DTT $(4 \mu \mathrm{l})$ and M-MLV reverse transcriptase $(2 \mu l)$. Samples were mixed carefully, centrifuged briefly, and incubated for $1 \mathrm{~h}$ at $38^{\circ} \mathrm{C}$ and subsequently for $10 \mathrm{~min}$ at $72{ }^{\circ} \mathrm{C}$ (Mülhardt, 2013b). Samples were put on ice and $120 \mu \mathrm{l}$ of water were added to obtain the working concentration for qRT-PCR.

Myoblast-mRNA (kindly provided by Prof. J. Schmidt, University Medical Center Göttingen) and murine muscle RNA served as positive controls for human and murine NT5C1A expression, respectively.

\subsubsection{4 qRT-PCR}

Quantitative PCR (Mülhardt, 2013a) was performed using TaqMan ${ }^{\circledR}$ probes. Universal PCR mastermix ( $5 \mu \mathrm{l} /$ sample), TaqMan ${ }^{\circledR}$ probes $(0.5 \mu \mathrm{l} /$ sample), and water were mixed $(3.5 \mu \mathrm{l} /$ sample) and added to the according wells of a 96-well PCR plate. $1 \mu$ of cDNA was added to each well and technical duplicates of samples were analyzed. $1 \mu \mathrm{l}$ of water was used for 
negative control wells. The PCR plate was closed using appropriate cover foils and centrifuged briefly. The thermoprofile shown in Table 18 was run at an Applied Biosystems real-time PCR system with the StepOne software for analysis. A list of TaqMan ${ }^{\circledR}$ probes is provided in Table 12.

\begin{tabular}{|l|l|l|}
\hline Number of cycles & Temperature & Duration \\
\hline 1 & $50^{\circ} \mathrm{C}$ & 2 min. \\
\hline 1 & $95^{\circ} \mathrm{C}$ & $10 \mathrm{~min}$. \\
\hline 40 & $95^{\circ} \mathrm{C}$ & $15 \mathrm{sec}$. \\
\cline { 2 - 3 } & $60^{\circ} \mathrm{C}$ & $1 \mathrm{~min}$. \\
\hline
\end{tabular}

Table 18: Thermoprofile for standard qRT-PCR.

\subsubsection{Protein biochemistry}

\subsubsection{Protein isolation from cells}

Cultured cells were washed twice with PBS and $40 \mu$ of lysis buffer were added per well to obtain whole cell lysates. Two wells of a 6 -well plate were pooled for protein isolation. Cells were removed from the plates using cell scrapper, treated with three short sonication impulses, and incubated on ice for at least $20 \mathrm{~min}$. Subsequently, lysates were centrifuged for $15 \mathrm{~min}\left(4^{\circ} \mathrm{C}, 13500 \mathrm{rpm}\right)$ and supernatants were stored at $-80^{\circ} \mathrm{C}$.

\subsubsection{Protein isolation from tissue}

Dependent on the tissue size, $300-400 \mu$ of protein lysis buffer were added to each tissue piece. Tissues were disrupted using stainless steel beads with the Qiagen Tissue lyser with a frequency of $30 / \mathrm{sec}$. for $2 \mathrm{~min}$. Lysates were immediately transferred back on ice and incubated for $30 \mathrm{~min}$. Samples were centrifuged and supernatants kept at $-80^{\circ} \mathrm{C}$.

\subsubsection{Bradford protein assay}

Protein concentration was determined with the Bradford method (Bradford, 1976; Rehm \& Letzel, 2016) using bovine serum albumin (BSA) standards. Protein samples were diluted with water to be in the range of the standard curve. All samples were measured in duplicates on a clear 96-well plate with flat bottom. Samples were incubated with the Coomassie Blue G-250 Protein Assay Reagent for 5-10 min. and absorption was subsequently measured at the PHOMO plate reader at $595 \mathrm{~nm}$. 


\subsubsection{Western blot analysis}

Common polyacrylamide gel electrophoresis was performed (Rehm \& Letzel, 2016) using $35 \mu \mathrm{g}$ of protein. Lysates were prepared with 4x NuPAGE loading buffer and $\beta$-mercaptoethanol (to reduce the disulfide bonds of the proteins). Samples were denatured for $5 \mathrm{~min}$. at $95^{\circ} \mathrm{C}$, cooled on ice, and centrifuged briefly.

Western bolt (WB) analyses were done by loading the prepared protein samples on precast 4-12\% Bis-Tris protein gels. Electrophoresis was conducted at $160 \mathrm{~V}$ for $1 \mathrm{~h}$ using NuPAGE ${ }^{\mathrm{TM}}$ MOPS SDS running buffer and proteins were subsequently transferred on $0.45 \mu \mathrm{m}$ nitrocellulose membranes ( $15 \mathrm{~V}, 90 \mathrm{~min}$.) using NuPAGE ${ }^{\mathrm{TM}}$ transfer buffer with addition of $10 \%$ methanol. Protein bands were visualized with Ponceau S solution and subsequently cut at appropriate positions. Membrane parts were then washed in PBS-T. Dependent on the primary antibodies' recommendations and in-house testing, $5 \%$ milk in PBS-T or $5 \%$ BSA in TBS-T were used for blocking of unspecific binding sites (incubation for at least $1 \mathrm{~h}$ at room temperature on an orbital shaker). Membranes were incubated with primary antibody solutions overnight at $4{ }^{\circ} \mathrm{C}$ on an orbital shaker. Subsequently, membranes were washed with PBS-T or TBS-T (3x $10 \mathrm{~min}$.), respectively, and incubated with horseradish peroxidase (HRP)-coupled secondary antibodies for $1 \mathrm{~h}$ at room temperature. Primary and secondary antibodies are listed in Table 9 and 10. Following another three washing steps, chemiluminescence substrate Plus-ECL or Ultra-ECL (for CC3-detection) were added to the membranes and protein bands were detected using the ChemiDoc $^{\text {TM }}$ XRS+ imaging system with Image Lab software. $3 \mu \mathrm{g}$ of murine muscle lysate were loaded as positive control for NT5C1A expression.

Quantification of Western blot analyses was performed using the rectangle volume tool of the Image Lab software. Each band was exactly marked by a rectangle form and background areas were marked as well. The values obtained for the volumes and the number of pixels per rectangle were utilized for further calculations. Values were normalized to the loading control.

\subsubsection{Tissue microarray analysis}

Images of the gemcitabine-metabolizing enzyme IHC-stainings were obtained from human TMAs from Oslo University Hospital, Norway (Hessmann \& Patzak et al., 2018).

TMAs for NT5C1A analysis were obtained from postoperative PDAC patients from the Department of Pathology, University Medical Center Göttingen (TMA-1, $n=77$ patients) and the Department of Pathology, University Medical Center Erlangen (TMA-2, $n=337$ patients) in accordance with ethical requirements. Written consent from every patient was 
received prior to tissue collection and analysis. Patient samples of the TMA-1 originate from patients of the University Medical Center Göttingen.

TMA-2 PDAC tumor samples were collected in Dresden (Institute of Pathology, University Hospital Dresden), Regensburg (Institute of Pathology, University Hospital Regensburg) and Jena (Institute of Pathology, University Hospital Jena) from 1993 to $2015.65 \%$ of these patients did not undergo adjuvant chemotherapy, the remaining $35 \%$ of patients were chiefly treated with 5-FU or gemcitabine-based regimens.

Standard IHC protocols were followed to stain for NT5C1A with hematoxylin counterstaining. Citrate buffer pH 6.0, NT5C1A antibody (Assay Biotech, 1:100), and the Vectastain ${ }^{\circledR}$ ABC Rabbit Kit with ImmPACT DAB Peroxidase Substrate Kit were used for TMA-1 staining. Reagents for NT5C1A staining of TMA-2 were the Pro Taqs II Antigen Enhancer pH 9.5, NT5C1A antibody (Atlas Antibodies AB, 1:100) and the ImmPress Reagent Kit Anti-Rabbit IgG with AEC-Plus Substrate-Chromogen.

The maximal NT5C1A expression was analyzed for each tumor sample by experienced pathologists from Göttingen and Erlangen. Mean values of replicate samples were used for data analysis and a semi-quantitative scoring system was applied, reaching from score 0 (no expression) to score 3 (strong expression).

\subsubsection{Liquid chromatography tandem mass-spectrometry}

LC-MS/MS analysis of the gemcitabine metabolites $\mathrm{dFdC}, \mathrm{dFdU}$, and dFdCTP, and of 5-FU was performed as previously described (Hessmann \& Patzak et al., 2018).

For in vitro studies, cell culture supernatants and cell pellets that were exposed to $1 \mu \mathrm{M}$ of gemcitabine-hydrochloride or $100 \mu \mathrm{M}$ of 5 -FU for $2 \mathrm{~h}$ were analyzed. Mouse tissue and blood samples that had been taken $2 \mathrm{~h}$ after administering the last dose of gemcitabine were used. Snap frozen tumor samples, frozen serum samples, as well as cell pellets and cell culture supernatants were processed and analyzed according to a published protocol (Bapiro et al., 2014; 2016).

\subsubsection{Statistical analysis}

Statistical analysis was performed using Graph Pad Prism (version 6.05 in chapter I and 7.03 in chapter II). Data are presented as mean \pm SEM. Statistical significance was considered for $p<0.05$ with ${ }^{*} p<0.05$, ${ }^{* *} p<0.01$, and ${ }^{* *} p<0.001$. If not stated otherwise in the figure legends, two-tailed Student t-test was used for analysis. 


\section{Results}

\subsection{Intratumoral gemcitabine accumulation in murine PDAC results from fibroblast drug scavenging}

The content of this chapter is part of the following publication and the descriptions refer to this publication. Further citations are only included in this chapter for additional data and for the presented figures.

Hessmann, E. *, Patzak, M.S. *, Klein, L., Chen, N., Kari, V., Ramu, I., Bapiro, T.E., Frese, K.K., Gopinathan, A., Richards, F.M., Jodrell, D.I., Verbeke, C., Li, X., Heuchel, R., Löhr, J.M., Johnsen, S.A., Gress, T.M., Ellenrieder, V., and Neesse, A. (2018). Fibroblast drug scavenging increases intratumoural gemcitabine accumulation in murine pancreas cancer. Gut, 67(3), 497-507. https://doi.org/10.1136/gutjnl-2016-311954 ( ${ }^{*}$ Co-first authors) ${ }^{1}$

In this project, I was mainly involved in the conception and design of experiments, in the analysis of results and in the preparation of the figures, as well as in reviewing the manuscript. Furthermore, I performed cell culture experiments, including establishment, analysis, and treatment of NT5C1A overexpressing cell lines, Co-ICC, CM assays, and histology stainings (mouse samples were obtained from previous preclinical trials with KPC mice), (Figures $11 \mathrm{~A}, \mathrm{~B}, \mathrm{C} ; 13$ murine tissues (NT5C1A, CDA, DCTD), $14 A, B, C, D ; 32$ of my thesis). Colleagues supported this project by performing ICC of fibroblasts, gemcitabine and 5-FU treatments for LC-MS/MS analysis, qRT-PCR of gemcitabine metabolizing enzymes, and IHC stainings of human tissues. LC-MS/MS measurements were carried out at the Cancer Research UK Cambridge Institute, University of Cambridge, Cambridge, United Kingdom.

\footnotetext{
${ }_{1}$ https://gut.bmj.com/content/67/3/497; published as an Open Access article (Creative Commons Attribution license CC BY 4.0; https://creativecommons.org/licenses/by/4.0/)
} 


\subsubsection{Gemcitabine treatment and the tumor stroma in pancreatic cancer}

The pronounced TME and the hypovascular nature of pancreatic tumors were intensively discussed in recent literature to exert a biophysical treatment barrier and to impair drug delivery to the tumor (Jacobetz et al., 2013; Olive et al., 2009; Provenzano et al., 2012). However, several studies showed that stromal ablation is not the method of choice to improve treatment effectiveness as tumors became even more aggressive (Oezdemir et al., 2014; Rhim et al., 2014).

Initially, to elucidate the impact of the tumor stroma and its different components on gemcitabine drug delivery, metabolism, and thus treatment response, we performed LC-MS/MS analysis of gemcitabine metabolites in KPC mouse tissue. Our group re-analyzed KPC mouse tumor tissues from a previously published preclinical trial (Neesse et al., 2013) to study whether a correlation between intratumoral gemcitabine concentrations and overall survival could be described, as it would be expected in case of a biophysical treatment barrier. Interestingly, no correlation between the intratumoral concentration of the active, cytotoxic gemcitabine metabolite dFdCTP and overall survival could be shown in the ten analyzed mice (Hessmann \& Patzak et al., 2018). Therefore, it was concluded that intratumoral dFdCTP concentrations in KPC bulk tumor tissue might not be a suitable marker for treatment response towards gemcitabine.

\subsubsection{Increased gemcitabine accumulation in primary KPC tumors compared with liver metastases and normal liver}

Consequently, we performed a detailed analysis of gemcitabine metabolites in KPC bulk tumor tissues, tissues from liver metastases, and well-perfused tissue from adjacent normal liver. It was already described that peak concentrations in the tumors are reached $2 \mathrm{~h}$ after i.p. injection (Neesse et al., 2013). Thus, KPC mice with detected tumors (Figure 6A and 6B) had been dosed with $100 \mathrm{mg} / \mathrm{kg}$ gemcitabine intraperitoneally and sacrificed exactly $2 \mathrm{~h}$ after injection. Using an established protocol for LC-MS/MS analysis of gemcitabine metabolites (Bapiro et al., 2014; 2016), the concentrations of native gemcitabine $\mathrm{dFdC}$, the active metabolite $\mathrm{dFdCTP}$, and the inactive metabolite of gemcitabine $\mathrm{dFdU}$ were determined in the above mentioned tissue samples $(n=15)$. 
A

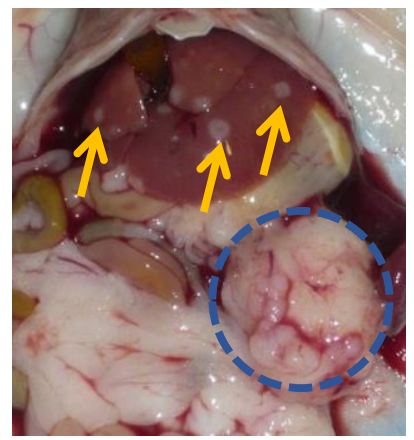

B

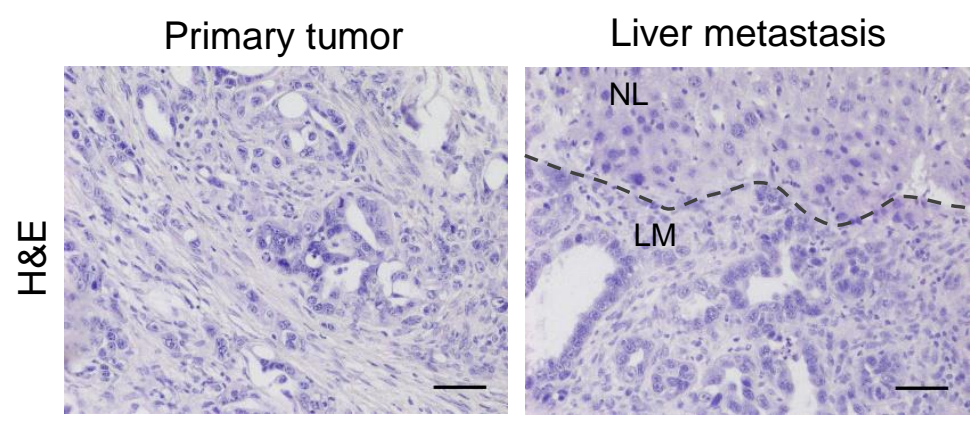

Figure 6: The KPC mouse model. A) Macroscopic view of a tumor-bearing KPC mouse at necropsy. The tumor in the pancreas is marked by the dotted blue circle and liver metastases are indicated by orange arrows. Adapted from (Hessmann \& Patzak et al., 2018). B) Microscopic H\&E images of a KPC mouse pancreatic tumor with matched liver metastasis (LM) and normal liver (NL). Scale bars $50 \mu \mathrm{m}$. Own illustration, based on (Hessmann \& Patzak et al., 2018).

Surprisingly, the highest concentrations of gemcitabine prodrug were found in the primary tumor tissues and were significantly higher than in liver metastases $(8.1 \mathrm{ng} / \mathrm{mg}$ vs. $4.6 \mathrm{ng} / \mathrm{mg} ; \mathrm{p}=0.04)$ and normal liver tissue $(8.1 \mathrm{ng} / \mathrm{mg}$ vs. $4.0 \mathrm{ng} / \mathrm{mg} ; \mathrm{p}=0.01)$. Concentrations in the liver metastases and in normal liver tissue were comparable (Figure 7A). Significant differences in the concentrations of the inactive gemcitabine metabolite between the three tissue types were not found (Figure 7B). The difference in the mean concentrations of the active metabolite dFdCTP between primary tumor tissues and liver metastases was also not significant $(4.5 \mathrm{ng} / \mathrm{mg}$ vs. $2.3 \mathrm{ng} / \mathrm{mg}$; ns). Yet, significantly elevated dFdCTP concentrations were found in the primary tumor samples compared to normal liver samples ( $4.5 \mathrm{ng} / \mathrm{mg}$ vs. $0.59 \mathrm{ng} / \mathrm{mg} ; \mathrm{p}=0.002$ ) (Figure $7 \mathrm{C}$ ).

\section{Legend to Figure 7:}

Pharmacokinetic distribution of gemcitabine metabolites in murine pancreatic cancer tissue. Pharmacokinetic profile of gemcitabine metabolites in KPC bulk tumor tissue, corresponding liver metastases, and normal liver samples. KPC mice with confirmed tumor growth were intraperitoneally treated with one dose of gemcitabine for $2 \mathrm{~h}$ with $100 \mathrm{mg} / \mathrm{kg}$ body weight. Tissue samples were subsequently processed using LC-MS/MS to analyze the main gemcitabine metabolites. A) The concentration of native gemcitabine $(\mathrm{dFdC})$ was significantly elevated in primary pancreatic tumor tissue compared to liver metastases $(p=0.04)$ and normal liver tissue $(p=0.01)(n=15)$. B) No differences between the three groups were observed for the inactive metabolite $\mathrm{dFdU}(n=15)$. C) Significantly higher concentrations of the active triphosphorylated gemcitabine metabolite dFdCTP were found in the primary tumor samples when compared to normal liver samples $(p=0.002)$ $(n=15)$. Mann-Whitney test was performed for all three metabolites. Graphs show mean \pm SEM. Adapted from (Hessmann \& Patzak et al., 2018). 
A

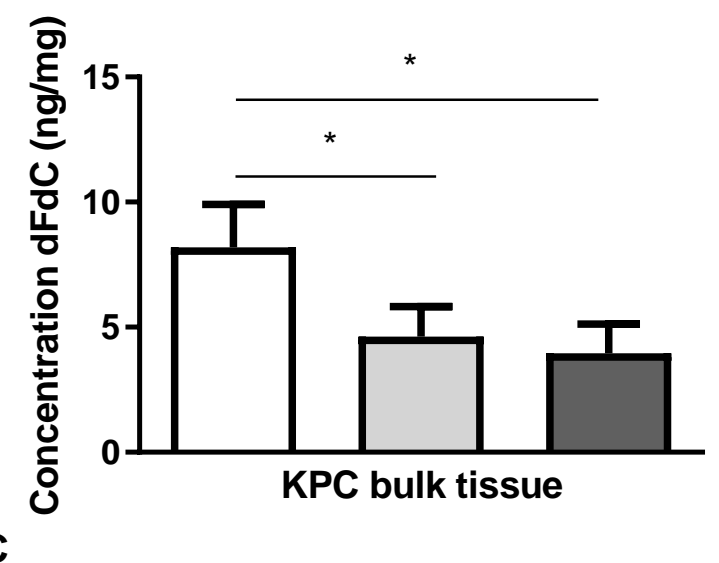

C

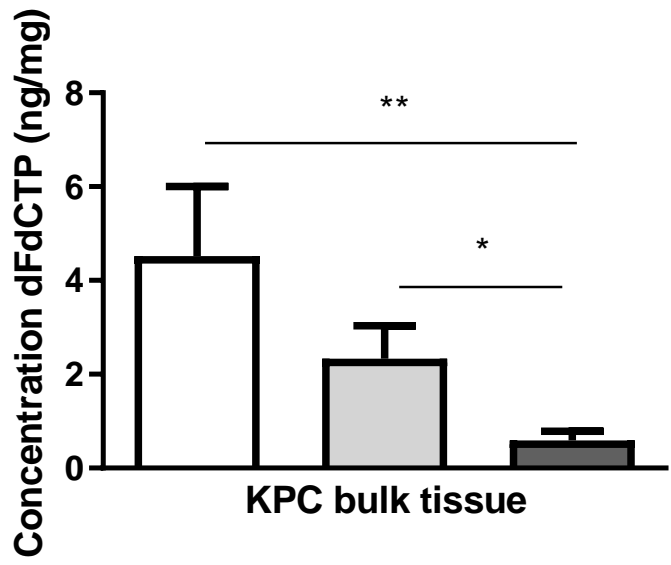

B

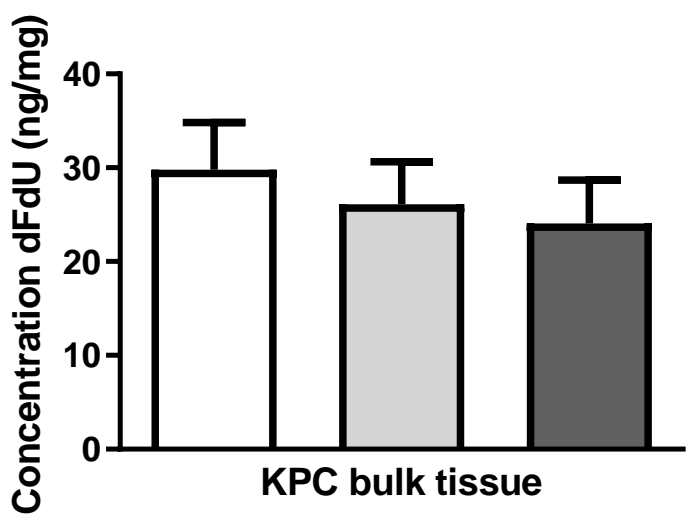

Figure 7: Pharmacokinetic distribution of gemcitabine metabolites in murine pancreatic cancer tissue. For legend, see bottom of previous page.

\subsubsection{Higher stromal content in primary pancreatic tumors than in liver metastases}

The finding that gemcitabine accumulates in the primary tumors was unexpected and in contrast to the hypothesis of a biophysical treatment barrier. Therefore, we hypothesized that either the stromal composition or the vascularization might be the reason for the significantly higher gemcitabine concentrations in the primary bulk tumor tissue.

For this purpose, our group determined the differences between the analyzed tissue types. IHC stainings for the fibroblast marker a-SMA, collagen, and SPARC clearly indicated reduced desmoplasia, especially lower fibroblast density, in matched liver metastases compared to primary tumor tissues (Hessmann \& Patzak et al., 2018). As expected, very low amounts of activated fibroblasts and ECM components were present in normal liver tissue (Hessmann \& Patzak et al., 2018). Moreover, mean vessel density did not differ significantly between primary tumors and liver metastases (Hessmann \& Patzak et al., 2018). 


\subsubsection{Fibroblast drug scavenging increases intratumoral gemcitabine accumulation}

\subsubsection{CAFs and PSCs accumulate significant amounts of gemcitabine in vitro}

The results regarding stromal content of primary tumor tissue and matched liver metastases suggested that the tumor stroma rather promotes gemcitabine accumulation in bulk tumor tissue than to impair drug delivery. Consequently, we hypothesized that the cellular components of the TME might be actively involved in drug accumulation. In order to understand the impact of the tumor stroma and the underlying mechanisms for gemcitabine ineffectiveness in pancreatic cancer, we determined gemcitabine metabolites in different cell types. We used four primary cell lines from pancreatic tumors $(n=4)$ and four cell lines from metastatic foci $(n=4)$ from KPC mice. Furthermore, primary CAF lines $(n=2)$ from primary pancreatic tumors and immortalized PSCs $(n=2)$ from healthy C57BL/6 mice were used for the study and will be referred to as "fibroblasts" in the following analyses. All fibroblast cell lines showed typical spindle-like morphology along with strong expression of a-SMA (Figure 8A), as well as fibronectin and SPARC (Hessmann \& Patzak et al., 2018). Moreover, the concentrations of intracellular AFdCTP were comparable between CAFs and PSCs (Figure 8B).

A

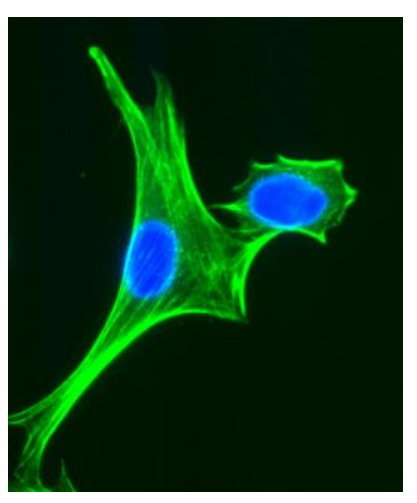

B

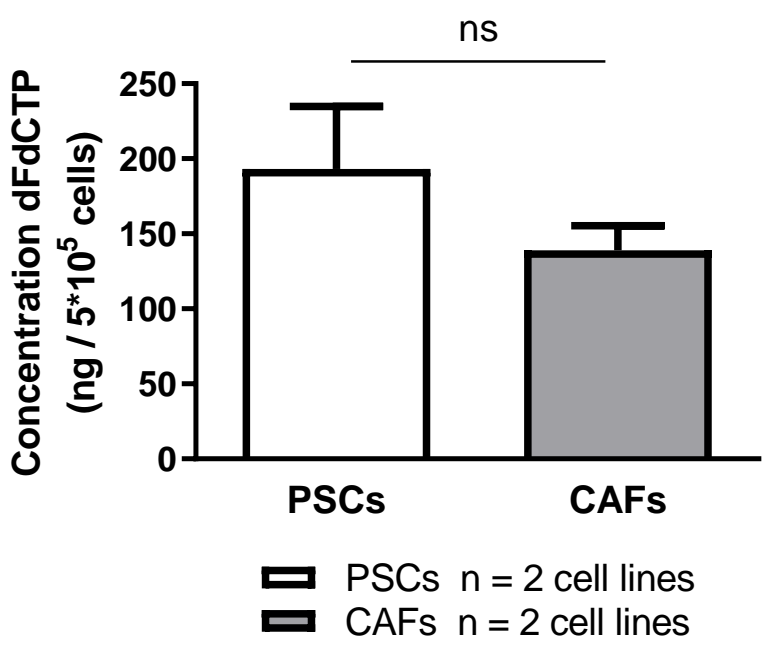

Figure 8: Characterization of CAFs and PSCs. A) Typical morphology of CAFs demonstrated by a-SMA ICC ( $\alpha$-SMA: green, DAPI nuclear staining: blue). B) LC-MS/MS analysis of cytotoxic dFdCTP in CAFs $(n=2)$ and PSCs $(n=2)$. Intracellular concentrations did not differ significantly. Graph shows mean \pm SEM of two different cell lines. Concentrations were determined from technical triplicates. Modified from (Hessmann \& Patzak et al., 2018). 
To determine the pharmacokinetic profile of gemcitabine metabolites in the three different cell types, we treated the cells with $1 \mu \mathrm{M}$ gemcitabine-hydrochloride for $2 \mathrm{~h}$ and harvested cell pellets as well as cell culture supernatants. Samples were subsequently subjected to LC-MS/MS analysis. Tumor cell lines derived from primary pancreatic tumors or from metastatic foci did not show significant differences in dFdCTP concentrations (Figure 9A). Yet strikingly, the dFdCTP concentrations in fibroblasts were significantly elevated compared to neoplastic cells (three- to fivefold increase, both $p=0.03, n=4$ ) (Figure 9A). Following the standardized treatment, intracellular native gemcitabine and dFdU concentrations were below the level of quantification in all tested cell lines. However, concentrations of inactive dFdU in the supernatants from cultured fibroblasts were reduced by factor five compared to neoplastic cells (Figure $9 B$ ) $(2.6 \mathrm{ng} / \mathrm{ml} \mathrm{vs} .12 \mathrm{ng} / \mathrm{ml}$ for primary tumor cells and $13.4 \mathrm{ng} / \mathrm{ml}$ for metastatic tumor cells; both $\mathrm{p}=0.03, \mathrm{n}=4$ ). Excess amounts of native $\mathrm{dFdC}$ were measured in cell culture supernatants of all cell types (each cell type $\mathrm{n}=4$ ), with all concentrations being above $570 \mathrm{nM}(150 \mathrm{ng} / \mathrm{ml}$ ) (Figure 9C). Therefore, the initial dFdC concentration was unlikely to be the limiting factor for gemcitabine uptake and activation.

Moreover, our group demonstrated that the accumulation of gemcitabine in stromal cells is not a general effect of chemotherapeutic drugs in pancreatic cancer. The three different cell types were treated, as described for gemcitabine, with $100 \mu \mathrm{M} 5$-FU, another antinucleoside chemotherapeutic drug. A higher concentration of 5-FU was required to reach detectable intracellular drug levels. The intracellular concentration of 5-FU was lowest in fibroblasts and did not differ significantly between neoplastic cell lines and fibroblasts $(p=0.06)$ (Figure 10A). Additionally, no differences were found in 5-FU concentrations in cell culture supernatants of all three cell types (Figure 10B). We therefore concluded that not the drug uptake to the tumor but drug metabolism could be the potential mechanism of action. 


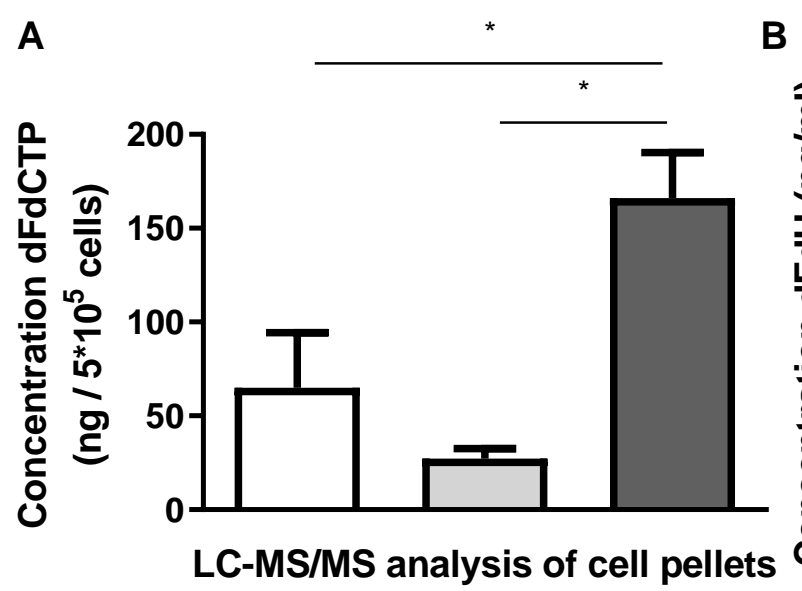

C

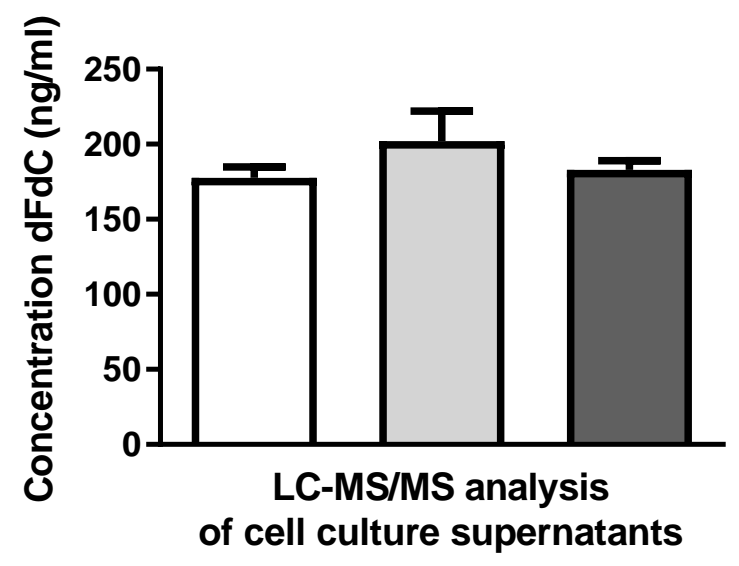

B

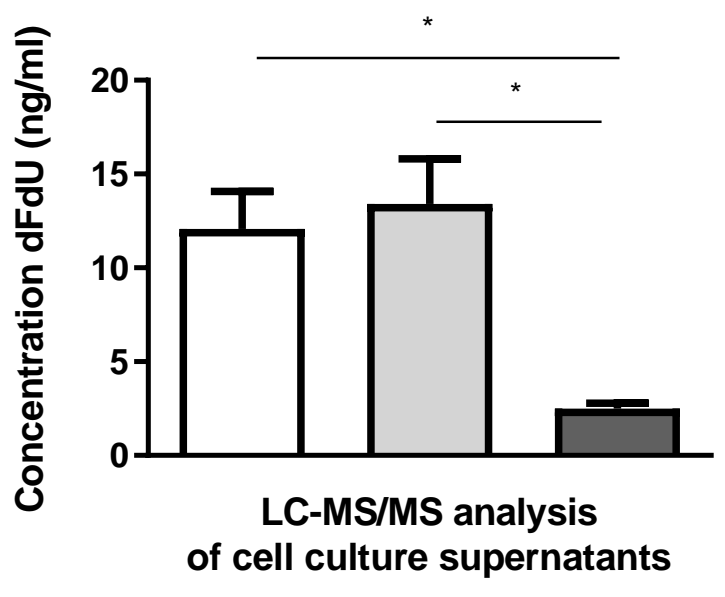

D Primary tumor cells $n=4$

D Metastatic tumor cells $n=4$

Fibroblasts $n=4$

Figure 9: Accumulation and decreased inactivation of gemcitabine in CAFs. A)-C) Pharmacokinetic profile of gemcitabine metabolites in primary murine pancreatic tumor cells, tumor cells from metastatic foci, and fibroblasts. Cells were treated with $1 \mu \mathrm{M}$ of gemcitabine-hydrochloride for $2 \mathrm{~h}$. Cell pellet homogenates and cell culture supernatants were subsequently subjected to LC-MS/MS analysis. A) The activated gemcitabine metabolite dFdCTP was found in significantly increased concentrations in fibroblasts (CAFs: $n=2$, PSCs: $n=2$ ) compared to tumor cells derived from the primary tumors and from metastatic foci (both $p=0.03$ ). B) Compared with tumor cells and cells from metastatic foci, the inactivated metabolite $\mathrm{dFdU}$ was significantly reduced in cell culture supernatants from fibroblasts (both $p=0.03$ ). C) No differences were observed between primary tumor cells, tumor cells from metastases, and fibroblasts regarding native gemcitabine concentrations in cell culture supernatants. All statistics were performed using the Mann-Whitney test with $\mathrm{n}=4$ for the three different cell categories (technical triplicates per cell line). Graphs show mean \pm SEM. Adapted from (Hessmann \& Patzak et al., 2018). 
A

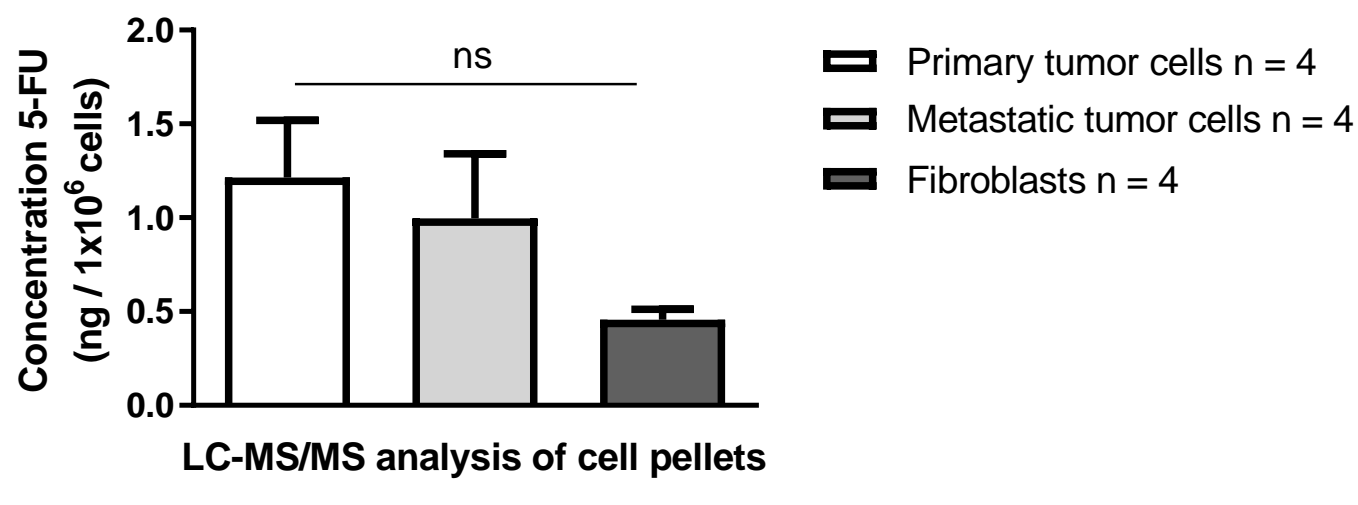

B

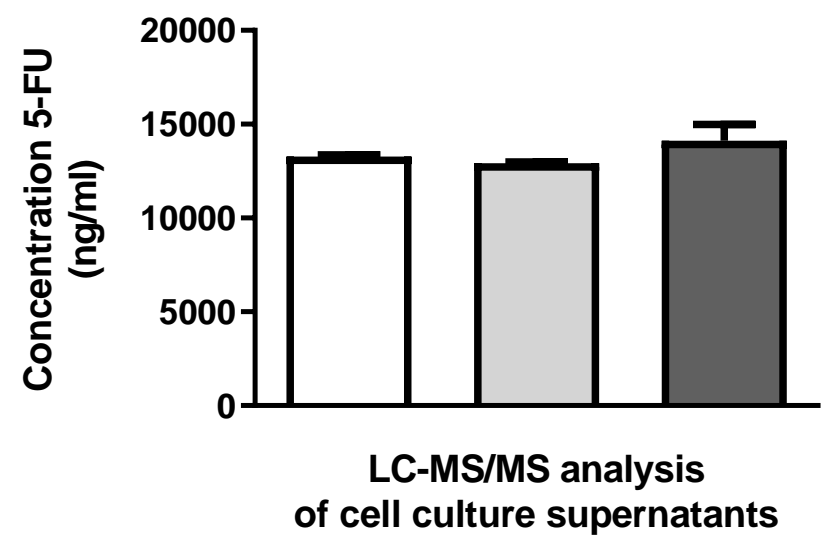

Figure 10: Pharmacokinetic analysis of 5-FU. A) LC-MS/MS analysis of intracellular 5-FU concentrations in tumor cell lines derived from primary KPC tumors and from metastatic sites and in fibroblasts. Cells were treated with $100 \mu \mathrm{M} 5$-FU $(13000 \mathrm{ng} / \mathrm{ml})$ for $2 \mathrm{~h}$. Lowest concentrations were found in fibroblasts. No significant differences were observed between the cell types (primary tumor cells vs. fibroblasts: $p=0.06$, Mann-Whitney test). Concentrations were below the limit of quantification in two metastatic tumor cell lines and in three of the fibroblast cell lines. Thus, $0.4 \mathrm{ng} / 10^{6}$ cells as the limit of quantification were used for statistics. B) 5 -FU concentrations in cell culture supernatants analyzed from the same cell lines. No difference of statistical significance was observed between the cell lines. Graphs show mean \pm SEM of four cell lines per cell type and three technical replicates per sample. Adapted from (Hessmann \& Patzak et al., 2018).

Following intracellular phosphorylation of $\mathrm{dFdC}$ to dFdCTP, the active gemcitabine metabolite is unable to pass the cell membrane and is thus entrapped in fibroblasts. Entrapped dFdCTP could be unavailable for tumor cell treatment. Therefore, I addressed the question whether this effect could reduce the therapeutic response by performing conditioned medium assays. Two KPC tumor cell lines were treated for $72 \mathrm{~h}$ with $\mathrm{CM}$ of two CAF cell lines that were pretreated for $24 \mathrm{~h}$ with therapeutically relevant doses of gemcitabine (approximate $\mathrm{Gl}_{50}$ concentration of tumor cell lines) (Figure 11A). Indeed, the viability of tumor cells significantly increased by $41 \%$ to $82 \%$ compared to treatment with $\mathrm{CM}$ with fresh gemcitabine, suggesting a drug scavenging effect of CAFs in vitro (Figure 11B and 11C). 
A
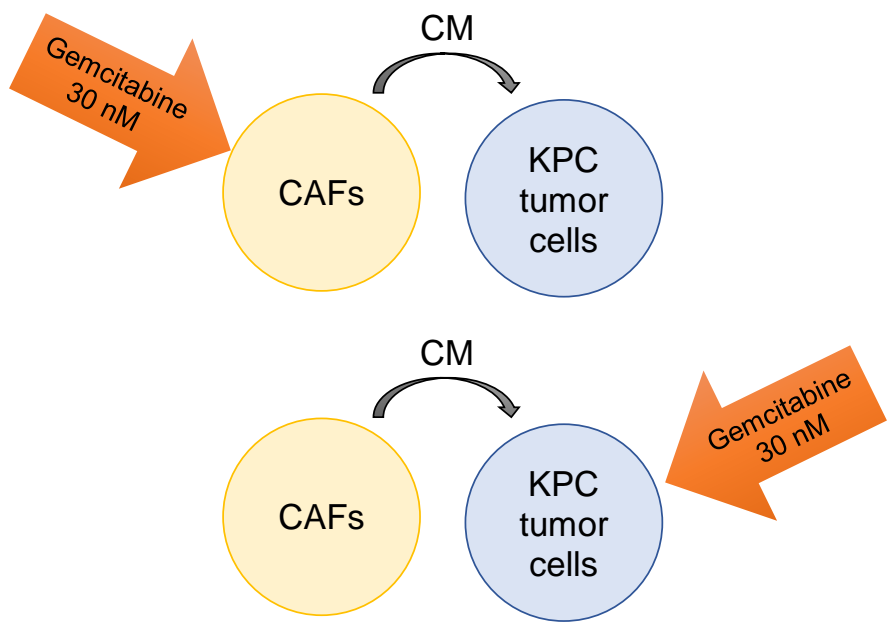

B

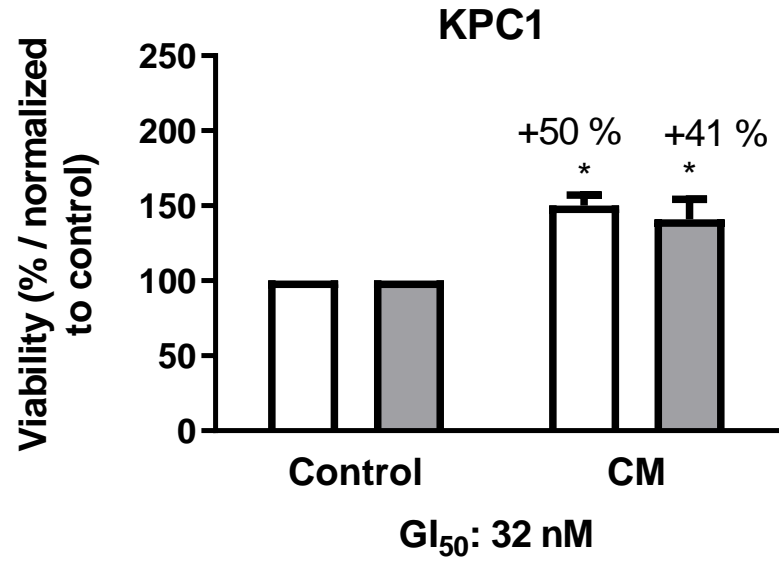

C

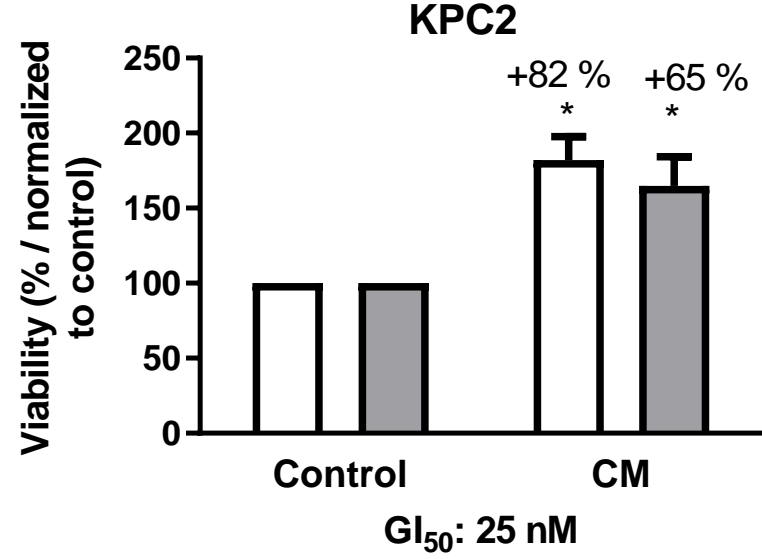

Figure 11: Fibroblasts increase murine pancreatic tumor cell survival in vitro by scavenging gemcitabine. A) Schematic illustration of the conditioned medium assay. Murine CAFs were pre-incubated for $24 \mathrm{~h}$ with $30 \mathrm{nM}$ of gemcitabine-hydrochloride to produce CM (upper panel). Control medium was taken from CAFs that were cultured for $24 \mathrm{~h}$ without gemcitabine and $30 \mathrm{nM}$ gemcitabine were added prior to tumor cell treatment (lower panel). B) and C) $72 \mathrm{~h}$ MTT cell viability assay of two murine tumor cell lines treated with CM of CAFs. KPC1 tumor cells showed $41 \%$ to $50 \%$ increase in viability after treatment with $\mathrm{CM}$ of $\mathrm{CAF} 1$ or CAF2, respectively $\left(\mathrm{Gl}_{50}: 32 \mathrm{nM}\right)(\mathrm{B})$. Cell viability was significantly increased $(65 \%$ to $82 \%)$ in the KPC2 tumor cell line following treatment with $\mathrm{CM}$ of CAF1 and CAF2 cells $\left(\mathrm{Gl}_{50}: 25 \mathrm{nM}\right)(\mathrm{C})$. Statistical results are KPC1-CAF1: $p=0.002 ;$ KPC1-CAF2: $p=0.04 ; \mathrm{KPC} 2-\mathrm{CAF} 1: \mathrm{p}=0.006$; KPC2-CAF2: $p=0.03$. Graphs show mean \pm SEM of three biological replicates. Figures $11 \mathrm{~B}$ and $11 \mathrm{C}$ adapted from (Hessmann \& Patzak et al., 2018). 


\subsubsection{Low expression of gemcitabine-inactivating genes in stromal cells in vitro and in vivo}

Many different enzymes and specific transporters are involved in gemcitabine activation and inactivation (Figure 5). The reduction of dFdU levels in supernatants of fibroblasts indicate that less inactivation occurs in these cells compared to tumor cells. Moreover, the elevated amounts of cytotoxic dFdCTP in fibroblast cell pellets point towards increased gemcitabine activation. To understand the molecular basis behind the drug scavenging of CAFs, we assessed the mRNA expression profile of different gemcitabine-metabolizing genes in primary tumor cells, metastatic tumor cells, and fibroblasts (Hessmann \& Patzak et al., 2018). Interestingly, the NT5C1A and cytosolic 5'-nucleotidase 3 (NT5C3) genes were significantly downregulated in CAFs and PSCs compared to neoplastic cell lines (Figure 12A and 12B). NT5C genes code for cytosolic 5'-nucleotidases that reverse the initial phosphorylation step of nucleotides (Bianchi \& Spychala, 2003). Accordingly, the low expression of these enzymes would increase the pool of dFdCMP in fibroblasts, finally resulting in elevated amounts of dFdCTP in these cells. The mRNA expression of the main activating kinase dCK did not differ significantly between the cell types (Figure 12C).

To determine the expression levels in vivo, archived KPC mouse tissue (Figure 13, upper panel) and tissue from pancreatic cancer patients (Figure 13, lower panel) were examined immunohistochemically. KPC mice had been screened for tumors by small animal highresolution ultrasound and were subsequently enrolled in a survival study. Gemcitabine had been administered at $100 \mathrm{mg} / \mathrm{kg}$ 3-4 times per week until endpoint (Hessmann \& Patzak et al., 2018). IHC revealed strong protein expression of NT5C1A in epithelial cells, yet, very low expression in the stromal compartment (Figure 13), which is in line with the prior mRNA analysis of tumor cells and fibroblasts. Further gemcitabine-inactivating enzymes like CDA and DCTD were not differentially expressed on mRNA level (Hessmann \& Patzak et al., 2018), however, strong protein expression was found in KPC mice and human pancreatic cancer tissues. The TME was mainly devoid of immunoreactivity for both enzymes (Figure 13). Markedly, the main activating kinase dCK was expressed at comparable levels in the neoplastic and the stromal compartment of KPC mice and in tumors of pancreatic cancer patients (Figure 13). 
A

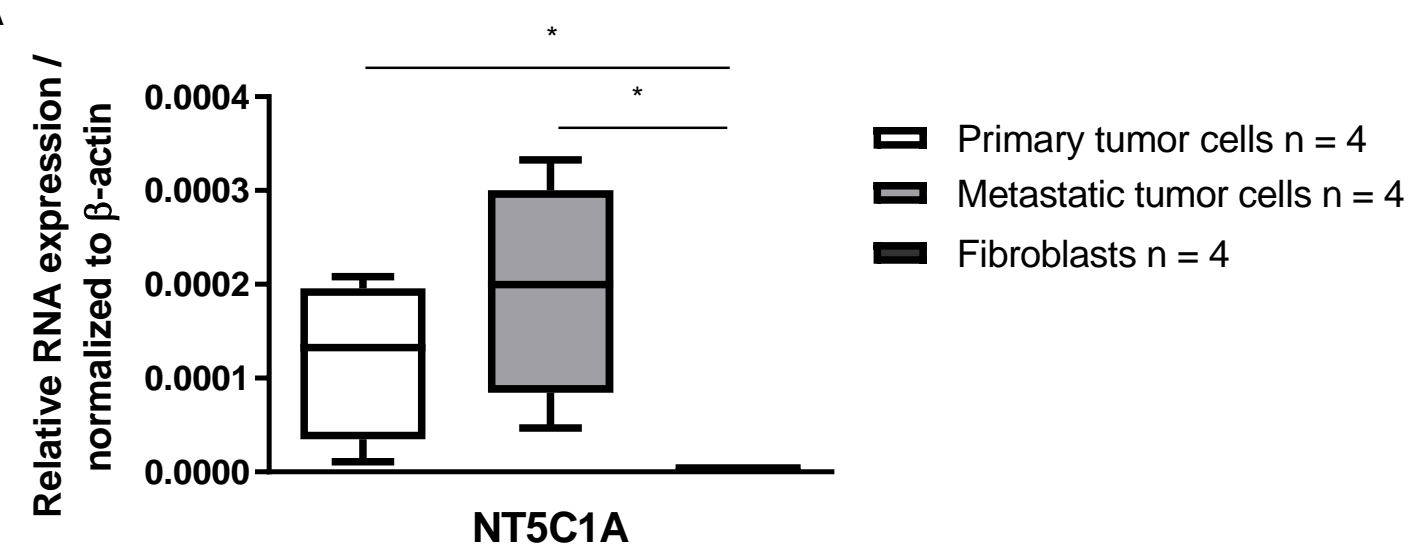

B

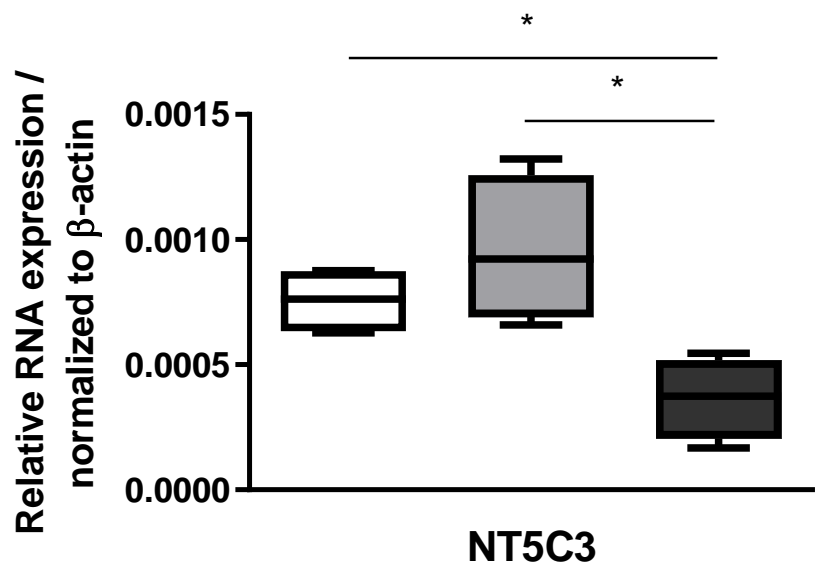

C

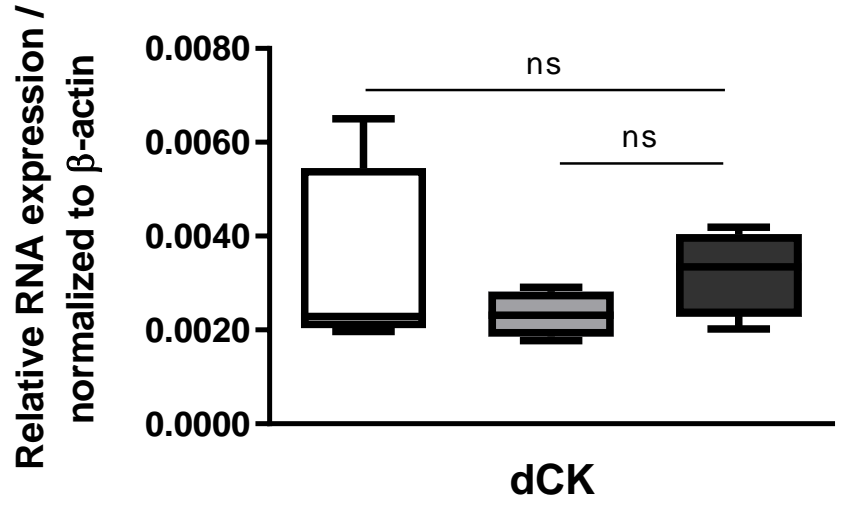

Figure 12: Low expression of gemcitabine-inactivating genes in stromal cells in vitro. RNA was isolated from murine CAFs $(n=2)$ and PSCs $(n=2)$, as well as from primary KPC tumor cells $(n=4)$ and cells from metastatic foci $(n=4)$. Quantitative RT-PCR revealed that the gemcitabineinactivating genes NT5C1A (A, both $p=0.03)$ and NT5C3 $(B$, both $p=0.03)$ were significantly downregulated in fibroblasts compared to tumor cells. Differences in gene expression for the main activating kinase $d C K$ between tumor cells, cells from metastatic foci, and fibroblasts were not significant (C). Mann-Whitney test was performed. The median is shown with the minimum and maximum values. Four cell lines per cell type with each two technical replicates were analyzed. Adapted from (Hessmann \& Patzak et al., 2018). 


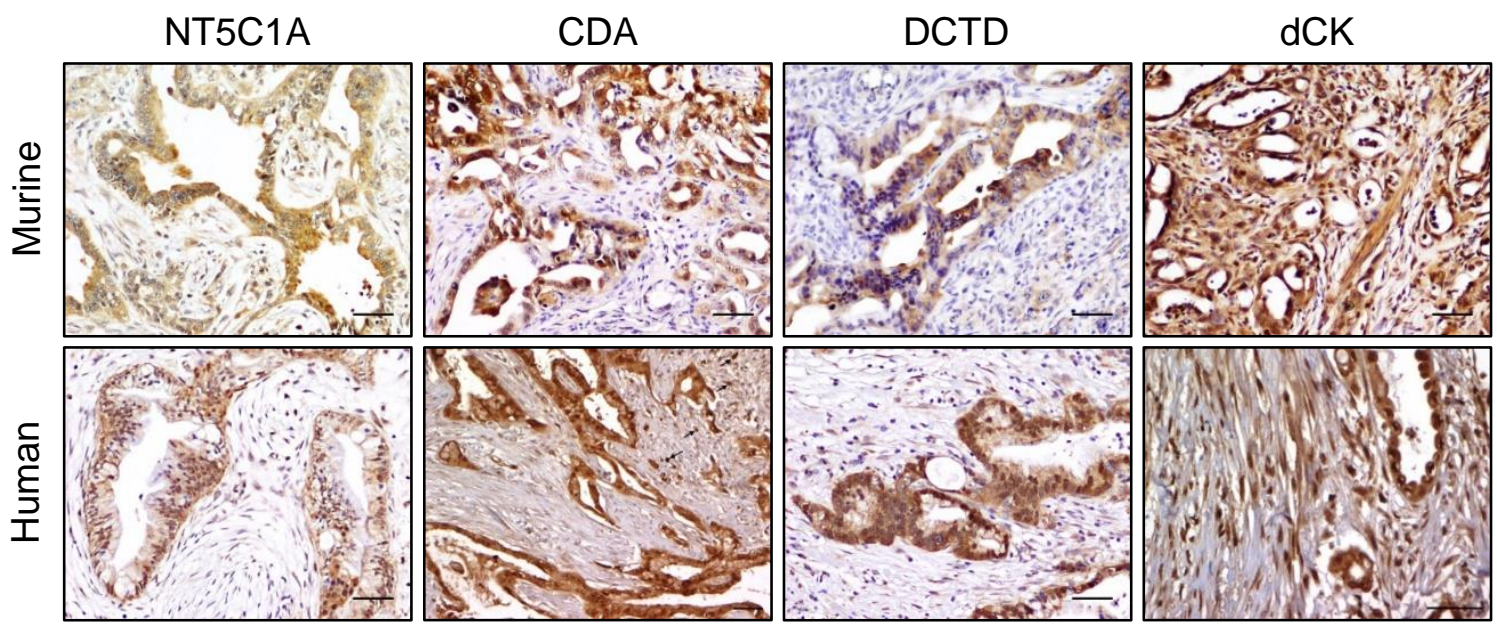

Figure 13: Gemcitabine-inactivating enzymes are hardly expressed in the pancreatic cancer stroma. Representative IHC images from gemcitabine-treated tumor bearing KPC mice and from human pancreatic cancer tissues demonstrate robust NT5C1A, CDA, and DCTD expression in the tumor cells. Stromal cells are mainly devoid of immunoreactivity. $\mathrm{dCK}$ is robustly expressed in tumor and stromal cells. Scale bars $50 \mu \mathrm{m}$. Figure adapted from (Hessmann \& Patzak et al., 2018).

\subsubsection{CAFs are intrinsically resistant to gemcitabine treatment}

It was shown that CAFs scavenge gemcitabine, which is then not available anymore for tumor cells. To address the question whether altered gemcitabine metabolism in these cells might result in increased sensitivity of fibroblasts towards gemcitabine treatment, I carefully analyzed proliferation and apoptosis rates in a-SMA-positive fibroblasts. Archived tissue from gemcitabine-treated KPC mice from a previous preclinical trial was used. These mice had been treated intraperitoneally with gemcitabine $(n=6)$ or vehicle $(n=6)$ for 9 days (Neesse et al., 2013). A proliferation rate of $2 \%$ to $5 \%$ was demonstrated in a-SMA-positive cells in control KPC tumors using Co-ICC. Gemcitabine treatment did not significantly change the proliferation rate (Figure 14A and 14B). Additionally, Co-IHC for CC3, indicating apoptotic cells, and for a-SMA revealed a low number of double-positive cells in vehicle- and gemcitabine-treated KPC mice without significant differences between both groups (Figure 14C and 14D). These findings point towards intrinsic resistance of CAFs to treatment with gemcitabine. It is quite likely that the low proliferation rate of fibroblasts in vivo is a main reason for their minimal chemosensitivity. 
A

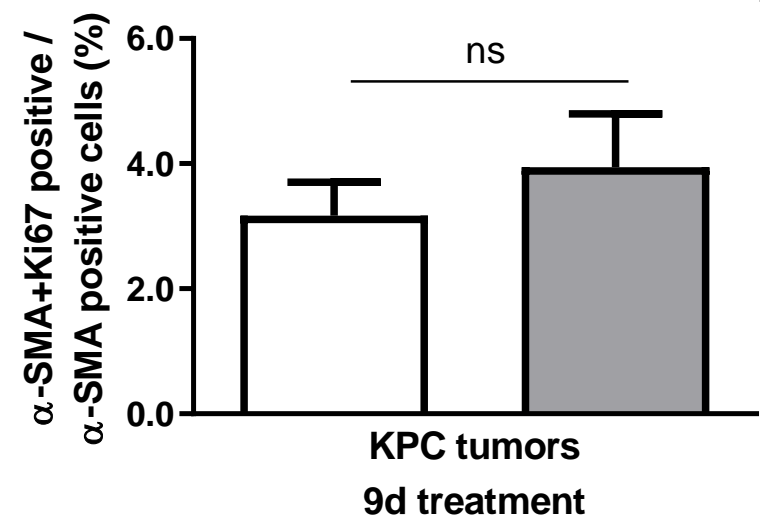

C

$$
\begin{aligned}
& \text { च Vehicle } n=6 \\
& \text { च Gemcitabine } n=6
\end{aligned}
$$

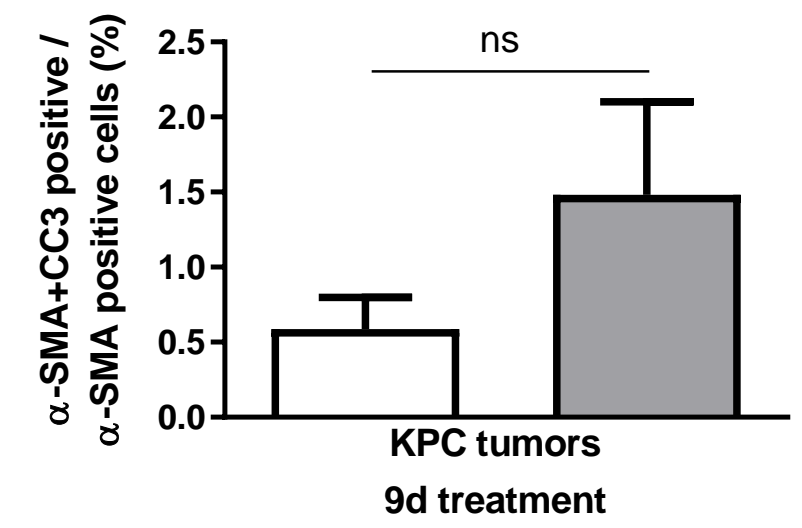

B

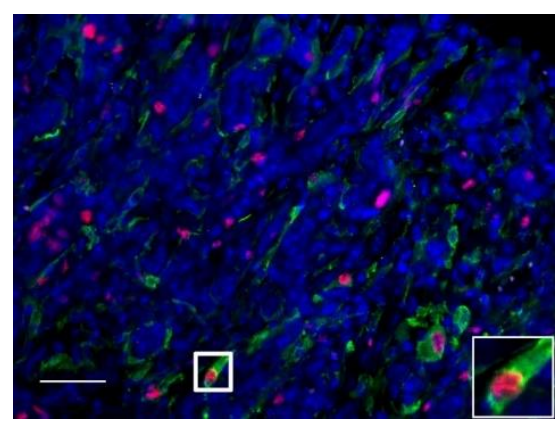

D

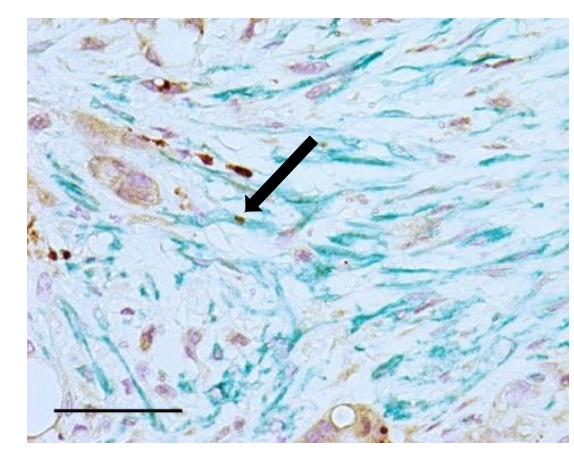

Figure 14: CAFs are intrinsically resistant to gemcitabine treatment. Archived tissues from tumor-bearing KPC mice were evaluated retrospectively for proliferating and apoptotic fibroblasts. Mice had been treated with gemcitabine $(100 \mathrm{mg} / \mathrm{kg})$ or control every 3-4 days for a total treatment period of 9 days. The last dose had been administered $2 \mathrm{~h}$ prior to sacrifice. A) and B) Co-IF for $\alpha$-SMA (green) and Ki67 (red; DAPI: blue) did not show significant differences in the proliferation rate in $\alpha$-SMA-positive cells $(p=0.5, n=6)$. Scale bar $50 \mu \mathrm{m}$. C) and D) Co-IHC for $\alpha$-SMA (green) and CC3 (brown) did not reveal significantly different percentages of apoptotic fibroblasts in gemcitabinetreated KPC tissues compared to control tissues $(p=0.2, n=6)$. Scale bar $50 \mu \mathrm{m}$, arrow indicates apoptotic fibroblast. Image $\mathrm{J}$ software was used for manual cell counting. Adapted from (Hessmann \& Patzak et al., 2018). 


\subsection{Cytosolic 5'-nucleotidase $1 \mathrm{~A}$ is overexpressed in pancreatic cancer and mediates gemcitabine resistance by reducing intracellular gemcitabine metabolites}

The content of this chapter is included in a manuscript, which was in revision at the time of thesis submission. The title, results, and figures of this chapter were directly taken from this manuscript with minor adaptions, mainly to the figure legends. Additionally, section 3.2.6, Figure 32, and Figure 37 are shown in this chapter of my thesis.

Patzak, M.S., Kari, V., Patil, S., Hamdan, F.H., Goetze, R.G., Brunner, M., Gaedcke, J., Kitz, J., Jodrell, D.I., Richards, F.M., Pilarsky, C., Gruetzmann, R., Rümmele, P., Knösel, T., Hessmann, E., Ellenrieder, V., Johnsen, S.A., and Neesse, A. Cytosolic 5'-nucleotidase $1 \mathrm{~A}$ is overexpressed in pancreatic cancer and mediates gemcitabine resistance by reducing intracellular gemcitabine metabolites. (in revision at the time of thesis submission); please refer to page 123 for the citation of the accepted manuscript.

For this manuscript, I chiefly conceived and designed the experiments, performed data analysis, assembled the data and wrote the manuscript. Moreover, I designed and performed cell culture and animal experiments and did histology stainings (Figures 15A, C; $17 B ; 18 A, B ; 19 A, B, C, D ; 20 A, B, C ; 21 A, B ; 22 A, B ; 23 A, B ; 24 A, B ; 25 A, B ; 26 A, B, C$; $28 A, B, C, D ; 29 A, B ; 30 ; 31 A, B ; 33 ; 34 ; 35 ; 36 A, B ; 37 ; 38 ; 39 ; 40$ of my thesis). Orthotopic transplantations, intraperitoneal injections of mice, staining of the Erlangen TMA cohort, scoring of TMA slides, collection of clinical data, and LC-MS/MS measurements were performed by lab colleagues and collaborators.

\subsubsection{NT5C1A is strongly expressed in murine and human PDAC and is not associated with overall survival}

Comprehensive expression data of NT5C1A in PDAC are not available so far. To address this question, we employed two independent TMAs of resected PDAC specimens. A semi-quantitative scoring system ranging between score 0 (no expression) to score 3 (strong expression) was utilized. A relevant subgroup of patients expressed NT5C1A at high levels (score 2 and 3). $56 \%$ of all patients showed moderate expression (score 2 ) of NT5C1A in the epithelial compartment of the tumors and $8 \%$ expressed NT5C1A at high levels (score 3 ) in TMA-1 with 77 samples (Figure 15A). 
A larger TMA dataset with 337 samples confirmed these findings with $44 \%$ scored with 2 , and $26 \%$ of all patient samples had score 3 (Figure 15B). Furthermore, only $13.0 \%$ (TMA-1) and $4.5 \%$ (TMA-2) of all tumors did not show immunoreactivity against NT5C1A (Figure 15A-C).

A
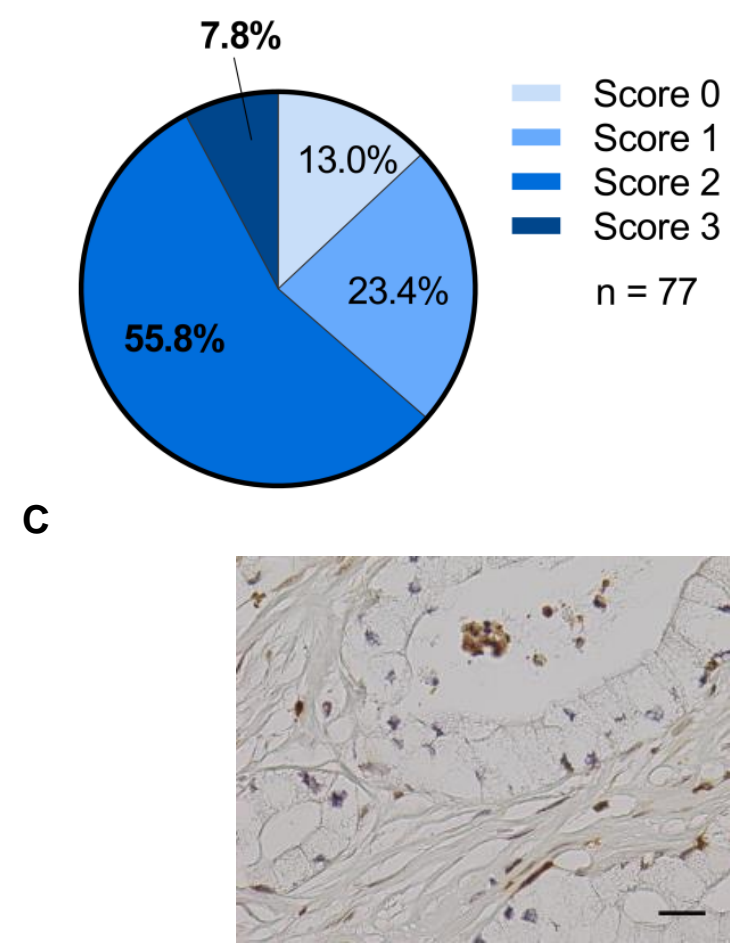

Tumor score 0

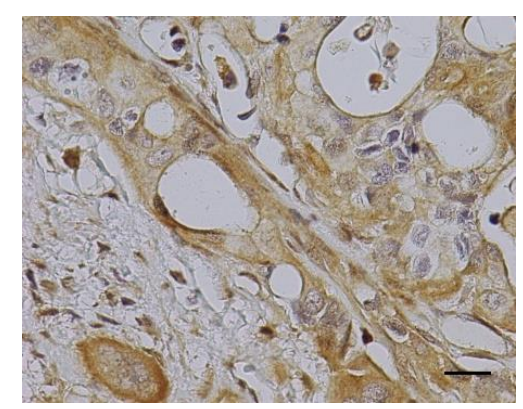

Tumor score 2
B
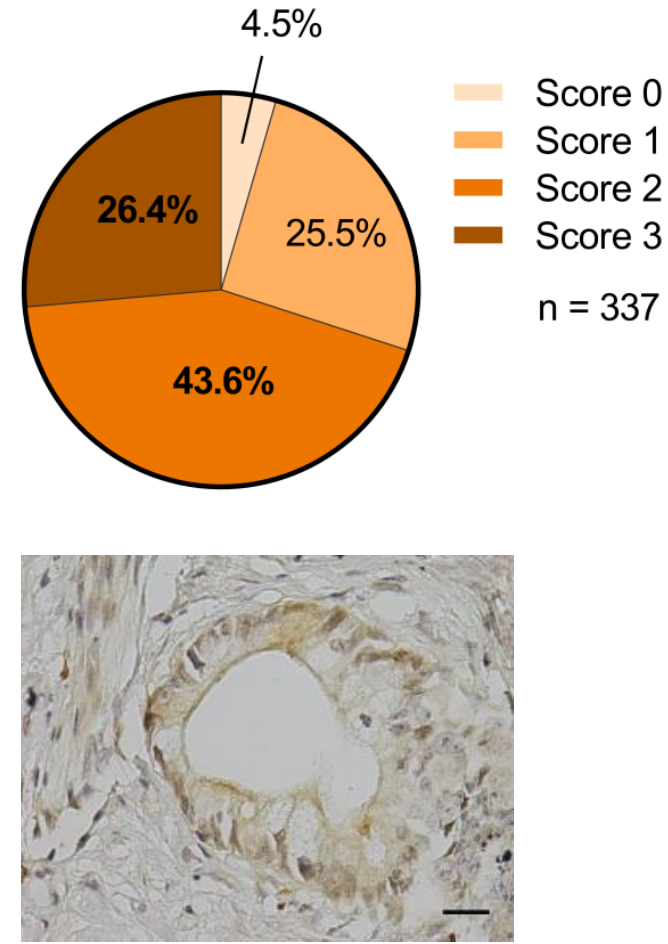

Tumor score 1

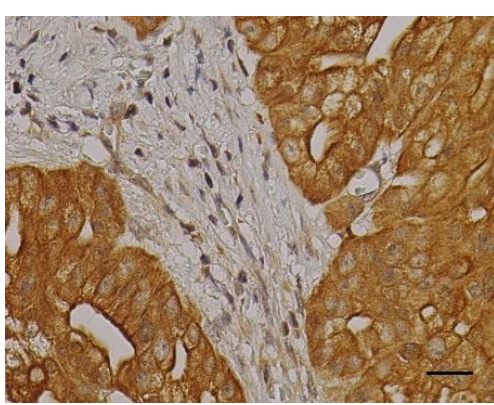

Tumor score 3

Figure 15: Expression of NT5C1A in resected PDAC patients. Tissue microarrays from A) Göttingen (TMA-1, $n=77$ ) and B) Erlangen (TMA-2, $n=337)$. Score $0=$ no NT5C1A expression, score 3 indicates strong intratumoral expression of NT5C1A. C) Representative images of TMA-1 for tumoral expression of NT5C1A scored with score 0 , score 1, score 2, and score 3. Scale bars $20 \mu \mathrm{m}$. 
Interestingly, NT5C1A expression did not correlate with overall survival in either TMA, comparing low NT5C1A expression (score 0 and 1 ) with high expression levels of NT5C1A (score 2 and 3). Median survival was 18.5 vs. 15 months in TMA-1 ( $p=0.5$ ), and 17 vs. 16.4 months in TMA-2 ( $p=0.3$ ) (Figure 16A and 16B). Moreover, KPC pancreatic tumors were analyzed for NT5C1A expression and robust expression could be confirmed by IHC staining in the majority of samples, and was already present in early stages of pancreatic cancer (Figure 17A). The expression was confirmed by qRT-PCR to determine mRNA levels for NT5C1A in KPC bulk tissue. As expected, no expression was found in healthy control pancreata (Figure 17B).

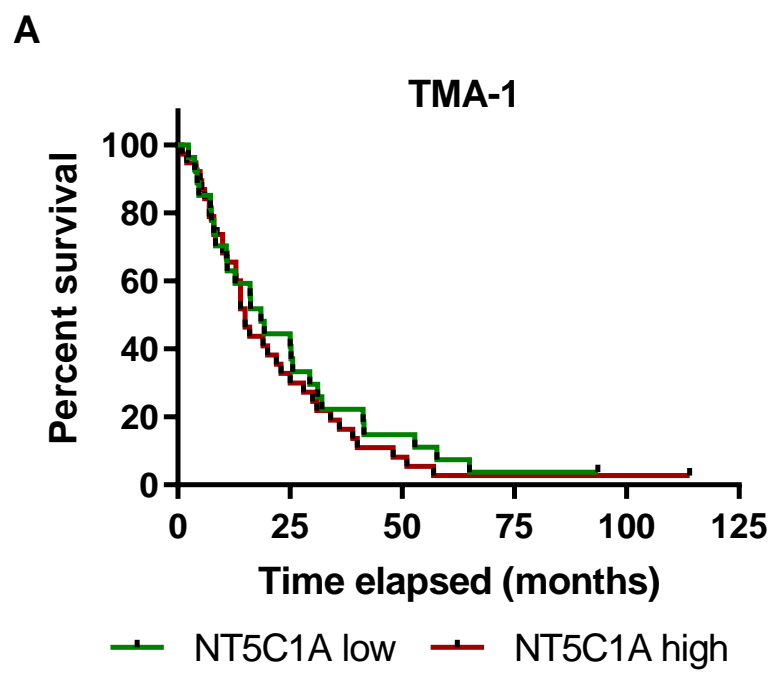

B

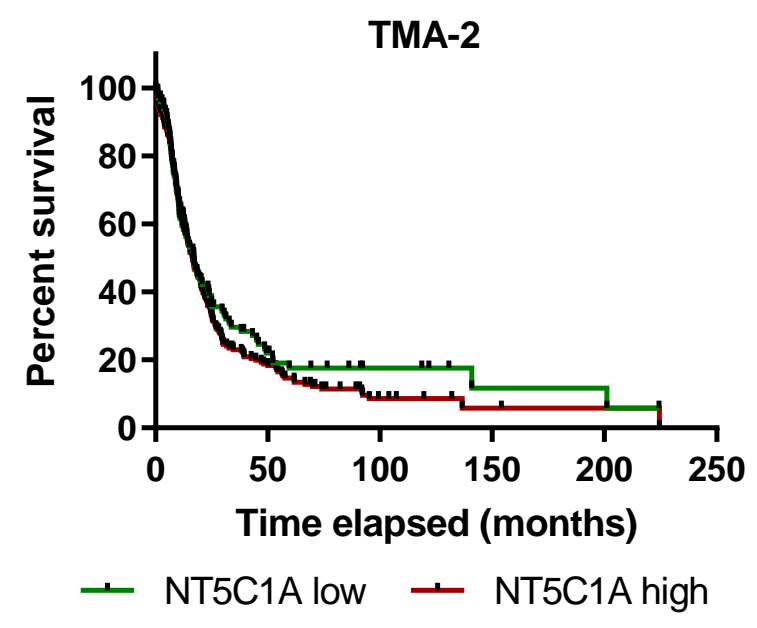

Figure 16: NT5C1A is not prognostic for the survival of PDAC patients. A) and B) Survival analysis of patients from the Göttingen TMA cohort (A) and the Erlangen TMA cohort (B). Median survival of TMA-1 with low NT5C1A expression $=18.5$ months $(n=27)$ and high NT5C1A expression $=15$ months $(n=38 ; p=0.5$, log-rank test $)$ and of TMA-2 with low NT5C1A expression $=17$ months $(n=101)$ and high NT5C1A expression $=16.4$ months $(n=235 ; p=0.3$, log-rank test $)$. Low expression indicates score 0 and score 1 , high expression refers to score 2 and score 3 . 
A
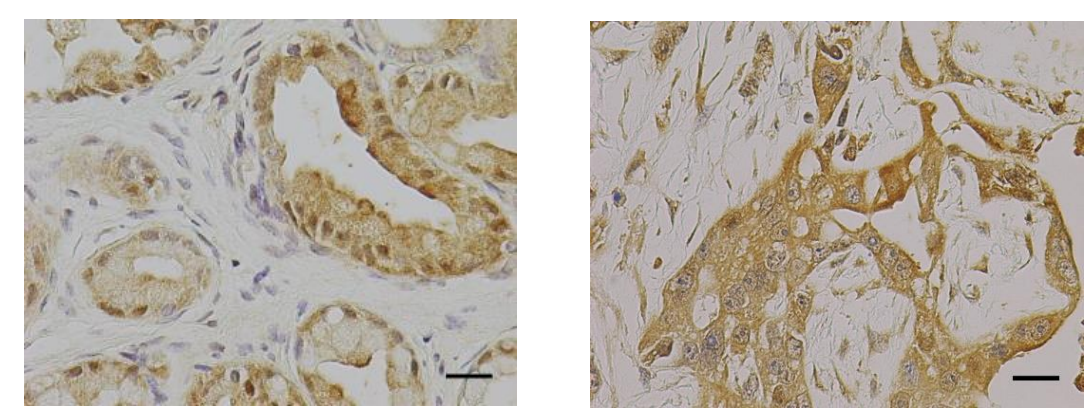

B

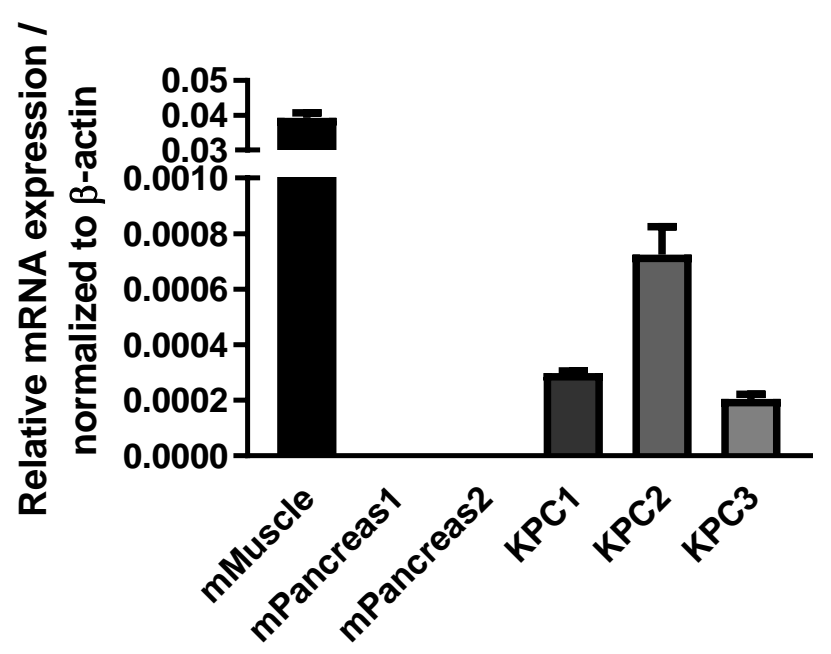

Figure 17: Expression of NT5C1A in the KPC mouse model. A) Representative images of NT5C1A-IHC in KPC mice with PanINs (left image) and invasive carcinoma (right image). Scale bars $20 \mu \mathrm{m}$. B) NT5C1A-mRNA expression in KPC bulk tissue ( $\mathrm{n}=3$ mice $)$ and control normal pancreas $(n=2$ mice). Mean \pm SEM of two technical replicates is shown for each mouse. Murine muscle was used as positive control and values were normalized to the housekeeping gene $\beta$-actin.

\subsubsection{NT5C1A expression in murine and human PDAC cell lines}

In analogy to our published data about gemcitabine drug scavenging of stromal cells (Hessmann \& Patzak et al., 2018), we hypothesized that high levels of NT5C1A within the tumor cells might be involved in chemoresistance in PDAC, in particular gemcitabine resistance. To this end, NT5C1A may affect gemcitabine metabolism by reversing the initial phosphorylation step of $\mathrm{dFdC}$ to $\mathrm{dFdCMP}$, resulting in decreased levels of cytotoxic dFdCTP. To test this hypothesis, NT5C1A expression was investigated in murine and human pancreatic cancer cell lines. Interestingly, murine and human pancreatic cancer cells revealed only low levels of NT5C1A expression in vitro compared to robust expression levels in the tumor tissue (Figure 18A and 18B). 
A

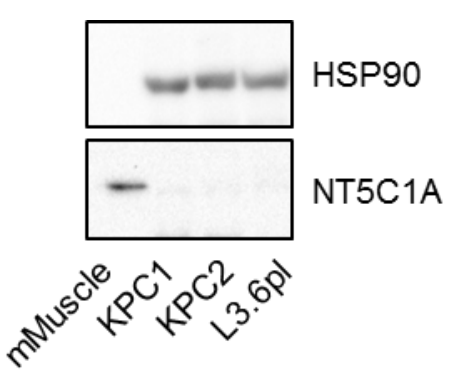

B

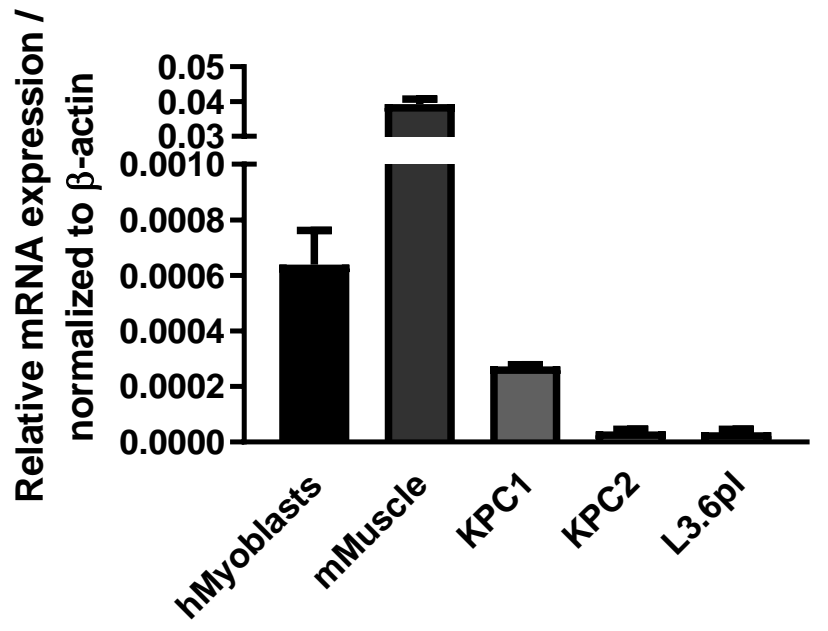

Figure 18: Reduced expression of NT5C1A in murine and human pancreatic cancer cell lines in vitro. A) Western blot analysis showing protein expression of untransfected KPC1 and KPC2 cells, as well as of human L3.6pl cells. HSP90 was used as loading control and murine muscle as positive control. B) mRNA-expression of NT5C1A in KPC1, KPC2, and L3.6pl cells. Values were normalized to the housekeeping gene $\beta$-actin. Murine muscle extract and human myoblasts were added as positive controls for NT5C1A-expression.

Therefore, NT5C1A was stably expressed in murine KPC cell lines (KPC1 and KPC2 $=\mathrm{KPC}-\mathrm{BL6}$ ) and in the human L3.6pl cell line. Stable cell lines were established using a pSG5-vector derivative with subsequent hygromycin selection. NT5C1A expression in stable cell lines was validated by Western blot analysis, ICC, and qRT-PCR analysis (Figure 19A-D). NT5C1A and the integrated HA-tag were robustly expressed in transfected cells. Control cells that were transfected with an empty vector, were shown to express endogenous NT5C1A at low levels and did not show HA-tag expression by ICC (Figure 19A and 19B). Additionally, qRT-PCR analysis was employed to confirm mRNA expression of NT5C1A, and Western blot analysis was used to determine NT5C1A protein levels in the overexpressing cells (Figure 19C and 19D). 
A

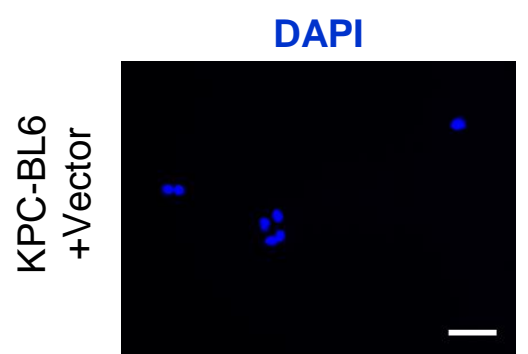

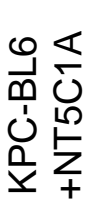

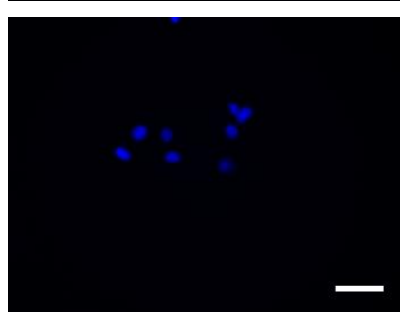

B

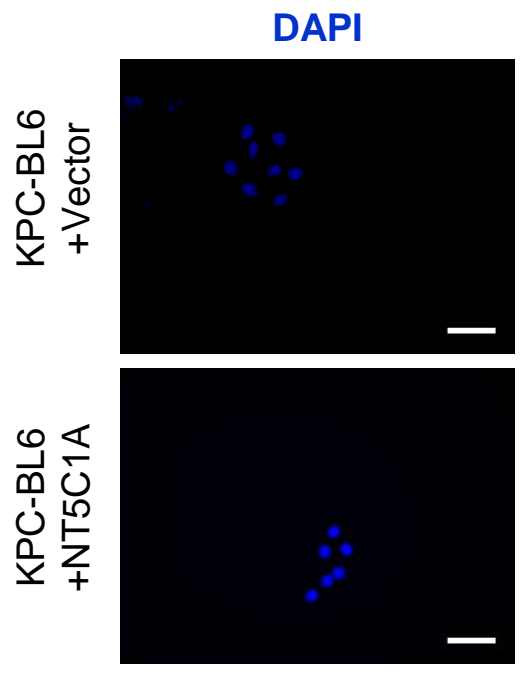

C

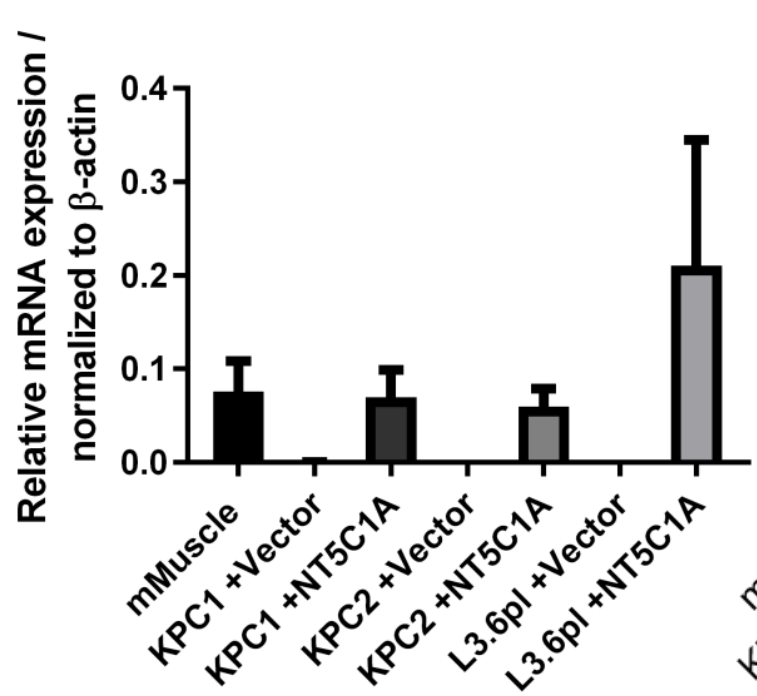

HA-tag
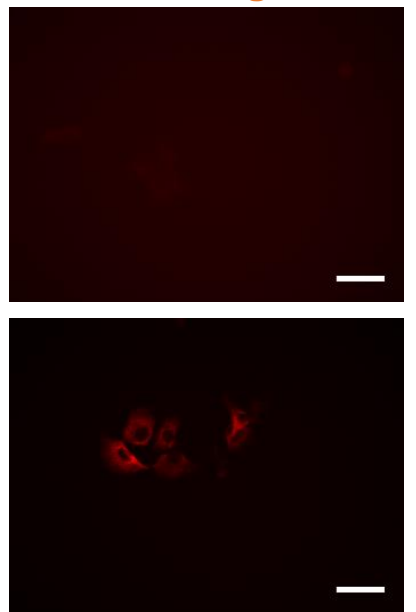

NT5C1A
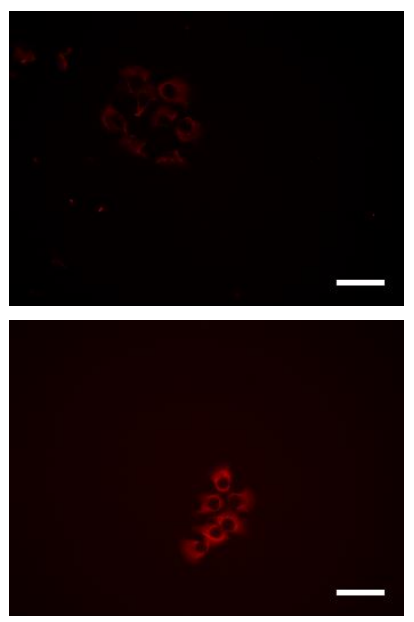

D
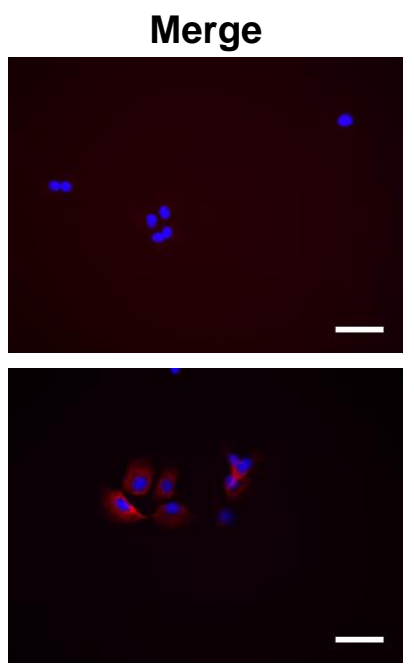

Merge

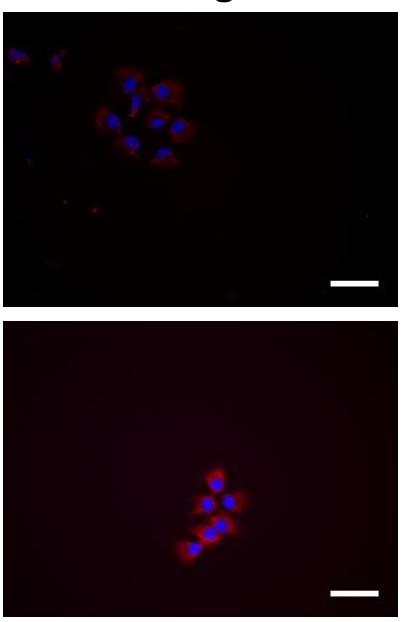

工
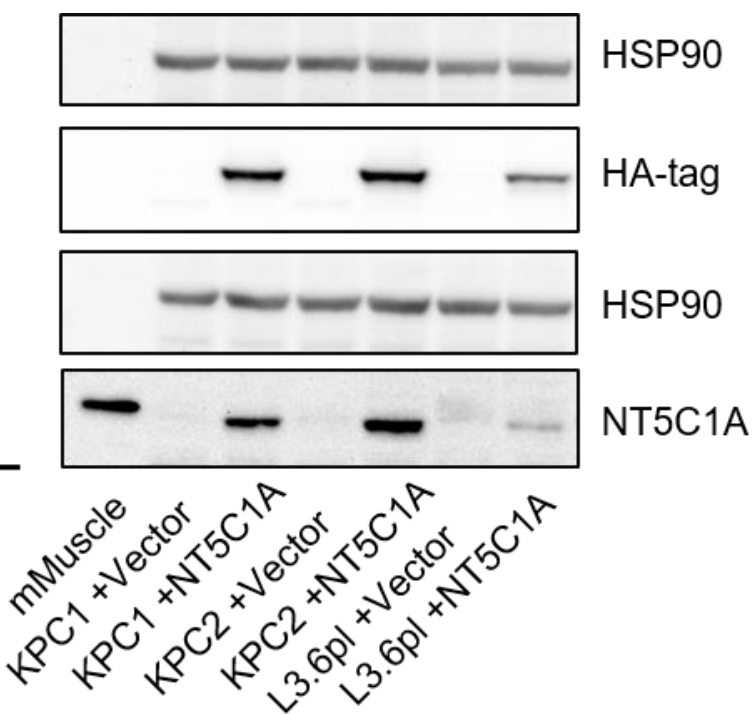

Figure 19: Recombinant expression of NT5C1A in human and murine pancreatic cancer cell lines. For legend, see top of next page. 


\section{Legend to Figure 19:}

Recombinant expression of NT5C1A in human and murine pancreatic cancer cell lines. A) and B) Representative images of two biological replicates of ICC staining for NT5C1A and HA-tag. Robust staining is shown for HA-tag (A, lower panel) and NT5C1A (B, lower panel) in transfected KPC-BL6 (= KPC2) cells. No staining of HA-tag (A, upper panel) and low endogenous NT5C1A expression (B, upper panel) were detected in vector control cells $(n=2)$, scale bars $50 \mu \mathrm{m} . C)$ Quantitative RT-PCR analysis confirmed overexpression of NT5C1A in transfected cells. Diagram indicates mean \pm SEM of three biological replicates. Murine muscle sample was used as positive control and values were normalized to the housekeeping gene $\beta$-actin. D) Western blot analysis confirmed NT5C1A protein expression in transfected tumor cells with hardly any expression in vector control cells. Robust expression of HA-tag is shown in all +NT5C1A cell lines. Representative image of three independent experiments is shown. Murine muscle lysate was used as positive control for NT5C1A expression.

\subsubsection{Pharmacokinetics of gemcitabine upon recombinant NT5C1A expression}

NT5C1A dephosphorylates gemcitabine monophosphate (dFdCMP) to the prodrug dFdC, thus potentially limiting the cytotoxicity of gemcitabine by increasing the pool of $\mathrm{dFdC}$ and decreasing the amount of cytotoxic dFdCTP. To test the implication of NT5C1A on gemcitabine metabolism in pancreatic cancer, we analyzed gemcitabine metabolites in cell pellets upon gemcitabine treatment using LC-MS/MS. The concentrations of the native form of gemcitabine $\mathrm{dFdC}$ as well as the triphosphate, the active metabolite of gemcitabine (dFdCTP), were measured using a previously established protocol (Bapiro et al., 2014; 2016). Following NT5C1A overexpression in the murine KPC-BL6 cell line, upon $2 \mathrm{~h}$ of gemcitabine treatment, the dFdCTP concentration was significantly reduced compared to control cells (27.3 vs. 9.4 pM per $1^{*} 10^{6}$ cells, $p=0.0008$ ) (Figure 20A). Equivalent results were seen for the human L3.6pl cell line ( 67.3 vs. $30.8 \mathrm{pM}$ per $1^{*} 10^{6}$ cells, $p=0.021$ ) (Figure 20B). Interestingly, intracellular dFdC levels were only detectable in the NT5C1Aoverexpressing KPC-BL6 cells, all values in the vector control cells were below the limit of quantification (Figure 20C). Thus, our findings suggest a significant contribution of NT5C1A towards the availability of active gemcitabine metabolites in PDAC, and possibly gemcitabine resistance. 
A

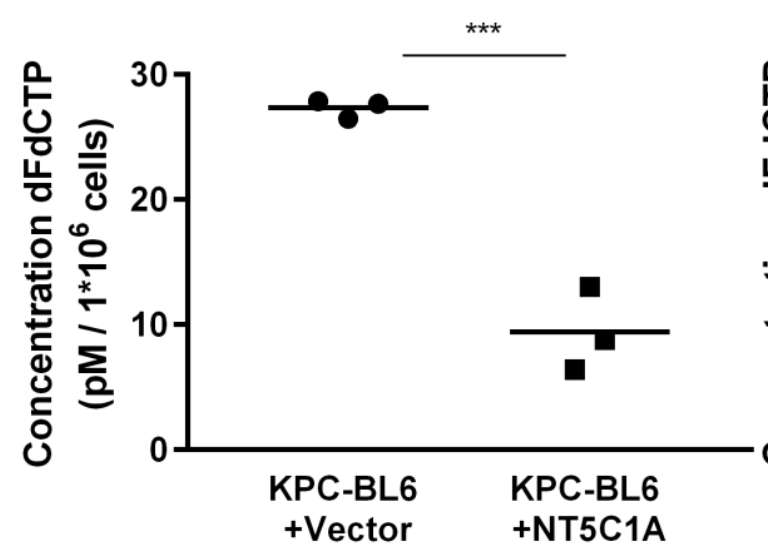

C

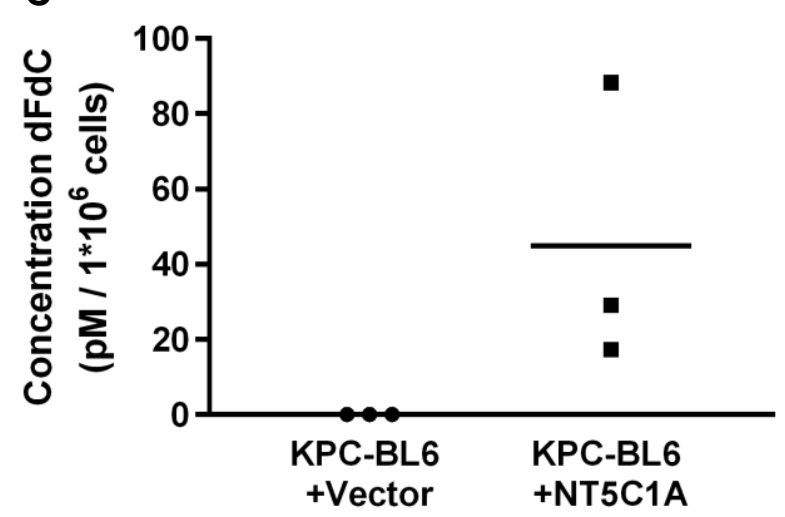

B

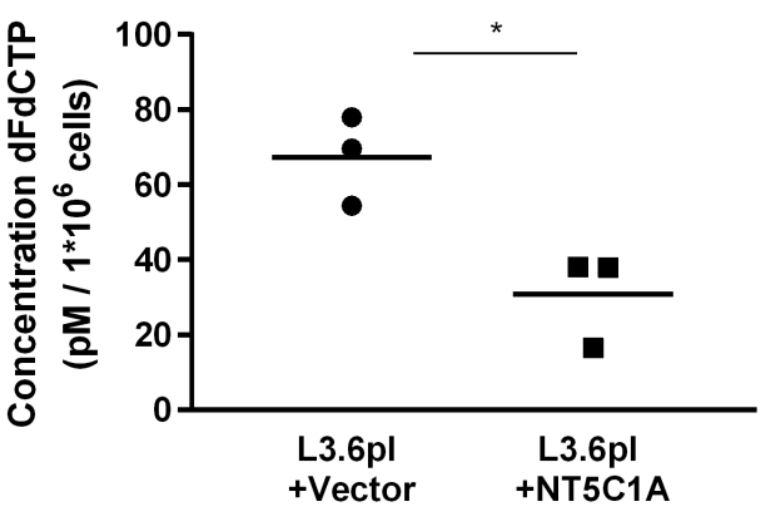

Figure 20: NT5C1A overexpression decreases dFdCTP accumulation in pancreatic cancer cell lines. A) Pharmacokinetic analysis of gemcitabine metabolites in murine PDAC cells. Murine KPC-BL6 cells (A) and human L3.6pl cells (B) (+NT5C1A) and respective control cells (+vector) were simultaneously treated with $1 \mu \mathrm{M}$ gemcitabine-hydrochloride for $2 \mathrm{~h}$. The concentration of the active gemcitabine metabolite dFdCTP (KPC-BL6: 27.3 vs. 9.4 pM per $1{ }^{*} 10^{6}$ cells, $p=0.0008$ and L3.6pl: 67.3 vs. $30.8 \mathrm{pM}$ per $1^{*} 10^{6}$ cells, $p=0.021$ ) and of native gemcitabine $\mathrm{dFdC}(\mathrm{C})$ were determined in homogenates of cell pellets using LC-MS/MS-analysis. Three biological replicates and the mean value are shown. Each dot represents the mean of three (KPC-BL6) or two (L3.6pl) technical replicates, respectively. All dFdC measurements of KPC-BL6 control cells were below the level of quantification, thus the values were set to zero.

\subsubsection{NT5C1A overexpression confers chemotherapeutic resistance towards gemcitabine in vitro}

We showed that NT5C1A decreases the concentration of dFdCTP in vitro, and thus, hypothesized that NT5C1A may be an important candidate in mediating gemcitabine resistance. Using crystal violet cytotoxicity assays for two murine KPC cell lines as well as the human L3.6pl pancreatic cancer cell line, we found that NT5C1A expression reverts chemosensitivity in a concentration-dependent manner in all cell lines (Figure 21A and 21B, Figure 22A and 22B). In contrast, all cell lines were still sensitive to treatment with paclitaxel, which is another important chemotherapeutic agent for the treatment of pancreatic cancer patients (Figure 23A and 23B). 
A
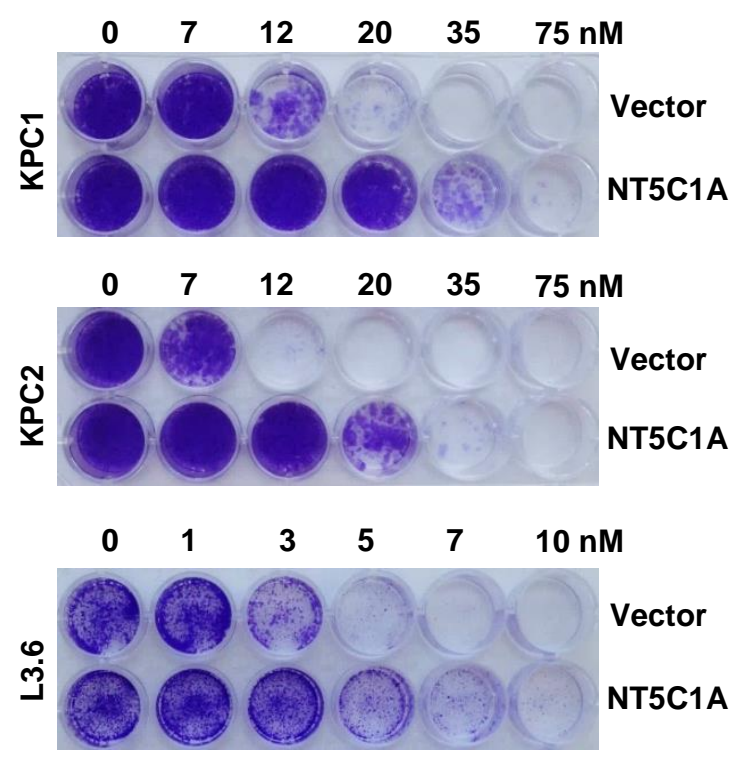

B

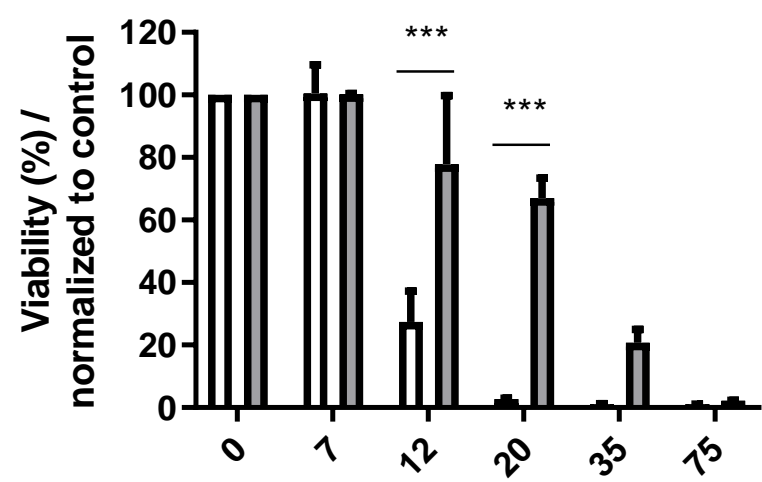

Concentration Gemcitabine (nM)

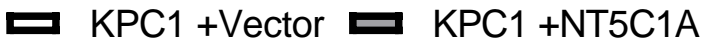

Figure 21: High levels of NT5C1A increase chemotherapeutic resistance towards gemcitabine in pancreatic cancer cells. A) Murine and human pancreatic cancer cell lines were incubated with different concentrations of gemcitabine for six days. Crystal violet staining was more pronounced in cell lines with high NT5C1A expression. Three independent experiments, with each two technical replicates, were performed for all cell lines shown. B) Quantification of crystal violet assays for KPC1 cells using $10 \%$ acetic acid to solubilize crystal violet stain and photometric measurements at $595 \mathrm{~nm}$. Results were normalized to untreated control cells. Two-way ANOVA with Sidak's multiple comparisons test was performed $(12 \mathrm{nM}: \mathrm{p}=0.0007,20 \mathrm{nM}: \mathrm{p}<0.0001)$. Graph shows mean \pm SEM.

A

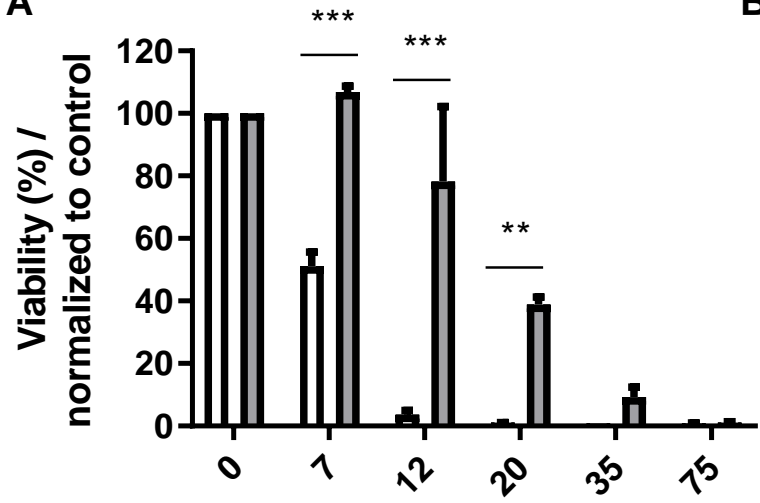

Concentration Gemcitabine (nM)

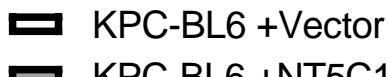

B

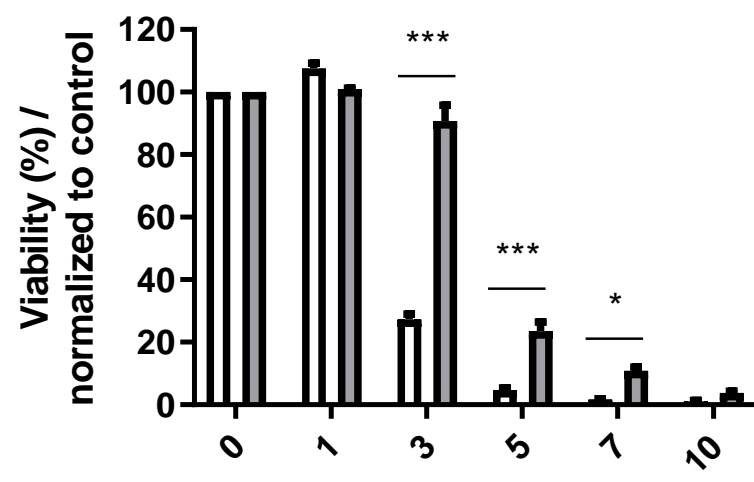

Concentration Gemcitabine (nM)

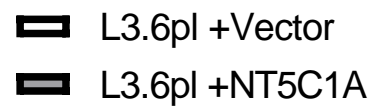

Figure 22: High levels of NT5C1A reduce chemotherapeutic response to gemcitabine in pancreatic cancer cells. A) and B) Crystal violet assay of murine KPC-BL6 cells and human L3.6pl cells. Crystal violet staining was performed following six days of gemcitabine treatment. Crystal violet staining intensity was more pronounced in NT5C1A overexpressing cell lines. Three independent experiments were performed, with each two technical replicates. Quantification of crystal violet assay was performed and results were normalized to untreated control cells. Graphs present mean \pm SEM, two-way ANOVA with Sidak's multiple comparisons test was performed (KPC-BL6: $7 \mathrm{nM}: \mathrm{p}<0.0001$, $12 n M: p<0.0001,20 n M: p=0.007$; L3.6pl: $3 n$ M: $p<0.0001,5 n$ M: $p<0.0001,7 n M: p=0.015)$. 
A

Paclitaxel concentration
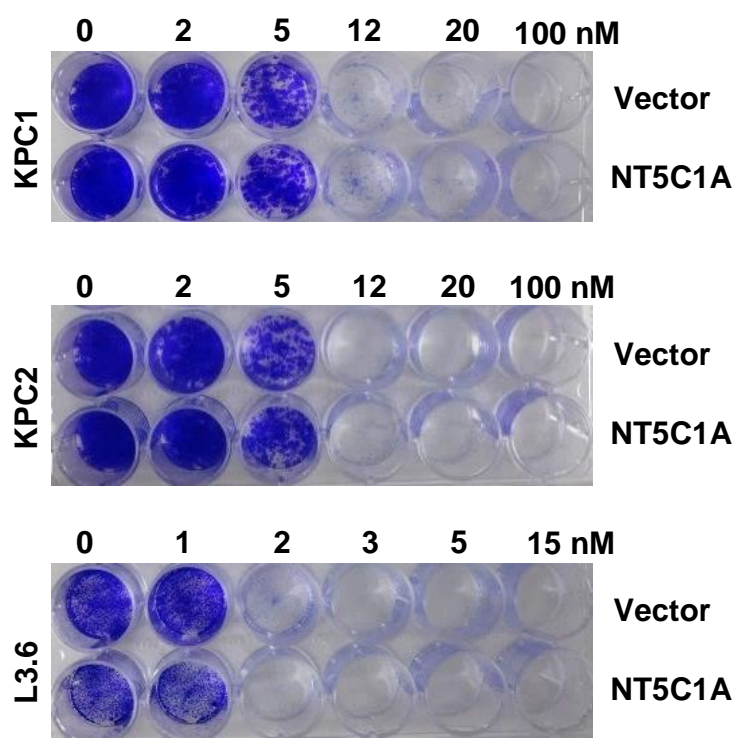

B

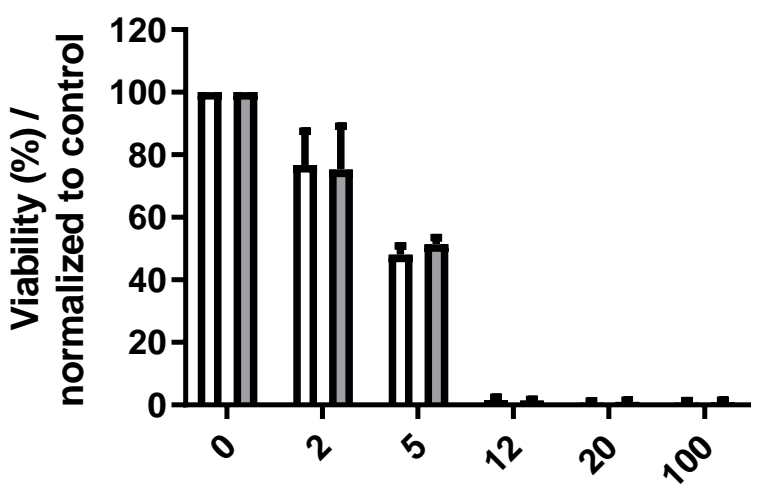

Concentration Paclitaxel (nM)

— KPC-BL6 +Vector

— KPC-BL6 +NT5C1A

Figure 23: Pancreatic cancer cell lines expressing high levels of NT5C1A are still sensitive to paclitaxel treatment. A) Crystal violet assay was performed with murine KPC cells and human L3.6pl cells that have been treated with increasing concentrations of paclitaxel for six days. The staining intensity was comparable between control cells and cells overexpressing NT5C1A. Two independent experiments were performed, with each two technical replicates. B) Quantification of crystal violet assay was performed. Diagram shows the quantification of murine KPC-BL6 cells. The results were normalized to untreated control cells. Graph presents mean \pm SEM, two-way ANOVA with Sidak's multiple comparisons test was performed (ns).

To confirm and further clarify the involvement of NT5C1A in gemcitabine resistance, we performed Western blot analysis for CC3 protein levels upon gemcitabine treatment. Gemcitabine-induced CC3-levels were reduced by factor 4 following recombinant NT5C1A expression in KPC1 cells (Figure 24A and 24B). Similar results were obtained for the KPC-BL6 cell line (factor 2, Figure 25A and 25B). These results confirmed the impact of NT5C1A on gemcitabine resistance in vitro. 
A

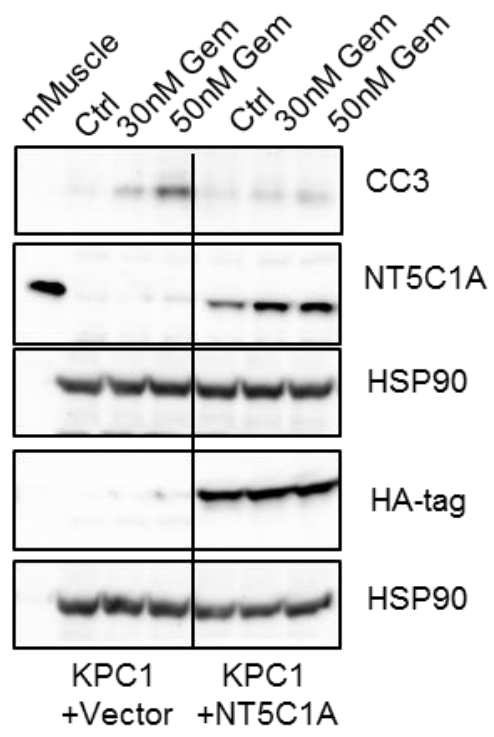

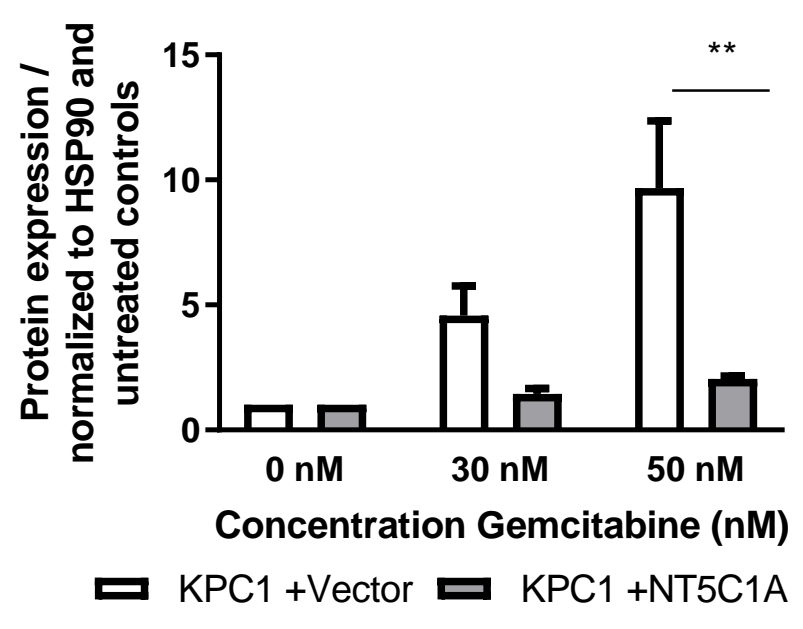

Figure 24: Reduced apoptosis in murine pancreatic cancer cells overexpressing NT5C1A. A) Western blot analysis revealed reduced CC3 protein levels in NT5C1A-expressing cells following gemcitabine treatment for $24 \mathrm{~h}$. Strong NT5C1A and HA-tag expression was demonstrated in the + NT5C1A-cell line. Three independent experiments were performed. B) Quantification of CC3 protein expression in these three Western blot analyses. Two-way ANOVA with Sidak's multiple comparisons test was performed ( $30 \mathrm{nM}: \mathrm{p}=0.249,50 \mathrm{nM}: \mathrm{p}=0.002)$. Graph shows mean \pm SEM.

A

B
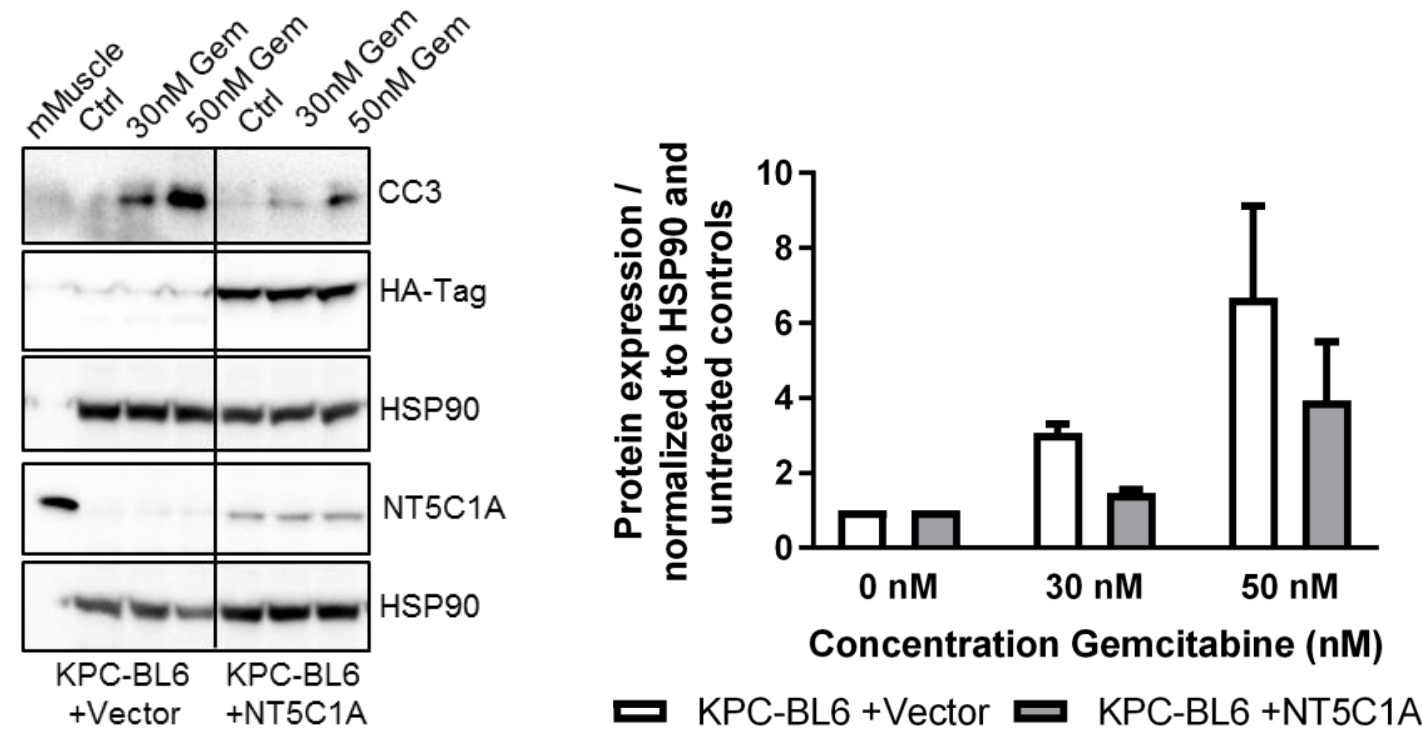

Figure 25: NT5C1A overexpression decreases CC3-levels in vitro. A) Western blot analysis of murine KPC-BL6 cells showed reduced protein levels of CC3 in NT5C1A-expressing cells following gemcitabine treatment for $24 \mathrm{~h}$. NT5C1A and HA-tag expressions were confirmed in the +NT5C1A-cell line. Three independent experiments were performed. HSP90 was used as loading control and murine muscle as positive control for NT5C1A. B) Quantification of CC3 protein expression in the three Western blot analyses. Graph shows mean \pm SEM. 


\subsubsection{NT5C1A expression and function in the tumor stroma}

With the objective to obtain a more comprehensive picture of the clinical situation regarding NT5C1A, we analyzed both TMAs for stromal NT5C1A expression. The same scoring system was employed with score 0 indicating no stromal expression of NT5C1A and score 3 indicating strong expression of NT5C1A. The proportion of PDAC patients without stromal NT5C1A expression was between $87.7 \%$ in TMA-1 $(n=77)$ and $47.3 \%$ in TMA-2 $(n=330)$. Low expression was detected in $11.0 \%($ TMA-1) and $33.3 \%($ TMA-2) of these patients. Interestingly, high scores (2 and 3 ) of stromal NT5C1A was only given to the samples of $1.4 \%$ (TMA-1) or $19.4 \%$ (TMA-2) of all patients (Figure 26A-C).

A

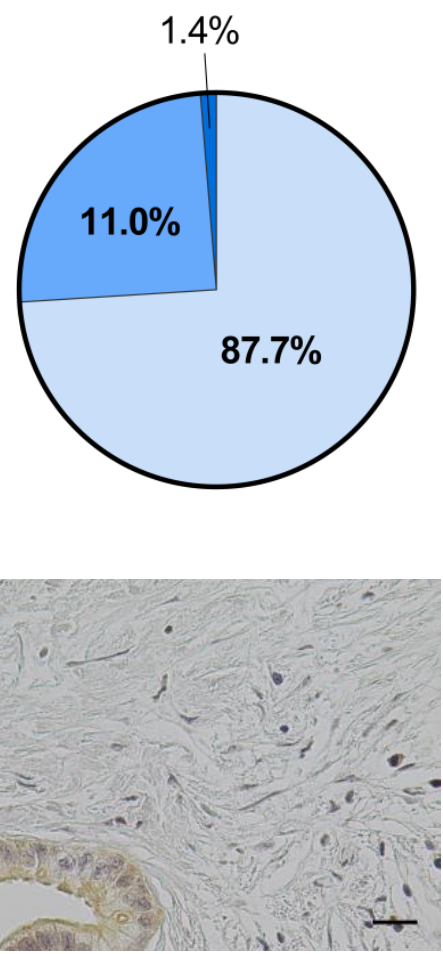

Stroma score 0

C
B

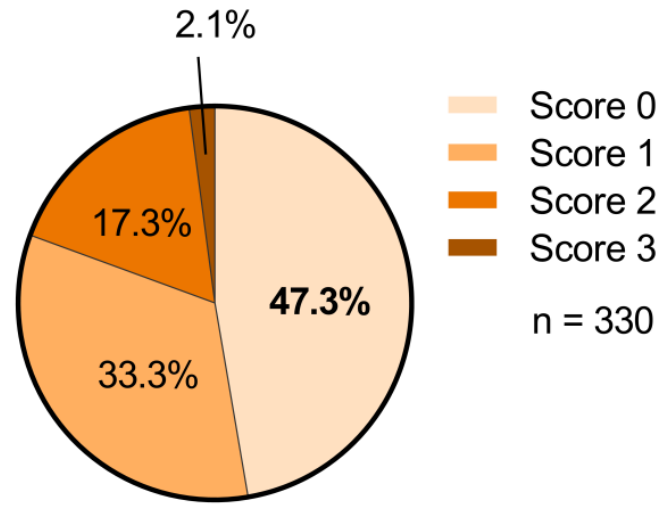

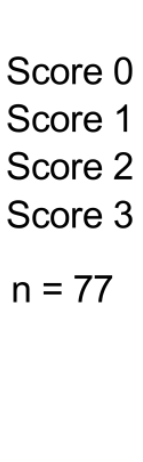

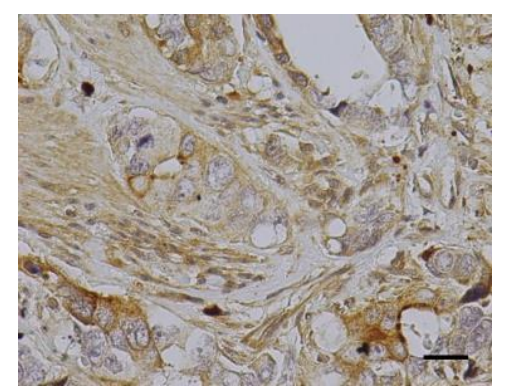

Stroma score 1

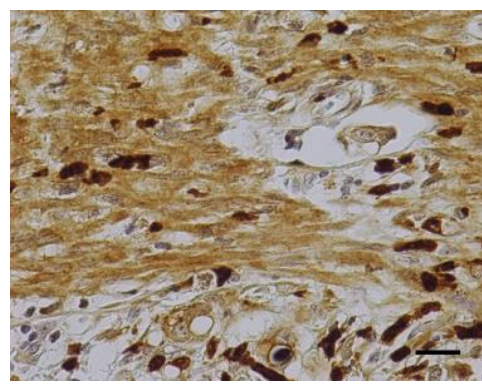

Stroma score 2

Figure 26: NT5C1A expression and function in PDAC stroma in vivo. A) and B) TMA analysis for NT5C1A expression revealed very low expression in the tumor stroma of resected PDAC patients. A semi-quantitative scoring system indicated no stromal expression with score 0 and strong stromal expression with score 3 . TMA-1 from Göttingen (A) with $n=77$ patients (none scored with 3 ) and TMA-2 from Erlangen (B) with $n=330$ patient samples. C) Representative IHC of NT5C1A expression showing no NT5C1A expression (score 0), low expression (score 1), and robust stromal expression (score 2 ) of TMA-1. Scale bars $20 \mu \mathrm{m}$. 
Consistent with the tumor data, stromal NT5C1A expression was not a prognostic marker. The median post-surgical survival time was 15.2 months for patients that did not express NT5C1A $(n=156)$ in the tumor stroma and 17.3 months for all other patients $(n=173$; $p=0.3$, TMA-2) (Figure 27). Due to the lack of treatment details, it remains to be answered whether stromal NT5C1A might be a predictive marker for gemcitabine response in PDAC patients.

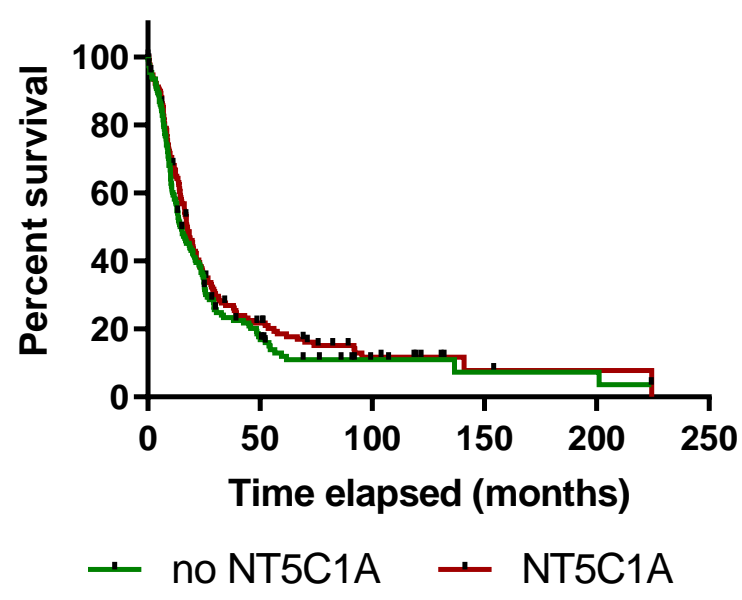

Figure 27: Stromal NT5C1A expression does not correlate with overall survival in resected pancreatic cancer patients. Survival analysis of the Erlangen TMA-2 cohort comparing no NT5C1A expression with any intensity of NT5C1A expression. Median survival was 15.2 months $(n=156)$ for no NT5C1A expression and 17.3 months $(n=173)$ with stromal expression of NT5C1A $(p=0.3$, log-rank test).

As shown by our group previously, NT5C1A is expressed at very low levels in CAFs and PSCs (Hessmann \& Patzak et al., 2018). Furthermore, PSCs do not differ significantly regarding intracellular dFdCTP accumulation compared to CAFs (Hessmann \& Patzak et al., 2018). Therefore, two PSC cell lines were stably transfected and +NT5C1A cells and vector control cells were analyzed by Western blot as previously shown (Hessmann \& Patzak et al., 2018), and also by ICC and qPCR. HA-tag expression and robust expression of NT5C1A was confirmed in the +NT5C1A-cells (Figure 28A-D). Crystal violet staining showed increased resistance of NT5C1A expressing PSCs to gemcitabine treatment (Figure 29A and 29B, Figure 30). 
A

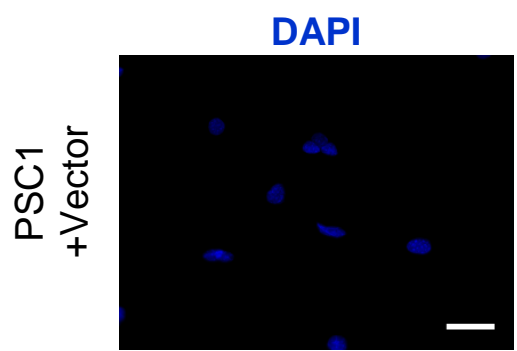

ত

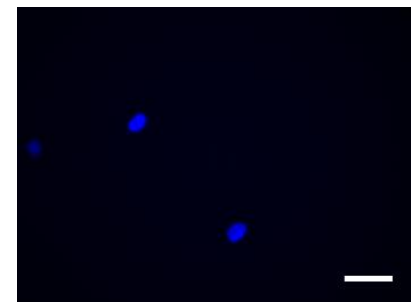

B
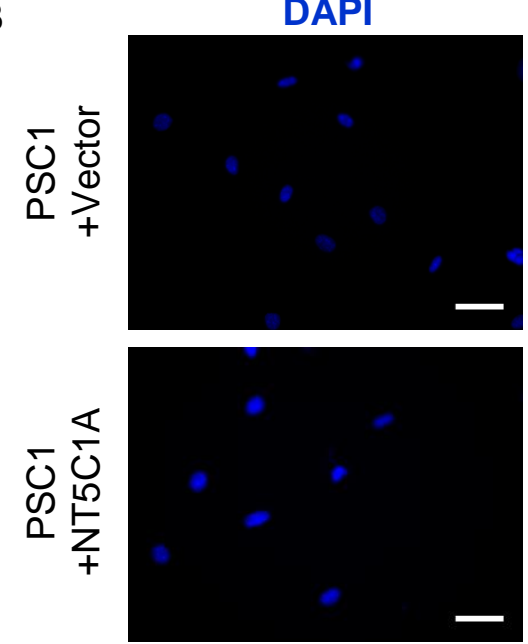

C

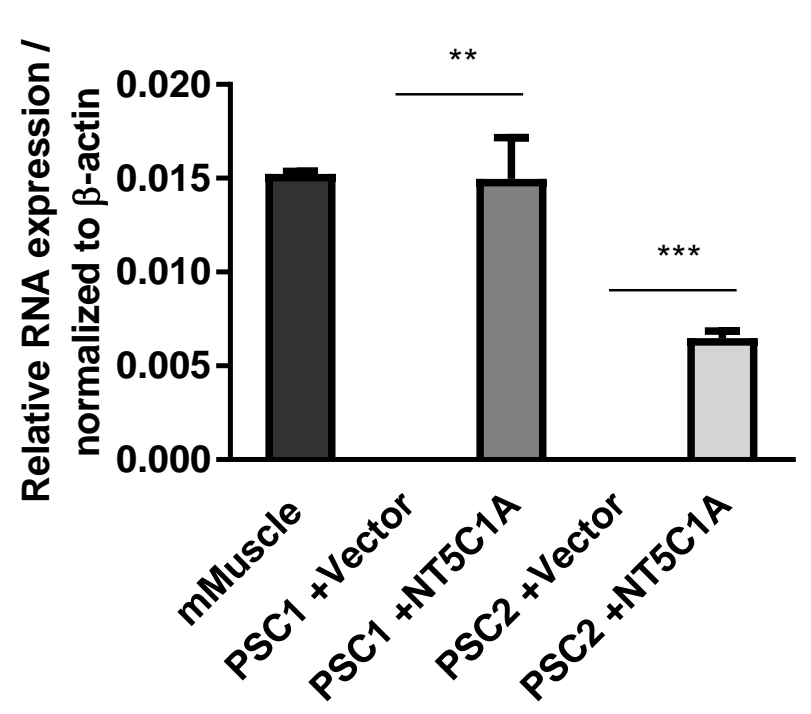

HA-tag
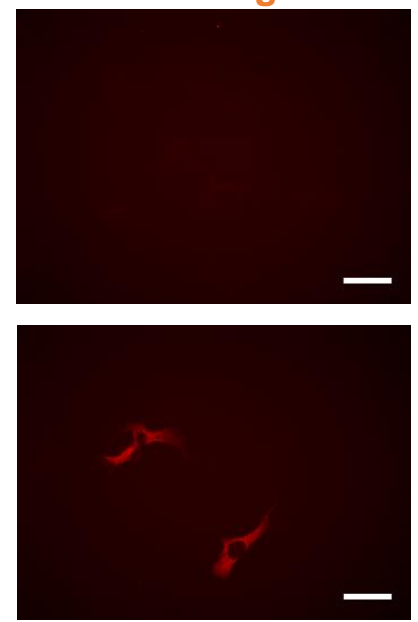

NT5C1A
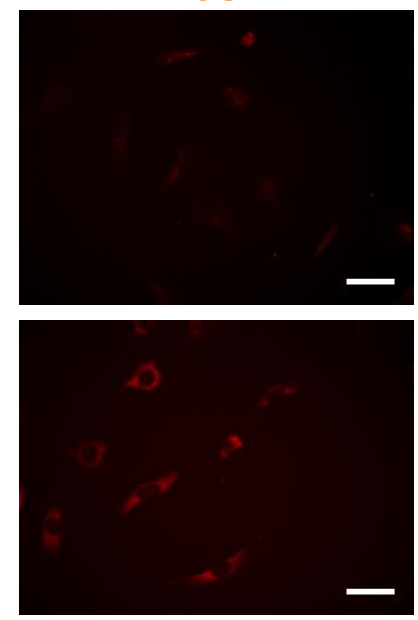

D

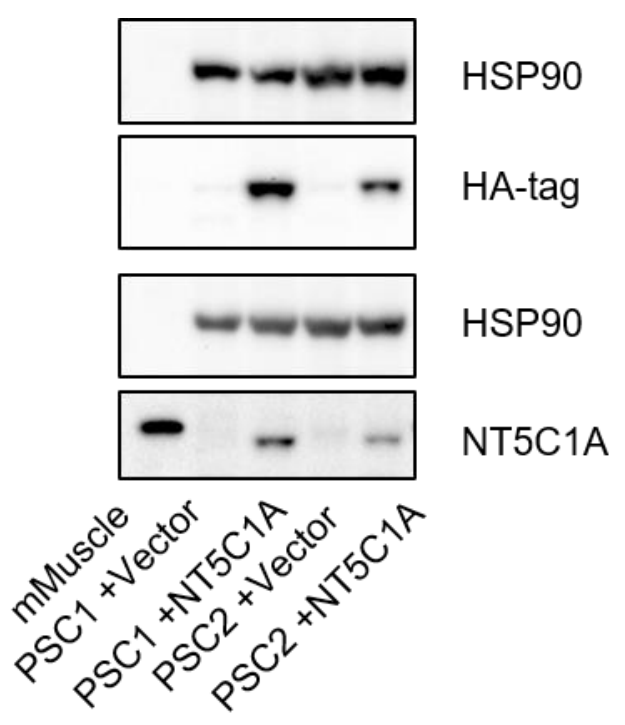

Figure 28: NT5C1A overexpression in stably transfected PSC cell lines. For legend, see top of next page. 


\section{Legend to Figure 28:}

NT5C1A overexpression in stably transfected PSC cell lines. A) and B) Representative ICC pictures for NT5C1A and HA-tag expression in stably transfected PSCs (red; DAPI nuclear staining: blue). HA-tag expression was exclusively shown for +NT5C1A cells (A, lower panel), control cells were devoid of immunoreactivity (A, upper panel). Very low endogenous levels of NT5C1A were demonstrated in vector control cells (B, upper panel) compared to NT5C1A expression in the NT5C1A-overexpressing cells (B, lower panel). Two technical replicates were analyzed per cell line and antibody. Scale bars $50 \mu \mathrm{m}$. C) Strong NT5C1A mRNA expression was shown in both +NT5C1A murine pancreatic stellate cell lines, as analyzed by quantitative RT-PCR (PSC1: $p=0.003$ and PSC2: $p=0.0001)$. NT5C1A expression was hardly detectable in vector control cells. Diagram indicates mean \pm SEM of three biological replicates. Murine muscle sample served as positive control. Values were normalized to $\beta$-actin as housekeeping gene. D) Western blot analysis of transfected PSCs showing robust NT5C1A and HA-tag protein expression in cells expressing NT5C1A and no detectable expression in vector control cells. Representative image of three independent experiments is shown with murine muscle lysate as positive control for NT5C1A expression.

A

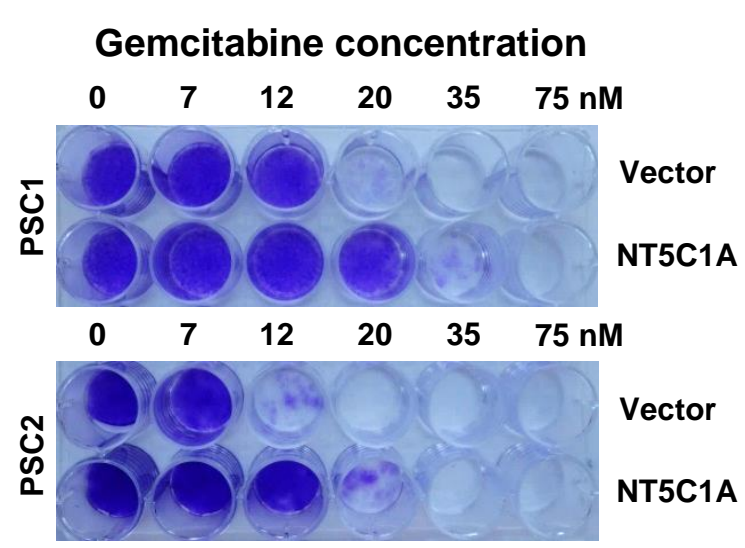

B

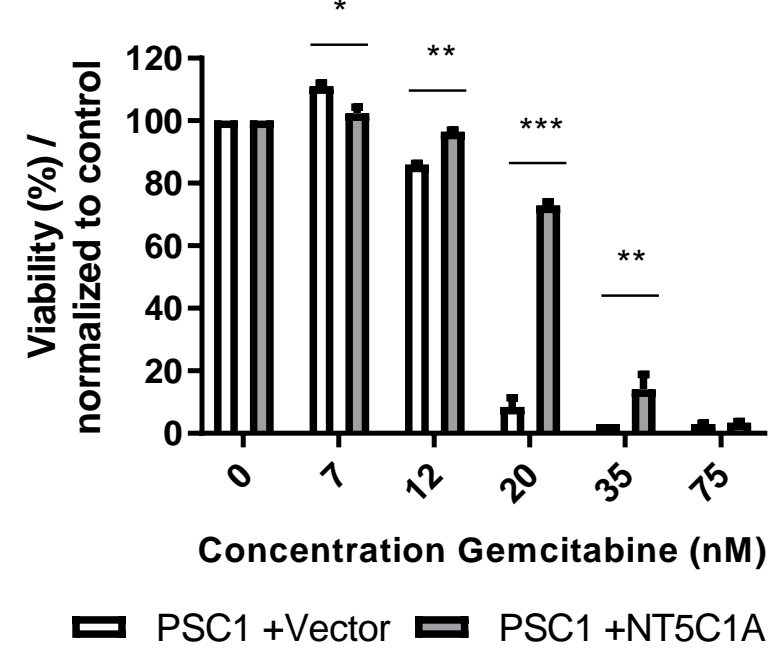

Figure 29: NT5C1A function in PDAC stroma. A) Murine PSCs were treated with increasing concentrations of gemcitabine for six days and crystal violet assays were performed. The staining was more pronounced in NT5C1A expressing cell lines. Representative images of two independent experiments, with each two technical replicates, are shown. B) Crystal violet stain intensity was quantified and results were normalized to untreated control cells. Graph indicates mean \pm SEM, two-way ANOVA with Sidak's multiple comparisons test was performed $(7 \mathrm{nM}: \mathrm{p}<0.035,12 \mathrm{nM}$ : $p<0.009,20 n M: p<0.0001,35 n M: p=0.007)$. 


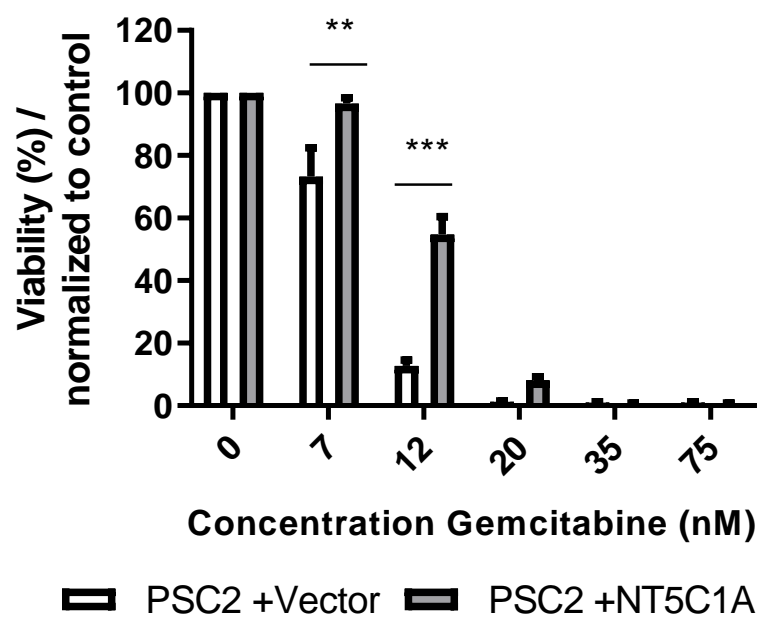

Figure 30: Stromal NT5C1A expression enhances gemcitabine resistance in vitro. Quantification of crystal violet assay for stably transfected PSC2 cells with and without NT5C1A expression. Two-way ANOVA with Sidak's multiple comparisons test was performed $(7 \mathrm{nM}$ : $p=0.002,12 n M: p<0.0001)$.

Considering our previously published findings that + NT5C1A-PSCs accumulate significant lower amounts of intracellular gemcitabine triphosphate (Hessmann \& Patzak et al., 2018), we hypothesized that gemcitabine availability would be significantly increased in the supernatant of NT5C1A-PSCs. To test this, MTT assays with conditioned media (CM) of transfected PSCs were performed. PSCs were incubated with $25 \mathrm{nM}$ of gemcitabinehydrochloride for $24 \mathrm{~h}$ and CM was then transferred to two KPC tumor cell lines (Figure 31A). Cell viability was determined $72 \mathrm{~h}$ later and demonstrated significantly decreased tumor cell viability with CM of +NT5C1A-PSCs, compared to vector control cells with only endogenous levels of NT5C1A. In the two KPC cell lines the viability decreased to $73 \%$ and $75 \%$, respectively (KPCa: $p=0.003$ and KPCb: $p=0.047$ ) (Figure 31B).

A

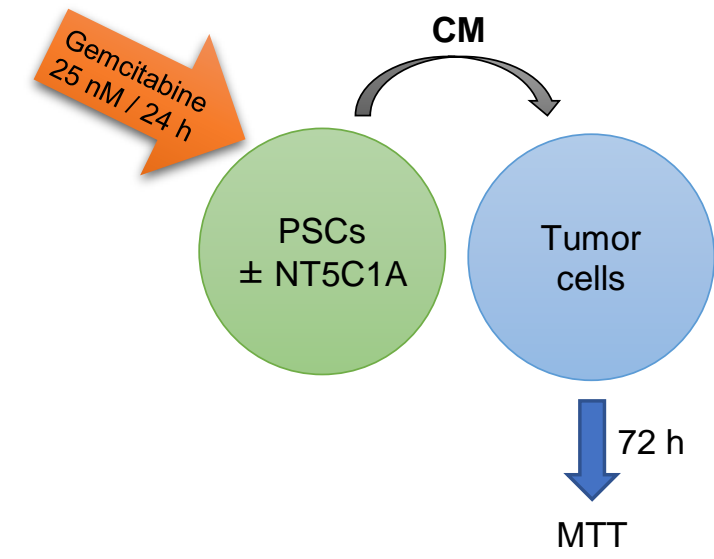

B

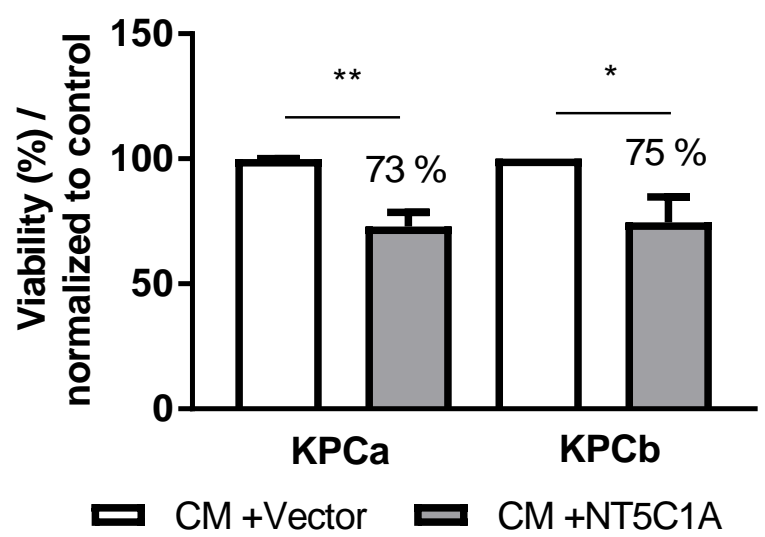

Figure 31: Stromal cells expressing NT5C1A increase available amounts of gemcitabine for tumor cells in vitro. For legend, see top of next page. 


\section{Legend to Figure 31:}

Stromal cells expressing NT5C1A increase available amounts of gemcitabine for tumor cells in vitro. A) and B) MTT cell viability assay for KPC cell lines treated with CM of NT5C1A expressing PSCs and control CM. A) Schematic experimental overview. CM from PSCs (+NT5C1A) and control PSCs (+vector) was obtained by preincubation with $25 \mathrm{nM}$ gemcitabine-hydrochloride for $24 \mathrm{~h}$. Subsequently, tumor cells were treated for $72 \mathrm{~h}$ with CM of PSCs and viability was assessed using MTT cell viability assay. B) Tumor cell viability of two different murine KPC cell lines was significantly decreased following treatment with CM of + NT5C1A-expressing PSCs (KPCa: $73 \% ; p=0.003$ and KPCb: $75 \% ; p=0.047$ ). Graphs indicate mean \pm SEM of four biological replicates.

\subsubsection{Reduced accumulation of the cytotoxic gemcitabine metabolite dFdCTP in NT5C1A expressing stromal cells}

The transfected PSCs were incubated with gemcitabine for $2 \mathrm{~h}$ and subjected to LC-MS/MS-analysis to investigate the hypothesis that NT5C1A expression in stromal cells would decrease intracellular gemcitabine accumulation, as it was already shown for tumor cell lines. Indeed, the concentration of intracellular dFdCTP was significantly decreased in both NT5C1A re-expressing PSC lines (Figure 32) (Hessmann \& Patzak et al., 2018). As a result, it could be assumed that the transfected cells would consequently increase the amount of available gemcitabine for tumor cells.

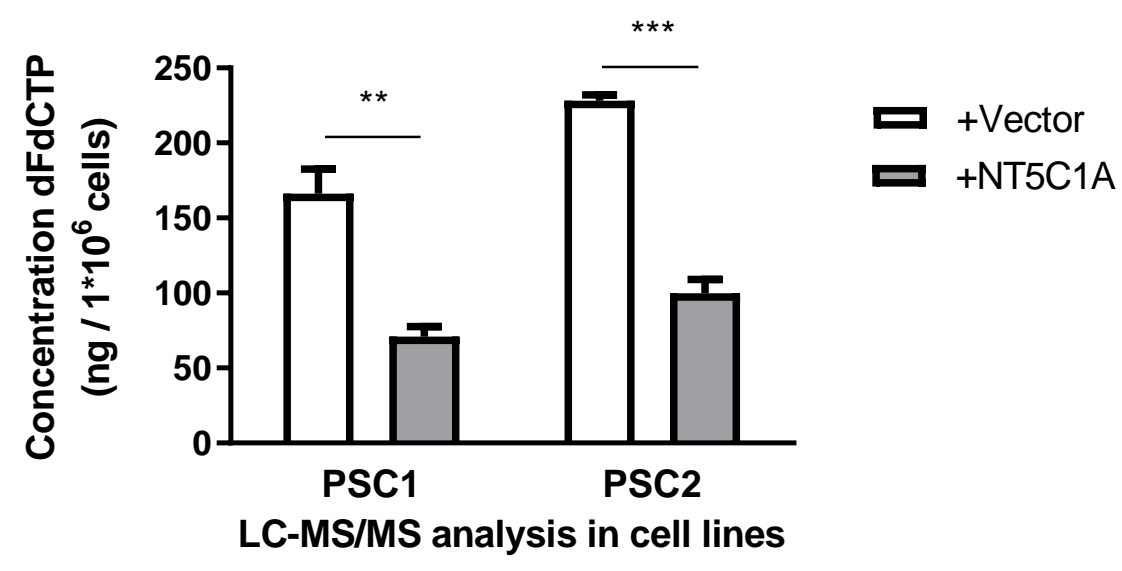

Figure 32: Pharmacokinetic analysis of the gemcitabine metabolite dFdCTP in murine PSCs. Cells were treated with $1 \mu \mathrm{M}$ of gemcitabine-hydrochloride for $2 \mathrm{~h}$ and cell pellets were harvested. Concentrations of the cytotoxic gemcitabine metabolite dFdCTP were determined using LC-MS/MS. Significantly lower amounts of dFdCTP were found in both transfected fibroblast cell lines (+NT5C1A) (compared to control cells (+vector) (PSC1: 166 vs. $71 \mathrm{ng} / 1 \times 10^{6}$ cells; $p=0.006$ and PSC2: 228 vs. $100 \mathrm{ng} / 1 \times 10^{6}$ cells; $\left.p=0.0002\right)$. Graph shows mean \pm SEM of three technical replicates. Adapted from (Hessmann \& Patzak et al., 2018). 


\subsubsection{NT5C1A expression mediates chemoresistance in vivo}

Finally, we aimed to investigate whether NT5C1A mediates chemoresistance in vivo. To this end, we employed a syngeneic, orthotopically transplanted mouse model using C57BL/6-J mice and stably transfected KPC-BL6 cells. Seven days after tumor cell transplantation, mice were treated with gemcitabine or saline for 14 days (Figure 33). High-resolution small animal ultrasound screening was performed on day 9 of the treatment to verify tumor growth upon transplantation (Figure 34). Intratumoral NT5C1A and HA-tag expression were confirmed by $\mathrm{IHC}$ and showed robust protein levels in tumors derived from stably transfected cells (Figure 35).

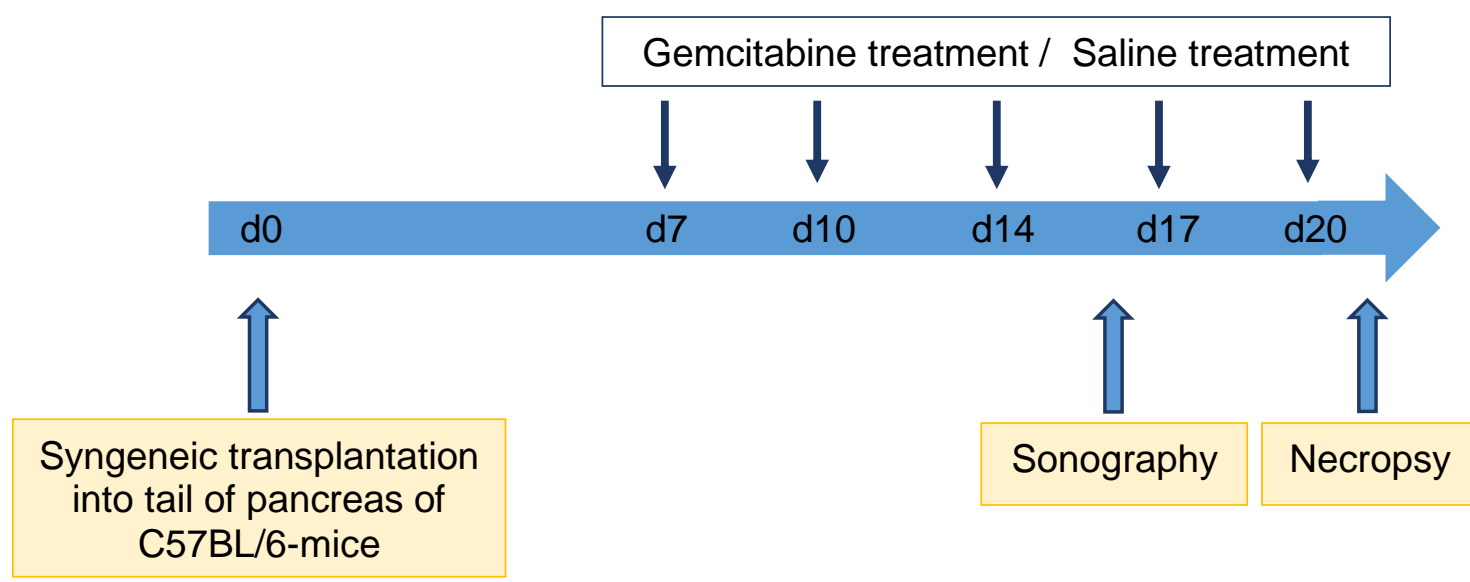

Figure 33: Syngeneic orthotopic transplantation of modified KPC tumor cells. A) Schematic presentation of orthotopic transplantations in C57BL/6-J mice and subsequent treatment schedule. Mice were treated seven days after transplantation with gemcitabine $100 \mathrm{mg} / \mathrm{kg}$ or saline, respectively, on treatment days $0,3,7,10$, and 13 . Sonography was performed on treatment day 9 .

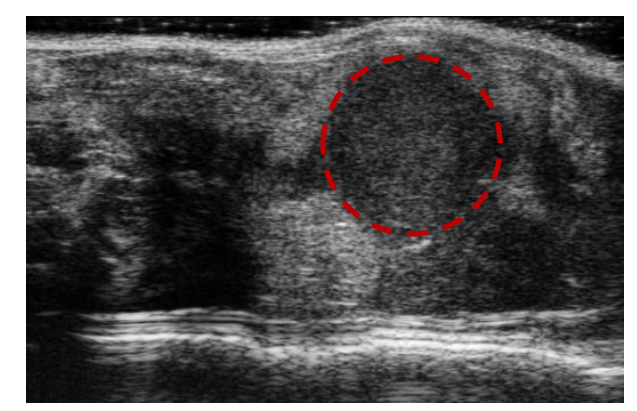

Figure 34: Tumor detection by high-resolution ultrasound. Tumor detection was performed by small animal high-resolution sonography of orthotopically transplanted mice in all groups on day 9 of treatment. Dotted line indicates the tumor. 

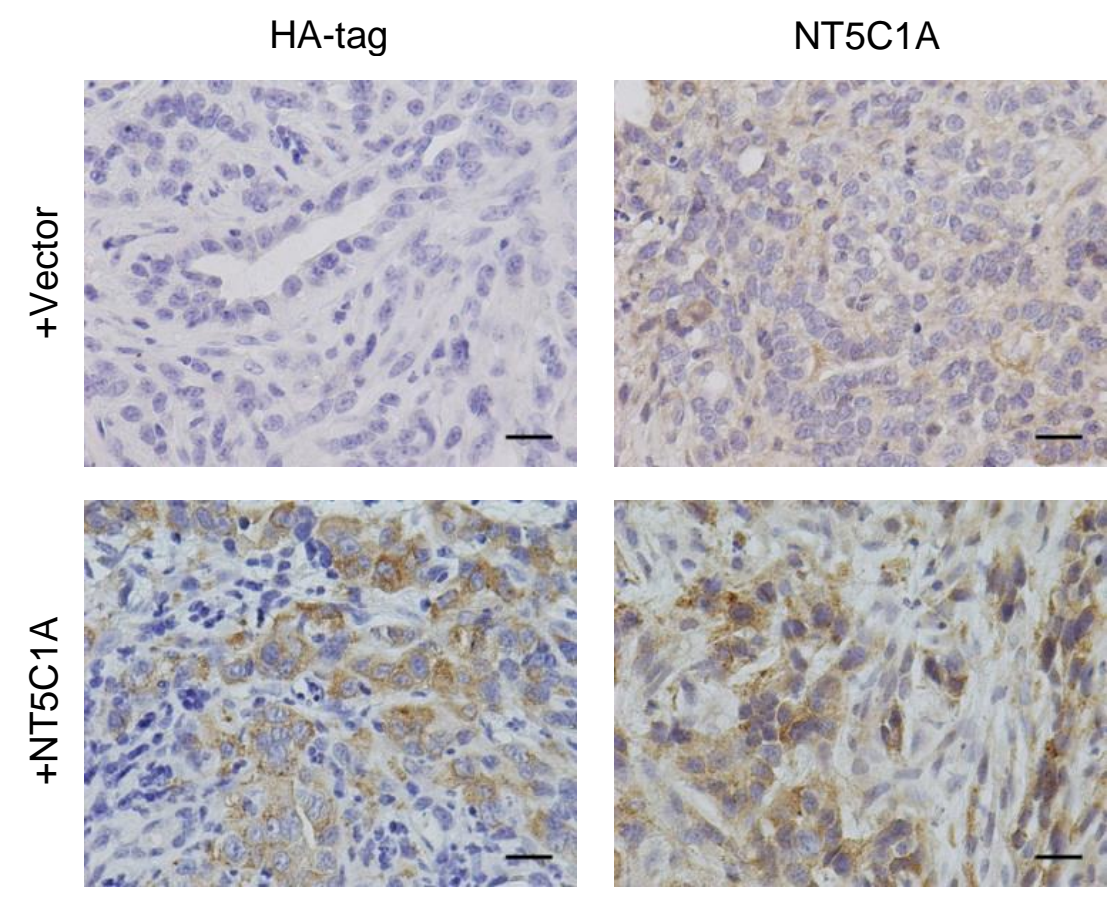

Figure 35: NT5C1A is robustly expressed in tumors from mice with orthotopically transplanted NT5C1A overexpressing tumor cells. Representative $\mathrm{IHC}$ showing HA-tag (left) and NT5C1A (right) stainings in vector (upper panel) and +NT5C1A (lower panel) orthotopic tumors. Scale bars $20 \mu \mathrm{m}$.

Tumor growth measured by absolute tumor weights was significantly increased following gemcitabine treatment in NT5C1A-overexpressing tumors compared to tumors derived from vector control cells ( $0.25 \mathrm{~g}$ vs. $0.37 \mathrm{~g} ; \mathrm{p}=0.03$ ) (Figure 36A and 36B). However, the overall number of apoptotic cells within the tumor was not significantly decreased upon NT5C1A overexpression (Figure 37). Moreover, serum levels of dFdU, the inactive gemcitabine metabolite, were significantly increased in mice bearing NT5C1A-overexpressing tumors with median concentrations of 14.1 vs. $17.6 \mu \mathrm{M} \mathrm{dFdU}(\mathrm{p}=0.009)$ (Figure 38). These data strongly support our hypothesis that high NT5C1A expression reduces sensitivity to gemcitabine. Accordingly, and in line with the patient data demonstrating NT5C1A not to be a prognostic marker (Figure 16A and 16B), we did not observe significant NT5C1A-dependent differences in tumor growth upon saline treatment of mice $(0.82 \mathrm{~g}$ vs. $0.99 \mathrm{~g} ; \mathrm{p}=0.07$ ) (Figure 39). Additionally, comparing gemcitabine treated tumors to saline treated tumors, we show that NT5C1A expression is not induced by gemcitabine treatment (Figure 40). 
A

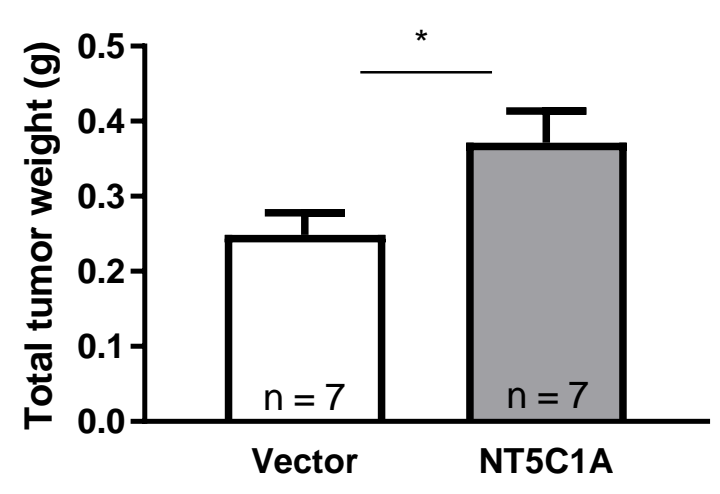

B

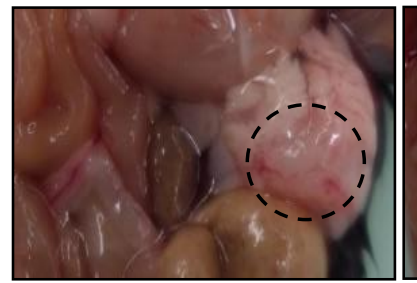

Vector

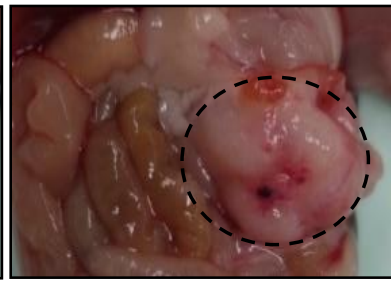

NT5C1A
Gemcitabine treatment

Gemcitabine treatment

Figure 36: NT5C1A expression mediates chemoresistance in vivo. A) Tumor weights upon necropsy are shown with significantly increased tumor weights upon NT5C1A overexpression in the gemcitabine treated cohort $(n=7$ each; $p=0.03)$. Graph shows mean \pm SEM. B) Necropsy pictures of orthotopically transplanted pancreatic tumors upon gemcitabine treatment with vector (left) and stable expression of NT5C1A (right).

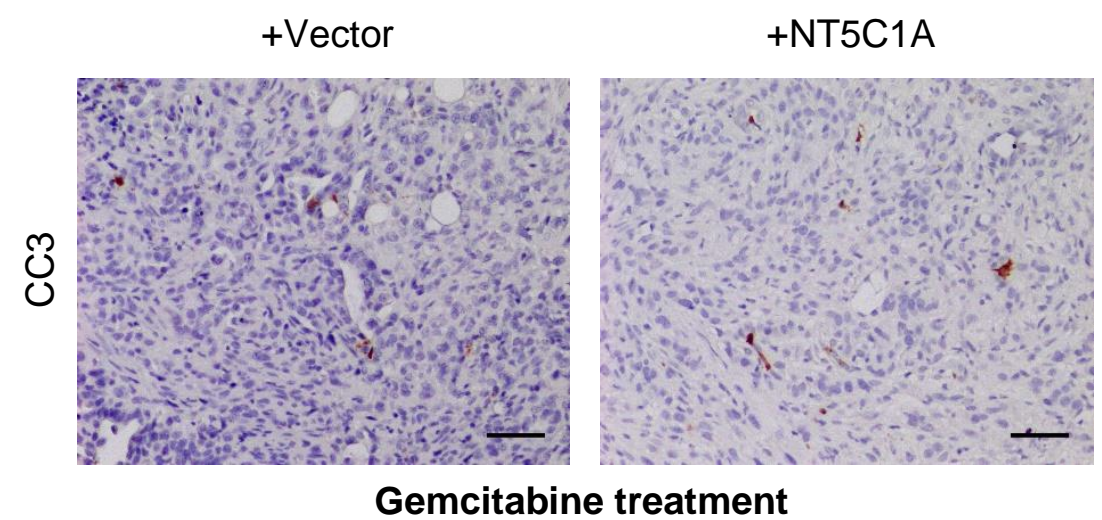

Figure 37: Apoptotic cell numbers were not changed upon NT5C1A expression in murine tumors. IHC for $\mathrm{CC} 3$-expression was performed to compare the overall numbers of apoptotic cells in NT5C1A expressing tumors and in control tumors of gemcitabine treated orthotopically transplanted mice. The overall numbers of CC3-positive cells were low and were comparable between NT5C1A expressing (right) and vector control tumors (left). Scale bars $50 \mu m(n=7$ mice each). 


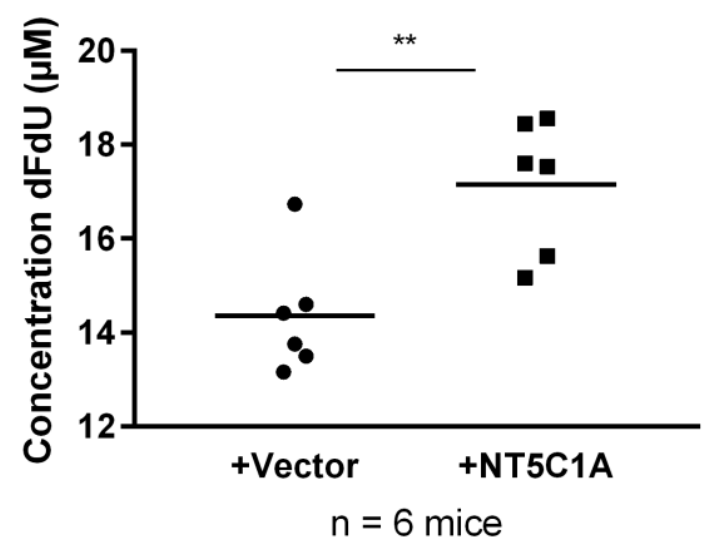

Figure 38: Enhanced inactivation of gemcitabine in NT5C1A expressing orthotopic tumors. The inactive gemcitabine metabolite $\mathrm{dFdU}$ was measured in serum samples of gemcitabine treated mice. Significantly higher values were detected in mice with + NT5C1A tumors (median: 14.1 vs. 17.6 $\mu \mathrm{M}, \mathrm{p}=0.009$, Mann-Whitney test). Single values of $\mathrm{n}=6$ mice per group and the mean values are shown.

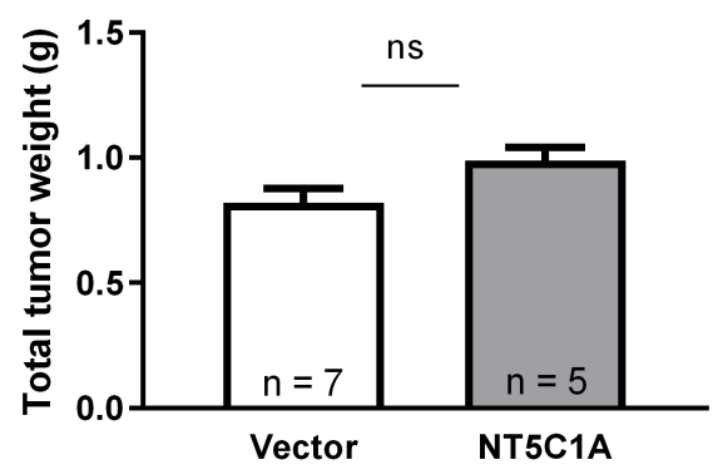

Saline treatment

Figure 39: Tumor growth was not altered in NT5C1A-expressing tumors following saline treatment. NT5C1A expression in saline treated control mice did not have a significant effect on tumor growth ( $p=0.07, n=7$ and 5 , respectively). Graph shows mean \pm SEM.
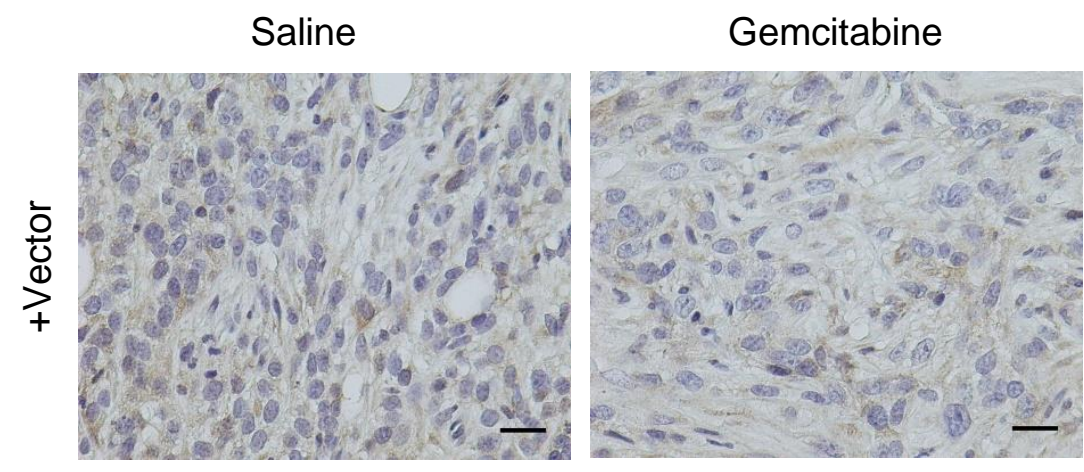

Figure 40: Gemcitabine treatment does not alter NT5C1A expression using an orthotopic mouse model of PDAC. Comparison of NT5C1A expression in control tumors treated with saline or gemcitabine, respectively. NT5C1A expression was not induced by gemcitabine treatment. Expression was low in both groups. Representative IHC images are shown. Scale bars $20 \mu \mathrm{m}$. 


\section{Discussion}

\subsection{Gemcitabine resistance and its association with the pancreatic cancer stroma}

Pancreatic cancer is one of the most aggressive solid tumors and effective treatment options are still missing. Increasing incidence and mortality rates in combination with very limited progress in the development of novel treatment strategies render pancreatic cancer a major challenge in industrial countries (Adamska et al., 2017; Gordon-Dseagu et al., 2018). Consequently, many international research groups aim to unravel the underlying molecular mechanisms for PDAC progression and therapeutic resistance.

In the present study, I aimed to elucidate the conundrum of gemcitabine effectiveness in vitro, in pancreatic cancer cells, but strong resistance in vivo in patients with PDAC. We also observed comparable treatment effectiveness of gemcitabine in primary tumor cells isolated from endogenous KPC tumors and metastatic liver lesions (Hessmann \& Patzak et al., 2018). In contrast to in vitro observations, Burris et al. described the overall response rate for gemcitabine in pancreatic cancer patients with $5.4 \%$ (Burris et al., 1997).

As pancreatic cancer characteristics are hypovascularity and a strong desmoplastic reaction, it is plausible that the pancreatic cancer microenvironment plays a crucial role in therapeutic resistance. A biophysical barrier that impairs the delivery of chemotherapeutic agents to the tumor, especially based on vessel compression through high interstitial fluid pressure, was proposed by several groups (Jacobetz et al., 2013; Olive et al., 2009; Provenzano et al., 2012). The stromal components like PSCs, collagen, hyaluronic acid, and SPARC as key regulators of the desmoplastic reaction (Neesse et al., 2015) were examined for their contribution to drug resistance in PDAC by various groups.

Consequently, stromal depletion approaches were conducted and promising results were obtained preclinically. In 2009 , Olive et al. presented data from a preclinical trial where the authors inhibited the desmoplasia promoting sonic hedgehog signaling pathway in KPC mice by administration of the Smoothened (Smo) inhibitor IPI-926 (Olive et al., 2009). This inhibitor led to increased mean vessel density and decreased stromal content with markedly reduced levels of collagen I and reduced proliferation of $\alpha$-SMA-positive stromal myofibroblasts. The delivery of gemcitabine and also doxorubicin to the primary tumors was improved in combination therapies with IPI-926. However, the effect on vascular content reversed over time, indicating adaption to the inhibitor treatment (Olive et al., 2009). Few years later, two studies were published regarding the influence of hyaluronan as central element of the stroma (Jacobetz et al., 2013; Provenzano et al., 2012). Provenzano et al. and Jacobetz et al. both investigated the influence of enzymatic depletion of hyaluronan on 
drug delivery and effectiveness. Intravenous treatment with the hyaluronidase PEGPH20 in KPC mice resulted in a normalization of interstitial fluid pressure and thus, in increased vessel diameters (Provenzano et al., 2012), and was shown to be directly related to re-expansion of existing vessels as mean vessel density was not affected (Jacobetz et al., 2013). Despite the slightly different preclinical trial design, the conclusions of these studies were similar. In both studies, median overall survival of mice was significantly increased following combination treatment of PEGPH20 and gemcitabine compared with gemcitabine monotherapy (Jacobetz et al., 2013; Provenzano et al., 2012). Moreover, Provenzano and colleagues described an intensive remodeling process of the tumor stroma following hyaluronidase treatment, with reduced numbers of PSCs and decreased collagen content (Provenzano et al., 2012). Regarding collagen content, the impact of angiotensin II should be emphasized. Angiotensin II enhanced DNA synthesis in PSCs, thereby promoted PSC proliferation (Hama et al., 2004). The angiotensin II type 1 receptor antagonist losartan was demonstrated to effectively inhibit collagen and hyaluronan production in murine orthotopic tumors derived from pancreatic tumor cells. Furthermore, this was associated with a reduction in CAF density and improved chemotherapeutic drug delivery (Chauhan et al., 2013). PEGPH20 is currently one of the most promising targets for personalized antistroma therapies. In a randomized phase II study (NCT01839487), progression-free survival times were significantly improved in patients that received PEGPH20 with nab-paclitaxel plus gemcitabine versus those patients that only received the combination of nab-paclitaxel plus gemcitabine and were especially pronounced in patients with high hyaluronan levels (Hingorani et al., 2018). Consequently, patients are currently enrolled in a phase III study for previously untreated hyaluronan-high stage IV pancreatic cancer (NCT02715804) to compare the efficacy and safety profiles between PEGPH20 with nab-paclitaxel plus gemcitabine and placebo with nab-paclitaxel plus gemcitabine administration (Halozyme Therapeutics, n.d.).

Altogether, these studies supported the assumption of a biophysical barrier that would be responsible for the low and disappointing response rate following gemcitabine administration in PDAC. As a result, stromal depletion was seen as method of choice to enhance chemotherapeutic efficacy in the treatment of pancreatic cancer.

\subsubsection{Gemcitabine accumulation in stroma-rich pancreatic tumors}

In our study, we addressed this hypothesis in more detail. We investigated dFdCTP concentrations in bulk tumor tissues from KPC mice and correlated our findings with overall survival times of these mice. However, and in contrast to the assumption of a biophysical treatment barrier, the intratumoral concentration of active gemcitabine was not a predictor 
for treatment response as there was no correlation between intratumoral gemcitabine accumulation and survival (Hessmann \& Patzak et al., 2018).

Furthermore, we compared bulk tumor tissues, liver metastases, and liver tissues from gemcitabine-treated KPC mice for their amounts of gemcitabine metabolites. Strikingly, we have demonstrated highest levels of dFdCTP in bulk tumor tissues of KPC mice compared with matched liver metastases and adjacent normal liver tissues. In regards to the discussed biophysical treatment barrier we would have expected to observe the highest levels in liver tissue, as the liver is a well-perfused organ. We cannot exclude a potential involvement of vessel compression, high interstitial fluid pressure, and hypovascularity of pancreatic tumors in mediating drug resistance. However, our findings strongly question the hypothesis of impaired drug delivery in pancreatic tumors as the limiting factor for gemcitabine efficacy. Moreover, two recently published studies showed an association of stromal depletion with a more aggressive, highly undifferentiated, and invasive tumor phenotype (Oezdemir et al., 2014; Rhim et al., 2014). These studies by Rhim et al. and Oezdemir et al. were both published in 2014 in the same issue of Cancer Cell and added another layer of complexity to this topic and challenged the stroma depletion approaches. Conditional depletion of sonic hedgehog (Shh) in a mouse model similar to the KPC model resulted in earlier tumor onset and significantly reduced survival times of these mice. Additionally, Shh depletion gave rise to poorly differentiated tumors with increased numbers of intratumoral blood vessels and resulted in a higher frequency of metastasis development (Rhim et al., 2014). Oezdemir and colleagues selectively depleted proliferating a-SMA-positive myofibroblasts, which resulted in a significant reduction in survival of these mice, which died from undifferentiated and aggressive tumors (Oezdemir et al., 2014). Moreover, the authors also showed that patients with low scores of a-SMA often have less differentiated tumors than the ones with higher a-SMA scores. The depletion of myofibroblasts reduced the amount of collagen I and the stiffness of the ECM. In spite of this, the depletion of CAFs did not improve the efficacy of gemcitabine therapy and survival was not prolonged in comparison to untreated mice (Oezdemir et al., 2014). This finding is in line with our data that gemcitabine anyhow reaches the primary tumors of KPC mice.

In addition, the outcome of two clinical trials (NCT01195415, NCT01064622) was disappointing as the combination treatment of gemcitabine with the hedgehog pathway inhibitor Vismodegib failed to induce significantly increased response rates, progressionfree-survival, or median overall survival rates of patients with metastatic pancreatic cancer when compared with single agent gemcitabine administration (Catenacci et al., 2015; Kim et al., 2014). These studies were followed by the premature termination of a similar clinical trial conducted by Infinity Pharmaceuticals, Inc. The company reported that the group receiving gemcitabine plus the Smo inhibitor Saridegib showed higher progression rates 
and the difference in survival favored the placebo plus gemcitabine group (Infinity Pharmaceuticals, n.d.). Taken these findings together, unselective depletion of the tumor stroma should be avoided as some stromal components might even have tumor restraining properties. Consequently, a more detailed picture about the exact function and interplay of the different stromal components is required.

The fact that gemcitabine accumulates in stroma-rich primary tumors and lower levels were observed in stroma-poor metastases (Hessmann \& Patzak et al., 2018) implicated that the stromal components are actively involved in drug metabolism. In line with this new hypothesis are the data presented by Neesse et al. from 2013. The authors demonstrated increased gemcitabine levels in plasma and tumor biopsies from KPC mice when gemcitabine therapy was combined with the CDA inhibitor THU, but did not observe significant changes of tumor volumes and of the number of apoptotic cells (Neesse et al., 2013). Taken together, increased gemcitabine concentrations in the tumor bulk of mice were not sufficient to improve the response to this drug. Consequently, an active involvement of the stromal components in gemcitabine metabolism and subsequent availability for tumor cells was further investigated.

\subsubsection{The tumor microenvironment is actively involved in drug metabolism}

Interestingly, we were able to describe a drug scavenging effect of CAFs in vitro. The levels of the active gemcitabine metabolite dFdCTP were highest in CAFs and PSCs and the inactive metabolite dFdU was significantly decreased in these cells. As phosphorylated gemcitabine is unable to cross the cell membrane, it is entrapped within the fibroblasts and thus, becomes unavailable for tumor cells. Consequently, we concluded that the pancreatic cancer stroma rather exerts a biochemical barrier to gemcitabine treatment by actively metabolizing the drug. Thus, the issue is not the drug delivery to the tumors, but the intratumoral redistribution of gemcitabine in stroma-rich pancreatic tumors. Putting these findings in context with the observations published by Jacobetz et al., Provenzano et al., and Olive et al. (Jacobetz et al., 2013; Olive et al., 2009; Provenzano et al., 2012), we gave an alternative explanation why gemcitabine treatment was shown to be more efficient in mice with reduced amounts of PSCs or activated $\alpha$-SMA-positive myofibroblasts. Increasing the mean vessel density by stromal depletion would consequently enhance gemcitabine drug scavenging by CAFs, instead of increasing effective concentrations in the tumor cells. Notably, in another study of our laboratory, higher levels of dFdC were observed in pancreatic tumors of SPARC-wildtype and SPARC-knockout KC mice compared with normal pancreatic tissue. This result was independent of SPARC and thus, unrelated to the 
SPARC dependent amount of collagen. The differences in overall cellularity were assumed to be the underlying mechanism for this observation (Ramu et al., 2018). Taken our findings together, we suggest the number of CAFs in pancreatic tumors to be a predictable marker for the response to gemcitabine.

Additionally, the effectiveness of gemcitabine and nab-paclitaxel on metastases in PDAC has been demonstrated in a preclinical study by Aiello et al. In this study, the metastases were characterized by their grade of desmoplasia, where smaller metastases presented reduced amounts of stromal components than larger metastases. The authors observed comparable chemotherapeutic effectiveness in metastases of all sizes (Aiello et al., 2016). This could be explained in part by our proposed drug scavenging effect, as the gemcitabine accumulation in fibroblasts would explain the effective killing of nano- and micro-metastases due to their lower number of fibroblasts, but not the effects on highly desmoplastic macrometastases. However, the authors based their finding on a single dose of gemcitabine with subsequent detection of CC3-positive tumor cells. The effect on the overall metastatic burden are in line with our findings as metastatic size was significantly reduced following long-term treatment, which suggests effective inhibition of progression of smaller metastases (Aiello et al., 2016).

In our present work, we did not observe the drug scavenging for 5-FU, another nucleoside analogue. However, further chemotherapeutics were not included in our study of the tumor stroma. Consequently, further data are required to assess whether this mechanism impacts on several classes of chemotherapeutic agents or if it is selective for gemcitabine.

Yet, we were not able to demonstrate the drug scavenging of fibroblasts in vivo as it was not possible, by the LC-MS/MS method that we used in our study, to distinguish between gemcitabine in stromal cells and in tumor cells of the bulk tumor tissue. Further data are required that explicitly show the tumor compartment specific distribution of gemcitabine. Labelling gemcitabine with a fluorescence marker could be a feasible approach to obtain these data.

\subsubsection{Stromal expression of gemcitabine-metabolizing enzymes and gemcitabine resistance}

Regarding the significantly lower intracellular dFdU levels in fibroblasts compared with tumor cells, we investigated whether drug influx, activation, or inactivation would be underlying mechanisms. No differences in the expression levels were found for dCK, which is considered to be the rate-limiting step in the activation of gemcitabine. Moreover, as dFdCTP levels had been significantly higher in fibroblasts, the transport of native prodrug into the cells was very unlikely to limit drug activation. Interestingly, gemcitabine inactivating 
enzymes were shown to be hardly expressed in the tumor stroma of human and murine pancreatic cancer tissue. In contrast, the expression detected in the epithelial compartment was very robust. Therefore, we concluded that the low levels of dFdU are a consequence of downregulated gemcitabine inactivation in stromal cells. The main inactivating enzymes are CDA, DCTD, and NT5C1A. CDA leads to quick inactivation of the gemcitabine prodrug to $\mathrm{dFdU}$, and DCTD deaminates the monophosphate metabolite, thus, preventing further phosphorylation of dFdCMP to the cytotoxic dFdCTP metabolite (De Sousa Cavalcante \& Monteiro, 2014). NT5C1A was a previously unrecognized gemcitabine inactivating enzyme and to the best of our knowledge, we have been the first group to describe differential expression of NT5C1A between CAFs and pancreatic cancer cells. Mechanistically, NT5C1A reverses the initial phosphorylation step, which results in the production of gemcitabine prodrug (De Sousa Cavalcante \& Monteiro, 2014). Consequently, we hypothesized that overexpression of NT5C1A in fibroblasts would be an opportunity to increase gemcitabine prodrug levels. Native gemcitabine would consequently be available for tumor cells. In a preliminary experiment, we were able to demonstrate decreased levels of intracellular dFdCTP in stably transfected PSCs that overexpress NT5C1A (Hessmann \& Patzak et al., 2018). Thus, upregulation of NT5C1A expression levels in stromal cells seems to be a suitable approach to reprogram the tumor stroma. Taken together, the data propose stromal reprogramming as a more appealing way to deal with ineffective responses to chemotherapeutic administration than unselective stromal depletion.

Additionally, it is important to understand how the expression of gemcitabine-metabolizing enzymes is regulated and which factors might affect protein expression. For instance, Frese et al. demonstrated that administration of nab-paclitaxel to KPC mice reduced CDA protein expression without changing its mRNA expression (Frese et al., 2012).

\subsubsection{Characteristics of CAFs}

In our study, we have used primary CAFs and immortalized PSCs as source of stromal cells. In general, quiescent PSCs are part of the normal pancreas and these cells become activated in response to tissue injury, thus, building the main source for CAFs in PDAC (Erkan, Adler, et al., 2012; Nielsen et al., 2016). In classical 2D cell culture, these cells develop the characteristic features of the activated state (Omary et al., 2007), like loss of vitamin $\mathrm{D}$ lipid droplets and acquisition of a myofibroblast-like phenotype with a spindle-shape morphology. Thus, standard 2D cell culture seems to activate PSCs. Furthermore, comparing the pharmacokinetic profiles of gemcitabine metabolites in these cells, we did not detect significant differences compared to CAF cells. Consequently, we 
considered our PSCs to be suitable for using them together with primary CAF cell lines to study the impact of stromal cells on gemcitabine resistance.

CAFs were described to be a heterogenous component of the tumor stroma. For instance, the myCAF and ICAF subgroups with differing marker expressions were identified by Öhlund et al. (2017). Consequently, it would be possible that these CAF subgroups also differ in their expression of drug metabolizing enzymes and consequently, contribute to gemcitabine drug scavenging to a different extent. Moreover, this study highlights that not only tumor heterogeneity is a central aspect in PDAC, but also the stromal heterogeneity. Another point to discuss is the significantly higher accumulation of active cytotoxic gemcitabine metabolites in CAFs and PSCs compared with tumor cells that we demonstrated in the present study. Using archived tissues from gemcitabine treated KPC mice and from vehicle treated mice, we determined if dFdCTP might affect viability of stromal cells itself. Interestingly, the number of apoptotic cells did not change following 9 days of gemcitabine treatment. Gemcitabine acts by interfering with DNA synthesis and consequently only harms proliferating cells. Thus, the very low proliferation rate of $2 \%$ to $5 \%$ of $\alpha$-SMA-positive cells gives a plausible explanation.

\subsubsection{Gemcitabine drug scavenging by further stromal components}

We have demonstrated drug scavenging in CAFs, which represent the predominant cell type in the pancreatic cancer stroma. This drug scavenging mechanism had significant impact on tumor cells when cultured in vitro. It still needs to be clarified if the amount of gemcitabine that is scavenged is enough to impair gemcitabine efficiency in patients. One could hypothesize that other cell types are not present in significant numbers or amounts to really impair drug availability for tumor cells. However, the concentration of scavenged gemcitabine could be significantly higher compared with fibroblasts and thus, could compensate for the differences in cell numbers. Therefore, it is definitely worth to investigate other cell types, like immune cells if these cells are able to intensify drug scavenging. Indeed, in vitro experiments from another study of our group revealed that tumor-associated macrophages (TAMs) also scavenge significant amounts of gemcitabine, which had an impact on tumor cell viability in vitro (Buchholz et al., 2018). Complementing our finding that TAMs directly metabolize gemcitabine, Weizman and colleagues had already demonstrated a paracrine crosstalk between tumor cells and TAMs, which resulted in reduced gemcitabine efficacy (Weizman et al., 2014). In their study, they have shown a 75 -fold upregulation of CDA expression on RNA level following treatment with gemcitabine and TAM conditioned medium. The authors confirmed their findings in vivo by macrophage depletion with clodronate in an orthotopic mouse model of pancreatic cancer (Weizman et 
al., 2014). Thus, tumor-stroma crosstalk might influence the expression of gemcitabinemetabolizing enzymes in general, which still requires further investigation. Additionally, acellular stromal components might directly or indirectly, through changes in the biophysical properties (e.g. hypoxia), alter the expression of relevant enzymes and consequently, modify the relevance of the described drug scavenging mechanism.

It is important to mention that intratumoral bacteria were recently demonstrated to be involved in the failure of gemcitabine therapy (Geller et al., 2017), which consequently supports our hypothesis that the tumor stroma exerts a biochemical treatment barrier. Geller et al. incidentally found co-cultures of primary human dermal fibroblasts and colorectal as well as pancreatic cancer cells to be more resistant towards gemcitabine treatment compared with single cultures (Geller et al., 2017). The authors associated this observation with the presence of a Mycoplasma hyorhinis infection of the fibroblasts and were able to reverse the resistance by treatment with antibiotics. Conditioned medium of the fibroblast cultures were analyzed by high-performance LC-MS/MS and high levels of $\mathrm{dFdU}$ were observed (Geller et al., 2017). The authors used several in vitro and in vivo assays to determine the reason on a molecular basis and found the long isoform of bacterial CDA to be responsible for the intensified gemcitabine inactivation. Importantly, bacteria were detected in 86 of 113 human PDAC samples and were only present in 3 of 20 normal pancreas controls (Geller et al., 2017). With their study, Geller et al. suggested to further explore the potential clinical benefit of co-administration of antibiotics with gemcitabine for patients with PDAC. In general, the microbiome is a topic of growing interest in the field of chemotherapeutic resistance mechanisms and it remains to be clarified if standard drugs like antibiotics might help to improve the treatment outcome for PDAC patients.

\subsection{NT5C1A in gemcitabine resistance in PDAC}

To the best of our knowledge, we have been the first group linking NT5C1A expression to chemotherapeutic resistance in PDAC (Hessmann \& Patzak et al., 2018). However, the idea that NT5C1A might be involved in mediating resistance towards gemcitabine is not new to the scientific community. For instance, Hunsucker et al. overexpressed human NT5C1A in HEK293 and in Jurkat cells. They observed a 22-fold increase of the $\mathrm{IC}_{50}$ value for $\mathrm{dFdC}$ in the HEK293 cells. However, the $\mathrm{IC}_{50}$ value did not change using Jurkat cells (Hunsucker et al., 2001). These findings propose cell type, organ, or disease specific impact of NT5C1A on gemcitabine inactivation. In pancreatic cancer, NT5C1A is a previously unrecognized enzyme in tumor cell-autonomous as well as non-cell-autonomous chemoresistance. Thus, intensive research on NT5C1A is required. 


\subsubsection{NT5C1A in inclusion body myositis and in malignancies}

Interestingly, relevant data on functional aspects of NT5C1A in cancer are still missing. The only studies available in the area of malignancies were published in 1993 and in 1999 (Dumontet et al., 1999; Kawasaki et al., 1993). Kawasaki et al. investigated the expression and activity levels of cytoplasmic 5'-nucleotidase (5'-NT) in cell lines that were derived from 2-chlorodeoxyadenosin-treated chronic lymphocytic leukemia and hairy cell leukemia patients. Nonresponders had higher levels of 5'-NT and furthermore, increased 5'-NT activity (Kawasaki et al., 1993). Dumontet et al. presented in vitro data linking acute myelogenous leukemia and NT5C1A overexpression with gemcitabine resistance. The authors observed a strong decrease in intracellular dFdCTP accumulation in chemotherapeutic resistant variants of the human erythroleukaemic cell line K562 following $2 \mathrm{~h}$ of gemcitabine treatment. They explained their findings with the overexpression of NT5C1A in all of their resistant cell lines (Dumontet et al., 1999).

Furthermore, NT5C1A is intensively discussed in inclusion body myositis (IBM) (Larman et al., 2013; Lilleker et al., 2017; Yeker et al., 2018), which is assumed to be autoimmunedriven and leads to progressive muscle degeneration (Dalakas, 2006; Greenberg, 2011; Needham \& Mastaglia, 2007). Larman et al. identified NT5C1A as an important muscle autoantigen, which is the target of circulating autoantibodies (Larman et al., 2013). Subgroup analysis of IBM patients presenting with anti-NT5C1A autoantibodies in their blood had a significantly reduced median survival of 17.6 years compared with 24.2 years in the antibody-negative subgroup (Lilleker et al., 2017). Furthermore, the presence of these autoantibodies against NT5C1A was associated with a more severe clinical phenotype in patients with juvenile myositis. For instance, these patients presented with more severe pulmonary symptoms and had a higher rate of hospitalizations (Yeker et al., 2018). Therefore, NT5C1A autoantibody status was suggested as biomarker for patient stratification (Lilleker et al., 2017).

Altogether, the literature provides first evidence that NT5C1A might play a role in drug resistance and might have the potential to be predictive for gemcitabine therapy responses.

\subsubsection{Influence of stromal NT5C1A expression on non-cell-autonomous gemcitabine resistance in PDAC}

In the first part of our study, we have identified NT5C1A as an interesting target in gemcitabine resistance (Hessmann \& Patzak et al., 2018). The analysis of two independent TMAs revealed that 50-90\% of the tumor tissues of resected PDAC patients were devoid of immunoreactivity for NT5C1A in the stromal compartment, thus, gemcitabine drug accumulation might be enhanced in the stromal cells of these patients. Therefore, the 
absence of stromal NT5C1A expression might mediate non-cell-autonomous resistance to gemcitabine. We proposed NT5C1A as a suitable target for stromal reprogramming by hypothesizing that NT5C1A re-expression in stromal cells might reduce intracellular dFdCTP concentrations, and in turn might lead to increased extracellular concentrations of $\mathrm{dFdC}$. Consequently, stromal re-expression could increase the available amount of gemcitabine for tumor cells and enhance chemosensitivity in pancreatic cancer. Examining NT5C1A overexpressing PSCs, we were able to demonstrate significantly reduced intracellular levels of dFdCTP (Hessmann \& Patzak et al., 2018), significantly increased resistance of these cells towards gemcitabine, and reduced tumor cell viability when treated with conditioned media of gemcitabine treated NT5C1A overexpressing PSCs. However, in vivo data regarding gemcitabine metabolism are still required for stromal NT5C1A.

\subsubsection{NT5C1A expression in the epithelial compartment of PDAC is not a prognostic factor}

The impact of tumoral NT5C1A expression on gemcitabine efficacy and PDAC patient survival has not been defined yet. Therefore, we aimed to complement our study by focusing on tumor cell-autonomous resistance by exploration of the detailed function of NT5C1A in the epithelial compartment of PDAC. Given its role in gemcitabine metabolism, we hypothesized that NT5C1A has potential as predictive biomarker for PDAC patient stratification for improved treatment regimens. Using TMAs, we could confirm that there is no prognostic significance on overall survival associated with NT5C1A expression in the

epithelial compartment of resected pancreatic cancer patients. Unexpectedly, a prognostic role for the gemcitabine transporter hENT1 was demonstrated by Kim et al. in surgically resected PDAC patients, based on mRNA expression data (Kim et al., 2011). One third of the patients did not receive adjuvant therapy and the other patients received various kinds of adjuvant treatment, mainly in combination with radiation (Kim et al., 2011). However, and in contrast to the data by Kim et al., Greenhalf et al. did not report a prognostic effect of hENT1 expression levels on survival of PDAC patients in the ESPAC-1 and ESPAC-3(v2)randomized trials, who underwent curative tumor resection (Greenhalf et al., 2014). In line with our experimental design, the results by Greenhalf et al. are also based on protein expression data obtained from IHC stainings (Greenhalf et al., 2014). Furthermore, mean DCTD and RRM1 protein expression levels were also not associated with overall survival of the observation groups of postoperative PDAC patients in the ESPAC-1 and ESPAC-3(v1) trials (Elander et al., 2018). Additionally, Thomas et al., Logan-Collins et al., and Tactacan et al. presented data on RON (recepteur d'origine nantais, also termed macrophage stimulating 1 receptor), a receptor tyrosine kinase that impacts on cellular 
motility and cancer cell survival upon ligand binding, which was reported to be another relevant factor in mediating gemcitabine resistance in pancreatic cancer (Logan-Collins et al., 2010; Tactacan et al., 2012; Thomas et al., 2007). Using KC mice, increasing expression of RON in the epithelial compartment during pancreatic cancer progression and metastasis was described, and blocking or downregulation of RON in pancreatic cancer cells and in a xenograft mouse model resulted in sensitization towards gemcitabine treatment (Logan-Collins et al., 2010; Thomas et al., 2007). However, comparable to our findings, RON was not associated with prognosis in resected PDAC patients (Tactacan et al., 2012).

\subsubsection{Recombinant overexpression of NT5C1A in pancreatic cancer cells}

Unexpectedly, dramatically reduced NT5C1A expression was observed in pancreatic cancer cells in 2D cell culture. We had previously shown robust in vivo expression of NT5C1A in KPC tumors (Hessmann \& Patzak et al., 2018), from which primary tumor cells were generated. Consequently, we speculate that signaling cues from the TME might be involved in the regulation of NT5C1A expression. These signals are absent during 2D cell culture. The multifaceted composition and dynamic changes of the tumor stroma in PDAC indicate a complex interplay with pancreatic cancer cells and therefore, could explain our observation. The lack of NT5C1A might explain why these cells respond well to gemcitabine treatment in vitro, but gemcitabine does not show notable anti-tumor effects in GEMMs of pancreatic cancer and in PDAC patients with strong desmoplasia.

A possibility to further investigate this hypothesis would be the use of 3D cell culture based on Matrigel, which is a common growth support matrix used in 3D cultures (Boj et al., 2016). Recent studies suggest cancer cell organoids or patient derived organoids as promising tools for in-depth molecular tumor characterization by transcriptomic and proteomic analyses. Furthermore, therapeutic profiling can be used in these organoids to identify targets and biomarkers for tailored therapy approaches (Boj et al., 2016; Tiriac et al., 2018). In further studies, this technique could be helpful in identifying the factors leading to differential expression of $\mathrm{NT5C1A}$ in vitro and in vivo and consequently, this knowledge could then be employed in patient stratification for improved treatment. Moreover, Hou et al. demonstrated differential responses to gemcitabine treatment between 2D cell cultures and 3D spheroid cultures of primary resected human pancreatic cancer cells as well as of the established cell line PANC1 (Hou et al., 2018).

A study by Dangi-Garimella et al. demonstrated an active involvement of the 3D microenvironment in pancreatic cancer cell proliferation following cell exposure to gemcitabine (Dangi-Garimella et al., 2011). The authors observed significant differences in 
proliferation following $24 \mathrm{~h}$ treatment with gemcitabine, when cells were grown as monolayers compared with cells grown in a 3D collagen I matrix (Dangi-Garimella et al., 2011). This study supports our hypothesis that the pancreatic cancer stroma might be involved in the regulation of NT5C1A expression.

\subsubsection{NT5C1A as predictive marker for gemcitabine therapy response}

Patient stratification and personalized treatment approaches are urgently required to achieve better treatment responses in pancreatic cancer patients. Accordingly, precision oncology is gaining importance. Remarkable progress was already made within the last years on the molecular understanding of PDAC and in patient stratification (Bailey et al., 2016; Collisson et al., 2011; Moffitt et al., 2015), however, the therapeutic strategies did not improve considerably. An example for encouraging results in patient stratification is the increasing evidence that patients with $B R C A$ mutations, the most common genetic alterations of familial pancreatic cancer, respond better to platinum-based agents and also benefit from poly-ADP-ribose polymerase (PARP) inhibitors (Kowalewski et al., 2018).

Beside this progress, the urgent need for novel biomarkers, either diagnostic, prognostic, or predictive, is demonstrated by the overwhelming amount of studies on this topic. In 2012 , Fong et al. reported that the research community studied already $10 \%$ of all coding genes in the human genome for their potential as pancreatic cancer biomarkers (Fong \& Winter, 2012). For diagnostic purposes, serum carbohydrate antigen 19-9 (CA-19-9) is approved by the Food and Drug Administration (FDA) as blood test for PDAC, as serum levels of CA-19-9 were observed to be elevated in patients with pancreatic cancer (Fong \& Winter, 2012). However, certain limitations such as lack of sensitivity and specificity do not allow CA-19-9 to be routinely used for patient screening. As a result, the restricted use in high-risk patients or for the diagnosis of recurrence following pancreatic tumor resection have been discussed as well, but was still not predictive enough for routine use (Fong \& Winter, 2012). Yet, established biomarkers for the selection of the most effective therapy for pancreatic cancer patients do not exist so far in the clinical routine.

In the present study, we aimed to identify the potential of NT5C1A as novel predictive biomarker for gemcitabine treatment response in PDAC. Several studies have suggested proteins that play important roles in gemcitabine transport and metabolism to be involved in gemcitabine resistance. These proteins might be suitable as predictive biomarkers for the selection of patients for gemcitabine therapy. For instance, an association of high hENT1 and dCK protein levels have been observed with improved survival times for PDAC patients who received adjuvant gemcitabine (Bird et al., 2017; Greenhalf et al., 2014; Maréchal et al., 2012). On the contrary, DCTD and RRM1 were not associated with PDAC patient 
outcome following gemcitabine therapy (Elander et al., 2018; Maréchal et al., 2012). Moreover, inactivating mutations of $\mathrm{dCK}$ were reported in vitro in gemcitabine-resistant cancer cell lines, including pancreatic cancer cell lines, compared to the gemcitabinesensitive parental cell lines (Saiki et al., 2012).

In the present study, overexpression of the gemcitabine inactivating enzyme NT5C1A was demonstrated to reduce the response to gemcitabine in vitro and in vivo. Using LC-MS/MS analysis, the direct involvement of $\mathrm{NT5C} 1 \mathrm{~A}$ in the metabolization of gemcitabine in pancreatic cancer cell lines could be determined. Furthermore, reduced apoptosis levels were observed in these cells. The mechanism of NT5C1A-mediated gemcitabine resistance is summarized in Figure 41.

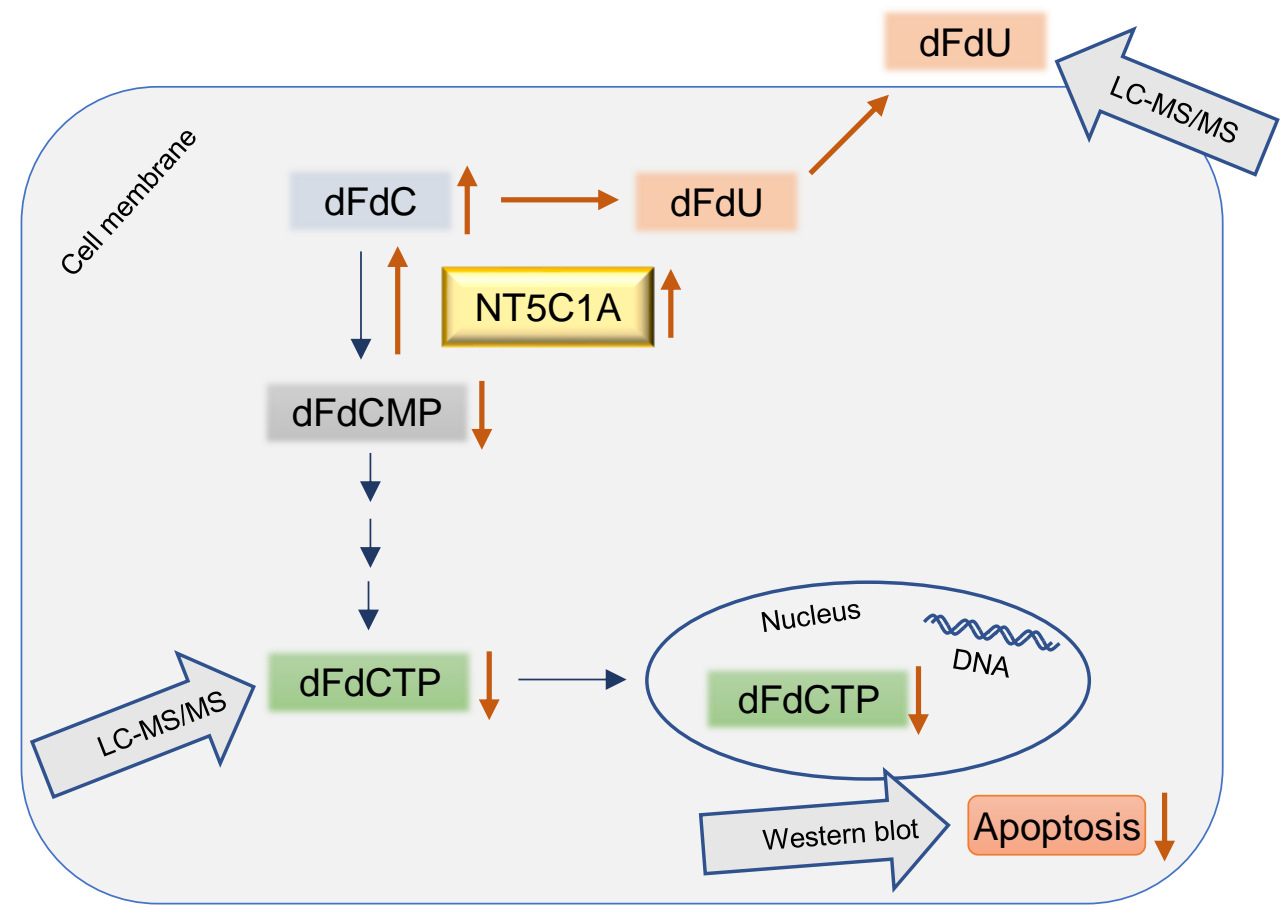

Figure 41: Mechanism of NT5C1A-mediated gemcitabine resistance. NT5C1A activity enhances the dephosphorylation of $\mathrm{dFdC}$-monophosphate to native gemcitabine $(\mathrm{dFdC})$, which can then be inactivated to dFdU. We observed increased levels of dFdU in the serum of mice with NT5C1Aoverexpressing tumors. In consequence, the formation of cytotoxic triphosphate metabolites (dFdCTP) was reduced in cells overexpressing NT5C1A, as shown by LC-MS/MS analysis. Protein levels of $\mathrm{CC} 3$ were reduced in cells with strong expression of NT5C1A. Thus, gemcitabine response was decreased in the overexpressing cell lines.

In our patient dataset with more than 400 samples, we showed NT5C1A overexpression in the majority of tumor cells. Additionally, in most cases, stromal cells lacked NT5C1A expression. Regarding the in vitro data of our PSCs, reduced levels of dFdCTP were observed upon NT5C1A re-expression, as measured by LC-MS/MS analysis (Hessmann \& Patzak et al., 2018). Moreover, the re-expression of NT5C1A in PSCs improved the sensitivity of pancreatic cancer cells towards gemcitabine treatment. 
This finding supports our hypothesis that high NT5C1A levels in pancreatic fibroblasts and low expression in pancreatic cancer cells, as demonstrated in vitro under 2D cell culture conditions, promote chemosensitivity to gemcitabine. Besides, the impact of NT5C1A on chemoresistance does not seem to be dependent on tumor stages, as strong epithelial NT5C1A expression was observed in invasive tumors, but also in PanIN lesions. Tumor weights were significantly increased in samples from mice that were orthotopically transplanted with NT5C1A overexpressing KPC cells and subsequently treated with gemcitabine for 14 days. This supports our hypothesis that NT5C1A might have the potential to serve as a predictive biomarker for gemcitabine therapy response. Moreover, increased levels of the inactive gemcitabine metabolite $\mathrm{dFdU}$ were found in the serum of these mice. This result seems to reflect the increased dephosphorylation of dFdUMP to $\mathrm{dFdC}$, which in turn might be deaminated to dFdU by CDA. Interestingly, Hodge et al. observed dFdU to be a substrate of hENT and hCNT transporters in HeLa cells, thus, suggested dFdU as a competitive inhibitor of gemcitabine transporters (Hodge et al., 2011). Though, the effect on intracellular gemcitabine accumulation was contradictory, as gemcitabine accumulation increased following longer incubation with $\mathrm{dFdU}$, which again suggests a complex interplay of gemcitabine transport and metabolism (Hodge et al., 2011). The hypothesis that $\mathrm{dFdU}$ might compete with $\mathrm{dFdC}$ for their transport into cancer cells is of interest for our study, as this would even increase the resistance of pancreatic cancer cells, which express high levels of NT5C1A, towards gemcitabine. Nevertheless, organ and disease specific effects, as demonstrated by Hunsucker et al. (2001), need to be investigated before conclusions can be made.

Furthermore, the presence and measurement of NT5C1A autoantibodies in patient plasma and serum samples have been described in IBM and juvenile myositis and were associated with a more severe disease phenotype and worse prognosis (Larman et al., 2013; Lilleker et al., 2017; Yeker et al., 2018). Therefore, an exciting approach to study the involvement of $\mathrm{NT5C1A}$ in chemotherapeutic resistance in PDAC would be the non-invasive determination of NT5C1A autoantibodies in PDAC patient plasma samples. It would be interesting to examine whether these autoantibodies are also present in PDAC patients and if so, whether the antibody status would correlate with tumoral NT5C1A expression and would be predictive for gemcitabine treatment response.

Altogether, it remains to be elucidated whether predictive effects for NT5C1A can be seen in PDAC patients following treatment with gemcitabine. Our TMAs were obtained from heterogenous cohorts of PDAC patients in regards to whether patients received adjuvant chemotherapy or not. Consequently, these clinical data were too limited to analyze potential predictive effects. For example, the samples from the ESPAC clinical trials would be a suitable option to further address this issue. 
Moreover, it needs to be seen whether NT5C1A alone would be suitable as predictive biomarker for gemcitabine treatment in PDAC patients. Maybe a combination with hENT1 expression levels might even be more beneficial to predict therapeutic response to gemcitabine. Further studies with PDAC patient samples are necessary to finally determine the impact of NT5C1A as potential predictive biomarker for gemcitabine-based treatment approaches in PDAC.

\subsubsection{Differential expression of NT5C1A fuels chemotherapeutic resistance}

Importantly, we have demonstrated $\mathrm{NT5C1A}$ as mediator of gemcitabine resistance resulting from strong epithelial expression of NT5C1A and low expression of stromal NT5C1A, which was detected in a large subgroup of post-operative PDAC patients. Each factor itself contributes to gemcitabine resistance in pancreatic cancer. Accordingly, the combination of both is assumed to exert the least response to gemcitabine treatment. Provided that this hypothesis is confirmed in patient samples, the best possibility to enhance gemcitabine efficacy for PDAC patients would be to increase NT5C1A expression in stromal cells and to decrease its expression in neoplastic cells (Figure 42). Even if selective reprogramming of stromal or epithelial NT5C1A expression would not be feasible, the potential for $\mathrm{NT5C1A}$ to become a predictive biomarker for personalized treatment approaches in pancreatic cancer would still be given.

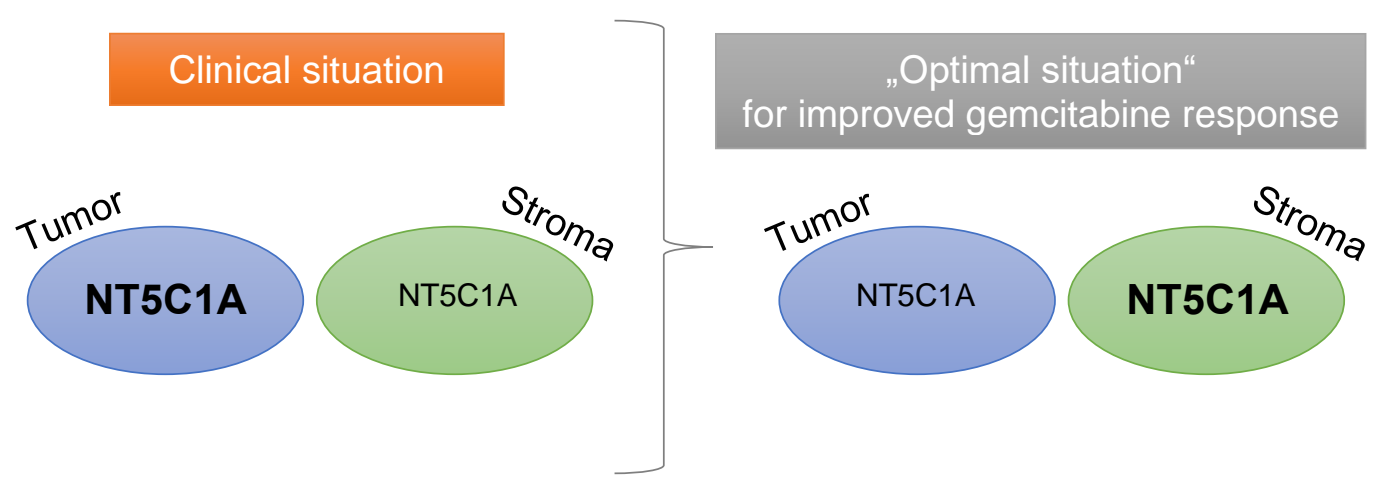

Figure 42: Schematic illustration of NT5C1A expression in pancreatic cancer. In the clinical situation, NT5C1A was shown to be strongly expressed in neoplastic cells of post-operative PDAC patients. Hardly any expression was demonstrated in the tumor stroma (left panel). According to our findings, the optimal situation for effective chemotherapy with gemcitabine would be low expression in the epithelial compartment and strong expression in stromal cells (right panel). 


\subsubsection{NT5C1A regulation in pancreatic cancer}

Taken our findings together, we have proposed NT5C1A as a novel mediator of cell-autonomous and non-cell-autonomous chemotherapeutic resistance towards gemcitabine in pancreatic cancer. As suggested, tumoral and stromal NT5C1A expression could possibly be involved in the decision whether defined patient subgroups would benefit from gemcitabine therapy or not. In case of stroma rich tumors, another chemotherapeutic agent might be more beneficial than gemcitabine due to fibroblast drug scavenging.

Aiming at further clinical benefit from the present study, it would be of utmost importance to unravel how NT5C1A is regulated in pancreatic cancer. The prerequisite that NT5C1A could become a therapeutic target would require different regulatory mechanisms of NT5C1A expression between the tumor stroma and the epithelial compartment. Possible mechanisms that might affect NT5C1A expression or activity in pancreatic cancer are epigenetic mechanisms, signaling cues from immune cells of the tumor stroma, microRNAs, metabolic changes, post-translational modifications, and various other factors. In reference to this, altered enzyme activity was demonstrated by Saliba et al. by investigation of genetic variations of the NT5C1A gene in HEK293 cells (Saliba et al., 2016). The NT5C1A variants were associated with differing responses to the standard nucleoside analogs gemcitabine, 5-FU, and cladribine (Saliba et al., 2016). Related to this study, enhanced nucleotidase activity was demonstrated in cells expressing NT5C2 mutant proteins, another member of the cytosolic 5'-nucleotidases, in the context of acute lymphoblastic leukemia (ALL), which resulted in increased resistance to standard chemotherapeutics for ALL treatment in vitro (Tzoneva et al., 2013).

Firstly, the involvement of epigenetic mechanisms in the regulation of NT5C1A expression should be discussed. Epigenetic changes in response to stromal cues might alter NT5C1A expression levels in tumor cells. As shown by Sherman et al., the soluble factors of fibroblasts are able to induce such changes in pancreatic cancer cells by increasing H3K9 and H3K27 histone acetylation (Sherman et al., 2017). It remains to be determined whether the resulting activation of promoters and enhancers alter NT5C1A expression and could consequently serve as important therapeutic targets. For instance, we found one study where NT5C1A was described to be part of a significantly downregulated gene set in histone deacetylase 7 (HDAC7)-overexpressing pancreatic beta cells (Daneshpajooh et al., 2017). Thus, we hypothesize that transcriptional repression through overexpression of HDACs in CAFs could lead to downregulation of NT5C1A in these cells. Consequently, treatment with HDAC-inhibitors might be able to restore the expression of NT5C1A in pancreatic fibroblasts. 
Secondly, metabolic pathways might be involved in the regulation of NT5C1A expression and activity. For instance, NT5C1A expression could be altered by AMP-activated protein kinase (AMPK). NT5C1A prefers AMP as its substrate, the latter in turn allosterically stimulates AMPK activity (Hardie, 2014; Hunsucker et al., 2005). Kulkarni et al. have shown that gene silencing of NT5C1A in mouse skeletal muscle increases AMPK phosphorylation by $60 \%$ (Kulkarni et al., 2011). Furthermore, AMPK can be activated through metformin, which is a standard agent for the treatment of diabetes mellitus type 2 (Gong et al., 2014). We speculate that a negative feedback loop could exist, which might result in reduced NT5C1A activity when AMPK activity is high. In this case, treatment with metformin could be beneficial to reduce cell-autonomous gemcitabine resistance.

Taken together, the knowledge about the regulation of NT5C1A expression and activity in pancreatic cancer is very limited and intensive research is required to determine the potential of NT5C1A to become a therapeutic target in PDAC treatment.

\subsubsection{Specificity of NT5C1A-driven chemoresistance towards gemcitabine}

A question raised by the previous data was whether the contribution of NT5C1A to chemotherapeutic resistance in PDAC would be specific for gemcitabine. To address this point, we used pharmacokinetic and pharmacodynamics approaches. First, we treated CAFs and PSCs with 5-FU and, using LC-MS/MS analysis, did not observe notable differences in intracellular 5-FU concentrations (Hessmann \& Patzak et al., 2018).

In regards to tumor cells, we treated murine KPC and human L3.6pl cells with paclitaxel, a standard chemotherapeutic drug that acts independently of intracellular phosphorylation. In contrast to gemcitabine, NT5C1A overexpressing pancreatic cancer cells were still sensitive to paclitaxel treatment. Consequently, drugs other than gemcitabine might still be suitable to induce relevant responses in pancreatic tumors with strong epithelial or low stromal NT5C1A expression, respectively. Therefore, NT5C1A might be suitable for patient stratification to different treatment options.

Taken together, the contribution of NT5C1A on gemcitabine resistance in pancreatic cancer does not extend to other classes of chemotherapeutic agents and seems to be specific for gemcitabine. Therefore, according to the in vitro and in vivo data, patients with high NT5C1A expression might not sufficiently benefit from gemcitabine treatment compared to the small percentage of patients with low or absent epithelial expression of NT5C1A. 


\subsection{Concluding remarks}

Despite intensive research and a much better understanding of the underlying molecular characteristics of PDAC, the 5-year relative survival rates are still staying below $10 \%$ (Siegel et al., 2018). The response rates towards available treatments are extremely poor and limited progress has been made in the successful development of novel therapeutic strategies over the past decades (Rossi et al., 2014).

In the present study, we have deepened the understanding of stroma-derived gemcitabine resistance mechanisms. Furthermore, a detailed characterization of NT5C1A and its role as mediator of cell-autonomous and non-cell-autonomous gemcitabine resistance in PDAC was performed.

The most important findings of the study are the following:

- The hypothesis of a biophysical drug delivery barrier in PDAC was challenged by demonstrating that the highest levels of gemcitabine accumulate in primary KPC tumors compared with liver metastases and well-perfused liver tissue

- CAFs actively metabolize gemcitabine and may act as drug scavengers

- Differential expression of gemcitabine inactivating enzymes in stromal and epithelial cells contribute to gemcitabine accumulation in the tumor stroma

- Identification of NT5C1A as important mediator of gemcitabine resistance in PDAC and potential predictive biomarker for treatment response

- NT5C1A is differentially expressed in the stromal and epithelial compartments of post-operative PDAC patients with strong expression in epithelial cells and low expression levels in the stroma

- Low stromal expression of NT5C1A enhances gemcitabine drug scavenging in vitro

- NT5C1A re-expression in PSCs enhanced gemcitabine availability for tumor cells in vitro by reducing gemcitabine accumulation in transfected PSCs

- Strong expression of NT5C1A in pancreatic cancer cells reduced intracellular dFdCTP concentrations, reduced apoptosis levels, and increased the resistance of these cells towards gemcitabine treatment in vitro

- In comparison to vector control cells, NT5C1A overexpression in murine KPC cells increased tumor weights of orthotopically transplanted C57BL/6-J mice following gemcitabine treatment 
- Response rates to paclitaxel treatment were not affected in NT5C1A overexpressing pancreatic cancer cells, suggesting specificity to gemcitabine

Taken the findings together, altered drug metabolism and not biophysical drug delivery to pancreatic tumors seems to determine the response to gemcitabine. Particularly, NT5C1A was demonstrated to play important roles as mediator of cell-autonomous and noncell-autonomous chemoresistance in PDAC. Consequently, NT5C1A might serve as predictive biomarker for the development of stratified treatment approaches for PDAC patients. Assuming that NT5C1A expression would be controlled by epigenetic mechanisms, NT5C1A might even be suitable as therapeutic target for the development of novel therapeutic strategies to treat PDAC patients more effectively. 


\section{References}

Adamska, A., Domenichini, A., \& Falasca, M. (2017). Pancreatic Ductal Adenocarcinoma: Current and Evolving therapies. International Journal of Molecular Sciences, 18(7), 1338. https://doi.org/10.3390/ijms18071338

Aiello, N. M., Bajor, D. L., Norgard, R. J., Sahmoud, A., Bhagwat, N., Pham, M. N., Cornish, T. C., lacobuzio-Donahue, C. A., Vonderheide, R. H., \& Stanger, B. Z. (2016). Metastatic progression is associated with dynamic changes in the local $\begin{array}{llll}\text { microenvironment. } & \text { Nature } & \text { Communications, } & 7,\end{array}$ https://doi.org/10.1038/ncomms12819

Almoguera, C., Shibata, D., Forrester, K., Martin, J., Arnheim, N., \& Perucho, M. (1988). Most human carcinomas of the exocrine pancreas contain mutant c-K-ras genes. Cell, 53(4), 549-554. https://doi.org/10.1016/0092-8674(88)90571-5

Alvarellos, M. L., Lamba, J., Sangkuhl, K., Thorn, C. F., Wang, L., Klein, D. J., Altman, R. B., \& Klein, T. E. (2014). PharmGKB summary: gemcitabine pathway. Pharmacogenetics and Genomics, 24(11), 564-574. https://doi.org/10.1097/FPC.0000000000000086

Amrutkar, M., \& Gladhaug, I. P. (2017). Pancreatic Cancer Chemoresistance to Gemcitabine. Cancers, 9(11), 157. https://doi.org/10.3390/cancers9110157

Apte, M. V., Park, S., Phillips, P. A., Santucci, N., Goldstein, D., Kumar, R. K., Ramm, G. A., Buchler, M., Friess, H., ... Wilson, J. S. (2004). Desmoplastic Reaction in Pancreatic Cancer: Role of Pancreatic Stellate Cells. Pancreas, 29(3), 179-187.

Assifi, M. M., Lu, X., Eibl, G., Reber, H. A., Li, G., \& Hines, O. J. (2011). Neoadjuvant Therapy in Pancreatic Adenocarcinoma: A Meta-Analysis of Phase II Trials. Surgery, 150(3), 466-473. https://doi.org/10.1016/j.surg.2011.07.006

Bachem, M. G., Schünemann, M., Ramadani, M., Siech, M., Beger, H., Buck, A., Zhou, S., Schmid-Kotsas, A., \& Adler, G. (2005). Pancreatic Carcinoma Cells Induce Fibrosis by Stimulating Proliferation and Matrix Synthesis of Stellate Cells. Gastroenterology, 128(4), 907-921. https://doi.org/10.1053/j.gastro.2004.12.036 
Bailey, P., Chang, D. K., Nones, K., Johns, A. L., Patch, A.-M., Gingras, M.-C., Miller, D. K., Christ, A. N., Bruxner, T. J. C., ... Grimmond, S. M. (2016). Genomic analyses identify molecular subtypes of pancreatic cancer. Nature, 531(7592), 47-52. https://doi.org/10.1038/nature16965

Bapiro, T. E., Frese, K. K., Courtin, A., Bramhall, J. L., Madhu, B., Cook, N., Neesse, A., Griffiths, J. R., Tuveson, D. A., ... Richards, F. M. (2014). Gemcitabine diphosphate choline is a major metabolite linked to the Kennedy pathway in pancreatic cancer models in vivo. British Journal of Cancer, 111, 318-325. https://doi.org/10.1038/bjc.2014.288

Bapiro, T. E., Richards, F. M., \& Jodrell, D. I. (2016). Understanding the Complexity of Porous Graphitic Carbon (PGC) Chromatography: Modulation of Mobile-Stationary Phase Interactions Overcomes Loss of Retention and Reduces Variability. Analytical Chemistry, 88(12), 6190-6194. https://doi.org/10.1021/acs.analchem.6b01167

Batabyal, P., Vander Hoorn, S., Christophi, C., \& Nikfarjam, M. (2014). Association of Diabetes Mellitus and Pancreatic Adenocarcinoma: A Meta-Analysis of 88 Studies. Annals of Surgical Oncology, 21(7), 2453-2462. https://doi.org/10.1245/s10434-0143625-6

Becker, A. E., Hernandez, Y. G., Frucht, H., \& Lucas, A. L. (2014). Pancreatic ductal adenocarcinoma: Risk factors, screening, and early detection. World Journal of Gastroenterology, 20(32), 11182-11198. https://doi.org/10.3748/wjg.v20.i32.11182

Bianchi, V., \& Spychala, J. (2003). Mammalian 5'-Nucleotidases. The Journal of Biological Chemistry, 278(47), 46195-46198. https://doi.org/10.1074/jbc.R300032200

BiolnfoWeb.com. (n.d.). Preparation of 50X TAE electrophoresis buffer. Retrieved January 22, 2016, from http://bioinfoweb.com/Protocol-preparation-of-50X-TAEelectrophoresis-buffer.htm

Bird, N. T. E., Elmasry, M., Jones, R., Psarelli, E., Dodd, J., Malik, H., Greenhalf, W., Kitteringham, N., Ghaneh, P., ... Palmer, D. (2017). Immunohistochemical hENT1 expression as a prognostic biomarker in patients with resected pancreatic ductal adenocarcinoma undergoing adjuvant gemcitabine-based chemotherapy. The British Journal of Surgery, 104(4), 328-336. https://doi.org/10.1002/bjs.10482 
Boj, S. F., Hwang, C. II, Baker, L. A., Engle, D. D., Tuveson, D. A., \& Clevers, H. (2016). Model organoids provide new research opportunities for ductal pancreatic cancer. Molecular and Cellular Oncology, 3(1), e1014757. https://doi.org/10.1080/23723556.2015.1014757

Bosetti, C., Lucenteforte, E., Silvermann, D. T., Petersen, G., Bracci, P. M., Ji, B. T., Negri, E., Li, D., Risch, H. A., ... La Vecchia, C. (2012). Cigarette smoking and pancreatic cancer: an analysis from the International Pancreatic Cancer Case-Control Consortium (Panc4). Annals of Oncology, 23(7), 1880-1888. https://doi.org/10.1093/annonc/mdr541

Bradford, M. M. (1976). A Rapid and Sensitive Method for the Quantitation of Microgram Quantities of Protein Utilizing the Principle of Protein-Dye Binding. Analytical Biochemistry, 72, 248-254.

Brat, D. J., Lillemoe, K. D., Yeo, C. J., Warfield, P. B., \& Hruban, R. H. (1998). Progression of Pancreatic Intraductal Neoplasias to Infiltrating Adenocarcinoma of the Pancreas. The American Journal of Surgical Pathology, 22(2), 163-169. https://doi.org/10.1097/00000478-199802000-00003

Bruns, C. J., Harbison, M. T., Kuniyasu, H., Eue, I., \& Fidler, I. J. (1999). In vivo Selection and Characterization of Metastatic Variants from Human Pancreatic Adenocarcinoma by Using Orthotopic Implantation in Nude Mice. Neoplasia, 1(1), 50-62. https://doi.org/10.1038/sj.neo.7900005

Buchholz, S. M., Goetze, R., Patzak, M., Richards, F., Jodrell, D., Griesmann, H., Michl, P., Buchholz, M., Ellenrieder, V., \& Neesse, A. (2018). Tumor associated macrophages (TAMs) scavenge gemcitabine but not 5-FU and paclitaxel in pancreatic cancer. Pancreatology, 18(4S), S148-S149. https://doi.org/10.1016/j.pan.2018.05.399

Burris, H. A. I., Moore, J. A., Andersen, J., Green, M. R., Rothenberg, M. L., Modiano, M. R., Cripps, M. C., Portenoy, R. K., Storniolo, A. M., ... Von Hoff, D. D. (1997). Improvements in Survival and Clinical Benefit With Gemcitabine as First-Line Therapy for Patients With Advanced Pancreas Cancer: A Randomized Trial. Journal of Clinical Oncology, 15(6), 2403-2413.

Carr, R. M., \& Fernandez-Zapico, M. E. (2016). Pancreatic cancer microenvironment, to target or not to target? EMBO Molecular Medicine, 8(2), 80-82. https://doi.org/10.15252/emmm.201505948 
Carrera, S., Sancho, A., Azkona, E., Azkuna, J., \& Lopez-Vivanco, G. (2017). Hereditary pancreatic cancer: related syndromes and clinical perspective. Hereditary Cancer in Clinical Practice, 15, 1-9. https://doi.org/10.1186/s13053-017-0069-6

Catenacci, D. V. T., Junttila, M. R., Karrison, T., Bahary, N., Horiba, M. N., Nattam, S. R., Marsh, R., Wallace, J., Kozloff, M., ... Kindler, H. L. (2015). Randomized Phase Ib/ll Study of Gemcitabine Plus Placebo or Vismodegib, a Hedgehog Pathway Inhibitor, in Patients With Metastatic Pancreatic Cancer. Journal of Clinical Oncology, 33(36), 4284-4292. https://doi.org/10.1200/JCO.2015.62.8719

Chand, S., O'Hayer, K., Blanco, F. F., Winter, J. M., \& Brody, J. R. (2016). The Landscape of Pancreatic Cancer Therapeutic Resistance Mechanisms. International Journal of Biological Sciences, 12(3), 273-282. https://doi.org/10.7150/ijbs.14951

Chari, S. T., Kelly, K., Hollingsworth, M. A., Thayer, S. P., Ahlquist, D. A., Andersen, D. K., Batra, S. K., Brentnall, T. A., Canto, M., ... Wong, D. (2015). Early Detection of Sporadic Pancreatic Cancer: Summative Review. Pancreas, 44(5), 693-712. https://doi.org/10.1097/MPA.0000000000000368

Chauhan, V. P., Martin, J. D., Liu, H., Lacorre, D. A., Jain, S. R., Kozin, S. V., Stylianopoulos, T., Mousa, A. S., Han, X., ... Jain, R. K. (2013). Angiotensin inhibition enhances drug delivery and potentiates chemotherapy by decompressing tumour blood vessels. Nature Communications, 4, 2516. https://doi.org/10.1038/ncomms3516

Cid-Arregui, A., \& Juarez, V. (2015). Perspectives in the treatment of pancreatic adenocarcinoma. World Journal of Gastroenterology, 21(31), 9297-9316. https://doi.org/10.3748/wjg.v21.i31.9297

Collisson, E. A., Sadanandam, A., Olson, P., Gibb, W. J., Truitt, M., Gu, S., Cooc, J., Weinkle, J., Kim, G. E., ... Gray, J. W. (2011). Subtypes of pancreatic ductal adenocarcinoma and their differing responses to therapy. Nature Medicine, 17(4), 500-503. https://doi.org/10.1038/nm.2344

Conroy, T., Desseigne, F., Ychou, M., Bouche, O., Guimbaud, R., Becouarn, Y., Adenis, A., Raoul, J. L., Gourgou-Bourgade, S., ... Ducreux, M. (2011). FOLFIRINOX versus Gemcitabine for Metastatic Pancreatic Cancer. The New England Journal of Medicine, 364(19), 1817-1825. https://doi.org/10.1056/NEJMoa1011923 
Cook, N., Frese, K. K., Bapiro, T. E., Jacobetz, M. A., Gopinathan, A., Miller, J. L., Rao, S. S., Demuth, T., Howat, W. J., ... Tuveson, D. A. (2012). Gamma secretase inhibition promotes hypoxic necrosis in mouse pancreatic ductal adenocarcinoma. The Journal of Experimental Medicine, 209(3), 437-444. https://doi.org/10.1084/jem.20111923

Dalakas, M. C. (2006). Sporadic inclusion body myositis - diagnosis, pathogenesis and therapeutic strategies. Nature Clinical Practice Neurology, 2(8), 437-447. https://doi.org/10.1038/ncpneuro0261

Daneshpajooh, M., Bacos, K., Bysani, M., Bagge, A., Ottosson Laakso, E., Vikman, P., Eliasson, L., Mulder, H., \& Ling, C. (2017). HDAC7 is overexpressed in human diabetic islets and impairs insulin secretion in rat islets and clonal beta cells. Diabetologia, 60(1), 116-125. https://doi.org/10.1007/s00125-016-4113-2

Dangi-Garimella, S., Krantz, S. B., Barron, M. R., Shields, M. A., Heiferman, M. J., Grippo, P. J., Bentrem, D. J., \& Munshi, H. G. (2011). Three-Dimensional Collagen I Promotes Gemcitabine Resistance in Pancreatic Cancer through MT1-MMP-Mediated Expression of HMGA2. Cancer Research, 71(3), 1019-1028. https://doi.org/10.1158/0008-5472.CAN-10-1855

De Sousa Cavalcante, L., \& Monteiro, G. (2014). Gemcitabine: Metabolism and molecular mechanisms of action, sensitivity and chemoresistance in pancreatic cancer. European Journal of Pharmacology, 741, 8-16. https://doi.org/10.1016/j.ejphar.2014.07.041

Drewes, A. M., Campbell, C. M., Ceyhan, G. O., Delhaye, M., Garg, P. K., van Goor, H., Laquente, B., Morlion, B., Olesen, S. S., ... Talukdar, R. (2018). Pain in pancreatic ductal adenocarcinoma: A multidisciplinary, International guideline for optimized management. Pancreatology, 18(4), 446-457. https://doi.org/10.1016/j.pan.2018.04.008

Duell, E. J. (2012). Epidemiology and Potential Mechanisms of Tobacco Smoking and Heavy Alcohol Consumption in Pancreatic Cancer. Molecular Carcinogenesis, 51(1), 40-52. https://doi.org/10.1002/mc.20786

Dumontet, C., Fabianowska-Majewska, K., Mantincic, D., Callet Bauchu, E., Tigaud, I., Gandhi, V., Lepoivre, M., Peters, G. J., Rolland, M. O., .. Mackey, J. (1999). Common resistance mechanisms to deoxynucleoside analogues in variants of the human erythroleukaemic line K562. British Journal of Haematology, 106(1), 78-85. 
Elander, N. O., Aughton, K., Ghaneh, P., Neoptolemos, J. P., Palmer, D. H., Cox, T. F., Campbell, F., Costello, E., Halloran, C. M., ... Greenhalf, W. (2018). Intratumoural expression of deoxycytidylate deaminase or ribonuceotide reductase subunit M1 expression are not related to survival in patients with resected pancreatic cancer given adjuvant chemotherapy. British Journal of Cancer, 118(8), 1084-1088. https://doi.org/10.1038/s41416-018-0005-1

Elangovan, S., Hsieh, T.-C., \& Wu, J. M. (2008). Growth Inhibition of Human MDA-MB-231 Breast Cancer Cells by $\delta$-Tocotrienol Is Associated with Loss of Cyclin D1/CDK4 Expression and Accompanying Changes in the State of Phosphorylation of the Retinoblastoma Tumor Suppressor Gene Product. Anticancer Research, 28(5A), 2641-2647.

Ellenrieder, V., König, A., \& Seufferlein, T. (2016). Current Standard and Future Perspectives in First- and Second-Line Treatment of Metastatic Pancreatic Adenocarcinoma. Digestion, 94(1), 44-49. https://doi.org/10.1159/000447739

Erkan, M., Adler, G., Apte, M. V., Bachem, M. G., Buchholz, M., Detlefsen, S., Esposito, I., Friess, H., Gress, T. M., ... Wilson, J. (2012). StellaTUM: Current consensus and discussion on pancreatic stellate cell research. Gut, 61(2), 172-178. https://doi.org/10.1136/gutjnl-2011-301220

Erkan, M., Hausmann, S., Michalski, C. W., Fingerle, A. A., Dobritz, M., Kleeff, J., \& Friess, $H$. (2012). The role of stroma in pancreatic cancer: diagnostic and therapeutic implications. Nature Reviews Gastroenterology \& Hepatology, 9(8), 454-467. https://doi.org/10.1038/nrgastro.2012.115

Eser, S., Schnieke, A., Schneider, G., \& Saur, D. (2014). Oncogenic KRAS signalling in pancreatic cancer. British Journal of Cancer, 111(5), 817-822. https://doi.org/10.1038/bjc.2014.215

Feldmann, G., Dhara, S., Fendrich, V., Bedja, D., Beaty, R., Mullendore, M., Karikari, C., Alvarez, H., lacobuzio-Donahue, C., ... Maitra, A. (2007). Blockade of Hedgehog Signaling Inhibits Pancreatic Cancer Invasion and Metastases: A New Paradigm for Combination Therapy in Solid Cancers. Cancer Research, 67(5), 2187-2196. https://doi.org/10.1158/0008-5472.CAN-06-3281 
Feoktistova, M., Geserick, P., \& Leverkus, M. (2016). Crystal Violet Assay for Determining Viability of Cultured Cells. Cold Spring Harbor Protocols, 2016(4), 343-346. https://doi.org/10.1101/pdb.prot087379

Ferlay, J., Soerjomataram, I., Dikshit, R., Eser, S., Mathers, C., Rebelo, M., Parkin, D. M., Forman, D., \& Bray, F. (2015). Cancer incidence and mortality worldwide: Sources, methods and major patterns in GLOBOCAN 2012. International Journal of Cancer, 136(5), E359-E386. https://doi.org/10.1002/ijc.29210

Fong, Z. V., \& Winter, J. M. (2012). Biomarkers in Pancreatic Cancer. The Cancer Journal, 18(6), 530-538. https://doi.org/10.1097/PPO.0b013e31827654ea

Frese, K. K., Neesse, A., Cook, N., Bapiro, T. E., Lolkema, M. P., Jodrell, D. I., \& Tuveson, D. A. (2012). nab-Paclitaxel Potentiates Gemcitabine Activity by Reducing Cytidine Deaminase Levels in a Mouse Model of Pancreatic Cancer. Cancer Discovery, 2(3), 260-269. https://doi.org/10.1158/2159-8290.CD-11-0242

Garrido-Laguna, I., \& Hidalgo, M. (2015). Pancreatic cancer: From state-of-the-art treatments to promising novel therapies. Nature Reviews Clinical Oncology, 12(6), 319-334. https://doi.org/10.1038/nrclinonc.2015.53

Geller, L. T., Barzily-Rokni, M., Danino, T., Jonas, O. H., Shental, N., Nejman, D., Gavert, N., Zwang, Y., Cooper, Z. A., ... Straussman, R. (2017). Potential role of intratumor bacteria in mediating tumor resistance to the chemotherapeutic drug gemcitabine. Science, 357(6356), 1156-1160. https://doi.org/10.1126/science.aah5043

Genkinger, J. M., Spiegelman, D., Anderson, K. E., Bergkvist, L., Bernstein, L., Van Den Brandt, P. A., English, D. R., Freudenheim, J. L., Fuchs, C. S., ... Smith-Warner, S. A. (2009). Alcohol Intake and Pancreatic Cancer Risk: A Pooled Analysis of Fourteen Cohort Studies. Cancer Epidemiology Biomarkers and Prevention, 18(3), 765-776. https://doi.org/10.1158/1055-9965.EPI-08-0880

Goetze, R.-G., Buchholz, S. M., Patil, S., Petzold, G., Ellenrieder, V., Hessmann, E., \& Neesse, A. (2018). Utilizing High Resolution Ultrasound to Monitor Tumor Onset and Growth in Genetically Engineered Pancreatic Cancer Models. Journal of Visualized Experiments: JoVE, (134). https://doi.org/10.3791/56979

Gong, J., Robbins, L. A., Lugea, A., Waldron, R. T., Jeon, C. Y., \& Pandol, S. J. (2014). Diabetes, pancreatic cancer, and metformin therapy. Frontiers in Physiology, 5, 426. https://doi.org/10.3389/fphys.2014.00426 
Gordon-Dseagu, V. L., Devesa, S. S., Goggins, M., \& Stolzenberg-Solomon, R. (2018). Pancreatic cancer incidence trends: evidence from the Surveillance, Epidemiology and End Results (SEER) population-based data. International Journal of Epidemiology, 47(2), 427-439. https://doi.org/10.1093/ije/dyx232

Gore, J., \& Korc, M. (2014). Pancreatic Cancer Stroma: Friend or Foe? Cancer Cell, 25(6), 711-712. https://doi.org/10.1016/j.ccr.2014.05.026

Greenberg, S. A. (2011). Inclusion body myositis. Current Opinion in Rheumatology, 23(6), 574-578. https://doi.org/10.1097/BOR.0b013e32834b53cc

Greenhalf, W., Ghaneh, P., Neoptolemos, J. P., Palmer, D. H., Cox, T. F., Lamb, R. F., Garner, E., Campbell, F., Mackey, J. R., ... Büchler, M. W. (2014). Pancreatic Cancer hENT1 Expression and Survival From Gemcitabine in Patients From the ESPAC-3 Trial. Journal of the National Cancer Institute, 106(1), djt347. https://doi.org/10.1093/jnci/djt347

Grover, S., \& Syngal, S. (2010). Hereditary pancreatic cancer. Gastroenterology, 139, 1076-1080. https://doi.org/10.1007/978-0-387-93846-2_7

Hall, J. E. (2016). Guyton and Hall textbook of medical physiology. Philadelphia: Elsevier, Inc.

Halozyme Therapeutics. (n.d.). A Study of PEGylated Recombinant Human Hyaluronidase in Combination With Nab-Paclitaxel Plus Gemcitabine Compared With Placebo Plus Nab-Paclitaxel and Gemcitabine in Participants With Hyaluronan-High Stage IV Previously Untreated Pancreatic Ductal Adenoca. Retrieved November 16, 2018, from https://clinicaltrials.gov/ct2/show/NCT02715804

Hama, K., Ohnishi, H., Yasuda, H., Ueda, N., Mashima, H., Satoh, Y., Hanatsuka, K., Kita, H., Ohashi, A., ... Sugano, K. (2004). Angiotensin II stimulates DNA synthesis of rat pancreatic stellate cells by activating ERK through EGF receptor transactivation. Biochemical and Biophysical Research Communications, 315(4), 905-911. https://doi.org/10.1016/j.bbrc.2004.01.155

Hardie, D. G. (2014). AMPK - Sensing Energy while Talking to Other Signaling Pathways. Cell Metabolism, 20(6), 939-952. https://doi.org/10.1016/j.cmet.2014.09.013 
Heinemann, V., Xu, Y. Z., Chubb, S., Sen, A., Hertel, L. W., Grindey, G. B., \& Plunkett, W. (1990). Inhibition of Ribonucleotide Reduction in CCRF-CEM Cells by 2',2'Difluorodeoxycytidine. Molecular Pharmacology, 38(4), 567-572.

Herreros-Villanueva, M., Hijona, E., Cosme, A., \& Bujanda, L. (2012). Mouse models of pancreatic cancer. World Journal of Gastroenterology, 18(12), 1286-1294. https://doi.org/10.3748/wjg.v18.i12.1286

Hessmann, E., Patzak, M. S., Klein, L., Chen, N., Kari, V., Ramu, I., Bapiro, T. E., Frese, K. K., Gopinathan, A., ... Neesse, A. (2018). Fibroblast drug scavenging increases intratumoural gemcitabine accumulation in murine pancreas cancer. Gut, 67(3), 497507. https://doi.org/10.1136/gutjnl-2016-311954

Hezel, A. F., Kimmelman, A. C., Stanger, B. Z., Bardeesy, N., \& DePinho, R. A. (2006). Genetics and biology of pancreatic ductal adenocarcinoma. Genes and Development, 20(10), 1218-1249. https://doi.org/10.1101/gad.1415606

Hingorani, S. R., Petricoin, E. F., Maitra, A., Rajapakse, V., King, C., Jacobetz, M. A., Ross, S., Conrads, T. P., Veenstra, T. D., ... Tuveson, D. A. (2003). Preinvasive and invasive ductal pancreatic cancer and its early detection in the mouse. Cancer Cell, 4(6), 437450.

Hingorani, S. R., Wang, L., Multani, A. S., Combs, C., Deramaudt, T. B., Hruban, R. H., Rustgi, A. K., Chang, S., \& Tuveson, D. A. (2005). Trp53R172H and KrasG12D cooperate to promote chromosomal instability and widely metastatic pancreatic ductal adenocarcinoma in mice. Cancer Cell, 7(5), 469-483. https://doi.org/10.1016/j.ccr.2005.04.023

Hingorani, S. R., Zheng, L., Bullock, A. J., Seery, T. E., Harris, W. P., Sigal, D. S., Braiteh, F., Ritch, P. S., Zalupski, M. M., ... Hendifar, A. E. (2018). HALO 202: Randomized Phase II Study of PEGPH20 Plus Nab-Paclitaxel/Gemcitabine Versus NabPaclitaxel/Gemcitabine in Patients With Untreated, Metastatic Pancreatic Ductal Adenocarcinoma. Journal of Clinical Oncology, 36(4), 359-366. https://doi.org/10.1200/JCO.2017.74.9564

Hodge, L. S., Taub, M. E., \& Tracy, T. S. (2011). Effect of its deaminated metabolite, 2',2'difluorodeoxyuridine, on the transport and toxicity of gemcitabine in HeLa cells. Biochemical Pharmacology, 81(7), 950-956. https://doi.org/10.1016/j.bcp.2011.01.016 
Hou, S., Tiriac, H., Sridharan, B. P., Scampavia, L., Madoux, F., Seldin, J., Souza, G. R., Watson, D., Tuveson, D., \& Spicer, T. P. (2018). Advanced Development of Primary Pancreatic Organoid Tumor Models for High-Throughput Phenotypic Drug Screening. SLAS Discovery, 23(6), 574-584. https://doi.org/10.1177/2472555218766842

Hruban, R. H., Goggins, M., Parsons, J., \& Kern, S. E. (2000). Progression Model for Pancreatic Cancer. Clinical Cancer Research, 6(8), 2969-2972.

Hruban, R. H., Maitra, A., \& Goggins, M. (2008). Update on Pancreatic Intraepithelial Neoplasia. International Journal of Clinical and Experimental Pathology, 1(4), 306316.

Hunsucker, S. A., Mitchell, B. S., \& Spychala, J. (2005). The 5'-nucleotidases as regulators of nucleotide and drug metabolism. Pharmacology \& Therapeutics, 107(1), 1-30. https://doi.org/10.1016/j.pharmthera.2005.01.003

Hunsucker, S. A., Spychala, J., \& Mitchell, B. S. (2001). Human Cytosolic 5'-Nucleotidase I: Characterization and Role in Nucleoside Analog Resistance. The Journal of Biological Chemistry, 276(13), 10498-10504. https://doi.org/10.1074/jbc.M011218200

Infinity Pharmaceuticals, I. (n.d.). Infinity Reports Update from Phase 2 Study of Saridegib Plus Gemcitabine in Patients with Metastatic Pancreatic Cancer - Press Release. Retrieved October 3, 2016, from http://phx.corporateir.net/phoenix.zhtml?c=121941\&p=irol-newsArticle\&ID=1653550\&highlight=

lodice, S., Gandini, S., Maisonneuve, P., \& Lowenfels, A. B. (2008). Tobacco and the risk of pancreatic cancer: a review and meta-analysis. Langenbecks Archives of Surgery, 393(4), 535-545. https://doi.org/10.1007/s00423-007-0266-2

Jacobetz, M. A., Chan, D. S., Neesse, A., Bapiro, T. E., Cook, N., Frese, K. K., Feig, C., Nakagawa, T., Caldwell, M. E., ... Tuveson, D. A. (2013). Hyaluronan impairs vascular function and drug delivery in a mouse model of pancreatic cancer. Gut, 62(1), 112 120. https://doi.org/10.1136/gutjnl-2012-302529

Jaffee, E. M., Hruban, R. H., Canto, M., \& Kern, S. E. (2002). Focus on pancreas cancer. Cancer Cell, 2(1), 25-28.

Junqueira, L. C. U., \& Carneiro, J. (2005). Histologie. Heidelberg: Springer Medizin Verlag. 
Kalluri, R. (2016). The biology and function of fibroblasts in cancer. Nature Reviews Cancer, 16(9), 582-598. https://doi.org/10.1038/nrc.2016.73

Kari, V., Mansour, W. Y., Raul, S. K., Baumgart, S. J., Mund, A., Grade, M., Sirma, H., Simon, R., Will, H., ... Johnsen, S. A. (2016). Loss of CHD1 causes DNA repair defects and enhances prostate cancer therapeutic responsiveness. EMBO Reports, 17(11), 1609-1623. https://doi.org/10.15252/embr.201642352

Kawasaki, H., Carrera, C. J., Piro, L. D., Saven, A., Kipps, T. J., \& Carson, D. A. (1993). Relationship of Deoxycytidine Kinase and Cytoplasmic 5'-Nucleotidase to the Chemotherapeutic Efficacy of 2-Chlorodeoxyadenosine. Blood, 81(3), 597-601.

Kim, E. J., Sahai, V., Abel, E. V., Griffith, K. A., Greenson, J. K., Takebe, N., Khan, G. N., Blau, J. L., Craig, R., ... Simeone, D. M. (2014). Pilot Clinical Trial of Hedgehog Pathway Inhibitor GDC-0449 (Vismodegib) in Combination with Gemcitabine in Patients with Metastatic Pancreatic Adenocarcinoma. Clinical Cancer Research, 20(23), 5937-5945. https://doi.org/10.1158/1078-0432.CCR-14-1269

Kim, R., Tan, A., Lai, K. K., Jiang, J., Wang, Y., Rybicki, L. A., \& Liu, X. (2011). Prognostic Roles of Human Equilibrative Transporter 1 (hENT-1) and Ribonucleoside Reductase Subunit M1 (RRM1) in Resected Pancreatic Cancer. Cancer, 117(14), 3126-3134. https://doi.org/10.1002/cncr.25883

Kleeff, J., Korc, M., Apte, M., La Vecchia, C., Johnson, C. D., Biankin, A. V, Neale, R. E., Tempero, M., Tuveson, D. A., ... Neoptolemos, J. P. (2016). Pancreatic cancer. Nature Reviews Disease Primers, 2, 16022. https://doi.org/10.1038/nrdp.2016.22

Klimstra, D. S., \& Longnecker, D. S. (1994). K-ras Mutations in Pancreatic Ductal Proliferative Lesions. American Journal Of Pathology, 145(6), 1547-1548.

Kochanek, K. D., Murphy, S. L., Xu, J., \& Tejada-Vera, B. (2016). Deaths: Final Data for 2014. National Vital Statistics Reports, 65(4), 1-122.

Kowalewski, A., Szylberg, Ł., Saganek, M., Napiontek, W., Antosik, P., \& Grzanka, D. (2018). Emerging strategies in BRCA-positive pancreatic cancer. Journal of Cancer Research and Clinical Oncology, 144(8), 1503-1507. https://doi.org/10.1007/s00432018-2666-9 
Kulkarni, S. S., Karlsson, H. K. R., Szekeres, F., Chibalin, A. V., Krook, A., \& Zierath, J. R. (2011). Suppression of 5'-Nucleotidase Enzymes Promotes AMP-activated Protein Kinase (AMPK) Phosphorylation and Metabolism in Human and Mouse Skeletal Muscle. The Journal of Biological Chemistry, 286(40), 34567-34574. https://doi.org/10.1074/jbc.M111.268292

Lang, G. (2013). Immunhistochemie. In Histotechnik: Praxislehrbuch für die Biomedizinische Analytik (pp. 269-304). Wien: Springer-Verlag. https://doi.org/10.1007/978-3-7091-1190-1_12

Larman, H. B., Salajegheh, M., Nazareno, R., Lam, T., Sauld, J., Steen, H., Won Kong, S., Pinkus, J. L., Amato, A. A., ... Greenberg, S. A. (2013). Cytosolic 5'-Nucleotidase 1 A Autoimmunity in Sporadic Inclusion Body Myositis. Annals of Neurology, 73(3), 408418. https://doi.org/10.1002/ana.23840

Lilleker, J. B., Rietveld, A., Pye, S. R., Mariampillai, K., Benveniste, O., Peeters, M. T. J., Miller, J. A. L., Hanna, M. G., MacHado, P. M., .. Van Engelen, B. G. M. (2017). Cytosolic 5'-nucleotidase $1 \mathrm{~A}$ autoantibody profile and clinical characteristics in inclusion body myositis. Annals of the Rheumatic Diseases, 76(5), 862-868. https://doi.org/10.1136/annrheumdis-2016-210282

Logan-Collins, J., Thomas, R. M., Yu, P., Jaquish, D., Mose, E., French, R., Stuart, W., McClaine, R., Aronow, B., ... Lowy, A. M. (2010). Silencing of RON Receptor Signaling Promotes Apoptosis and Gemcitabine Sensitivity in Pancreatic Cancers. Cancer Research, 70(3), 1130-1140. https://doi.org/10.1158/0008-5472.CAN-09-0761

Lunardi, S., Muschel, R. J., \& Brunner, T. B. (2014). The stromal compartments in pancreatic cancer: Are there any therapeutic targets? Cancer Letters, 343(2), 147155. https://doi.org/10.1016/j.canlet.2013.09.039

Luttmann, W., Bratke, K., Küpper, M., \& Myrtek, D. (2014). Der Experimentator Immunologie. Berlin Heidelberg: Springer-Verlag. https://doi.org/10.1007/978-3-64241899-0_6

Makohon-Moore, A., \& lacobuzio-Donahue, C. A. (2016). Pancreatic cancer biology and genetics from an evolutionary perspective. Nature Reviews Cancer, 16(9), 553-565. https://doi.org/10.1038/nrc.2016.66 
Maréchal, R., Bachet, J. B., Mackey, J. R., Dalban, C., Demetter, P., Graham, K., Couvelard, A., Svrcek, M., Bardier-Dupas, A., ... Van Laethem, J. L. (2012). Levels of Gemcitabine Transport and Metabolism Proteins Predict Survival Times of Patients Treated With Gemcitabine for Pancreatic Adenocarcinoma. Gastroenterology, 143(3), 664-674. https://doi.org/10.1053/j.gastro.2012.06.006

Miele, E., Spinelli, G. P., Miele, E., Tomao, F., \& Tomao, S. (2009). Albumin-bound formulation of paclitaxel (Abraxane $\mathrm{ABI}-007$ ) in the treatment of breast cancer. International Journal of Nanomedicine, 4, 99-105.

Mini, E., Nobili, S., Caciagli, B., Landini, I., \& Mazzei, T. (2006). Cellular pharmacology of gemcitabine. Annals of Oncology, 17(Supplement 5), v7-v12. https://doi.org/10.1093/annonc/mdj941

Moffitt, R. A., Marayati, R., Flate, E. L., Volmar, K. E., Loeza, S. G. H., Hoadley, K. A., Rashid, N. U., Williams, L. A., Eaton, S. C., ... Yeh, J. J. (2015). Virtual microdissection identifies distinct tumor- and stroma-specific subtypes of pancreatic ductal adenocarcinoma. Nature Genetics, 47(10), 1168-1178. https://doi.org/10.1038/ng.3398

Mosmann, T. (1983). Rapid Colorimetric Assay for Cellular Growth and Survival: Application to Proliferation and Cytotoxicity Assays. Journal of Immunological Methods, 65(1-2), $55-63$.

Mülhardt, C. (2013a). Die Polymerase-Kettenreaktion (PCR). In C. Mülhardt (Ed.), Der Experimentator Molekularbiologie/Genomics (pp. 81-114). Berlin, Heidelberg: Springer Berlin Heidelberg. https://doi.org/10.1007/978-3-642-34636-1_4

Mülhardt, C. (2013b). RNA. In C. Mülhardt (Ed.), Der Experimentator Molekularbiologie/Genomics (pp. 115-131). Berlin, Heidelberg: Springer Berlin Heidelberg. https://doi.org/10.1007/978-3-642-34636-1_5

Needham, M., \& Mastaglia, F. L. (2007). Inclusion body myositis: current pathogenetic concepts and diagnostic and therapeutic approaches. Lancet Neurology, 6(7), 620631. https://doi.org/10.1016/S1474-4422(07)70171-0

Neesse, A., Algül, H., Tuveson, D. A., \& Gress, T. M. (2015). Stromal biology and therapy in pancreatic cancer: a changing paradigm. Gut, 64(9), 1476-1484. https://doi.org/10.1136/gutjnl-2015-309304 
Neesse, A., Frese, K. K., Bapiro, T. E., Nakagawa, T., Sternlicht, M. D., Seeley, T. W., Pilarsky, C., Jodrell, D. I., Spong, S. M., \& Tuveson, D. A. (2013). CTGF antagonism with $\mathrm{mAb}$ FG-3019 enhances chemotherapy response without increasing drug delivery in murine ductal pancreas cancer. Proceedings of the National Academy of Sciences, 110(30), 12325-12330. https://doi.org/10.1073/pnas.1300415110

Neesse, A., Michl, P., Frese, K. K., Feig, C., Cook, N., Jacobetz, M. A., Lolkema, M. P., Buchholz, M., Olive, K. P., ... Tuveson, D. A. (2011). Stromal biology and therapy in pancreatic cancer. Gut, 60(6), 861-868. https://doi.org/10.1136/gut.2010.226092

Neoptolemos, J. P., Palmer, D. H., Ghaneh, P., Psarelli, E. E., Valle, J. W., Halloran, C. M., Faluyi, O., O’Reilly, D. A., Cunningham, D., ... Büchler, M. W. (2017). Comparison of adjuvant gemcitabine and capecitabine with gemcitabine monotherapy in patients with resected pancreatic cancer (ESPAC-4): a multicentre, open-label, randomised, phase 3 trial. The Lancet, 389(10073), 1011-1024. https://doi.org/10.1016/S01406736(16)32409-6

Neoptolemos, J. P., Stocken, D. D., Tudur Smith, C., Bassi, C., Ghaneh, P., Owen, E., Moore, M., Padbury, R., Doi, R., ... Büchler, M. W. (2009). Adjuvant 5-fluorouracil and folinic acid vs observation for pancreatic cancer: composite data from the ESPAC-1 and $-3(\mathrm{v} 1)$ trials. British Journal of Cancer, 100(2), 246-250. https://doi.org/10.1038/sj.bjc. 6604838

Nielsen, M. F. B., Mortensen, M. B., \& Detlefsen, S. (2016). Key players in pancreatic cancer-stroma interaction: Cancer-associated fibroblasts, endothelial and inflammatory cells. World Journal of Gastroenterology, 22(9), 2678-2700. https://doi.org/10.3748/wjg.v22.i9.2678

Oberstein, P. E., \& Olive, K. P. (2013). Pancreatic cancer: why is it so hard to treat? Therapeutic Advances in Gastroenterology, 6(4), 321-337. https://doi.org/10.1177/1756283X13478680

Oettle, H., Neuhaus, P., Hochhaus, A., Hartmann, J. T., Gellert, K., Ridwelski, K., Niedergethmann, M., Zülke, C., Fahlke, J., ... Riess, H. (2013). Adjuvant Chemotherapy With Gemcitabine and Long-term Outcomes Among Patients With Resected Pancreatic Cancer - The CONKO-001 Randomized Trial. JAMA, 310(14), 1473-1481. https://doi.org/10.1001/jama.2013.279201 
Oezdemir, B. C., Pentcheva-Hoang, T., Carstens, J. L., Zheng, X., Wu, C. C., Simpson, T. R., Laklai, H., Sugimoto, H., Kahlert, C., ... Kalluri, R. (2014). Depletion of CarcinomaAssociated Fibroblasts and Fibrosis Induces Immunosuppression and Accelerates Pancreas Cancer with Reduced Survival. Cancer Cell, 25(6), 719-734. https://doi.org/10.1016/j.ccr.2014.04.005

Öhlund, D., Handly-Santana, A., Biffi, G., Elyada, E., Almeida, A. S., Ponz-Sarvise, M., Corbo, V., Oni, T. E., Hearn, S. A., ... Tuveson, D. A. (2017). Distinct populations of inflammatory fibroblasts and myofibroblasts in pancreatic cancer. The Journal of Experimental Medicine, 214(3), 579-596. https://doi.org/10.1084/jem.20162024

Olive, K. P., Jacobetz, M. A., Davidson, C. J., Gopinathan, A., Mclntyre, D., Honess, D., Madhu, B., Goldgraben, M. A., Caldwell, M. E., ... Tuveson, D. A. (2009). Inhibition of Hedgehog Signaling Enhances Delivery of Chemotherapy in a Mouse Model of Pancreatic Cancer. Science, 324(5933), 1457-1461. https://doi.org/10.1126/science.1171362

Omary, M. B., Lugea, A., Lowe, A. W., \& Pandol, S. J. (2007). The pancreatic stellate cell: a star on the rise in pancreatic diseases. The Journal of Clinical Investigation, 117(1), 50-59. https://doi.org/10.1172/JCI30082

Philip, P. A., Mooney, M., Jaffe, D., Eckhardt, G., Moore, M., Meropol, N., Emens, L., O'Reilly, E., Korc, M., ... Tepper, J. (2009). Consensus Report of the National Cancer Institute Clinical Trials Planning Meeting on Pancreas Cancer Treatment. Journal of Clinical Oncology, 27(33), 5660-5669. https://doi.org/10.1200/JCO.2009.21.9022

Phillips, P. A., McCarroll, J. A., Park, S., Wu, M. J., Pirola, R., Korsten, M., Wilson, J. S., \& Apte, M. V. (2003). Rat pancreatic stellate cells secrete matrix metalloproteinases: Implications for extracellular matrix turnover. Gut, 52(2), 275-282. https://doi.org/10.1136/gut.52.2.275

Ponz-Sarvise, M., Tuveson, D. A., \& Yu, K. H. (2015). Mouse Models of Pancreatic Ductal Adenocarcinoma. Hematology/Oncology Clinics of North America, 29(4), 609-617. https://doi.org/10.1016/j.hoc.2015.04.010

Prinz, C. (2012). Pankreas. In Basiswissen Innere Medizin. Springer-Lehrbuch (pp. 232246). Heidelberg: Springer Medizin Verlag. https://doi.org/10.1007/978-3-642-12377$1 \_12$ 
Provenzano, P. P., Cuevas, C., Chang, A. E., Goel, V. K., Von Hoff, D. D., \& Hingorani, S. R. (2012). Enzymatic Targeting of the Stroma Ablates Physical Barriers to Treatment of Pancreatic Ductal Adenocarcinoma. Cancer Cell, 21(3), 418-429. https://doi.org/10.1016/j.ccr.2012.01.007

Quante, A. S., Ming, C., Rottmann, M., Engel, J., Boeck, S., Heinemann, V., Westphalen, C. B., \& Strauch, K. (2016). Projections of cancer incidence and cancer-related deaths in Germany by 2020 and 2030. Cancer Medicine, 5(9), 2649-2656. https://doi.org/10.1002/cam4.767

Rahib, L., Smith, B. D., Aizenberg, R., Rosenzweig, A. B., Fleshman, J. M., \& Matrisian, L. M. (2014). Projecting Cancer Incidence and Deaths to 2030: The Unexpected Burden of Thyroid, Liver, and Pancreas Cancers in the United States. Cancer Research, 74(11), 2913-2921. https://doi.org/10.1158/0008-5472.CAN-14-0155

Raimondi, S., Lowenfels, A. B., Morselli-Labate, A. M., Maisonneuve, P., \& Pezzilli, R. (2010). Pancreatic cancer in chronic pancreatitis; aetiology, incidence, and early detection. Best Practice \& Research Clinical Gastroenterology, 24(3), 349-358. https://doi.org/10.1016/j.bpg.2010.02.007

Ramu, I., Goetze, R., Patzak, M., Ströbel, P., Sipos, B., Richards, F., Jodrell, D., Hessmann, E., Ellenrieder, V., \& Neesse, A. (2018). Overall cellularity but not acellular stroma deposition increases gemcitabine accumulation in a genetically engineered mouse model of pancreatic cancer. Pancreatology, 18(4S), S70-S71. https://doi.org/10.1016/j.pan.2018.05.190

Rehm, H., \& Letzel, T. (2016). Der Experimentator Proteinbiochemie/ Proteomics. Berlin Heidelberg: Springer-Verlag.

Renz-Polster, H., \& Krautzig, S. (2013). Basislehrbuch Innere Medizin. München: Elsevier $\mathrm{GmbH}$, Urban \& Fischer Verlag.

Rhim, A. D., Oberstein, P. E., Thomas, D. H., Mirek, E. T., Palermo, C. F., Sastra, S. A., Dekleva, E. N., Saunders, T., Becerra, C. P., ... Stanger, B. Z. (2014). Stromal Elements Act to Restrain, Rather Than Support, Pancreatic Ductal Adenocarcinoma. Cancer Cell, 25(6), 735-747. https://doi.org/10.1016/j.ccr.2014.04.021

Rossi, M. L., Rehman, A. A., \& Gondi, C. S. (2014). Therapeutic options for the management of pancreatic cancer. World Journal of Gastroenterology, 20(32), 1114211159. https://doi.org/10.3748/wjg.v20.i32.11142 
Saiki, Y., Yoshino, Y., Fujimura, H., Manabe, T., Kudo, Y., Shimada, M., Mano, N., Nakano, T., Lee, Y., ... Horii, A. (2012). DCK is frequently inactivated in acquired gemcitabineresistant human cancer cells. Biochemical and Biophysical Research Communications, 421(1), 98-104. https://doi.org/10.1016/j.bbrc.2012.03.122

Saliba, J., Zabriskie, R., Ghosh, R., Powell, B. C., Hicks, S., Kimmel, M., Meng, Q., Ritter, D. I., Wheeler, D. A., ... Plon, S. E. (2016). Pharmacogenetic characterization of naturally occurring germline NT5C1A variants to chemotherapeutic nucleoside analogs. Pharmacogenetics and Genomics, 26(6), 271-279. https://doi.org/10.1097/FPC.0000000000000208

Schindelin, J., Arganda-Carreras, I., Frise, E., Kaynig, V., Longair, M., Pietzsch, T., Preibisch, S., Rueden, C., Saalfeld, S., ... Cardona, A. (2012). Fiji: An open-source platform for biological-image analysis. Nature Methods, 9(7), 676-682. https://doi.org/10.1038/nmeth.2019

Schmitz, S. (2011). Der Experimentator Zellkultur. Heidelberg: Spektrum Akademischer Verlag.

Sherman, M. H., Yu, R. T., Tseng, T. W., Sousa, C. M., Liu, S., Truitt, M. L., He, N., Ding, N., Liddle, C., ... Evans, R. M. (2017). Stromal cues regulate the pancreatic cancer epigenome and metabolome. Proceedings of the National Academy of Sciences, 114(5), 1129-1134. https://doi.org/10.1073/pnas.1620164114

Shukla, S. K., Purohit, V., Mehla, K., Gunda, V., Chaika, N. V., Vernucci, E., King, R. J., Abrego, J., Goode, G. D., ... Singh, P. K. (2017). MUC1 and HIF-1alpha Signaling Crosstalk Induces Anabolic Glucose Metabolism to Impart Gemcitabine Resistance to Pancreatic Cancer. Cancer Cell, 32(3), 71-87. https://doi.org/10.1016/j.ccell.2017.06.008

Siegel, R. L., Miller, K. D., \& Jemal, A. (2018). Cancer Statistics , 2018. CA: A Cancer Journal for Clinicians, 68(1), 7-30. https://doi.org/10.3322/caac.21442

Stathis, A., \& Moore, M. J. (2010). Advanced pancreatic carcinoma: current treatment and future challenges. Nature Reviews Clinical Oncology, 7(3), 163-172. https://doi.org/10.1038/nrclinonc.2009.236

Stromiedel, M., \& Wittmann, E.-M. (n.d.). TBS-Stammlösung herstellen ohne lästiges Feinjustieren des pH-Wertes. Retrieved September 29, 2016, from https://www.laborjournal.de/rubric/tricks/tricks/trick152.lasso 
Tactacan, C. M., Chang, D. K., Cowley, M. J., Humphrey, E. S., Wu, J., Gill, A. J., Chou, A., Nones, K., Grimmond, S. M., ... Daly, R. J. (2012). RON is not a prognostic marker for resectable pancreatic cancer. BMC Cancer, 12, 395. https://doi.org/10.1186/14712407-12-395

The Breast Cancer Linkage Consortium. (1999). Cancer Risks in BRCA2 Mutation Carriers. Journal of the National Cancer Institute, 91, 1310-1316.

Thomas, R. M., Toney, K., Fenoglio-Preiser, C., Revelo-Penafiel, M. P., Hingorani, S. R., Tuveson, D. A., Waltz, S. E., \& Lowy, A. M. (2007). The RON Receptor Tyrosine Kinase Mediates Oncogenic Phenotypes in Pancreatic Cancer Cells and is Increasingly Expressed during Pancreatic Cancer Progression. Cancer Research, 67(13), 6075-6082. https://doi.org/10.1158/0008-5472.CAN-06-4128

Tiriac, H., Belleau, P., Engle, D. D., Plenker, D., Deschênes, A., Somerville, T., Froeling, F. E. M., Burkhart, R. A., Denroche, R. E., ... Tuveson, D. A. (2018). Organoid Profiling Identifies Common Responders to Chemotherapy in Pancreatic Cancer. Cancer Discovery, 8(9), 1112-1129. https://doi.org/10.1158/2159-8290.CD-18-0349

Townsend, N., Nichols, M., Scarborough, P., \& Rayner, M. (2015). Cardiovascular disease in Europe - epidemiological update 2015. European Heart Journal, 36(40), 2696-2705. https://doi.org/10.1093/eurheartj/ehv428

Tzoneva, G., Perez-Garcia, A., Carpenter, Z., Khiabanian, H., Tosello, V., Allegretta, M., Paietta, E., Racevskis, J., Rowe, J. M., ... Ferrando, A. (2013). Activating mutations in the NT5C2 nucleotidase gene drive chemotherapy resistance in relapsed ALL. Nature Medicine, 19(3), 368-371. https://doi.org/10.1038/nm.3078

Van Heek, N. T., Meeker, A. K., Kern, S. E., Yeo, C. J., Lillemoe, K. D., Cameron, J. L., Offerhaus, G. J. A., Hicks, J. L., Wilentz, R. E., ... Maitra, A. (2002). Telomere Shortening is Nearly Universal in Pancreatic Intraepithelial Neoplasia. American Journal of Pathology, 161(5), 1541-1547.

Von Hoff, D. D., Ervin, T., Arena, F. P., Chiorean, E. G., Infante, J., Moore, M., Seay, T., Tjulandin, S. A., Ma, W. W., ... Renschler, M. F. (2013). Increased Survival in Pancreatic Cancer with nab-Paclitaxel plus Gemcitabine. New England Journal of Medicine, 369(18), 1691-1703. https://doi.org/10.1056/NEJMoa1304369 
Wang, L., Munch-Petersen, B., Herrström Sjöberg, A., Hellman, U., Bergman, T., Jörnvall, H., \& Eriksson, S. (1999). Human thymidine kinase 2: molecular cloning and characterisation of the enzyme activity with antiviral and cytostatic nucleoside substrates. FEBS Letters, 443(2), 170-174. https://doi.org/10.1016/S00145793(98)01711-6

Weizman, N., Krelin, Y., Shabtay-Orbach, A., Amit, M., Binenbaum, Y., Wong, R. J., \& Gil, Z. (2014). Macrophages mediate gemcitabine resistance of pancreatic adenocarcinoma by upregulating cytidine deaminase. Oncogene, 33(29), 3812-3819. https://doi.org/10.1038/onc.2013.357

Wong, A., Soo, R. A., Yong, W. P., \& Innocenti, F. (2009). Clinical pharmacology and pharmacogenetics of gemcitabine. Drug Metabolism Reviews, 41(2), 77-88. https://doi.org/10.1080/03602530902741828

Yeker, R. M., Pinal-Fernandez, I., Kishi, T., Pak, K., Targoff, I. N., Miller, F. W., Rider, L. G., \& Mammen, A. L. (2018). Anti-NT5C1A autoantibodies are associated with more severe disease in patients with juvenile myositis. Annals of the Rheumatic Diseases, 77(5), 714-719. https://doi.org/10.1136/annrheumdis-2017-212436

Ying, H., Dey, P., Yao, W., Kimmelman, A. C., Draetta, G. F., Maitra, A., \& DePinho, R. A. (2016). Genetics and biology of pancreatic ductal adenocarcinoma. Genes and Development, 30(4), 355-385. https://doi.org/10.1101/gad.275776.115 


\section{Acknowledgements}

Many people have supported me during the last years and I would like to take the opportunity to express my gratitude to all of them!

Most importantly, I like to acknowledge my supervisor PD Dr. Dr. med. A. Neeße. I am very thankful to him for giving me the opportunity to conduct the research for this thesis in his group at the University Medical Center Göttingen. Your constant encouragement and support helped me to develop my skills and to grow as a scientist. I am grateful that you believed in my abilities to surmount the challenges that occurred throughout the project. It was an exciting experience to be part of this young and developing research group.

On a special note, I would like to express appreciation and thanks to Prof. Dr. Steven A. Johnsen. Thank you for supporting my project with various discussions, thanks for the scientific input you gave to drive the project in the right direction, and thanks for your collaboration. I am fascinated how passionate you are about science and I am very grateful that you were part of my thesis advisory committee. Moreover, I very much like to thank Prof. Dr. med. F. Alves for being part of my thesis advisory committee as well. I am grateful for your feedback on the project, for your suggestions, and the constructive discussions.

Moreover, I very much would like to express my gratitude to PD Dr. med. E. Heßmann and Dr. S. Singh for their constant support, advice, and fruitful discussions. Furthermore, I would like to thank Dr. N. Chen for his support in the initial time of my thesis project.

Furthermore, I am grateful to all the collaborators. Without them this project would not have reached the level it has now. Thanks to Dr. Vijayalakshmi Kari, Dr. Wanhua Xie, Dr. Florian Wegwitz, and Feda Hamdan from the AG Johnsen for their support with the overexpression study, especially for sharing their knowledge about the establishment of the stable cell lines. Furthermore, I would like to thank Prof. D. I. Jodrell and Dr. F. M. Richards from the Cancer Research UK Cambridge Institute, University of Cambridge, for the performance of liquid chromatography tandem mass spectrometry measurements. I am grateful to Dr. med. J. Kitz, Prof. Dr. med. J. Gaedcke, Dr. med. M. Brunner, Prof. Dr. C. Pilarsky, Prof. Dr. med. R. Grützmann, PD Dr. med. P. Rümmele, and Prof. Dr. med. T. Knösel for their contributions to the tissue microarray studies. Moreover, I would like to acknowledge Marcel Zoremba and Prof. Dr. med. W. Zimmermann for supporting our sonography studies by allowing us to use their equipment. Special thanks to the veterinarians Dr. A. Wiese, Dr. V. Reupke, 
and to the animal care takers of the UMG. Additionally, I am grateful to the members of the Department of Medical Statistics for statistics advice.

A special thanks goes to the technicians of the AG Neeße, Jutta Blumberg and Ulrike Wegner. Thanks for your expert technical assistance and most importantly for your help with the mouse experiments. I am also very grateful to the further members of the AG Neeße, my fellow PhD-student Iswarya Ramu, Dr. med. Robert G. Goetze, and Sören Buchholz for support with mouse work, and to the medical students Lukas Klein, Laurin Wolf, Lisa Knoll, and also to Roberta Roggiolani.

Furthermore, I would like to acknowledge the constant support from my former and present colleagues of the Department of Gastroenterology and Gastrointestinal Oncology. I very much appreciate the professional and pleasant working atmosphere you all provided and I am thankful for all the discussions, your scientific input, and your motivation. I am grateful to Prof. Dr. med. V. Ellenrieder, to my fellow PhD-students Shilpa Patil, Marie Hasselluhn, Mengyu Tu, Zhe Zhang, Lennart Versemann, and Umair Latif. A very special thanks to Geske Schmidt for your encouragement and your advice. I would further like to thank Waltraut Kopp, Kristina Reutlinger, Jessica Spitalieri, Regine Köpp, Dr. Martina Blaschke, Lina Frank, and Kevin Weimer.

On a special note, I am grateful to the patients who enabled the expression studies by providing their tumor tissue for our research. I very much appreciate their decision and I hope that the knowledge we gained from these studies might contribute in any way to the development of novel therapeutic strategies in the future.

Very special thanks to everyone from the khg Göttingen, for welcoming me in your community and for all the wonderful moments I was able to spend with you. Furthermore, I would like to express my deep gratitude to my friends who supported me over the last years, everyone in an own special way. I would also like to thank all the people who made my time in Göttingen special.

Last but not least, I like to express my deep gratitude to my parents! Thank you for your constant support, your encouragement, and your understanding over all the years of my studies. Moreover, I would like to thank my grandparents, with a special thanks to my grandmother for her great support along my way. 


\section{Comment}

The manuscript mentioned in chapter II of the results part was later published in the open access journal EBioMedicine:

Patzak, M.S., Kari, V., Patil, S., Hamdan, F.H., Goetze, R.G., Brunner, M., Gaedcke, J., Kitz, J., Jodrell, D.I., Richards, F.M., Pilarsky, C., Gruetzmann, R., Rümmele, P., Knösel, T., Hessmann, E., Ellenrieder, V., Johnsen, S.A., and Neesse, A (2019). Cytosolic 5 -nucleotidase $1 \mathrm{~A}$ is overexpressed in pancreatic cancer and mediates gemcitabine resistance by reducing intracellular gemcitabine metabolites. EBioMedicine, 40, 394-405. https://doi.org/10.1016/j.ebiom.2019.01.037 